\title{
IMPACT OF A COMPARTMENTALIZATION AND VENTILATION SYSTEM RETROFIT STRATEGY ON ENERGY USE IN HIGH-RISE RESIDENTIAL BUILDINGS
}

by

Mathew Carlsson

BASc Mechanical Engineering, University of Ottawa, 2003

\author{
A thesis \\ Presented to Ryerson University \\ In partial fulfilment for the degree of \\ Master of Applied Science \\ In the program of \\ Building Science
}

Toronto, Ontario, Canada, 2017

(C) Mathew Carlsson, 2017 
I hereby declare that I am the sole author of this thesis. This is a true copy of the thesis, including any required final revisions, as accepted by my examiners.

I authorize Ryerson University to lend this thesis to other institutions or individuals for the purpose of scholarly research.

I further authorize Ryerson University to reproduce this thesis by photocopying or by other means, in total or in part, at the request of other institutions or individuals for the purpose of scholarly research.

I understand that my thesis may be made electronically available to the public. 
Impact of a compartmentalization and ventilation system retrofit strategy on energy use in highrise residential buildings

Master of Applied Science, 2017

Mathew Carlsson

Building Science - Ryerson University

\begin{abstract}
A compartmentalization and in-suite ventilation system (ISVS) retrofit strategy was investigated for an existing high-rise residential building in Vancouver. Computer simulation using EnergyPlus ${ }^{\mathrm{TM}}$ was used to examine the impact of the proposed retrofit on heating energy and GHG emissions for the building's original 1983 condition, and its current condition which incorporates a 2012 enclosure retrofit. Results show annual heating energy decreased by $51 \%$ and overall GHG emissions decreased by $29 \%$ for the proposed retrofit applied to the building in its current condition. When applied to the building in its original condition, heating energy decreased by $49 \%$ and overall GHG emissions decreased by $21 \%$. The main benefit of the proposed retrofit, however, is improved effectiveness of the mechanical ventilation system. Because building enclosure air-tightness improvements can negatively impact air distribution in buildings with pressurized corridor ventilation systems, the proposed retrofit should be applied in combination with, or before, an enclosure retrofit.
\end{abstract}




\section{Acknowledgements}

First and foremost, I want to thank Gillian Pillion for her unfaltering support and patience throughout this long and unlucrative career-changing pursuit. Without you I would have given up on this long ago!

I want to thank Dr. Marianne Touchie for all her valuable insights into my research, as well as for providing the original inspiration for this work.

I want to thank Dr. Russell Richman for encouraging this academic endeavour in the first place, and for his guidance and patience while I did my own thing.

I also want to extend my gratitude to Brittany (Hanam) Coughlin, Lorne Ricketts, and Graham Finch of RDH Building Science Inc. in Vancouver for providing me with a case study building and the critical data behind this analysis, along with their own invaluable insights. 
Table of Contents

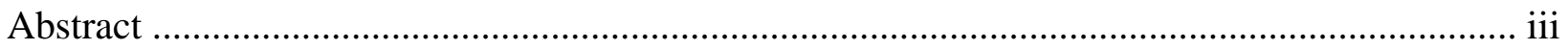

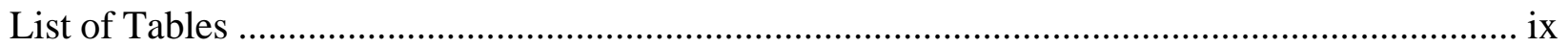

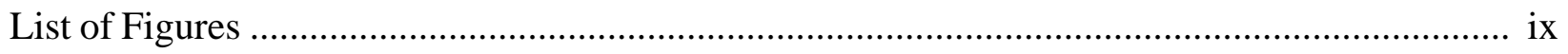

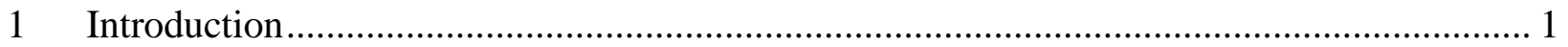

Problem

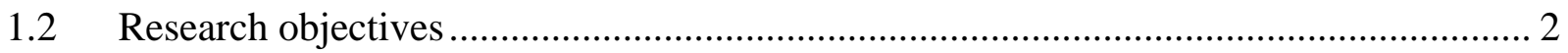

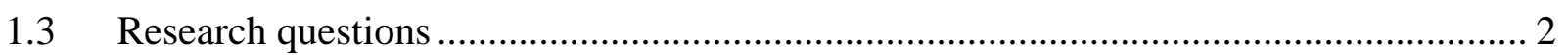

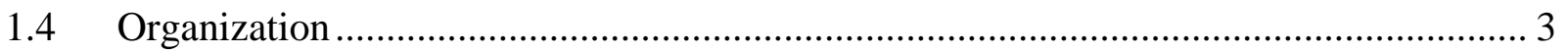

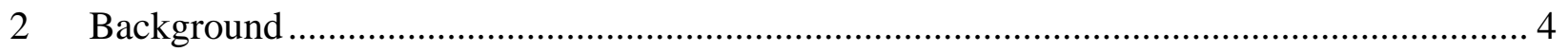

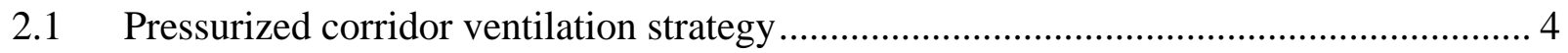



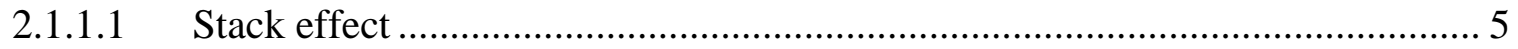



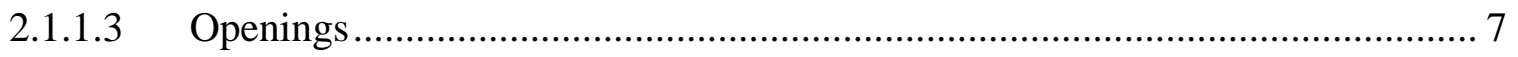

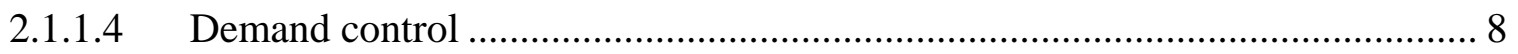

2.1.2 Aggravating factors................................................................................... 8

2.1.2.1 Building operation and occupant behaviour .......................................... 8

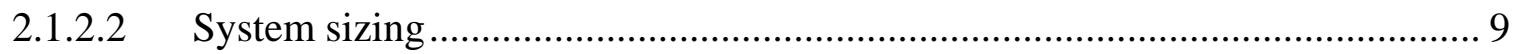

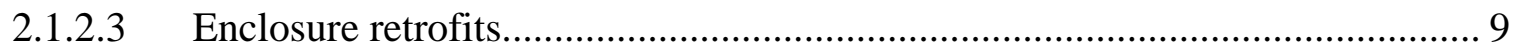

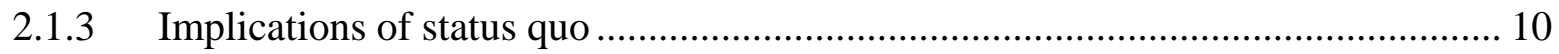

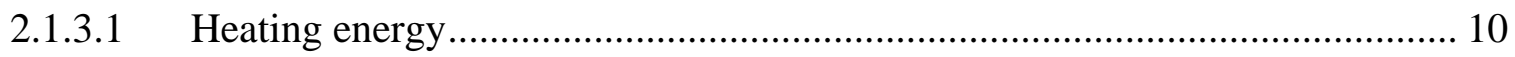

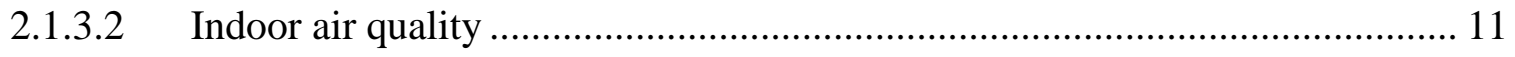

2.2 Previous research....................................................................................... 12 
2.2.1 Pressurized corridor ventilation strategy .......................................................... 12

2.2.2 Compartmentalization and dedicated in-suite ventilation systems ......................... 13

2.2.3 Computer modelling approaches ..................................................................... 15

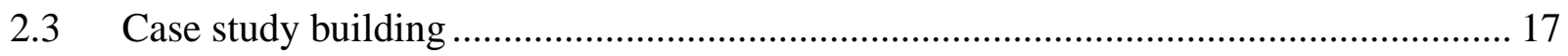



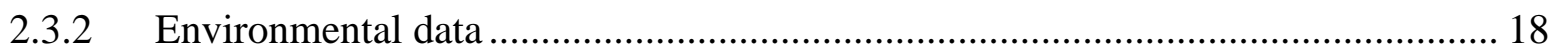

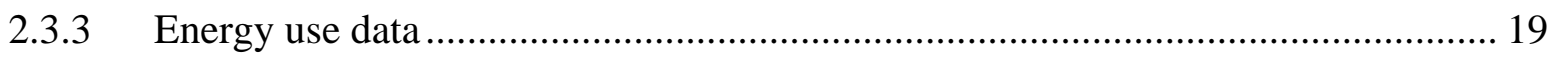

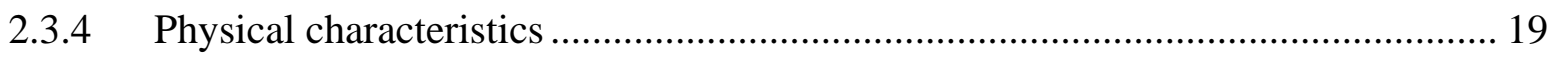



2.3.5.1 Mechanical ventilation .............................................................................. 20

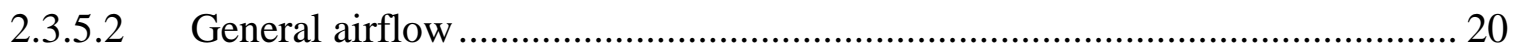

2.3.5.3 Airflow characteristics used for energy model calibration.............................. 24

$2.4 \quad$ Retrofit proposal............................................................................................... 26

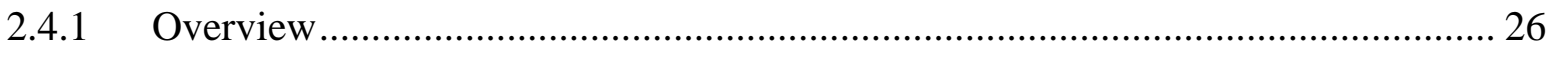

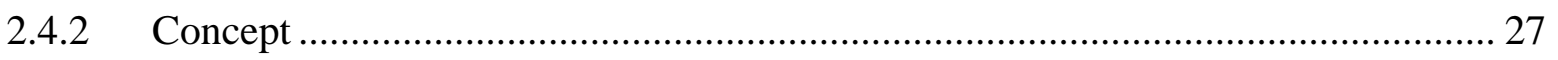

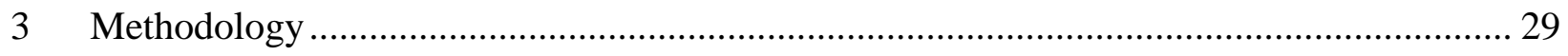

3.1 Energy end use analysis ..................................................................................... 29

3.1.1 Energy use - current condition (retrofitted enclosure) …....................................... 29

3.1.1.1 Natural gas consumption ..................................................................... 30

3.1.1.2 Electricity consumption .......................................................................... 32

3.1.1.3 Overall energy use breakdown .................................................................. 37

3.1.2 Energy use - original condition (prior to enclosure retrofit) ................................ 38

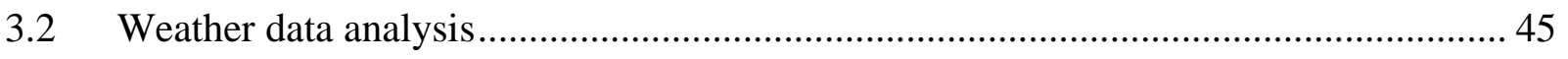

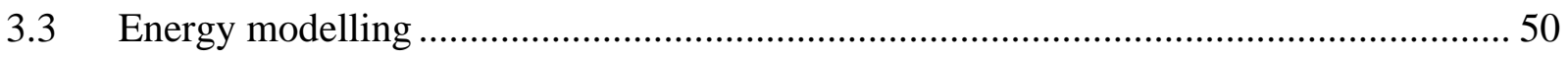

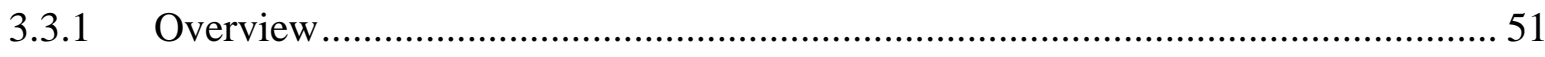




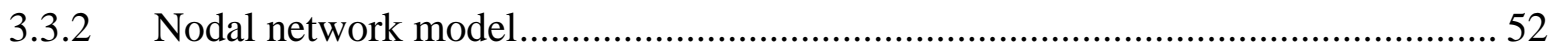

3.3.3 Base model B2: current condition (retrofitted enclosure)....................................... 53

3.3.3.1 Base model B2 setup ............................................................................ 53

3.3.3.2 Base model B2 calibration....................................................................... 55

3.3.4 Retrofit model R2: proposed retrofit on current building condition (B2 base model) 68

3.3.5 Base model B1: original building construction ................................................... 69

3.3.5.1 Base model B1 setup ……………………............................................... 70

3.3.5.2 Base model B1 calibration...................................................................... 72

3.3.6 Retrofit model R1: proposed retrofit on original building construction .................. 84

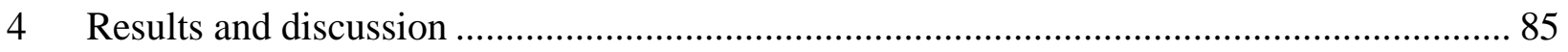

4.1 R2 vs B2 - Proposed compartmentalization and ISVS retrofit from current building

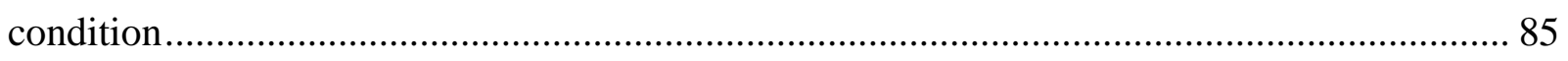

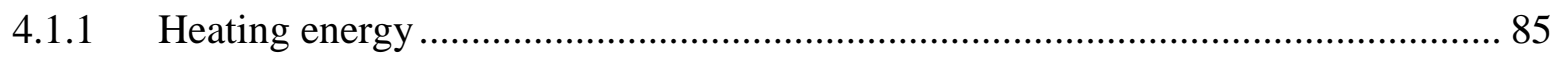

4.1.1.1 MAU supply air heating energy ……………….................................... 85

4.1.1.2 Space heating load due to mechanical ventilation........................................... 87

4.1.1.3 Overall heating energy associated with mechanical ventilation...................... 90

4.1.1.4 Overall heating energy - all sources............................................................. 92

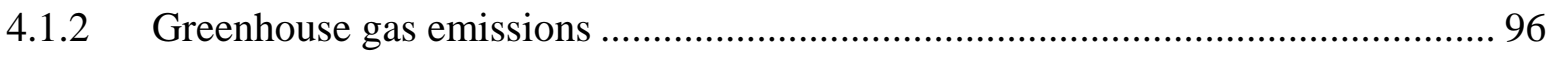

4.2 R1 vs B1 - Proposed retrofit from original building condition ..................................... 98

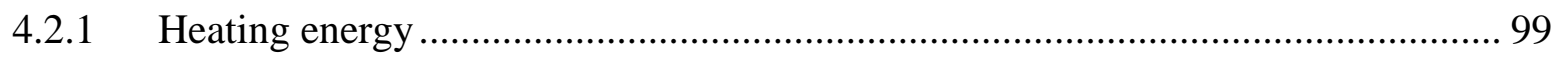

4.2.1.1 MAU supply air heating energy ................................................................. 99

4.2.1.2 Space heating load due to mechanical ventilation........................................ 100

4.2.1.3 Overall heating energy associated with mechanical ventilation..................... 101

4.2.1.4 Overall heating energy - all sources........................................................... 102 


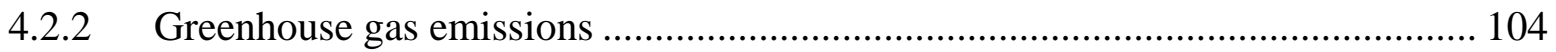

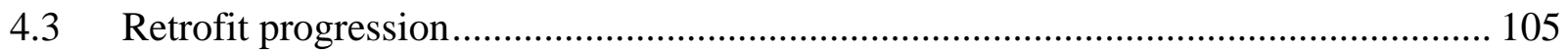

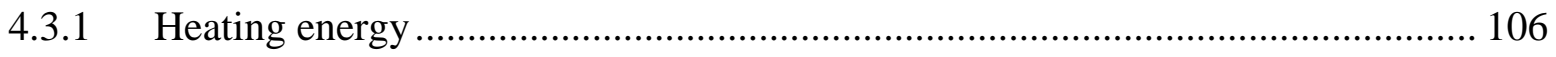

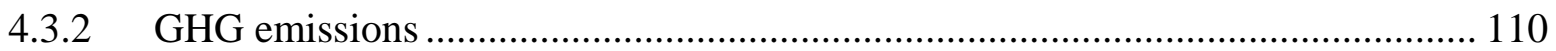

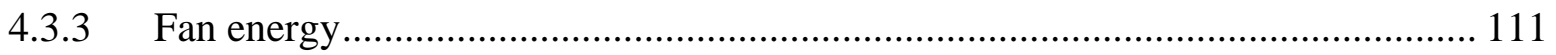

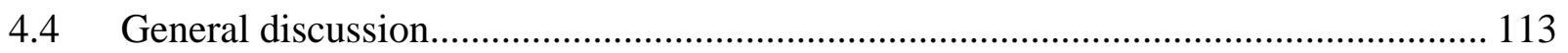



4.4.2 Execution of the proposed retrofit ............................................................... 119

4.4.3 Practical considerations for implementation..................................................... 120

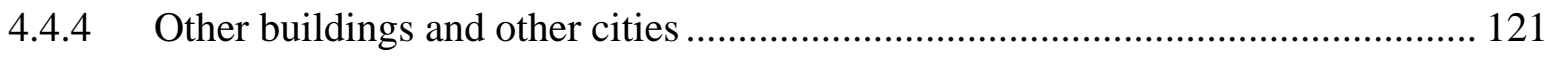

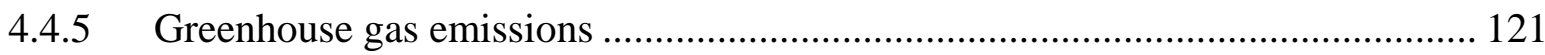

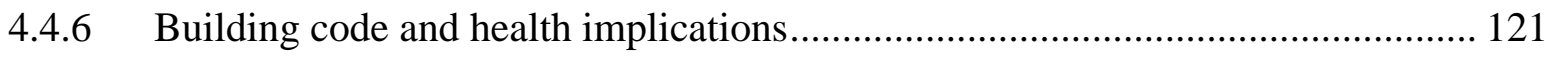

4.4.7 Financial barriers ..................................................................................... 123

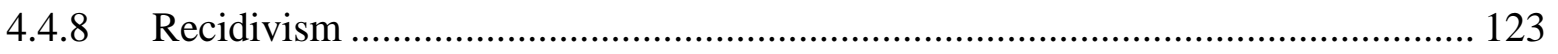

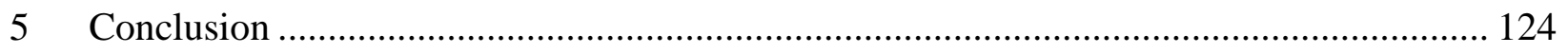

$6 \quad$ Further research \& future recommendations ...................................................................... 127



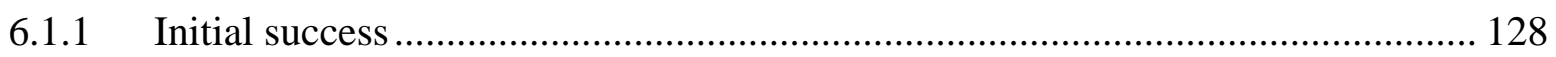

6.1.2 AirFlowNetwork input data limitations ............................................................ 133

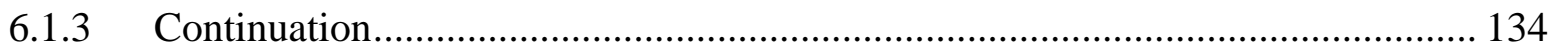

6.1.4 AirFlowNetwork software limitations ........................................................... 135

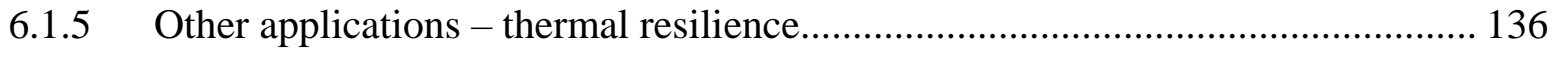

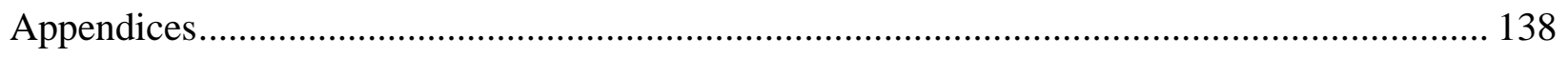

Appendix A: Case Study Building - Layout and sections .................................................... 138

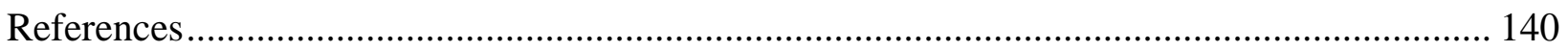




\section{List of Tables}

Table 3-1: Monthly calculated energy use for original building model calibration based on 5-year energy consumption regression analysis, normalized to CWEC HDD ................................... 42 Table 3-2: Base model B2 inputs - key passive physical characteristics impacting energy use.. 54

Table 3-3: Base model B2 inputs - HVAC equipment performance specifications .................... 55

Table 3-4: B2 calibration statistical indices for fuel type and end use ...................................6 67

Table 3-5: Base model B1 inputs - key passive physical characteristics impacting energy use .. 71

Table 3-6: Base model B1 calibration performance summary - 2011 reference year................. 75

Table 4-1: British Columbia GHG emissions factors (source: B.C. Greenhouse Gas Inventory

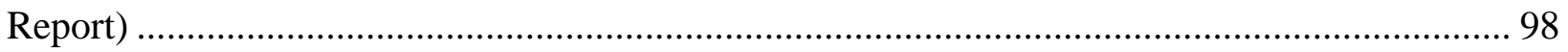

Table 4-2: Annual heating energy change summary for retrofit progressions ........................ 109

Table 4-3: Annual GHG emission change summary for retrofit progressions ........................ 111

Table 4-4: Site wind direction, duration, and average speed, January - September 2013 ......... 116

\section{List of Figures}

Figure 2-1: Illustration of various airflow paths and causes in a high-rise MURB with a pressurized corridor ventilation system

Figure 2-2: Idealized internal airflows resulting from stack effect (left), and the pressure gradient causing these flows due to stack effect (right), for the heating season................................... 5

Figure 2-3: PFT test measured airflow rates into suites from adjacent corridors ....................... 6

Figure 2-4: Estimated annual suite-level heating electricity by floor ................................... 11

Figure 2-5: Case study building circa 2012 during enclosure retrofit, and circa 2013 after retrofit

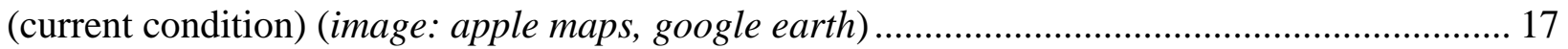

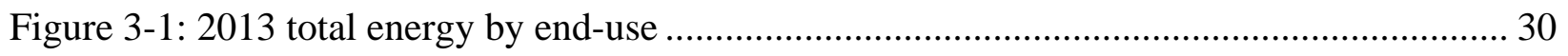

Figure 3-2: Total metered monthly natural gas use breakdown -2013 ................................. 31

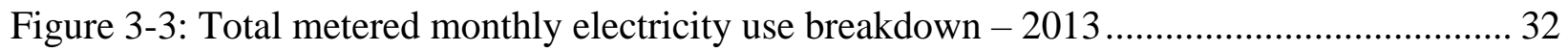

Figure 3-4: Monthly suite-level electricity consumption by floor 2013 [kWh] ....................... 34

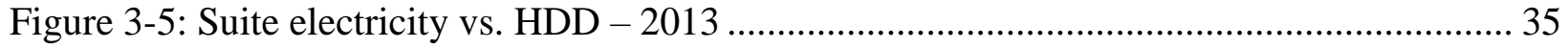


Figure 3-6: 2013 Calculated total annual suite-level electricity breakdown estimate ................. 36

Figure 3-7: 2013 Total energy use breakdown by fuel type and end use ............................... 37

Figure 3-8: Total monthly energy use intensity by fuel source prior to enclosure retrofit........... 38

Figure 3-9: Regression analysis for weather normalization of 2007 - 2011 common electricity use

Figure 3-10: Regression analysis for weather normalization of 2007 - 2011 suite-level electricity

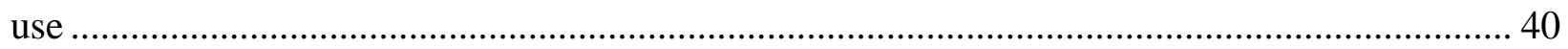

Figure 3-11: Regression analysis for weather normalization of 2007 - 2011 natural gas use ..... 41

Figure 3-12: 2007 - 2011 average annual energy use breakdown ....................................... 43

Figure 3-13: HDD calculation methodology for CWEC weather file (BC Hydro, 2010) ........... 45

Figure 3-14: Dry bulb temperature regression analysis ................................................... 46

Figure 3-15: Dew point temperature regression analysis ................................................. 47

Figure 3-16: Barometric pressure regression analysis ................................................ 47

Figure 3-17: Total solar radiation and relative humidity regression analysis.......................... 48

Figure 3-18: Wind speed and direction regression analysis ................................................ 48

Figure 3-19: Visualization of case study building in energy model .................................... 50

Figure 3-20: Base model and retrofit energy model naming convention ................................ 52

Figure 3-21: 2013 monthly metered vs modelled DHW natural gas consumption .................... 58

Figure 3-22: MAU supply air temperature vs. ambient outdoor temperature [degrees Celsius].. 59

Figure 3-23: MAU measured airflow rate and 24 moving average ........................................ 60

Figure 3-24: 2013 metered vs B2 modelled MAU natural gas consumption ........................... 61

Figure 3-25: 2013 metered vs B2 modelled fireplace natural gas consumption....................... 62

Figure 3-26: 2013 monthly common electricity consumption - B2 calibration......................... 63

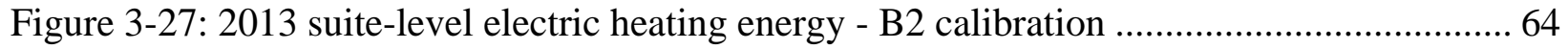

Figure 3-28: 2013 monthly suite-level electricity consumption - B2 calibration ...................... 65

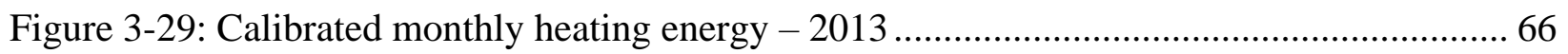

Figure 3-30: 2013 Energy use by sub-meter breakdown - modelled vs metered ..................... 67

Figure 3-31: B1 calibration - first attempt, using weather-normalized metered energy data and

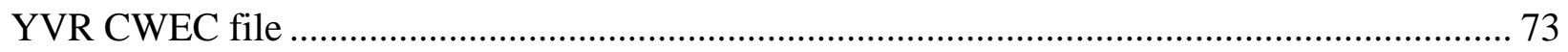

Figure 3-32: B1 calibration - 2011 metered vs. simulated energy use intensity........................ 76

Figure 3-33: 2011 monthly suite electricity base load estimation ........................................ 76 
Figure 3-34: 2011 monthly natural gas base load estimation 77

Figure 3-35: B1 monthly electric heating energy - 2011 simulated vs estimated actual............ 78

Figure 3-36: B1 monthly DHW natural gas consumption - 2011 simulated vs. estimated actual79

Figure 3-37: Fireplace natural gas consumption regression analysis ..................................... 80

Figure 3-38: MAU natural gas consumption regression analysis .......................................... 80

Figure 3-39: 2011 monthly MAU heating energy - simulated vs. estimated actual .................. 81

Figure 3-40: 2011 monthly fireplace heating energy - simulated vs. estimated actual.............. 82

Figure 3-41: Monthly total natural gas consumption - 2011 simulated vs metered .................. 83

Figure 3-42: Monthly fireplace natural gas consumption - 2011 simulated vs estimated actual . 84

Figure 4-1: B2 vs R2 ventilation heating energy - monthly natural gas ................................. 86

Figure 4-2: B2 vs R2 monthly ventilation heating energy breakdown................................... 87

Figure 4-3: B2 vs R2 mechanical ventilation component of annual zone heating load ............. 89

Figure 4-4: B2 vs R2 total annual heating energy associated with mechanical ventilation ......... 91

Figure 4-5: B2 vs R2 total annual heating energy from mechanical ventilation (incl. ASHRAE

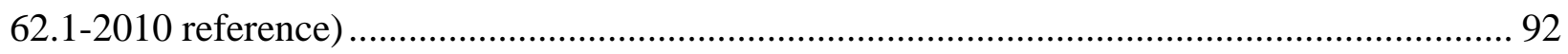

Figure 4-6: B2 vs R2 total monthly electricity heating energy ......................................... 93

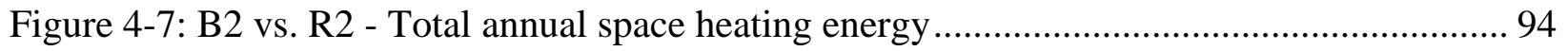

Figure 4-8: B2 vs R2 total annual greenhouse gas emissions by fuel type.............................. 96

Figure 4-9: B1 vs R1 Monthly natural gas space heating EUI ........................................... 99

Figure 4-10: B1 vs R1 mechanical ventilation contribution to annual space heating energy..... 100

Figure 4-11: B1 vs R1 total annual heating energy associated with mechanical ventilation ..... 101

Figure 4-12: B1 vs R1 monthly electricity space heating energy ...................................... 102

Figure 4-13: B1 vs R1 total annual space heating energy ............................................... 103

Figure 4-14: B1 vs R1 total annual greenhouse gas emissions by fuel type........................... 104

Figure 4-15: Retrofit progression from original and current base conditions ......................... 105

Figure 4-16: Annual heating energy comparison for progression of retrofits ......................... 106

Figure 4-17: Metered energy use data for B1 \& B2 calibration - normalized to 2013 HDD for

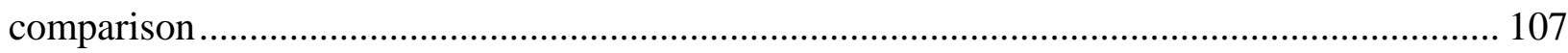

Figure 4-18: Baseload and heating energy reduction from B1 to B2 .................................. 108

Figure 4-19: Annual GHG emissions by fuel type for progression of retrofits ....................... 110

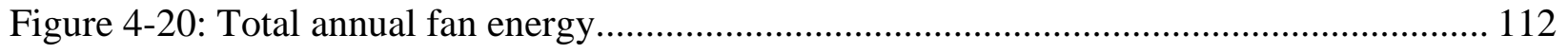


Figure 4-21: Exterior enclosure hourly pressure differentials

Figure 4-22: Average positive pressure differential across enclosure (exfiltration)......

Figure 4-23: Average negative pressure differential across enclosure (infiltration) .....

Figure 4-24: Site wind direction and duration, January - September 2013

Figure 4-25: Wind direction and duration for Vancouver airport, 2013 (source:

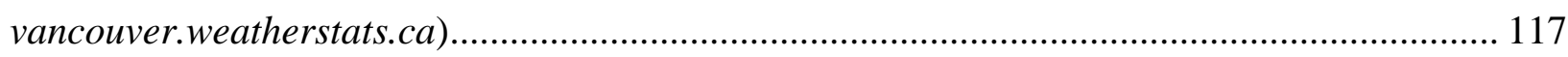

Figure 6-1: Typical floor layout showing perimeter and core zones .................................... 129

Figure 6-2: Visualization of nodal network building model geometry .................................. 130

Figure 6-3: AirFlowNetwork stack-induced internal floor-to-floor airflows - maximum

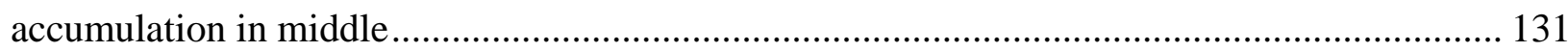

Figure 6-4: AirFlowNetwork stack-induced infiltration - floor by floor ACH ...................... 132 Figure 6-5: AirFlowNetwork stack-induced airflows ground floor - high infiltration, low vertical flow

Figure 6-6: AirFlowNetwork stack-induced airflows middle floor - low infiltration, high vertical flow 133

Figure 7-1: Floorplan of typical floor in case study building 138

Figure 7-2: East elevation of case study building 139 


\section{Introduction}

Ventilation systems in high-rise multi-unit residential buildings (MURBs) are designed to provide fresh air to the breathing zones for the occupants, as well as mitigate odour transfer among suites. These functions are typically performed with a centralized system, supplying air to the common corridors, then relying on air flow past the door undercuts, driven by pressure difference, to ventilate the suites. This unidirectional airflow design is intended to prevent odour transfer between suites, and provide a fresh air source to replenish the air exhausted from the suites by the kitchen and bathroom fans. This ventilation strategy is attractive in its simplicity and relatively very low capital cost, requiring minimal ductwork and HVAC equipment. For this reason, most existing MURBs in North America, as well as the majority of new MURB construction, employ the corridor pressurization ventilation strategy.

\subsection{Problem}

It has long been known in the building science community that the corridor pressurization ventilation systems are both inefficient and ineffective. Research published by Canada Mortgage \& Housing Corporation (CMHC) almost 2 decades ago concluded that "conventional ventilation strategies are unable to meet the ventilation requirements of multi-unit residential buildings" (Canada Mortgage \& Housing Corporation, 1999)

There are numerous underlying reasons why corridor pressurization-based ventilation systems are inherently ineffective which have been known for decades but are generally ignored in design practice. These reasons are discussed in more detail in Section 2.1, but ultimately result in variations in mechanical ventilation rates from floor to floor - or even among suites on the same floor - from severely under-ventilated to wastefully over-ventilated. The resulting consequences for building occupants can be degradation of indoor environmental quality in any number of ways including poor air quality through accumulation of air-borne pollutants and odours, condensation issues, mould growth, and cold drafts.

In addition to being ineffective, corridor pressurization ventilation systems have been demonstrated to be highly inefficient, delivering only a small fraction of the total ventilation air to 
the suites where it is needed, the rest being lost through unintended pathways. During heating and cooling seasons this can be an energy intensive penalty.

Despite mounting evidence supporting the 1999 CMHC findings, pressurized corridor ventilation systems continue to be pervasive today in all but the most high-performance high-rise residential buildings.

\subsection{Research objectives}

The objective of this research is to investigate a retrofit strategy for existing high-rise residential buildings with corridor pressurization ventilation systems, and examine the various potential impacts through building performance simulation. The proposed retrofit involves suitecompartmentalization and a decentralized ventilation strategy. A high-rise MURB in Vancouver is modelled in order to present a case study of the potential merits of the retrofit. The intent is that the findings can inform other high-rise MURB rehabilitation projects and support feasibility studies into ventilation strategy retrofits.

\subsection{Research questions}

This research paper specifically explores the proposed retrofit in the context of a specific case study building, and answers the following questions:

What are the implications of the proposed retrofit on:

1) Overall energy consumption by end use and fuel type?

2) Overall greenhouse gas (GHG) emissions?

These implications are examined for the proposed retrofit on both,

a) The building in its current condition (enclosure retrofitted 2012)

b) The original construction of the building 


\subsection{Organization}

\section{Introduction}

This section sets out the general research objectives and specific research questions which make up the focus of this thesis.

\section{Background}

This section gives a summary of pressurized corridor ventilation systems in high-rise MURBs and introduces their underlying performance problems. A review of previous relevant research is presented, setting the context for this thesis. A brief description of the case study building used in this research and an introduction to the proposed retrofit is given.

\section{Methodology}

A complete account of the methods employed in answering the research questions is given in this section, including data analysis and energy modelling strategy and procedures.

\section{Results \& Discussion}

This section presents the findings of the energy model simulations, and includes a discussion of the results for clarity and continuity.

\section{Conclusion}

A summary of the critical findings and their relevance is given in this section.

\section{Further Research \& Future Recommendations}

Recommendations for further research based on what was learned through this research are provided in this section. 


\section{Background}

\subsection{Pressurized corridor ventilation strategy}

\subsubsection{Influences on system performance}

Mechanical ventilation designs relying on corridor pressurization are in constant competition with other, often more dominant, influences on internal airflow. A positive pressure differential between corridors and adjacent suites is required to ensure the desired ventilation air movement in this type of system. This pressure differential is often disturbed, sometimes even reversed, by factors such as varying wind conditions, stack effect, elevator operation, and window opening.

Figure 2.1 depicts some of the common airflows in high-rise residential buildings.

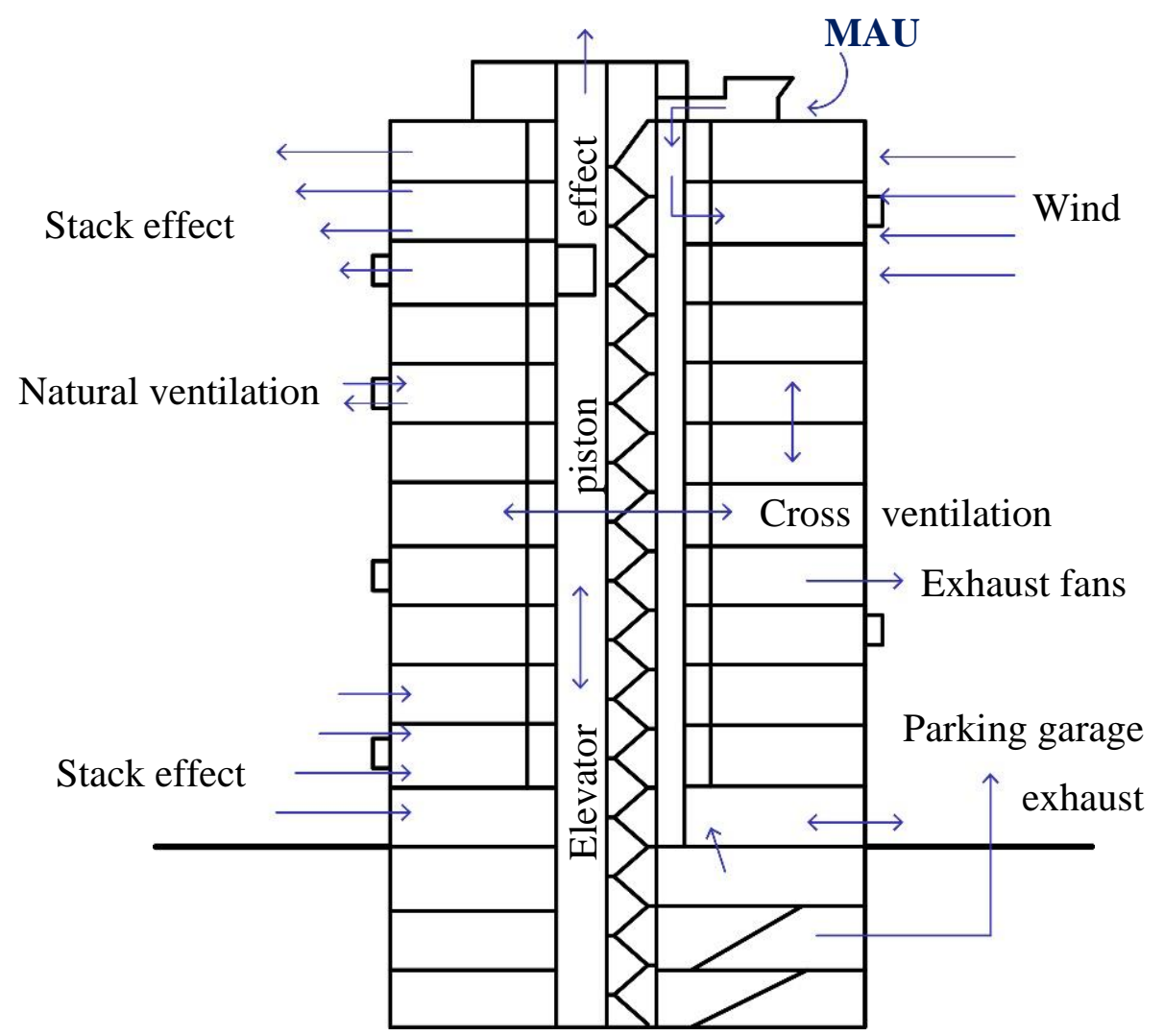

Figure 2-1: Illustration of various airflow paths and causes in a high-rise MURB with a pressurized corridor ventilation system 


\subsubsection{Stack effect}

Stack effect is the term given to the natural tendency for air to rise within a building due to its buoyancy, caused by the density difference between indoor and outdoor air during the heating season, or fall during cooling season. This produces a pressure gradient within a building from bottom to top different from the atmospheric gradient outdoors, causing a driving force for air leakage and infiltration. During heating season for example, the upward airflows within the building induce a pressure regime within the lower floors which is less than outside atmospheric pressure. A lower indoor ambient pressure results in outside air being drawn in through cracks and openings in the building enclosure to equalize the pressure imbalance. The reverse phenomenon occurs on the upper floors, with a higher pressure indoors than outdoors, resulting in exfiltration through the building enclosure.

Figure 2.2 shows an idealized schematic of the internal airflows resulting from stack effect during heating season (left), and the pressure gradient causing these flows due to stack effect (right). The neutral pressure plane (NPP) is the level at which indoor and outdoor ambient air pressure is equal.

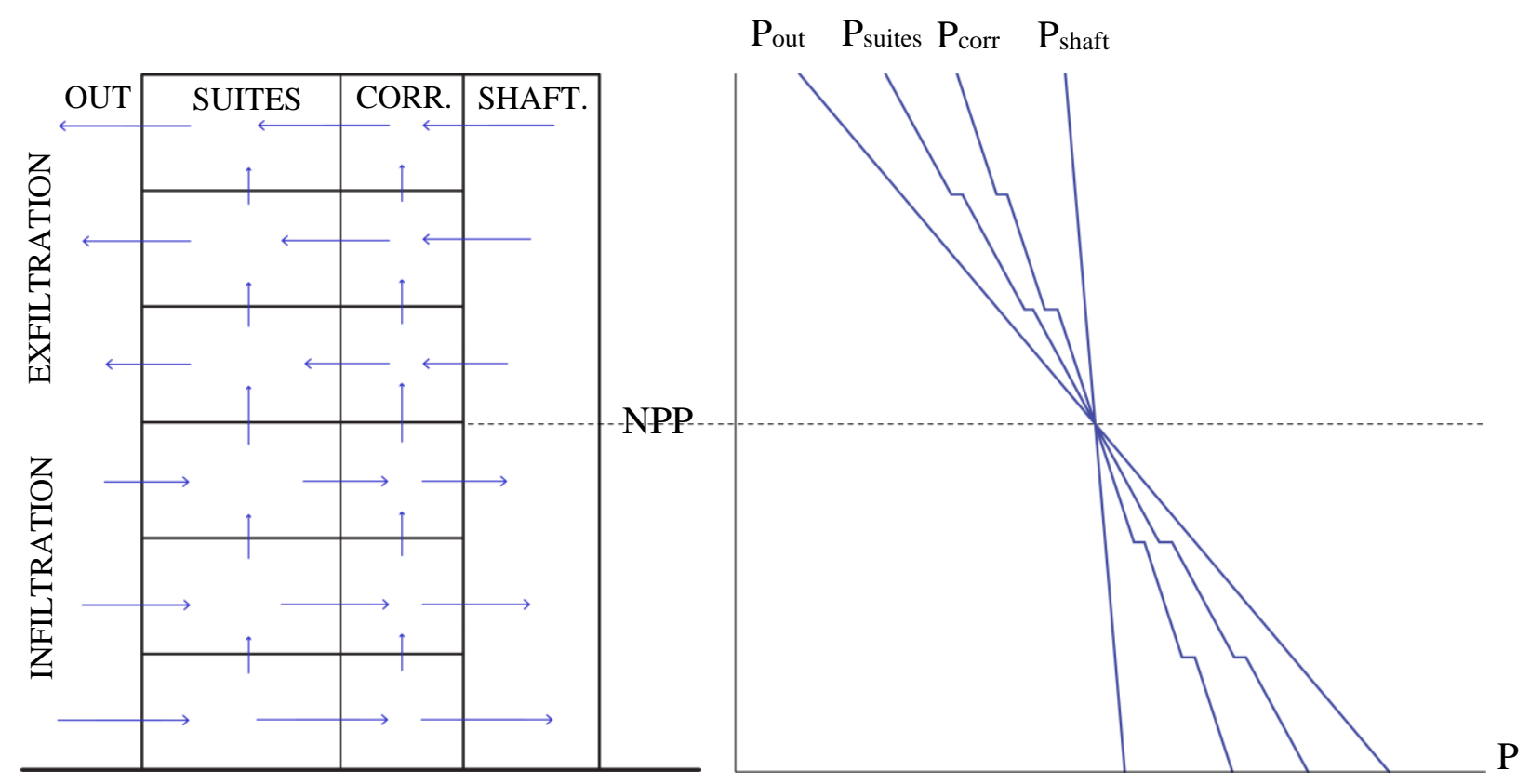

Figure 2-2: Idealized internal airflows resulting from stack effect (left), and the pressure gradient causing these flows due to stack effect (right), for the heating season 
The stack effect phenomenon is exaggerated in older buildings or any building with poor enclosure air-tightness, as a lower resistance to airflow facilitates these unwanted effects.

The core of the building containing the vertical shafts for the elevator, stairwell, garbage chute, and mechanical chase, offers the least resistance to upward airflow, and acts as the main artery for vertical airflows within the building. Because the mechanical ventilation air is delivered to the corridors there is a tendency for this air to be drawn upward along with the stack-induced airflows through these vertical shafts. The resulting distribution of mechanical ventilation heavily favours the upper floors, with the suites on the lower floors receiving very little. Figure 2-3 shows sample measurements from the case study building demonstrating this mechanical ventilation distribution inequality between upper and lower floors during heating season.



Figure 2-3: PFT test measured airflow rates into suites from adjacent corridors

Figure 2-3 shows that even some of the upper suites may not be receiving their design ventilation rate. This is due to losses in the system through duct leakage and the increased upper corridor pressures, which work to counteract and neutralize the mechanical ventilation system pressure, effectively reducing ventilation air delivery to those corridors as well as exacerbating the duct leakage problem. Measurements in a high-rise MURB in one study found that when the these corridor pressures "are of similar magnitude to mechanically induced pressure differences, there 
is significant potential for overwhelming of the mechanically induced pressures and consequently for alteration of airflow rates and direction.” (Ricketts \& Straube, 2014a)

The ineffective delivery of ventilation air is a waste of energy. A study of 39 MURBs in BC found that central ventilation systems provided on average $69 \%$ of the overall space heating energy (RDH Building Engineering Ltd., 2012). Another study of 13 high-rise MURBs in the Vancouver area concluded that conditioning of the central make-up air accounted for 39\% of their total heating energy consumption (Hanam, Finch, \& Hepting, 2011). This ventilation strategy is relatively energy intensive, and yet much of the air does not reach the suites. For a particular high-rise MURB in Vancouver it was found that over half the heating energy went to condition the ventilation air , yet as much as $92 \%$ of that air was lost to the outdoors through unintended pathways such as the elevator shaft and stairwell (Ricketts \& Straube, 2014a).

\subsubsection{Wind}

Compounding the pressures induced by mechanical ventilation and stack effect is the addition of wind pressures on the exterior of the building. A building will experience an increase in exterior pressure on its windward side, and a decrease in pressure on the leeward sides as wind flows around it. The pressure on the windward side, known as stagnation pressure, is proportional to the square of the wind velocity. Wind speed increases with height according to a power law function, meaning the upper surfaces of a building will experience stronger winds than the lower surfaces. Because stagnation pressure increases exponentially with wind speed, and wind speeds increase with height, the pressures developed on the exterior enclosure increase rapidly with increasing building height. At the same time, the pressure difference across the building enclosure increases dramatically from the lower to the upper floors, and from windward to leeward side. Any given floor may experience infiltration on its windward side and exfiltration on its leeward side. Because of this, the corridor-supplied mechanical ventilation will tend to flow toward the leeward suites, and suites on the side of the prevailing wind direction will consistently receive less ventilation.

\subsubsection{Openings}

Operable windows and balcony doors in high-rise buildings add an additional impediment to effective mechanical ventilation. Openings in the building enclosure tend to equalize the connecting zone's air pressure with the outdoor pressure, disrupting the pressure regime in the connected zones and change the local airflow pattern. For example, if a window in a suite is opened 
on an upper floor during heating season when the indoor air pressure is above the outdoor air pressure, the air in that suite would rush out until the suite pressure is equalized with the outdoors. Because pressurized air will take the path of least resistance, the ventilation air in the corridor will tend to flow toward the suite with the open window, and flow to the surrounding suites on the same floor would decrease. Because openings in the building enclosure reduce the resistance to airflows in and out of the building, open windows or patio doors on both upper and lower floors at the same time will also tend to increase airflows induced by stack effect.

\subsubsection{Demand control}

Centralized corridor pressurization ventilation systems have another major drawback limiting their overall efficiency which is that they are designed to be always on, and for most older systems, typically at one constant volume. This means demand controls cannot be implemented to meet the individual requirements of each suite. All suites, including vacant suites and those which are temporarily unoccupied during work hours, are intended to receive the same ventilation supply air rate. A recent report titled "Development of Energy Efficiency Requirements for the Toronto Green Standard" highlights the significance of demand-controlled ventilation and heat recovery in reducing a building's overall energy use (Bach \& Lamb, 2012).

\subsubsection{Aggravating factors}

In addition to the reasons described above for the ineffectiveness of corridor pressurization ventilation systems, three common factors which serve to aggravate the problem are building operation and occupant behaviour, over-sized ventilation equipment, and building enclosure retrofits.

\subsubsection{Building operation and occupant behaviour}

Building operators in cold climates looking to save heating energy costs, may look to the ventilation system. In fact one study found that turning off the corridor ventilation system at $-15^{\circ} \mathrm{C}$ is a common practice for some MURB operators looking to save energy, claiming a reduction in ventilation and infiltration heating energy by $5 \%$ to $24 \%$. (Edwards, 1999) 


\subsubsection{System sizing}

Because the corridor to suite pressure differential required to allow the pressurized corridor ventilation strategy to work is often disturbed by other pressure gradients caused by wind, stack effect, elevator operation, and window opening, equipment for central ventilation systems is often oversized. A study of ten Canadian high-rise MURBs built in the early 1990's found design airflows ranging from $154 \%$ to $461 \%$ of the minimum outdoor air capacity requirements of ASHRAE Standard 62.1, with an average of 264\% (Edwards, 1999). Replacement of oversized ventilation systems represents an important energy savings opportunity in building retrofits.

\subsubsection{Enclosure retrofits}

Retrofits of MURBs generally focus on increasing the insulation and air-tightness of the enclosure to improve overall thermal performance. This can amplify the deficiencies of pressurized corridor ventilation systems, worsening indoor air quality (BC Housing, 2015). One study examining the effect of enclosure retrofits on six MURBs in Canada showed that the average air leakage rates through the exterior enclosure were reduced by $31 \%$ (CMHC, 2013). Proskiw and Phillips (2001) found air leakage after enclosure retrofits decreased by an average of $15 \%$, ranging from $7 \%$ to $24 \%$.

Although air leakage can be a significant source of energy loss, enclosure air-tightness improvements without ventilation system changes will just redirect more ventilation air out through unintended pathways and penetrations. If the central ventilation strategy remains unchanged, but the enclosure is more air tight, the resulting decrease in airflow out through the suite exterior walls will mean a corresponding increase in airflow out of the building through the vertical shafts connected to the corridors.

Enclosure rehabilitation projects can have a negative impact on the already poor effectiveness of pressurized corridor ventilation systems. Reducing leakage pathways through the enclosure means that a greater portion of the ventilation air reaching the suites from the corridors will exit the through the kitchen and bathroom exhaust ducts, or open windows and balcony doors. This path of least resistance tends to short-circuit rooms which are farthest from the entrance door where it 
entered, which is often the bedrooms where the air is needed most during the night. Attempts to improve ventilation by opening windows exacerbates stack effect and is wasteful in terms of energy. On the upper floors there is an increased amount of conditioned air lost to the outdoors, and on the lower floors unconditioned air is brought in through the windows, increasing the amount of supplemental heating required.

For any building enclosure retrofit project involving air-tightness improvements, there should be an examination of the effect on air quality in the living spaces, and consideration for other new ventilation strategies as a part of the rehabilitation work.

\subsubsection{Implications of status quo}

\subsubsection{Heating energy}

Unmitigated stack effect drives infiltration on the lower levels of a building during the heating season. This cold outside air entering the building creates an additional heating load on the lower floors, from the neutral pressure plane and increasing down to the ground floor. This has a negative impact on thermal comfort for the occupants on these lower floors for buildings with centrally controlled heating systems. For buildings with in-suite thermostats and independently controlled heaters this infiltration causes a discrepancy in the heating energy consumption for the occupants on the lower floors, as is the situation with the case study building examined in this research project and introduced in Section 2.3. Figure 2-4 shows the estimated total annual suite-level heating energy per floor for the case study building. Some irregularities can be seen for certain floors which will be discussed later in Section 3.1.1.2, but the general floor by floor discrepancy trend can be seen in the figure below. This trend would in theory also be much more pronounced in taller buildings in colder climates than Vancouver's. 


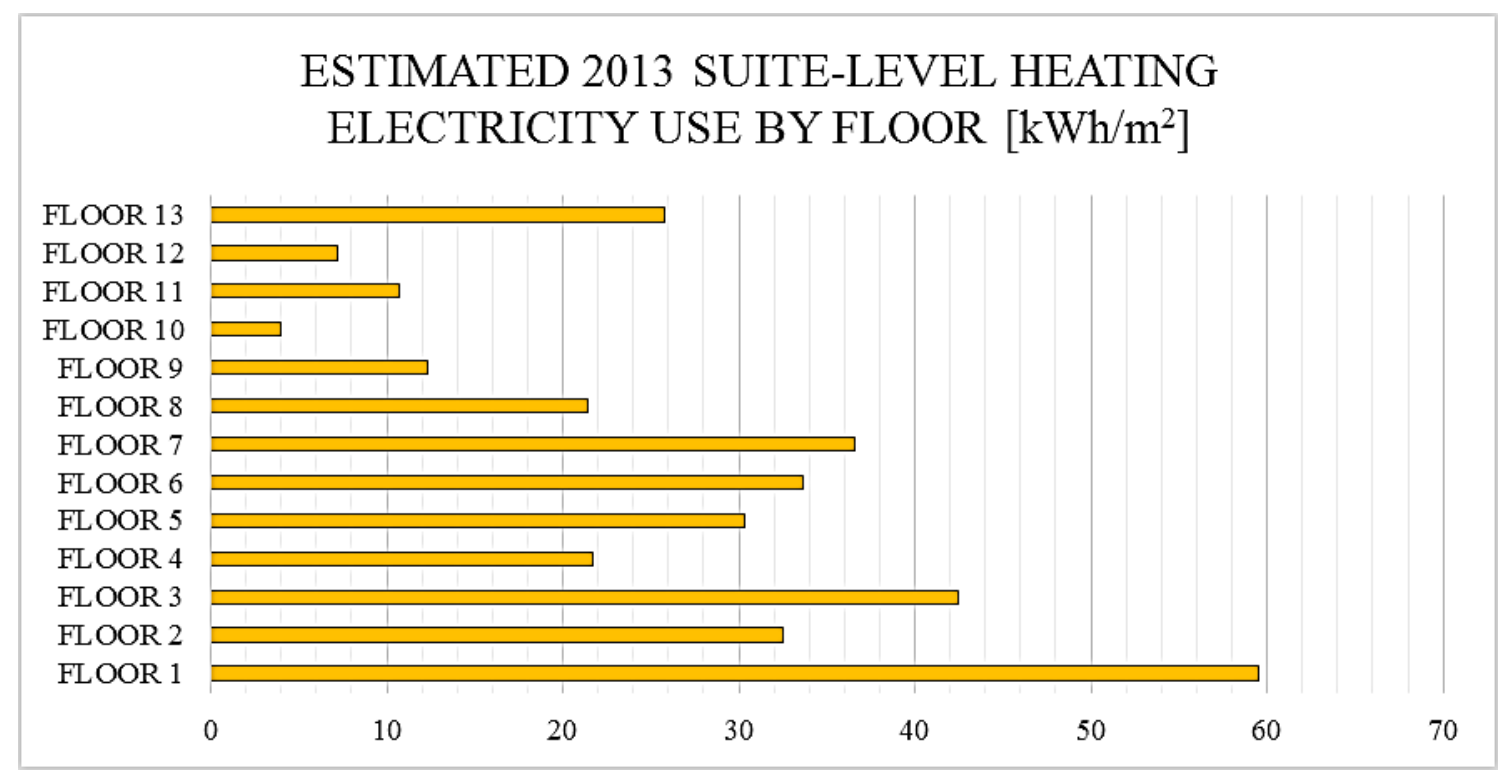

Figure 2-4: Estimated annual suite-level heating electricity by floor

\subsubsection{Indoor air quality}

The deficiency of the corridor pressurization strategy in providing recommended ventilation rates to the living quarters within a building has a number of negative implications. The lack of air exchange within a suite can create an unpleasant indoor environment for occupants through a buildup of humidity and odours. A buildup of humidity can in turn result in condensation on the inside surfaces of exterior walls, leading to water damage and mold growth. Mold growth due to moisture accumulation in walls is not an uncommon problem, and can cause respiratory illness.

Perhaps more problematic is the impact that stack effect can have on the indoor air quality in suites on the lower floors of high-rise MURBs with underground parking garages. There are serious health implications connected with exposure to car exhaust fumes (Health Canada, 2012), and the upward airflows induced by stack effect during the heating season has been found to draw air up from the underground parking garage (Montgomery, 2015). Vehicle exhaust contains a number of airborne pollutants which are harmful to the health of the building's residents, including carbon monoxide, an odourless and very deadly by-product of all internal combustion engines. In the case study building for example, perfluorocarbon tracer (PFT) testing found a significant amount of air within the corridors and suites originating from the parking garage. The testing found that "the total airflow from the parking garage to the corridors was $343 \mathrm{~L} / \mathrm{s}$, which is approximately $60 \%$ of 
the average total supply airflow to all corridors from the MAU....significant airflow from the parking garage was measured, even four floors [ground level]...” (Ricketts, 2014)

It was also noted by Ricketts (2014) that the outside conditions during testing were relatively mild $\left(8^{\circ} \mathrm{C}\right.$ average), so this measured quantity of air drawn up from the parking garage would not represent a worst case scenario given the even greater magnitude of stack effect which would occur during colder weather periods.

\subsection{Previous research}

\subsubsection{Pressurized corridor ventilation strategy}

Research on the ineffectiveness of the pressurized corridor ventilation strategy extends back at least 20 years. Research by Canada Mortgage \& Housing Corporation (CMHC) in the late 1990's and early 2000's indicates that there are significant issues with this standard ventilation practice for high-rise residential buildings. CMHC concludes in no uncertain terms that "conventional corridor air supply and bathroom-kitchen exhaust systems do not, and cannot, ventilate individual apartments." adding also "Most importantly, conventional ventilation systems can compromise the integrity of fire and smoke control because they are dependent on a high level of interconnectivity between individual apartments and public areas" (Canada Mortgage \& Housing Corporation, 2003)

In another study, the corridor pressurization system in a high-rise MURB was found "to unevenly distribute ventilation air to both the corridors and suites of the building with upper zones receiving significantly higher ventilation rates than lower zones, and many suites either being significantly over ventilated or under ventilated", and that the "low flow rates measured are due to a combination of a lack of control of the ventilation air once brought in to the building and the inability of the ventilation system to overcome stack effect pressures" (Ricketts, 2014)

Perhaps because the actual behaviour of these ventilation systems has so many influencing factors and is so unpredictable once in operation, it has been found that they are designed more using crude rules of thumb than any precise methods (CMHC, 2003). Wray, Theaker, \& Moffatt (1998) conducted a survey of mechanical ventilation system designers for high-rise MURBs in Canada: 
[Designers] typically do not specify, and have little or no information regarding the actual airtightness of the combined corridor wall and suite access door assemblies, or of the airtightness of the building envelope or other components effecting corridor pressurisation. Furthermore, they seldom take into account the effects of stack- and wind-induced pressure differences. They typically use safety factors of 25 to $125 \mathrm{~Pa}$ to take some of these uncertainties into account.... Consequently, the pressure in the corridor relative to the suites is unknown, the amount of air leaking from the corridor into the suites is unknown, and suite ventilation occurs more through accident than design.

Wray, Theaker, \& Moffatt (1998) also measured corridor ventilation system airflows in ten Canadian high-rise MURBs up to 32 storeys in height built in the early 1990's. Results showed significant differences in the supply air design specifications, ranging from 25 to $109 \mathrm{~L}$ per suite. According to ASHRAE Standard 62.1 guidelines, this translates to oversizing from $50 \%$ to $350 \%$. Actual supply airflow rates at the corridor however were measured at only $34 \%$ to $81 \%$ of the design flows (Edwards, 1999). It would seem that many pressurized corridor ventilation systems in Canadian MURBs have been designed without enough information to ensure their effectiveness, and with no practical requirement to operate as designed.

\subsubsection{Compartmentalization and dedicated in-suite ventilation systems}

Despite the significant research indicating the corridor pressurization ventilation strategy is ineffective, and none found to the contrary, very little has changed in high-rise MURB ventilation system design. In some new building developments, which are either striving to decrease their energy use intensity or achieve some form of certification, or in some more modern MURBs which are very tall - 40 storeys and above, more or less - the suites are being compartmentalized and dedicated in-suite ventilation systems installed. Unfortunately, at the time of writing, no information on the energy implications of this strategy have been found, and only a single report on the effectiveness of the strategy by Brown \& Gorgolewski (2014) summarizing a qualitative observations of a post-occupancy evaluation, discussed briefly again in Section 4.4.2. 
A fair amount of literature has been produced describing the benefits of suite compartmentalization with dedicated in-suite ventilation in high-rise MURBs, however no published research has been found describing the actual performance of such a strategy - perhaps because it is so rare. A small amount of research was found specifically looking at this strategy as a retrofit measure for existing high-rise MURBs, however none was employed on a case study building.

A research study by CMHC in 2003 titled "Ventilation Systems for Multi-unit Residential Buildings - Performance Requirements and Alternative Approaches" is a fairly comprehensive investigation of ventilation strategy alternatives. The report aimed to "develop recommendations and specifications for effective and efficient ventilation strategies for individual apartments, and compare the cost and performance of these improved systems against conventional systems." (Canada Mortgage \& Housing Corporation, 2003) A suite compartmentalization strategy with balanced dedicated in-suite ventilation was one of four options examined and was determined to be the least impacted by stack effect, and have "excellent ventilation performance when combined with airtight suite design". None of these retrofit options was implemented, but rather investigated through simplified analysis.

Another research project conducted by CMHC in 2005 aimed to explore the air-tightness characteristics and ventilation system performance in eight high-rise MURBs in Toronto, built around the early 2000's. The intent was also to investigate implications of suite compartmentalization and determine associated design considerations for this type of building. Entrance doors were temporarily sealed in order to emulate some degree of suite compartmentalization. Corridor to suite pressure differences were measured with and without the central ventilation system running, and with and without the suite exhaust fans running, to determine the range of operation. The study concluded that "airtight interior and exterior partitions, or compartmentalization, of individual suites and the installation of in-suite ventilation systems represent two improvements in the design and construction of MURBs that can improve the overall performance of this class of building." The study also went on to qualify that "the provision of relatively well-sealed suites cannot be done in isolation. Consideration must be given to in-suite ventilation, make-up air issues, suite depressurization tolerances and combustion appliance safety." (Canada Mortgage \& Housing Corporation, 2005) 
A study of another Canadian high-rise MURB concluded that "interior compartmentalizing elements between suites and between the suites and the corridor should be relatively airtight such that the operation of windows in one suite does not significantly impact airflow and ventilation rates in other parts of the building." The study went on to say that "if suites are to be compartmentalized relative to adjacent to zones, the corridor pressurization based ventilation system is no longer a feasible option for ventilation of the suites, and the ventilation air would need to be ducted directly to each suite or supplied by in-suite systems." (Ricketts \& Straube, 2014b)

A study in British Columbia of 39 mid- and high-rise MURBs also identified the traditional pressurized corridor approach as being problematic, and that independent suite-based ventilation and space heating systems should be considered, in conjunction with suite compartmentalization to mitigate pressure differentials across the enclosure due to stack effect. Energy modelling of a typical building showed "significant benefits with the use of heat-recovery ventilators....the average space heat savings from $80 \%$ efficient in-suite HRVs was 33.8\%." (RDH Building Engineering Ltd., 2012)

\subsubsection{Computer modelling approaches}

Early work by both Lstiburek (2000) and Richman (2002) contributed to the prediction of airflows in buildings through an understanding of the transient zonal pressure regimes. Whole building analysis of large multi-zone buildings was made difficult by software and processing limitations at the time. Most research which followed involving airflow analysis within a building using whole building energy modelling tools has tended to focus on IAQ. The main body of research seems to focus on contaminant dispersion prediction and the occupant exposure, natural ventilation analysis, and various combined energy modelling/CFD analysis techniques. Such analyses of airflows within buildings will use a nodal network approach. These nodal airflow network models tend to use CONTAM ${ }^{\mathrm{TM}}$, software specifically designed to analyze contaminant dispersion. CONTAM ${ }^{\mathrm{TM}}$ is also used in industry to help predict the pressure regimes in tall buildings, informing design decisions to mitigate and control stack effect. 
Research which examines the energy impact of air-tightness measures on energy use tends to focus on whole-building enclosure air-tightness and not suite-level compartmentalization. Emmerich, Anis, \& McDowell (2005) for example examined the energy impact of improving envelope airtightness in U.S. commercial buildings. CONTAM ${ }^{\mathrm{TM}}$ multi-zone airflow and TRNSYS ${ }^{\mathrm{TM}}$ building energy simulation tool was used to predict the energy use for the buildings at a target tightness level relative to a baseline level based on measurements in existing buildings.

Despite no research involving whole building energy modelling of suite compartmentalization and any suite-dedicated ventilation strategy having been found, as a building retrofit or otherwise, there is good research indicating that the EnergyPlus ${ }^{\mathrm{TM}}$ AirFlowNetwork object is an appropriate tool for this analysis.

Several papers contain thorough outlines or analyses of the AirFlowNetwork object capabilities. $\mathrm{Gu}$ (2007) validated an EnergyPlus ${ }^{\mathrm{TM}}$ airflow network model against measured data from both the Oak Ridge National Laboratory (ORNL) and the Florida Solar Energy Center, validating specific portions of its airflow network model. The study concludes good agreement between the simulation results and the measured data. Research from Ernest Orlando Lawrence Berkeley National Laboratory investigated the airflow network and air-handling system simulation capabilities of EnergyPlus $^{\mathrm{TM}}$ as of 2014, highlighting the shortcomings of the standard infiltration and ventilation objects in EnergyPlus ${ }^{\mathrm{TM}}$ as motivation for the work, as well as modelling limitations outlined by ASHRAE's Multidisciplinary Task Group on High Performance AirHandling Systems for Buildings Except Low-Rise Residential Buildings (MTG.EAS). Their investigation concludes that improvements on the standard modelling methods of air distribution systems in buildings "can largely be accommodated within the modeling framework already provided by the EnergyPlus ${ }^{\text {TM }}$ AirflowNetwork capability.” (Lorenzetti \& Wray, 2014)

Little research has been found which employs energy modelling to simulate the potential impact of a suite-level compartmentalization retrofit strategy combined with dedicated balanced ventilation with heat recovery for high-rise residential buildings. Some similar research touches on aspects of the topic, but not in a comprehensive manner, and without the extent of measured data which was available for the case study building examined in this research. This topic is discussed in further detail in Section 3.3.2. 


\subsection{Case study building}

A 13-storey multi-unit residential building in Vancouver, British Columbia (B.C.), constructed in 1983, underwent an enclosure retrofit in 2012 to address water ingress issues and improve its durability, air-tightness, and thermal performance. An elevation drawing and typical floor plan can be seen in Appendix A. Various performance characteristics of the building were measured before and after the retrofit, including air-tightness and energy consumption.

\subsubsection{Overview}

Figure 2-5 below shows aerial satellite photographs of the case study building during and after the 2012 enclosure retrofit, for visual reference.
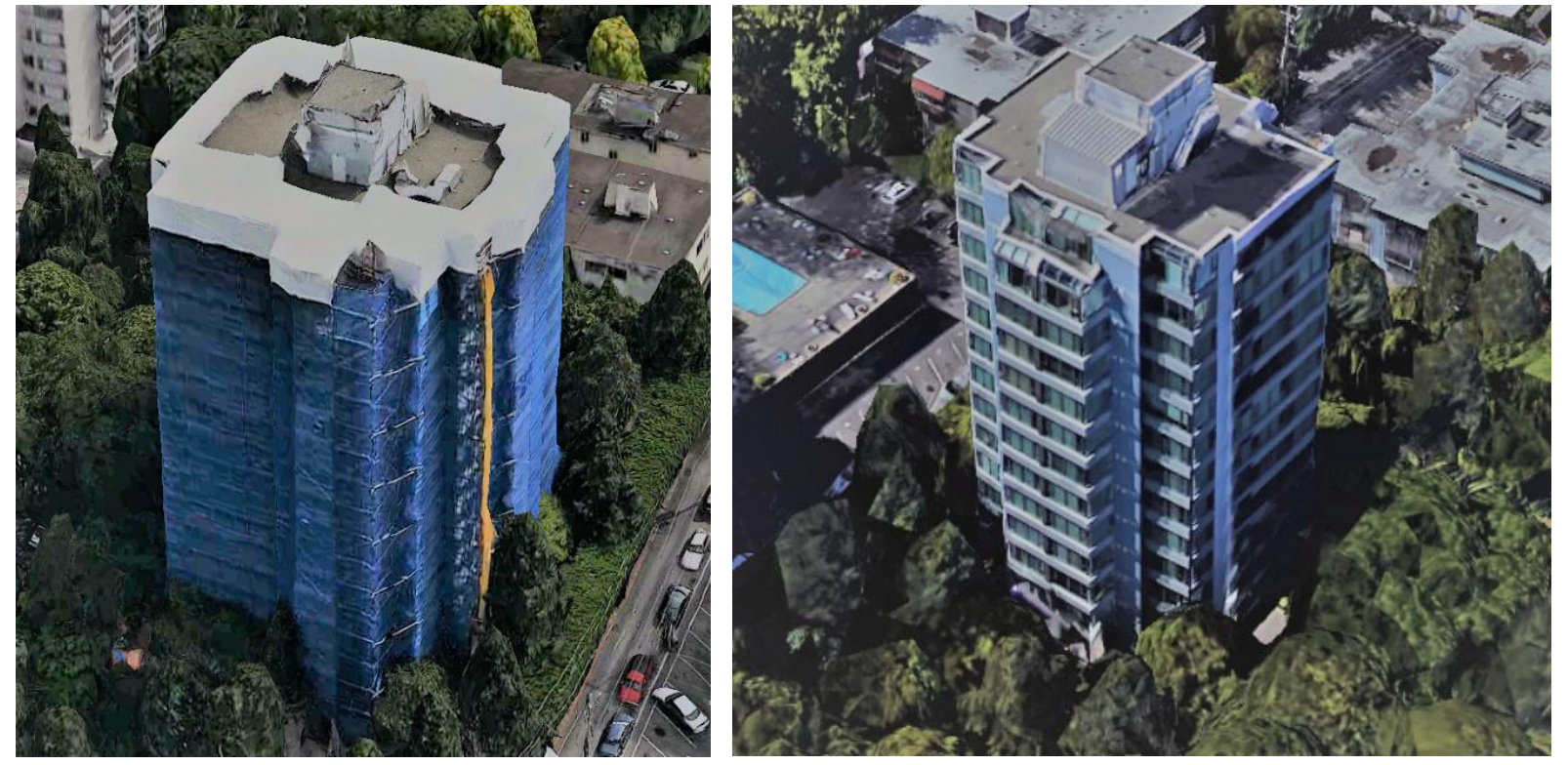

Figure 2-5: Case study building circa 2012 during enclosure retrofit, and circa 2013 after retrofit (current condition) (image: apple maps, google earth)

An initiative by various municipal and industry stakeholders led to the building being fitted with extensive environmental and performance monitoring system prior to the retrofit work taking place. Comprehensive data was collected for at least a full year (2013) following the retrofit. The retrofit project was coordinated and executed by RDH Building Science Inc., who continues to 
monitor the building's performance at the time of writing. The enclosure retrofit served to resolve the water ingress issues, improve durability and air-tightness, and significantly reduce electric heating energy. Measured evidence, however, indicated that the ventilation system was not performing as intended by design, and certainly not as desired by the building's occupants. As noted by Ricketts \& Straube (2014b), “Overall, the pressurized corridor based ventilation system at the case study building was found to unevenly distribute ventilation air to both the corridors and suites of the building, with upper zones receiving significantly higher ventilation rates than lower zones, and most suites being significantly over- or under-ventilated...". The residents of the building are predominantly retirees, and as such spend more time inside the building than typical for working professionals, and may also be more sensitive to its indoor environmental quality. There has been interest expressed by the condominium corporation in improving to the building's ventilation system.

This research into the potential impacts of a proposed retrofit on the case study building involving suite compartmentalization and dedicated in-suite ventilation is intended to build on and complement the existing research, and help inform future considerations of performance improvement measures for the building's ventilation system.

The following is a summary of the data from the case study building which were made available for this research.

\subsubsection{Environmental data}

Monitoring equipment and a weather station were installed on the case study building during the summer and fall of 2012. The data monitoring period began in January, 2013 and continued through December, 2013. The weather station on the roof recorded outside temperature, relative humidity, wind speed and direction, solar radiation, precipitation, and barometric pressure at hourly intervals. These data was used to create a custom weather file for use in the calibration procedure of an energy model of the case study building. Details of this analysis are described in Section 3.2 . 


\subsubsection{Energy use data}

Suite level electricity consumption was monitored using BC Hydro smart meters. However, these data were available only at an aggregated level for the whole building on a monthly basis. Common area electricity consumption was also available on a monthly basis. Detailed analysis of electricity consumption is provided in Sections 3.1.1.2 and 3.1.2.

Natural gas consumption was sub-metered for the make-up air unit (MAU) and domestic hot water (DHW) boiler for a 7 month period from February $2^{\text {nd }}$ to September $30^{\text {th }}, 2013$. Gas consumption at the whole building level is available for several years prior to the 2013 monitoring period. Although there was no direct measurement of natural gas consumption for fireplaces located on the $9^{\text {th }}-12^{\text {th }}$ floors, their gas consumption was determined from the remainder. Detailed analysis of the natural gas consumption is provided in Sections 3.1.1.1 and 3.1.2.

\subsubsection{Physical characteristics}

\section{Enclosure assembly}

A comprehensive retrofit of the building enclosure had been carried out in 2012 involving replacement of the original windows with triple-pane insulated glazing units, the addition of exterior insulation (89mm (3 1/2") mineral fibre insulation) and a thermally broken and more effective rain screen cladding system, as well as overall air-tightness improvements. On the roof, a $100 \mathrm{~mm}$ (4”) layer of extruded polystyrene (XPS) insulation was added above the concrete topping. The overall window-to-wall ratio remained unchanged at approximately $65 \%$. Details of these improvement measures are described further in Table 3-2 in Section 3.3.3.1. The original enclosure assembly details are described in Table 3-5 in Section 3.3.5.1.

\section{Mechanical systems}

The building's HVAC systems are representative of most high-rise residential buildings in B.C., and elsewhere in North America. An indirect-fired natural gas MAU provides conditioned mechanical ventilation (heating only) air to the building using the corridor pressurization strategy 
previously described. Zone heating is provided by electric convection, or "baseboard" heaters in each suite, and a natural gas boiler provides hot water for domestic use. Mechanical system upgrades during the enclosure retrofit were limited to replacing the natural gas-fired boiler for domestic hot water production, with a more efficient model. Details of the mechanical systems are outlined in Table 3-3 of Section 3.3.3.1.

\subsubsection{Building performance}

\subsubsection{Mechanical ventilation}

Mechanical ventilation airflow rates had been monitored in the supply trunk of the MAU, as well as inside the building at the register in each corridor. Over a year's worth of data were available from during and after the enclosure retrofit. Total volume flowrate delivered to the building was recorded by measuring the airspeed just downstream of the MAU. The airspeed was determined through transverse pressure measurements across a duct section using a pitot tube, with the airspeed calibrated to these measurements using a powered flow hood. Volumetric flow rate was determined to be $1.44 \mathrm{~m}^{3} / \mathrm{s}$ on average, close to the nameplate value on the MAU of $1.5 \mathrm{~m}^{3} / \mathrm{s}$.. Airflow rates in the corridors were measured using unpowered "balometer" flow hoods. Actual airflow delivery to the corridors was determined to be only approximately $40 \%$ of the total MAU rate, meaning $60 \%$ was being lost through duct leakage in the mechanical chase or elsewhere. Details of the test setup and measurement equipment used can be found in Ricketts (2014). MAU supply air measurements are shown in Figure 3-22 and Figure 3-23 of Section 3.3.3.1.

\subsubsection{General airflow}

Results were available from testing conducted to determine the airflow characteristics of the building prior to and following the enclosure retrofit. Two airflow test methods were used:

1) Perfluorocarbon tracer (PFT) gas testing was done, which indirectly measures airflow patterns and rates through controlled particle dispersion, and

2) zone pressure monitoring with sequentially neutralized zone pressurization and depressurization testing. This method measures the resistance to airflow of the various building partitions, which then combine with pressure measurements to determine the resulting airflows. 
Not all of the airflow test data were ultimately incorporated into this research, but a summary of the available results is included here for complete context, and as an introduction to the two different energy modelling strategies employed, which will be discussed further later on.

\section{Perfluorocarbon tracer gas testing airflow results}

PFT testing was conducted during a typical week in the heating season from April $10^{\text {th }}$ to 17 th, 2013 shortly after the enclosure retrofit. An outline of the test methodology of can be found in Ricketts (2014b). Test results show a general increasing trend in zone air changes going up the building, in line with what would be expected due to stack effect. As mentioned previously, air originating from the underground parking garage was detected up to four floors above grade, also in keeping with the stack effect phenomenon. Some assumptions which had to be made by the laboratory in the analysis of the data however were not realistic, and skewed the subsequent airflow calculation results by some unknown factor. Most notably, in determining ventilation air change rates in the corridors it was assumed that the mechanical ventilation air, used as a transport medium for the tracer gas, was distributed evenly throughout the floors and suites of the building. This assumption was not accurate, as demonstrated through actual airflow measurements at each corridor.

Other PFT tests where the tracer gas was not carried by the MAU airstream were not as flawed, however the measurements of airflow rates from the corridor to the suites were also insufficient to determine actual mechanical ventilation delivery rates to the suites. This is because the air in the corridors is a mixture from many sources other than from the MAU, and measured flow reversals indicate that some proportion of the air entering the suites would be re-entrained air which had originally flowed out of the suites. Results from this method differ by a factor of nearly ten from the results determined through air-tightness testing, discussed next. Despite concerns regarding the magnitude of the airflows calculated using the PFT results, the general trend in airflows observed coincides with the trend expected due to stack effect.

The measured airflows in and out through the exterior enclosure also appear to be flawed in some way. Test results from floors 3 and 11 showed airflow out of the suite to the outdoors was to be negative. Because of the nature of the test, this negative result does not simply indicate a flow reversal to infiltration, but indicates an error in the data. No distinct trend could be detected in 
airflows based on the limited sample size, and so these calculated airflow rates were not used as model inputs for infiltration.

Ricketts (2014b) also observes that "no correlation beyond order of magnitude was found between the measured airtightness of a pressure boundary and the amount of airflow through that pressure boundary as measured by the PFT testing."

Unfortunately, the accuracy of the PFT test results for neither the mechanical ventilation air distribution or the infiltration rates was well enough understood, and therefore not used in model. However, PFT testing in general can contribute very valuable information to the analysis of stack effect in a building, and is discussed further in Section Error! Reference source not found.

\section{Airflow resistance data and zone pressure monitoring results}

For the second airflow analysis technique employed, air-tightness data was available from the sequentially neutralized pressurization/depressurization air-tightness testing. Testing followed a variation based on standardized ASTM, CGSB and USACE test procedures. An outline of the specific methodology of the testing procedure can be found in Ricketts (2014b). Testing had been conducted on floors 3 and 9 , representing a sample of a typical floor from both the upper and lower halves of the building.

For the suites on these floors, air-tightness characteristics were determined for each of the following boundaries: suite-to-outside, suite-to-corridor, and suite-to-suite both above and below.

For the corridors on these floors, a modified approach involved sequentially sealing all but one of the openings from the corridor (doors to elevator, suites, stairwells, garbage chute, ventilation grill, etc.) and repeating the pressurization/depressurization testing each time. This allowed for the relative proportion of mechanical ventilation air flowing through each of the various openings to be determined, as well as the calculation of the airflow resistance characteristics of each of these elements, as described below.

Measured airflow rates through the various partitions at the various known pressure differences of the test conditions can be used to determine the airflow resistance characteristics specific to that 
building element. From Hutcheon \& Handegord (1995), the relation for this can be defined by the "crack flow" or power law equation:

$$
Q=C \Delta P^{n}
$$

Equation 2.1

Where $\mathrm{Q}=$ volumetric flow rate $\left[\mathrm{m}^{3} / \mathrm{s}\right]$

$\mathrm{C}=$ flow coefficient $\left[\mathrm{m}^{3} /\left(\mathrm{s} \cdot \mathrm{Pa}^{\mathrm{n}}\right)\right]$

$\Delta \mathrm{P}=$ pressure difference $[\mathrm{Pa}]$

$\mathrm{n}=$ flow exponent $[-]$

Through graphical analysis of the test data the flow coefficient $C$ and exponent $n$ can be determined for each building element. With these characteristics established, transient internal flow rates within the building during normal operation can be determined if the pressure differences across connected zones are known over time.

A pressure monitoring program had been set up in order to collect hourly data throughout the year. Pressure sensors were installed throughout the building's corridors and suites, including exterior pressure taps. These data, combined with the airflow resistance characteristics of the various partitions determined through the air-tightness testing, could be used to calculate the transient airflows within the building.

Although this method is ideal and quite accurate in theory, there are a number of confounding factors which make it difficult in practice. Abrupt and random changes in the airflow resistance characteristics of the various partitions - caused by the opening of elevator, suite, and stairwell doors, for example - will have an impact on the surrounding pressure regime beyond just that partition's two adjacent zones, and for a time period longer than the duration the door is actually open. A sudden pressure equalization measured across a partition would result in a corresponding sudden drop in the calculated airflow, if one assumes that the measured airflow resistance characteristics for that partition are constant. In fact, the airflow would instead suddenly increase across the partition until pressures are equalized, because in reality the airflow resistance would have suddenly decreased dramatically due to the temporary opening. Intermittent operation of the bathroom and kitchen exhaust fans would also effectively temporarily alter the airflow resistance 
characteristics of the exterior enclosure from the measured values, changing the pressure regime and disrupting surrounding airflow patterns. Operation of windows and balcony doors would have the same effect as well. However, because the duration that a window or balcony door is open would tend to be measured in hours or even in days, significant error in calculated airflows across the enclosure over time would be introduced. Without monitored data on the schedule and duration of the various openings in partitions, and secondary measurements of the corresponding airtightness in these various possible altered states, these operational irregularities of the building make it difficult to understand the transient airflow patterns.

\subsubsection{Airflow characteristics used for energy model calibration}

Airflow patterns for calibration of the case study building energy model in this research were based on a combination of the measured airflow resistance characteristics and direct mechanical ventilation flow measurements deemed to be the most reliable in accuracy.

Much of the monitored field data had high degree of precision, but without the ability to determine its accuracy, the fidelity of a more granular analysis based on the fundamental driving forces (i.e., pressure differences) would be unknown. To avoid propagation of this uncertainty, a granular airflow pattern analysis (from pressure data) was traded for a more global airflow analysis based on test results deemed to be more accurate at the whole-building level.

A more complete understanding of the accuracy of the available measured building data, and the

implications on the airflow analysis and associated energy use, was only gained after efforts to model the building as a nodal network were made. These details are discussed further in Section 3.3.2.

\section{Infiltration}

The average air flow resistance characteristics of the exterior enclosure, as determined through pressure-neutralized air-tightness testing were used in estimating global infiltration levels for the whole building. The flow coefficient $C$ was calculated to be 9.99, and flow exponent $n 0.63$. A reference pressure differential across the envelope of $4 \mathrm{~Pa}$ was used as outlined by Sherman \& Grimsrud (1980). The suitability of this assumption is discussed further in Section 4.4.1. A 
constant infiltration rate was then calculated using Equation 2.1. The impact of wind was accounted for using a linear wind speed coefficient of 0.224 in the EnergyPlus ${ }^{\text {TM }}$ ZoneInfiltration object based on the DOE-2 infiltration model as recommended by Gowri, Winiarski, \& Jarnagin (2009) and discussed further in Section 3.3.3.1. This approach was thought to produce more reliable results than the infiltration rates measured through PFT testing, for the reasons described previously.

The resulting baseline infiltration rate for the case study building was $0.29 \mathrm{~L} / \mathrm{s} / \mathrm{m}^{2}$. This result was compared with other published values from previous studies of similar buildings and found to be lower but in the same order of magnitude. The air-tightness improvements of the enclosure retrofit would explain the lower leakage rate, as compared to the un-renovated buildings of similar vintage from the studies. One study of air-tightness of comparable buildings reported an average leakage rate of 3.2 L/s/m² @75 Pa (Proskiw \& Phillips, 2001), or about 0.36 L/s/m² at $4 \mathrm{~Pa}$. CMHC (2013) found comparable leakage rates of $3.66 \mathrm{~L} / \mathrm{s} / \mathrm{m}^{2} @ 75 \mathrm{~Pa}$, or about $0.410 \mathrm{~L} / \mathrm{s} / \mathrm{m}^{2}$ at $4 \mathrm{~Pa}$.

Although this is a simplified approach of estimating infiltration rates, it is based on direct measurements of the enclosure's airflow resistance characteristics with an average pressure difference across it based on standard practice. This is an improvement over another common modelling practice of simply assuming an infiltration rate based on benchmarks for similar buildings (a necessity when no measured data is available), and was considered to be more reliable than the PFT results, as discussed earlier. The resulting infiltration is also comparable to other published results for similar buildings.

\section{Mechanical ventilation}

Internal airflow rates were not estimated using the measured airflow resistance characteristics of the interior partitions, for the reasons described above regarding the monitored pressure field data. The PFT testing results in this case were also unreliable due to flawed assumptions in the laboratory analysis. Instead, the actual measured proportion of airflow into the suites from the corridors was used. The measured percentage of total mechanical ventilation air delivery to each corridor had been determined through flow hood testing, and the relative proportion of that air which reached the suites was determined from the sequentially neutralized pressurization and 
depressurization testing described above. The data used as inputs to the model are outlined in further detail in Section 3.3. The implications of the available building performance data for the nodal network energy modelling approach are discussed in Section 3.3.2.

\subsection{Retrofit proposal}

\subsubsection{Overview}

A rehabilitation strategy for high-rise MURBs which mitigates uncontrolled airflows within the building and enables efficient and effective ventilation air distribution will result in a more energy efficient and comfortable building to live in. The retrofit proposed in this paper is to compartmentalize the suites by isolating them from the corridors, and install dedicated balanced heat recovery ventilators $(\mathrm{HRV} \mathrm{s})$ in each.

By isolating the suites from the corridors through air-tightness measures, uncontrolled airflow between the suites and the outdoors would be reduced. These measures would shift stack-induced pressure differentials from across the exterior enclosure to across the corridor-suite boundary. Suite ambient pressures could then equalize with outside atmospheric pressure, thereby reducing airflows in and out through the enclosure. The central ventilation system delivery rate could then be reduced significantly to the level required to serve only the common corridors, resulting in a corresponding decrease in natural gas consumption used to condition the outside air.

Fresh air would be provided to each suite through a dedicated HRV, allowing ventilation rates to be predictably controlled. The HRV's balanced intake and exhaust flows help to avoid pressurization or depressurization of the suite, and reduce uncontrolled air leakage. Demandcontrolled ventilation is then possible so that individual suites do not have to be ventilated unnecessarily while unoccupied.

The specific compartmentalization retrofit investigated in this research was a simple air-sealing measure on the entrance doors of the suites. The entrance door, with an undercut to allow airflow, represents the leakiest component of the interior separation between the suite and corridor. Increasing the air-tightness of the entrance door therefore has the greatest potential impact to compartmentalizing the suite. In fact, because high-rise residential buildings are nearly always 
cast-in-place concrete construction, the interior walls of the suites are generally quite air tight. A study in 2005 of contemporary high-rise MURBs in Toronto found that "the normalized leakage areas of the apartments tested were very close to the stringent airtightness requirements of the R2000 energy efficiency house program.” (Canada Mortgage \& Housing Corporation, 2005).

\subsubsection{Concept}

Figure 2.6 depicts the proposed compartmentalization strategy schematically, with air sealing measures shown as a dashed vertical red line along the suite to corridor partition. The red arrows represent the corresponding change in magnitude of the stack-induced airflows in the building (during heating season), as compared to the original blue arrows representing the airflows prior to compartmentalization.

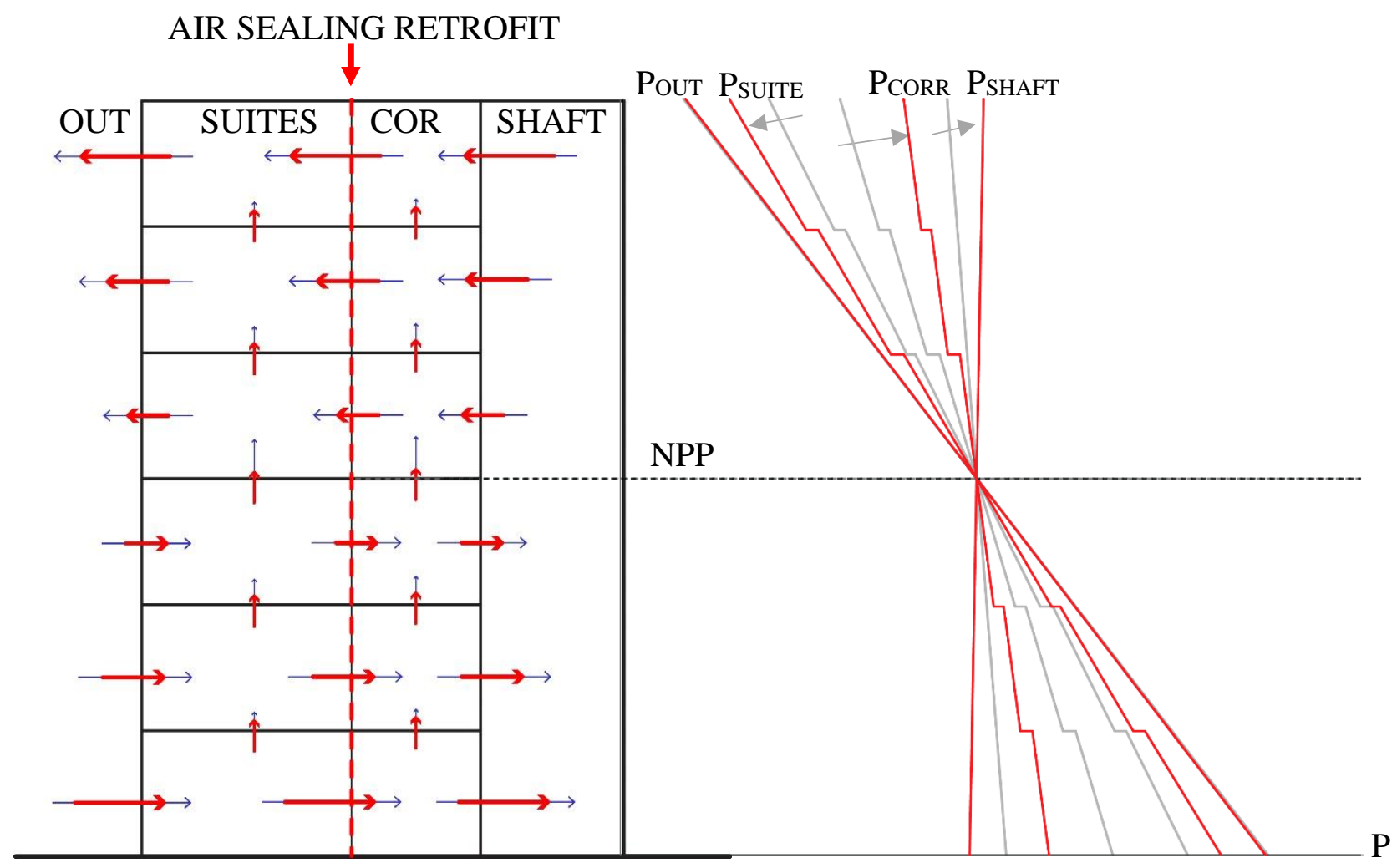


The concept is that if the suite-to-corridor partition is made more air-tight the airflow rate between the two zones should decrease. This is intuitive, and supported by Equation 2.1 ( $Q=$ $C \Delta P^{n}$ ) described earlier in Section 2.3.5, where increasing air tightness essentially decreases the flow coefficient $\mathrm{C}$. The flow coefficient $\mathrm{n}$ is typically assumed to be constant in these analyses. It follows that, due to conservation of mass $\left(Q_{\text {in }}=Q_{\text {out }}\right)$, airflow between the suite and outdoors would decrease. Again looking at Equation 2.1, if the airflow Q decreases, and the flow coefficient $C$ of the exterior wall hasn't changed, then the result is a decrease in the pressure difference P. At the same time as the airflow between suite and corridor decreases airflow between the corridor and elevator shaft will decrease, again from a conservation of mass. This also results in a drop in the pressure difference $\mathrm{P}$ between the corridor and elevator shaft, as before. The overall result is a decrease in all airflows within, into, and out of the building, as depicted in Figure 2.6 by the red arrows. The resulting change pressure gradient is shown to the right of the building in the Figure, with the previous pressure gradient shown in gray. It should be noted that the pressure differences between the suites and the outdoors, and between the corridor and elevator shaft decrease. At the same time there is a corresponding increase in the pressure difference between the suites and corridor. This pressure difference is of particular importance because it can cause whistling noises and difficulty in opening or closing suite entrance doors if it is too large. This parameter creates design limitations particularly for much taller buildings, and is discussed further in Section 4.4.3.

Because each suite is now isolated, the opening of windows or balcony doors in one suite would no longer affect airflow patterns of its neighbouring suites. Residents on the upper floors of the building would now be able to open their windows for natural ventilation during the heating season whereas, without compartmentalization, they would otherwise only experience outward flow of air due to stack effect. Residents on lower floors could also open their windows now without excessive cold air rushing in, and unwanted drafts would be reduced. Because of the reduction in infiltration with compartmentalization, the impact of operable windows and balcony doors on overall heating energy for the building would decrease.

Residents of buildings with suite-based heating systems such as the case study building would also be encouraged to be more energy conscious in their window and balcony door opening habits in the heating season, as this would now have a greater impact on their utility bills. Residents on upper floors who may have had no reason to ensure their windows were closed during the winter 
because air always moved outward would now have a reason to change their habits as their heating bills would increase and their suites would become drafty.

\section{Methodology}

The proposed retrofit strategy was analyzed through computer simulation using a calibrated energy model of a case study building. Analysis began with construction of a model of the building in its current condition. The available energy use data and recorded weather information was then used to calibrate the model to the building's actual performance. The proposed retrofit was then applied to the calibrated base model to predict its impact on building performance. Next, the base model was modified to create a second base model of the building in its original as-built condition. The proposed retrofit was then applied to this second base model to estimate its incremental performance improvement independently from the recent building enclosure retrofit.

The following Sections of this chapter describe the analysis of the available site-measured energy use and weather data, as well as the energy modelling and calibration procedure.

\subsection{Energy end use analysis}

Available utility data pre-retrofit (2007-2011) and post-retrofit (2013) were analysed and compared. Building performance during 2012 was excluded as the enclosure retrofit occurring during this year generated anomalous results.

\subsubsection{Energy use - current condition (retrofitted enclosure)}

Monthly energy use data were available for both natural gas and electricity. The most detailed enduse breakdown was for the 2013 monitoring period, which included sub-metering of the natural gas consumption for DHW and the MAU. Fireplace consumption made up the remainder of the natural gas consumption. Energy end use data were analyzed first for use with the energy model calibration process. Suite-level electricity was disaggregated into its heating and weatherindependent components for further refinement of the model calibration. 
Electricity usage reports from the utility provider was divided in two readings - one for all common areas of the building, and one for all the suites combined. Because each suite is equipped with electric baseboard heaters, a portion of the suite-level electricity consumption data accounts for heating energy. These data were broken down further through analysis, described in the following sections, in order to separate the weather-dependent electrical heating energy from the weather-independent electrical consumption (lighting, miscellaneous electrical loads, etc.) for use in the energy model calibration.

Figure 3-1 shows the total available metered energy data for 2013. Natural gas consumption is shown in blue, and electricity in yellow.

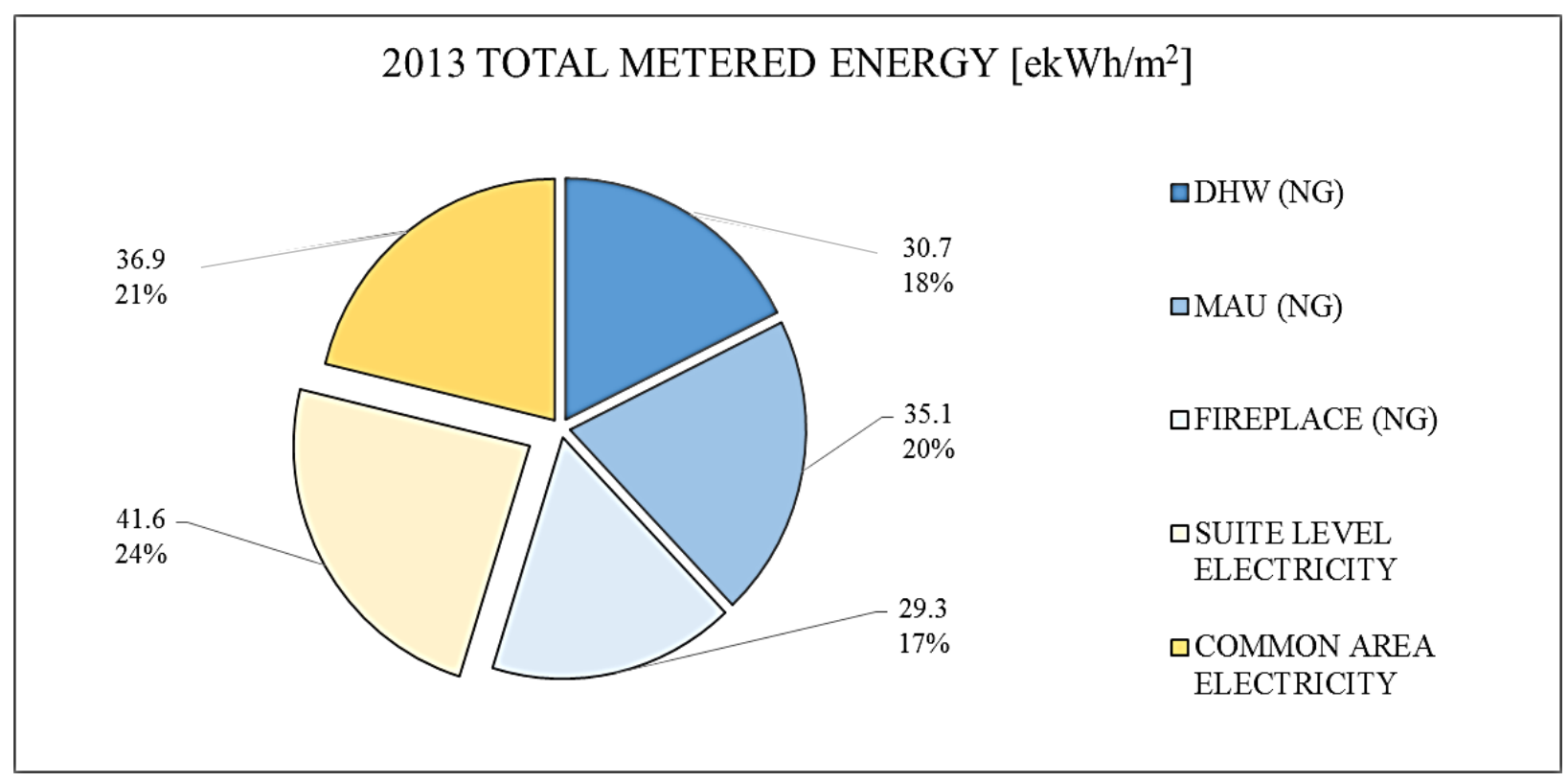

Figure 3-1: 2013 total energy by end-use

\subsubsection{Natural gas consumption}

Figure 3-2 shows the data available for the total metered monthly natural gas use for 2013. 


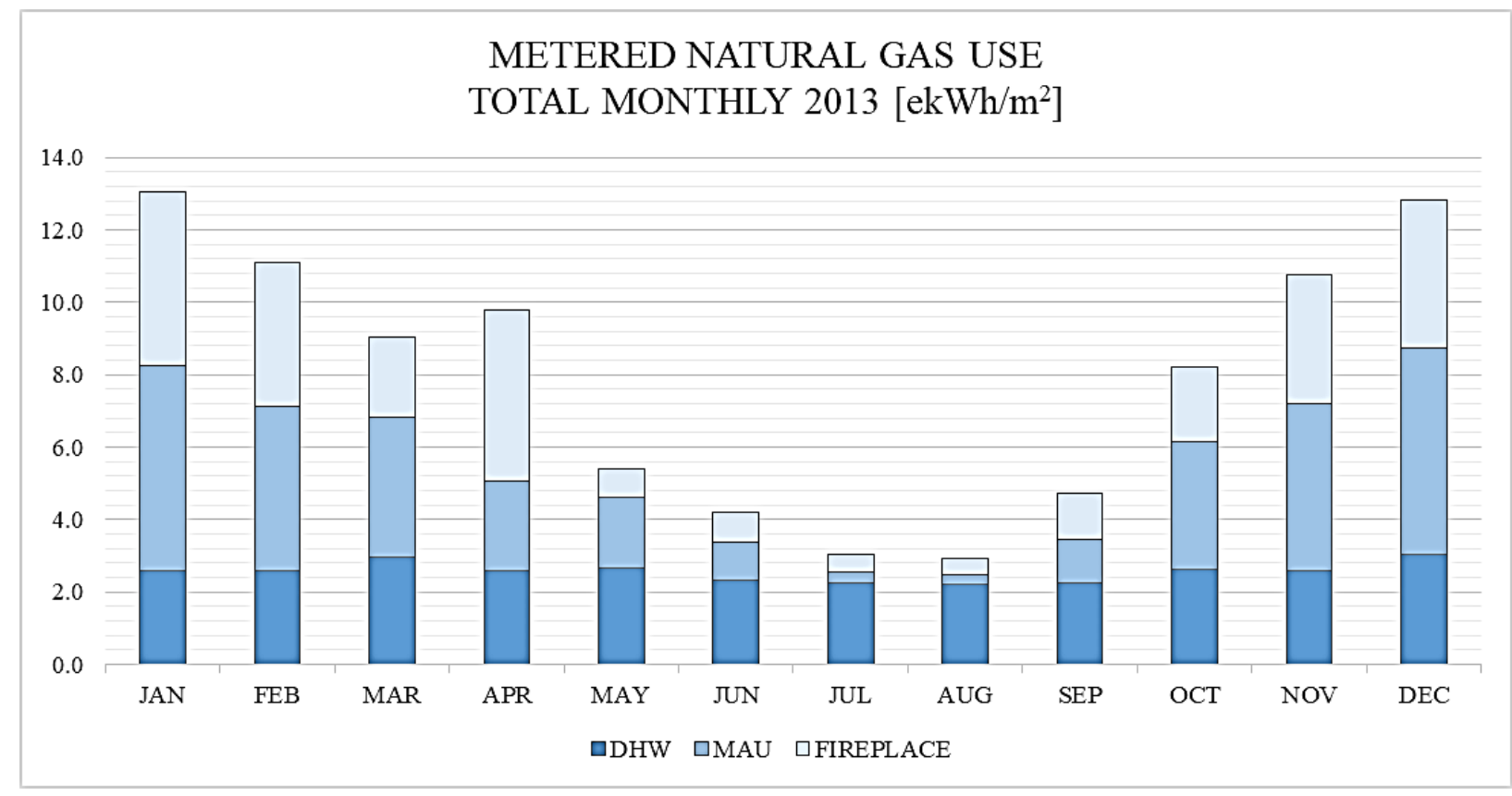

Figure 3-2: Total metered monthly natural gas use breakdown - 2013

The fireplace natural gas consumption during the heating season is comparable to that of the MAU, which represents a significant source of wasted energy in the case study building. The fireplaces are only on five of the thirteen floors, yet they use almost as much natural gas as the entire central ventilation system, and more than the total suite-level heating system energy for all the floors combined. The fireplaces are only about $40 \%$ efficient (RDH, 2013) due to the heat lost through the flue, meaning about $60 \%$ of the heating energy is lost to the outdoors. The majority of the heat gain to the suite for this style of fireplace is transmitted radiantly, however a portion of this energy, and most of the convective energy will be lost quickly due to exfiltration as the air in the suite is replaced by the air from the corridor. Because the fireplaces are only on the upper floors, stack effect causes the air to predominantly flow from the corridor through the suites and outside, carrying with it a portion of the heat gained from the fireplaces.

If this were not true, the available energy consumption data indicate a strong possibility that some of the suites would have experienced significant overheating. As an example, the $10^{\text {th }}$ floor used an estimated $4 \mathrm{kWh} / \mathrm{m}^{2}$ in electric heating energy in 2013. The metered average fireplace energy per floor for that year, reduced to $40 \%$ to account for nameplate heating efficiency, was about 2.3 $\mathrm{ekWh} / \mathrm{m}^{2}$. This would represent a $59 \%$ increase in heating energy over the in-suite electric heating 
for the suites on the $10^{\text {th }}$ floor. Although this represents the worst case scenario, and the actual contribution of fireplace natural gas consumption for that floor was not known, the assumption seems reasonable with an understanding of the general stack-induced airflow patterns of the building. So the fireplaces using $29.3 \mathrm{ekWh} / \mathrm{m}^{2}$ per year, represent a significant source of wasted energy, consuming nearly as much natural gas as the MAU which used $35.1 \mathrm{ekWh} / \mathrm{m}^{2}$.

\subsubsection{Electricity consumption}

Figure 3-3 shows the total metered monthly electricity consumption data available for 2013. Common area electricity did not include any heating energy and is therefore weather-independent. The suites on the other hand have electric baseboard heaters, so the suite-level electricity consumption was a combination of weather-dependent heating energy, and unregulated loads such as lighting, appliances, and other miscellaneous plug loads.

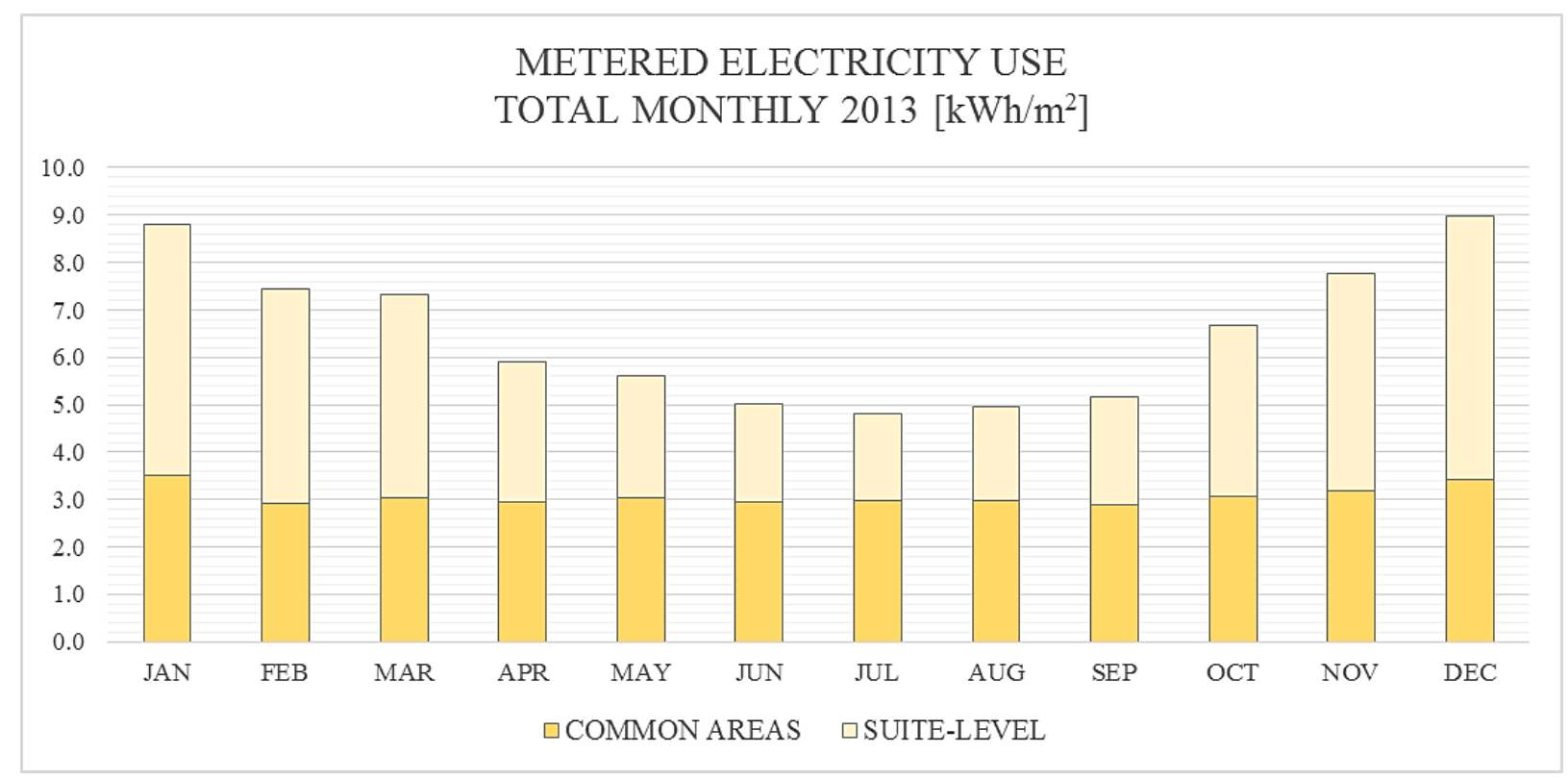

Figure 3-3: Total metered monthly electricity use breakdown - 2013

The electrical heating energy was disaggregated from weather independent electricity at the suite level for the purposes of energy model calibration. Monthly floor by floor suite-level electricity consumption data was available for this. 
As each suite uses electric baseboard convectors for heating, the proportion of total suite electricity attributed to heating was estimated and separated from the suite-level electric base load. The total monthly suite electricity usage was compared to the monthly heating degree days for that year, and a correlation was determined through linear regression. The best fit line relating these data using this approach was for a $15^{\circ} \mathrm{C}$ balance point temperature, which is much lower than anticipated for a building maintained at $23^{\circ} \mathrm{C}$ with only moderate internal gains. A balance point temperature represents the outside air temperature above which the building would require no heating, accounting for internal heat gains. The use of linear regression to calculate balance point yielded an impossibly high approximation of the weather-independent baseline, and was therefore not used. The resulting y-intercept (an approximation of the weather-independent base load) was just over $1.93 \mathrm{kWh} / \mathrm{m}^{2} / \mathrm{mo}$ which was greater than the minimum electricity usage of $1.83 \mathrm{kWh} / \mathrm{m}^{2}$, occurring in July. The regression analysis process of determining the heating energy per heating degree day, while practical for estimating the base load of buildings with more complex energy consumption patterns, is inherently imprecise due to a number of factors (EnergyLens, n.d.). Instead, the minimum monthly suite electricity consumption for the whole building, occurring in the summer months, was assumed to be predominantly weather-independent energy as this was when the minimum heating requirement occurred.

\section{Floor by floor breakdown}

Data for monthly suite-level electrical consumption for 2013 was available on a floor by floor basis, allowing further refinement of this estimate. The variation in electric heating energy from floor to floor, shown in Figure 3-4, is the result of a number of factors, including variation in occupant behaviour and the influences of unpredictable internal airflows as described in Section 2.3.5.2. 


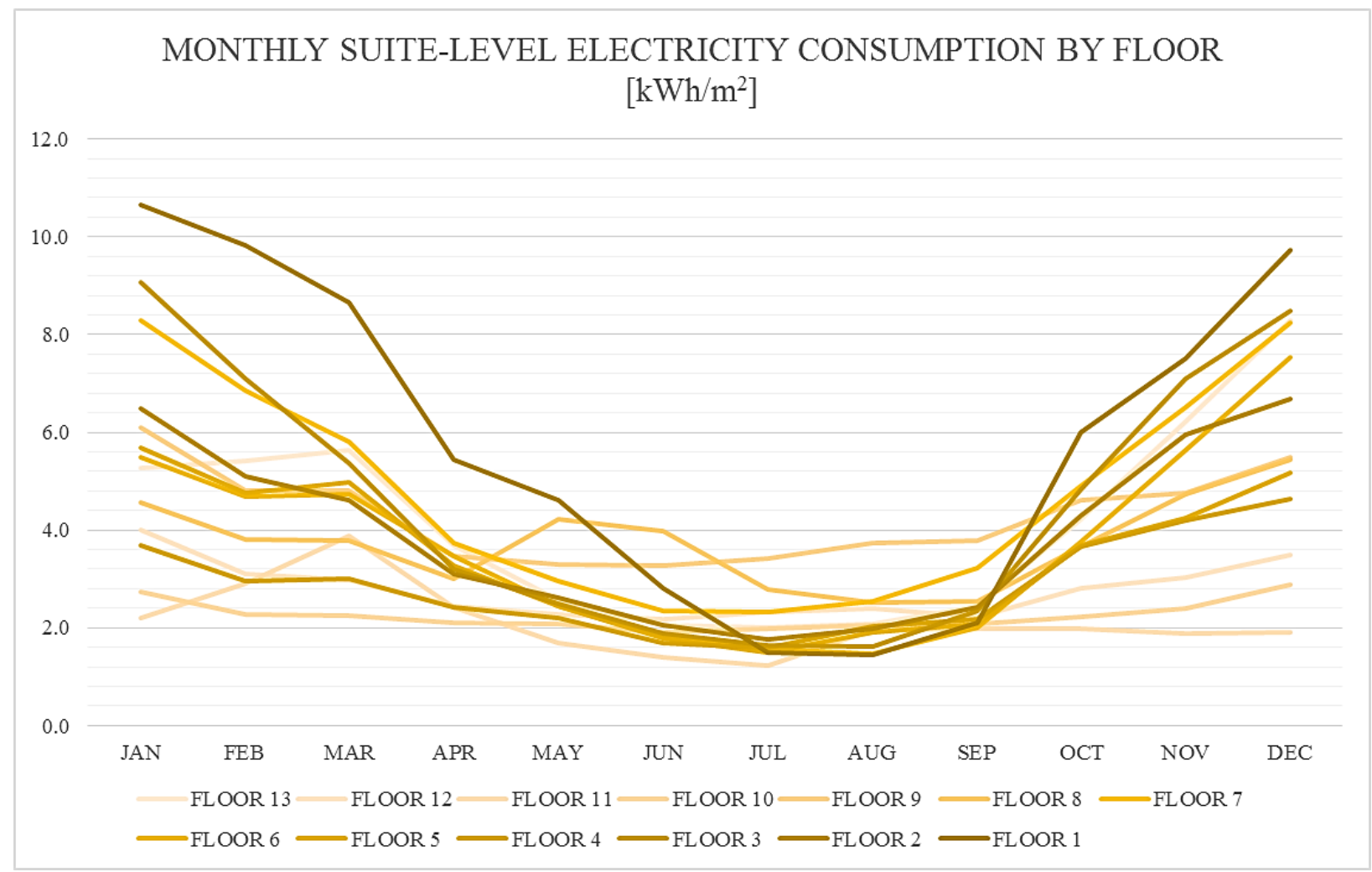

Figure 3-4: Monthly suite-level electricity consumption by floor 2013 [kWh]

This floor-by-floor electricity consumption was useful in estimating a unique base load for each floor. A base load value was determined for each floor using the lowest monthly energy use of each floor, and subtracted it from all monthly energy use values for each corresponding floor. The monthly were then combined on a whole building level, resulting in a new estimated base load of $1.77 \mathrm{kWh} / \mathrm{m}^{2}$ occurring in July.

In addition, the data showed some natural gas consumption for fireplaces throughout the summer. Although fireplaces usage is determined by occupant preference for reasons other than heating, a conservative approach was taken in assuming that some level of additional heating during the summer was desired by the residents. Following this, a portion of the above estimated summertime electrical base load for the floors without fireplaces was assumed to be heating energy. As gas fireplaces were only located on five of the upper floors, it was assumed that an approximately equivalent per-floor amount of heat would have been supplied instead by the electric baseboard heaters for the remaining eight floors of the building. This assumption was based on the fact that 
stack effect should be minimal during the summer months, resulting in minimal infiltration on the lower floors which would otherwise drive a discrepancy in the floor to floor baseboard heating energy. This assumption should be fairly reasonable as the inside and outside temperatures in July are relatively close, with limited heating and no cooling. The July total fireplace heating energy value was adjusted down to account for heating energy lost through the flue. The fireplace heating energy for July was calculated to be approximately 205 ekWh per month for each of the 8 floors, or $0.3 \mathrm{ekWh} / \mathrm{m}^{2}$ area weighted for the whole building. This additional summertime electric heating load was then subtracted from the monthly suite electricity totals, resulting in an estimated suitelevel electric base load of $1.47 \mathrm{kWh} / \mathrm{m}^{2} / \mathrm{mo}$.

Figure 3-5 below shows that this monthly suite-level electric base load fits well with a regression analysis that uses a $19^{\circ} \mathrm{C}$ balance point temperature. It has a y-intercept of $7613 \mathrm{kWh}$ or 1.47 $\mathrm{kWh} / \mathrm{m}^{2}$, matching the the value calculated using minimum monthly values. This balance point temperature is much closer to what would be expected, and closer to the default value of $18.3^{\circ} \mathrm{C}$ commonly used in North America.

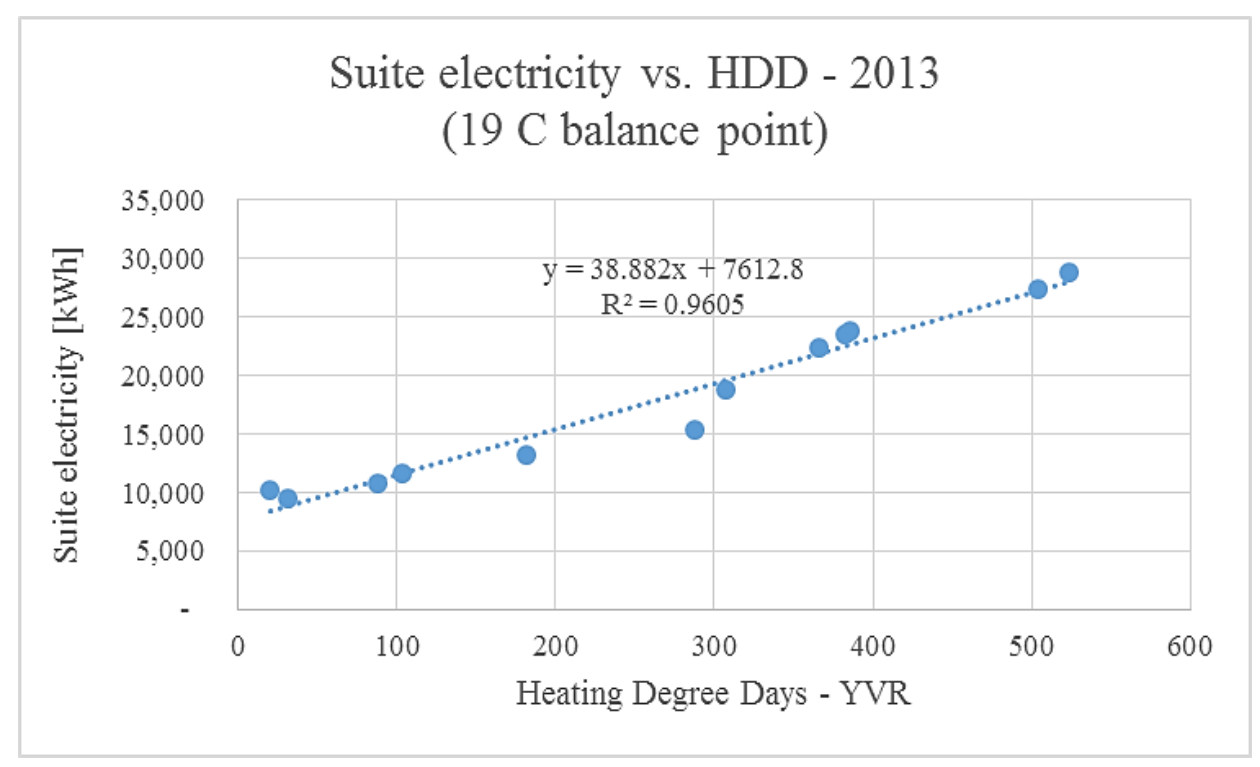

Figure 3-5: Suite electricity vs. HDD - 2013 
Figure 3-6 shows the total annual suite-level electricity breakdown by floor for heating energy and weather-independent base load, estimated using the procedure outlined above.

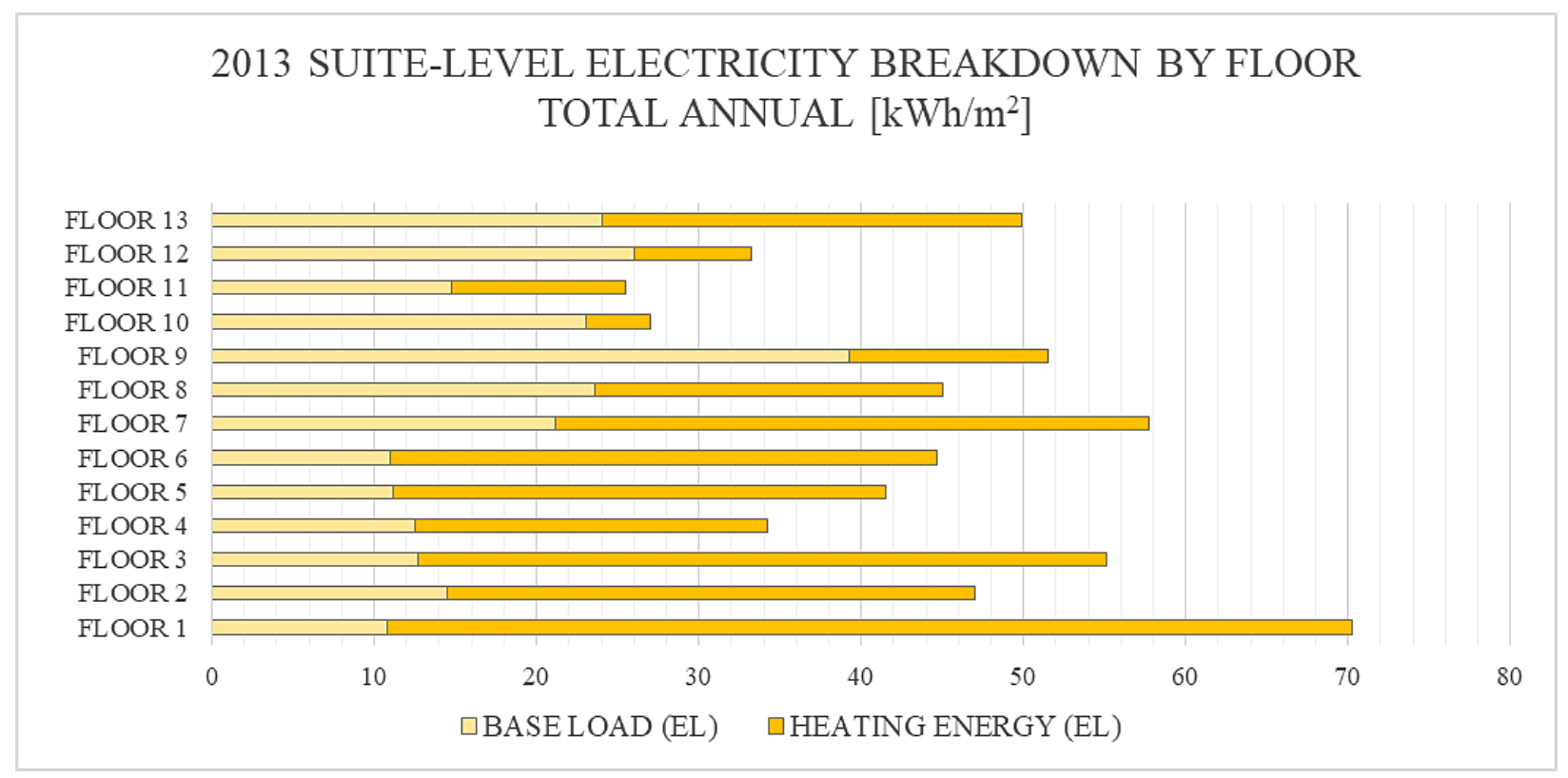

Figure 3-6: 2013 Calculated total annual suite-level electricity breakdown estimate

The figure illustrates a general increasing trend in the suite-level heating energy going down from the top to the bottom of the building. Some anomalies are present, however they can be explained in part by certain observed variances. The fire dampers at the corridor ventilation grills on the $4^{\text {th }}$, $8^{\text {th }}$, and $12^{\text {th }}$ floors were closed. This would reduce the conditioned ventilation air supplied to these floors, effectively reducing the mechanically induced corridor pressurization. Suite-level heating energy should increase on floors below the neutral pressure plane because there is less backpressure from the corridors on the suite to slow outside air infiltration. For floors above the neutral pressure plane with the fire dampers closed, suite-level heating energy should decrease because the air moving up inside the building and out through the suites due to stack effect would be conditioned approximately to the set point temperature and not mixing with makeup air which is at a lower temperature, at least in this case study building. Each of the three floors with the fire dampers closed was above the $3^{\text {rd }}$ floor neutral pressure plane, and the suite-level heating energy appears to be less than what the trend would predict. The ground floor and the penthouse appear 
to have suite-level heating energy above what the trend would predict. This is likely due to the effect of the high air exchange of the lobby, being the main entrance and exit of the building, and the additional exposed surface area of the penthouse ceiling/roof and its associated heat loss. It is interesting to note that each floor appears to have significantly different base loads, likely a result of varying occupant behaviour. It is not clear why the estimated suite-level electric heating energy of floor 10 is so low. Occupancy patterns in the building were not tracked, and because the residents of the building are predominantly retirees, their vacation habits are unique, and certain suites may have been unoccupied for extended periods of time.

\subsubsection{Overall energy use breakdown}

Figure 3-7 shows the updated annual energy use breakdown for 2013 with the heating energy sources separated. The heating energy makes up 50\% of the total annual energy consumption for the building. It is also interesting to note that the in-suite heating system uses less energy than either the ventilation system or the fireplaces, both of which have been shown to be highly inefficient.

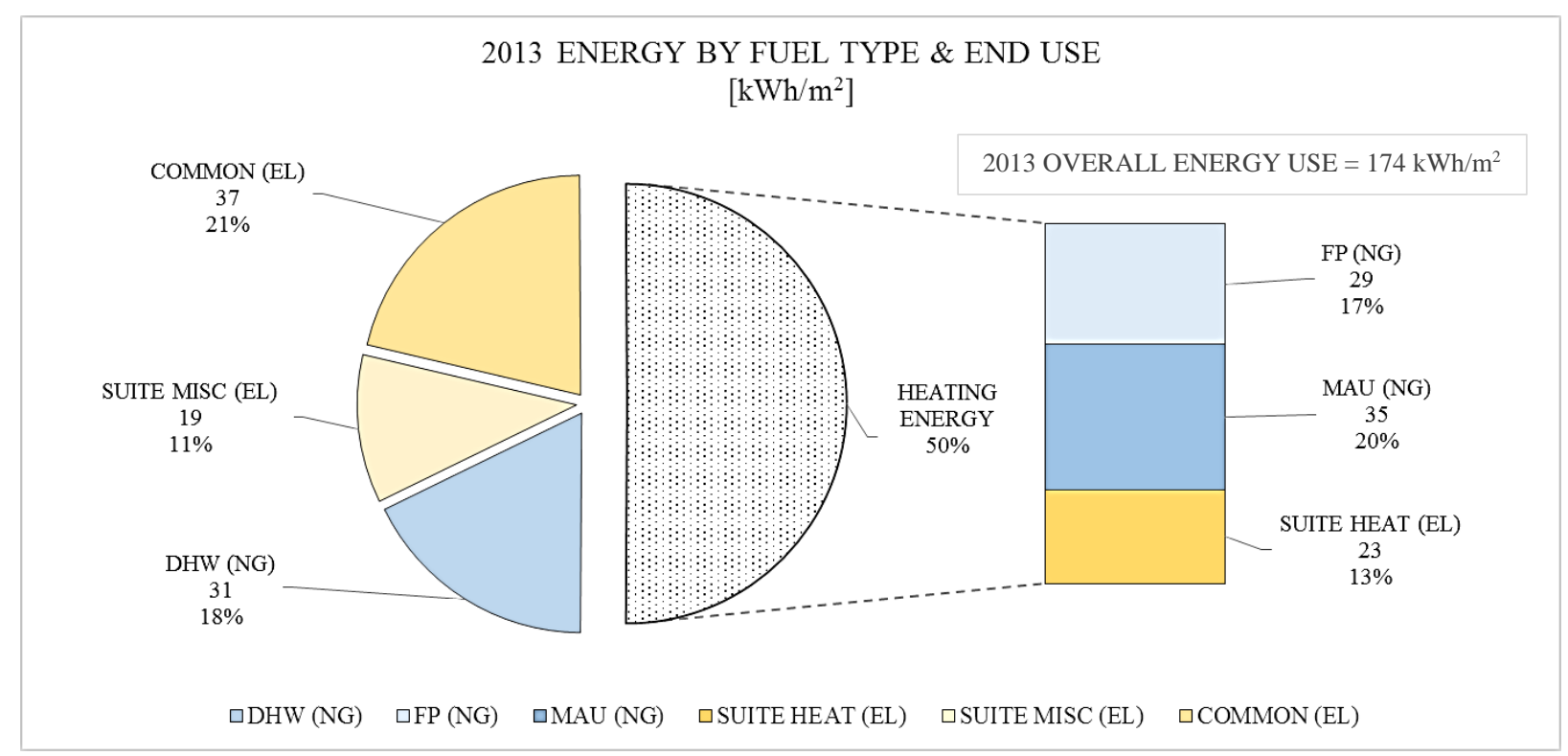

Figure 3-7: 2013 Total energy use breakdown by fuel type and end use 
This energy use breakdown provided insight on the case study building's actual performance, and was used to calibrate the energy model using the site's weather conditions from 2013, discussed further in Section 3.2.

\subsubsection{Energy use - original condition (prior to enclosure retrofit)}

Energy use data was available for the five-year period (2007-2011) leading up to the enclosure retrofit, however it was not disaggregated to the level of detail of the 2013 data. Total natural gas consumption, common area electricity, and total aggregated suite-level electricity consumption were available on a monthly basis, as seen below in Figure 3-8.

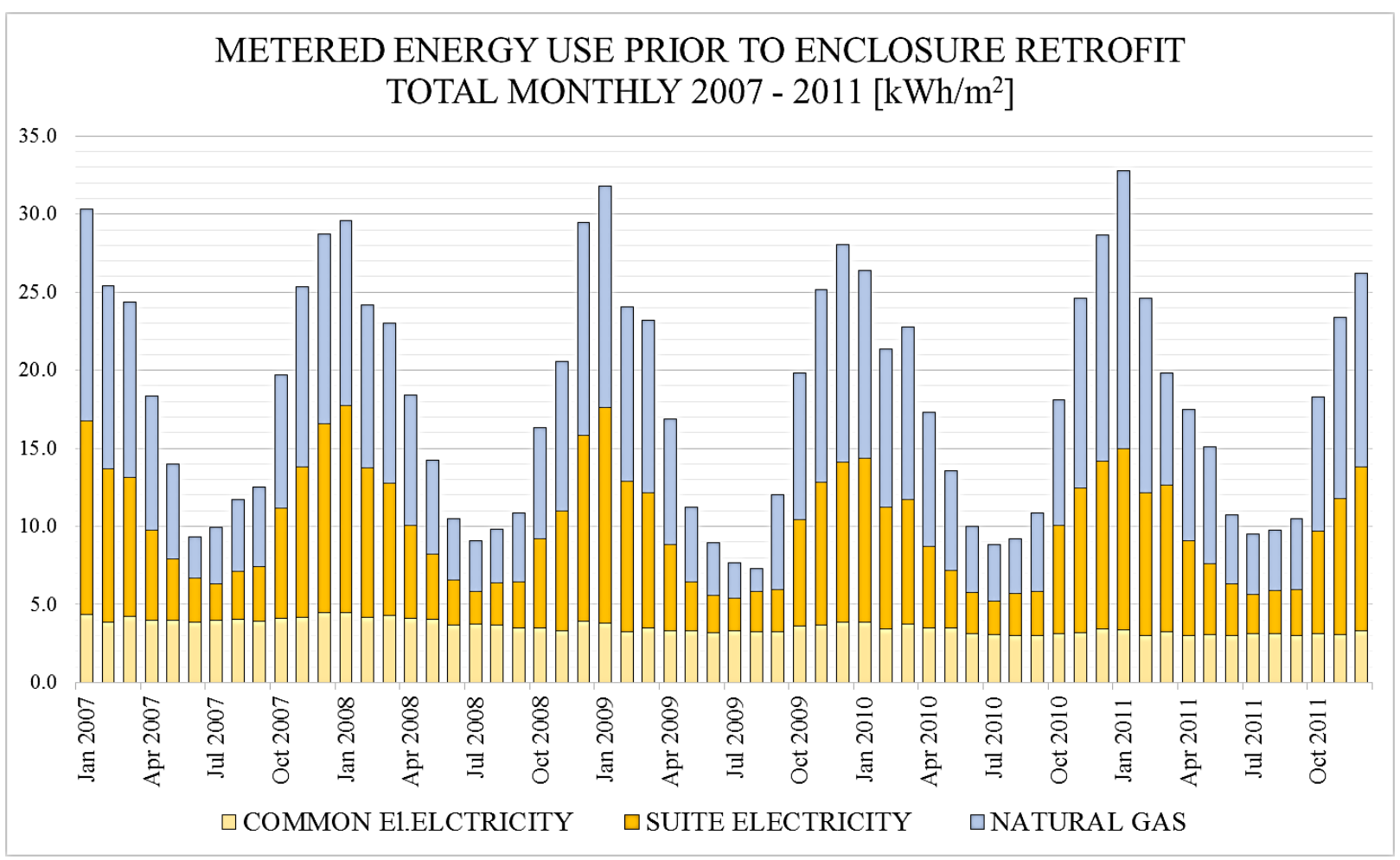

Figure 3-8: Total monthly energy use intensity by fuel source prior to enclosure retrofit

Energy use data for 2012 was evaluated but not used in any performance analysis. The enclosure retrofit occurred during 2012 and, despite the fact that energy use did not appear to be dramatically 
different in comparison to the years prior, it was not a typical year for building operation. The intrusive construction work that took place such as replacement of the windows, the addition of insulation, and any abnormal activity associated with it would have had an impact on the building's performance that year.

The five-year period from 2007 to 2011, inclusive, was analyzed for the calibration of an energy model of the case study building prior to its 2012 enclosure retrofit, which was then used as a base model for estimating the impact of the proposed retrofit on the building from its original condition. Regression analysis was used to estimate the weather-dependent (heating energy) and weatherindependent (base load) portions of the energy use in order to improve the energy model calibration fidelity.

Monthly energy consumption data from each of the three metered sources was plotted against the corresponding monthly heating degree days for the five-year span for the nearby Vancouver airport. The three Figures below show the regression analyses for weather normalization process of the energy data from $2007-2011$. 


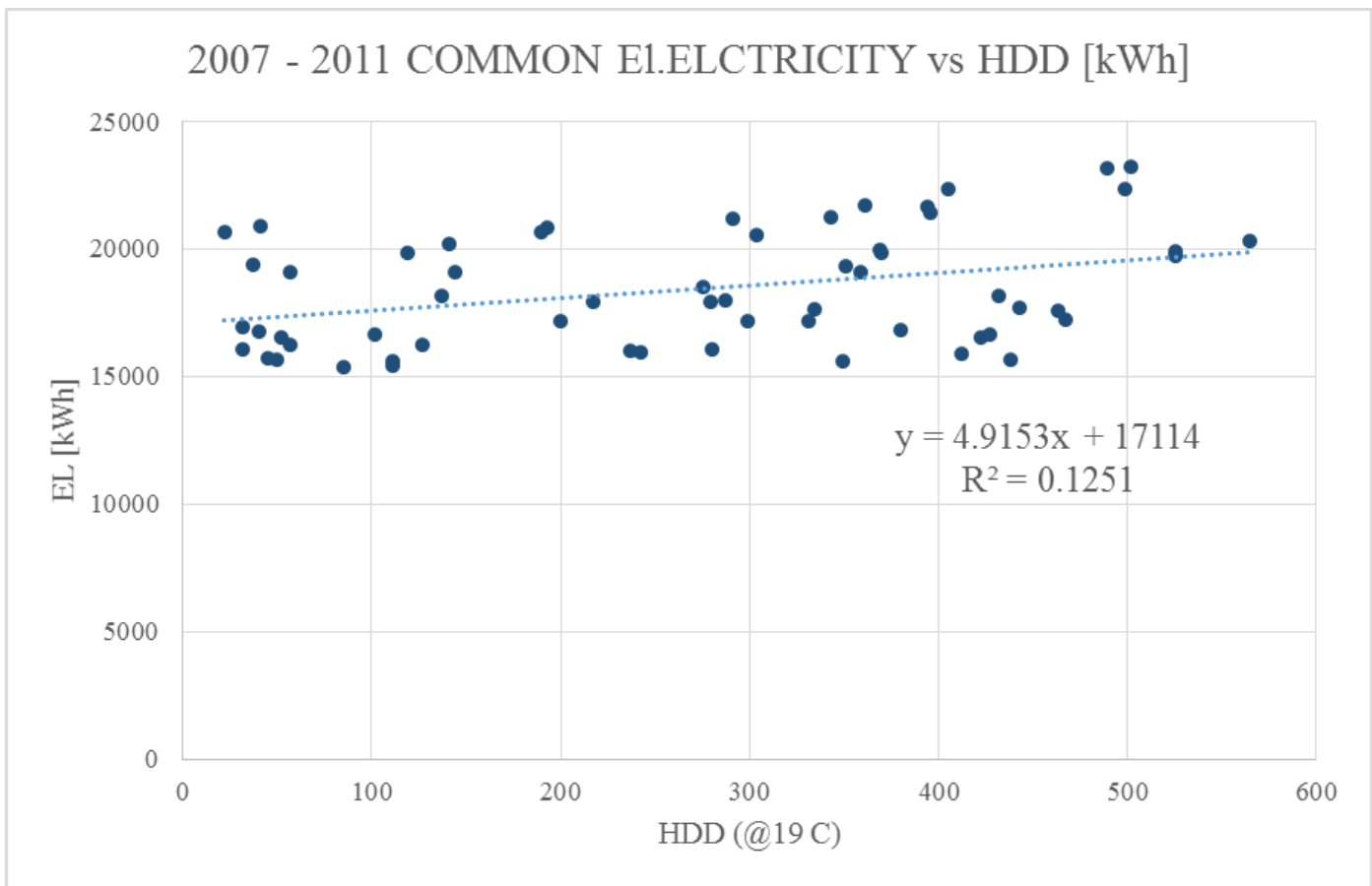

Figure 3-9: Regression analysis for weather normalization of 2007 - 2011 common electricity use



Figure 3-10: Regression analysis for weather normalization of 2007 - 2011 suite-level electricity use 


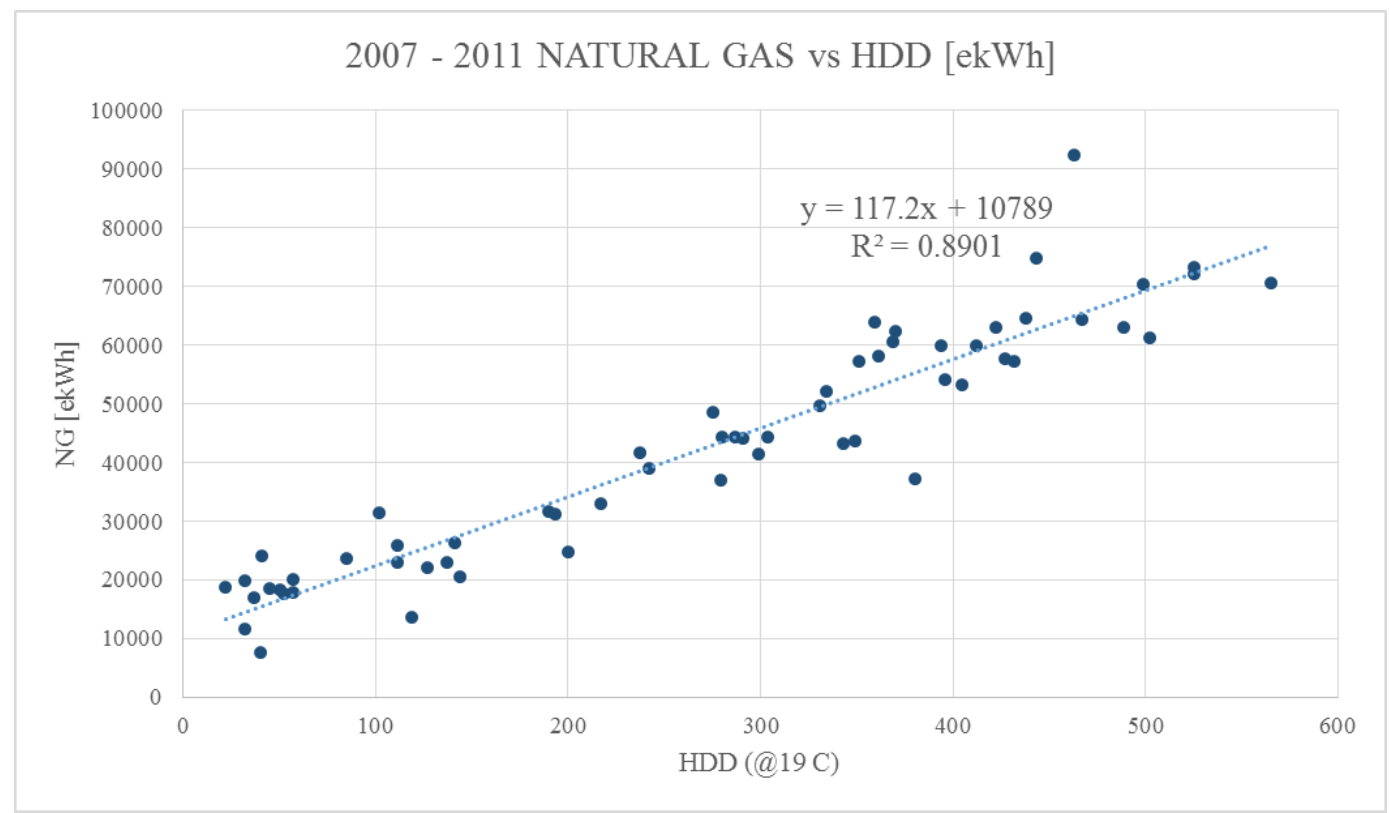

Figure 3-11: Regression analysis for weather normalization of 2007 - 2011 natural gas use

These graphs were used to determine the relationship between energy use and heating degree days. The values of the y-intercepts for the lines of best fit were used to estimate the weather-independent base load portions of the energy consumption, an important element of the model calibration procedure for which they would be used. The y-intercept represents the building's energy consumption at 0 HDDs, or the base level energy use when no heating energy is required. The slope is the incremental energy use trend with increasing HDDs. The equations of these three lines were then used to calculate the monthly energy consumption for natural gas and electricity by substituting the heating degree days from the CWEC weather file. Table 3-1 below contains the results of the weather-normalized energy data which would be used for the first calibration attempt of the building in its original condition (pre-2012). 
Table 3-1: Monthly calculated energy use for original building model calibration based on 5-year energy consumption regression analysis, normalized to CWEC HDD

\begin{tabular}{rrrrr}
\hline & $\begin{array}{r}\text { CWEC } \\
\text { HDD }\end{array}$ & $\begin{array}{r}\text { COMMON } \\
\text { ELECTRICITY }\end{array}$ & $\begin{array}{r}\text { SUITE } \\
\text { ELECTRICITY }\end{array}$ & $\begin{array}{r}\text { NATURAL } \\
\text { GAS }\end{array}$ \\
\hline JAN & 441 & 19,282 & 51,605 & 62,474 \\
FEB & 368 & 18,923 & 43,810 & 53,919 \\
MAR & 367 & 18,918 & 43,704 & 53,801 \\
APR & 285 & 18,515 & 34,948 & 44,191 \\
MAY & 196 & 18,077 & 25,444 & 33,760 \\
JUN & 111 & 17,660 & 16,368 & 23,798 \\
JUL & 73 & 17,473 & 12,310 & 19,345 \\
AUG & 62 & 17,419 & 11,136 & 18,055 \\
SEP & 146 & 17,832 & 20,105 & 27,900 \\
OCT & 254 & 18,362 & 31,638 & 40,558 \\
NOV & 346 & 18,815 & 41,461 & 51,340 \\
DEC & 426 & 19,208 & 50,004 & 60,716 \\
\hline TOT [ekWh] & $\mathbf{3 , 0 7 5}$ & $\mathbf{2 2 0 , 4 8 3}$ & $\mathbf{3 8 2 , 5 3 3}$ & $\mathbf{4 8 9 , 8 5 8}$ \\
\hline
\end{tabular}

Figure 3-12 shows the results of this analysis. The estimated average annual energy consumption is broken down by fuel type and end use for the five-year period from 2007 - 2011. Weatherdependent heating energy is separated from the weather-independent base load energy for clarity. 


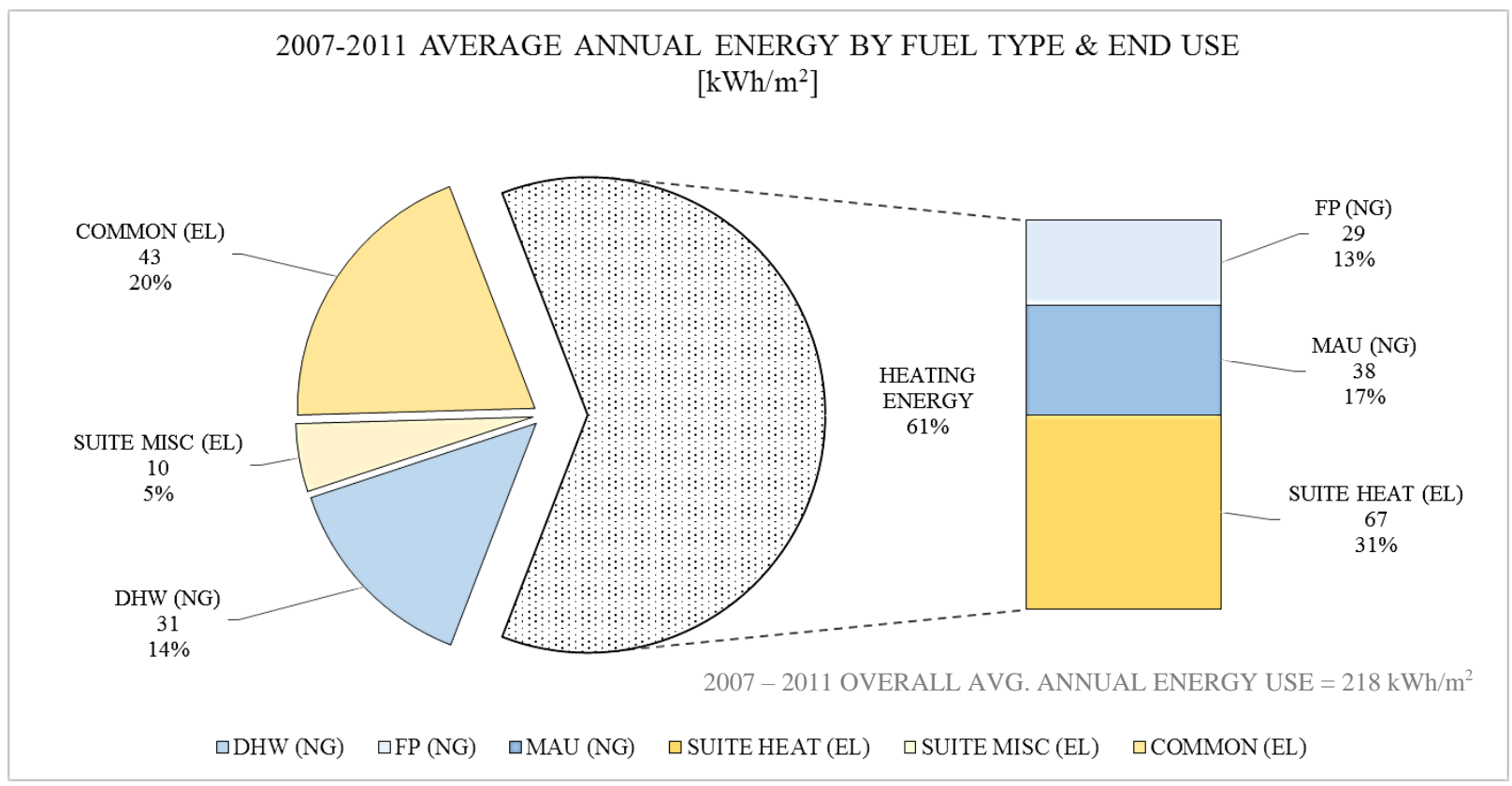

Figure 3-12: 2007 - 2011 average annual energy use breakdown

For comparison purposes with the energy consumption presented previously in Figure 3-7 for 2013, the results presented in Figure 3-12 were normalized to the monthly heating degree days for 2013. The results are very similar because the weather in 2013 in Vancouver was fairly similar to the average weather from the $2007-2011$ period.

Heating energy is estimated to make up $62 \%$ of the building's total annual energy use, which was significantly higher than the amount used in 2013 after the enclosure retrofit was complete. The enclosure retrofit brought the heating energy down to $50 \%$ of the total energy consumption as seen in Figure 3-7 earlier. The majority of the energy savings come from a reduction in the suite-level heating energy, which decreased from $31 \%$ to $13 \%$ of the overall energy consumption. The electric baseboard energy itself decreased by $65 \%$, from $66 \mathrm{kWh} / \mathrm{m}^{2}$ to $23 \mathrm{kWh} / \mathrm{m}^{2}$ per year.

Overall, the average energy consumption for this pre-retrofit condition was $215 \mathrm{ekWh} / \mathrm{m}^{2}$ for the whole building, based on 2013 HDD. The average energy use intensity for a sample of 39 similar buildings in the same geographic region of British Columbia is $213 \mathrm{ekWh} / \mathrm{m}^{2}$ per year (RDH, 2013). 


\section{Data preparation for energy model calibration}

In order to use this performance data to calibrate an energy model of the building in its original condition, the monthly energy use data presented above was normalized to a standard weather year. This was done to both match the weather file to be used in simulation, and to a create common reference conditions for all the energy model simulations. This standard weather year is represented by statistically selected weather conditions from a period of 42 years and compiled in a data set known as a Canadian Weather for Energy Calculations (CWEC) weather file. The CWEC files represent historically typical weather, and are available for most cities in Canada and are the most widely used weather data sets for building performance simulations in the Canadian context.

The least square error fit equations were used to calculate monthly energy use for the standard weather year by substituting the number of heating degree days for each month from the CWEC weather file for the nearest weather station at Vancouver airport (YVR). This same CWEC weather file would be later used in the various energy model simulations to allow for direct comparison between the models.

The quantity of heating degree days in the CWEC weather file was calculated using the methodology shown in Figure 3-13 from BC Hydro (2010), but based on a $19^{\circ} \mathrm{C}$ balance point temperature instead of $18^{\circ} \mathrm{C}$, as was determined previously to be more representative of the case study building: 
CWEC data sets HDD and CDD

Monthly heating degree days, HDD, [kelvin days], based on an $18^{\circ} \mathrm{C}$ balance temperatur and hourly dry bulb temperature, $\mathrm{t}_{d b}$, observations were calculated in SAS software in three steps, namely

Step 1: Calculate daily mean air temperature (dry bulb, ${ }^{\circ} \mathrm{C}$ )

$$
\overline{\mathrm{t}}_{d b}=\frac{\sum_{i=1}^{24} t_{d b i}}{24}
$$

Step 2: Calculate daily heating degree days (kelvin'days)

$$
\text { Daily_HDD }=\sum_{j=1}^{24}\left(18-\bar{t}_{d b}\right)_{j}
$$

Step 3: Calculate monthly heating degree days (kelvin-days)

$$
\text { Monthly_HDD }=\sum_{k=1}^{N} \text { Daily_HDD }
$$

where $\mathrm{N}=$ number of days in month (February always has 28 days).

Figure 3-13: HDD calculation methodology for CWEC weather file (BC Hydro, 2010)

Discussion of this energy model calibration procedure for the building's original condition is continued in Section 3.3.5.2.

\subsection{Weather data analysis}

A weather station located on the roof of the case study building had recorded all the relevant weather data variables required for hourly simulations for the 2013 monitoring year, comprised of dry bulb temperature $\left(\mathrm{T}_{\mathrm{db}}\right)$, dew point temperature $\left(\mathrm{T}_{\mathrm{dp}}\right)$, relative humidity $(\mathrm{RH})$, total (diffuse plus direct normal) solar radiation, wind speed and wind direction. A custom weather file for this period was created using these data, supplemented with weather data from the nearby airport (YVR) to substitute for any missing data periods. Instead of direct substitution, the augmenting data from the airport weather file were adjusted using linear regression by correlating the two weather data sets, as seen in Figure 3-14 through Figure 3-18.

Before the two weather data sets could be correlated, pre-processing of the raw data from the rooftop weather station was required. Visual inspection of the data showed some missing data for 
different variables at various periods of time due to either faulty sensors or other unknown technical issues. Solar radiation values were cross-checked with the historical sunrise and sunset times for 2013 and found to be unsynchronized; outside air temperatures also appeared to follow this same pattern. Another cross-check against the data contained in the weather file for the actual 2013 meteorological year for nearby Vancouver airport (YVR AMY file), similar to the weather at the site, confirmed that the phase shift should apply to all data variables. An 8 hour phase shift forward was made on all data to align the diurnal weather patterns with the time stamp of the weather file.

After this realignment, a correlation was made between each of the variables of the two weather files, for the remainder of the 8,760 hours which contained two matching data points. Linear regression was then used to find the line of best fit. The equation of this line was used to calculate a new value for the custom weather file based on the Vancouver airport value.

The following figures illustrate the correlations made between the two weather files.

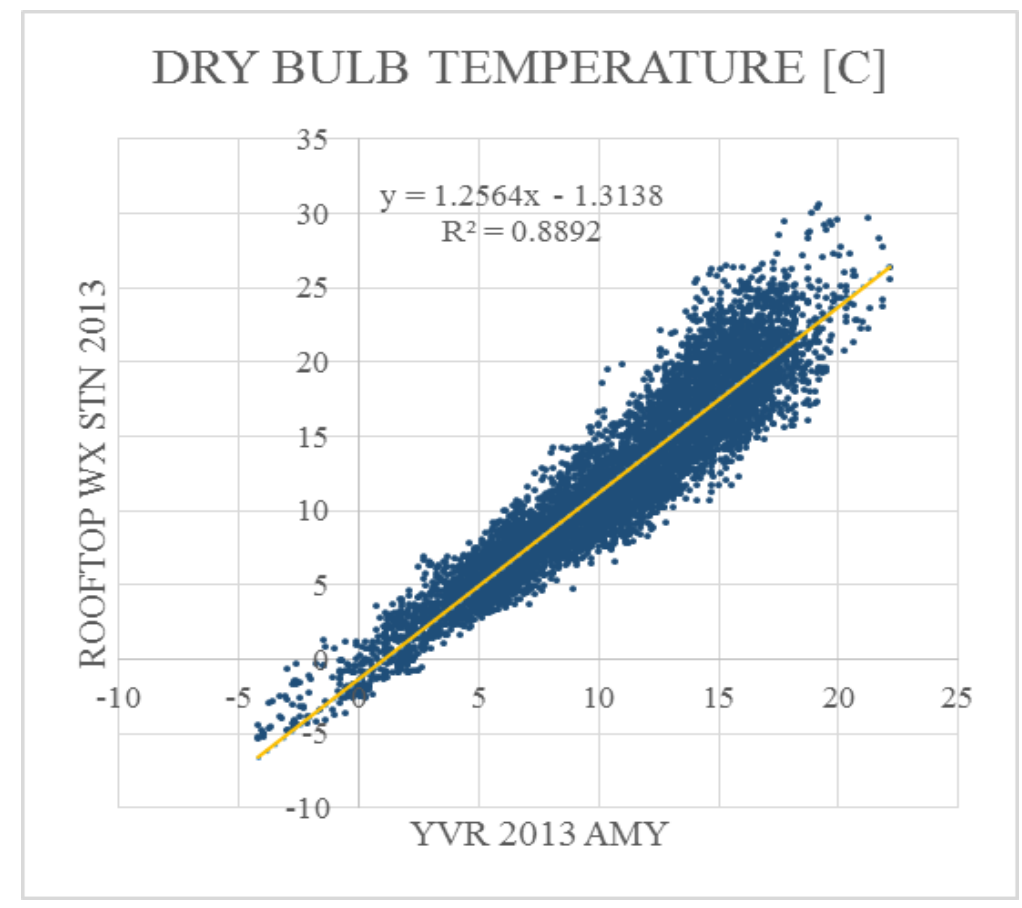

Figure 3-14: Dry bulb temperature regression analysis 


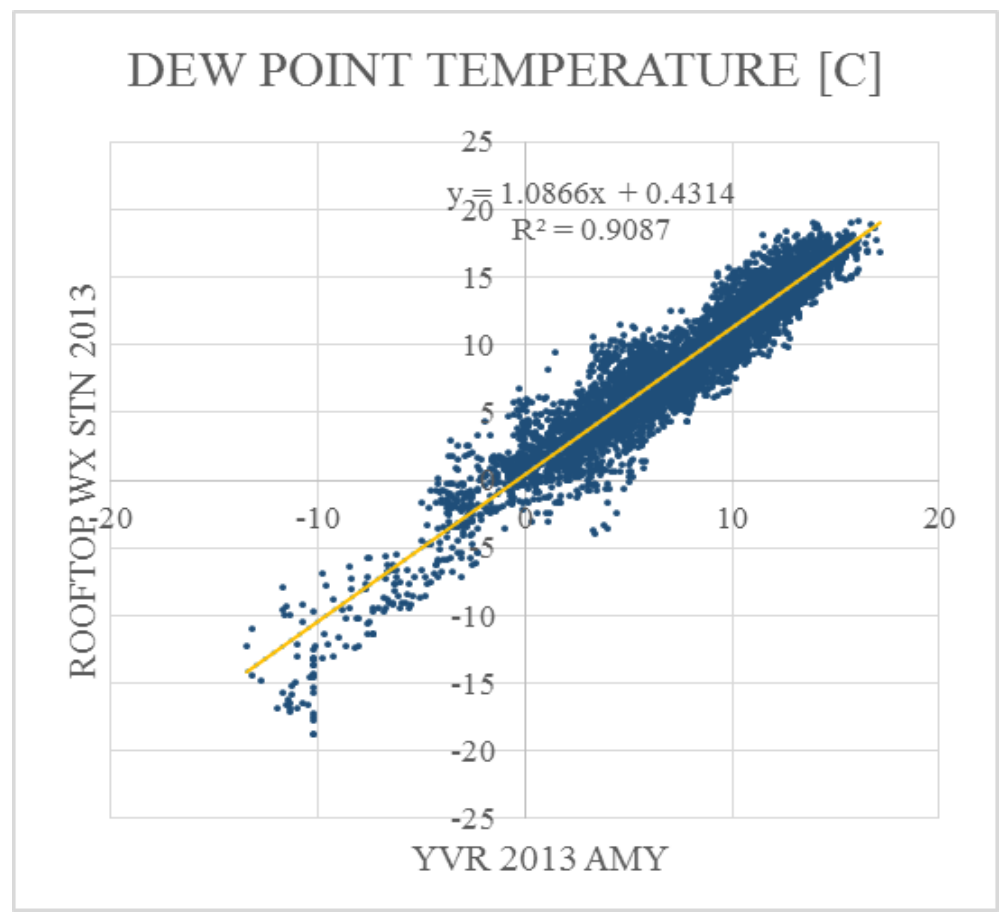

Figure 3-15: Dew point temperature regression analysis

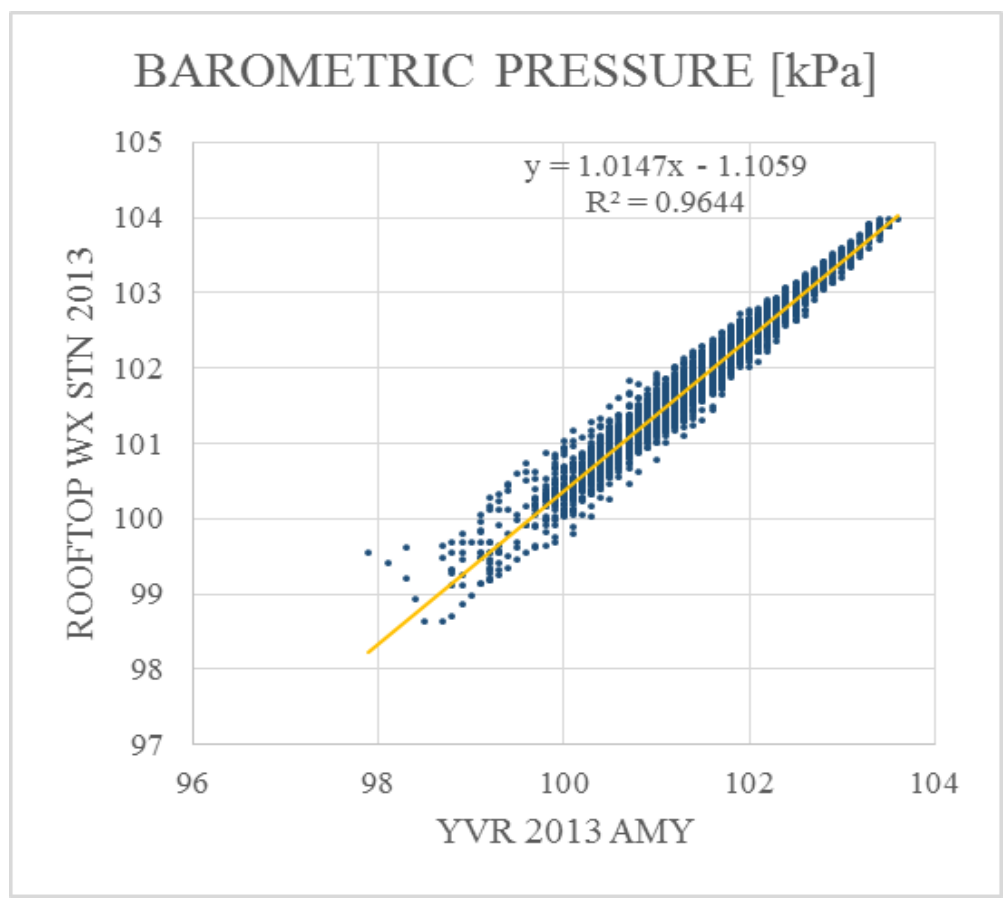

Figure 3-16: Barometric pressure regression analysis 

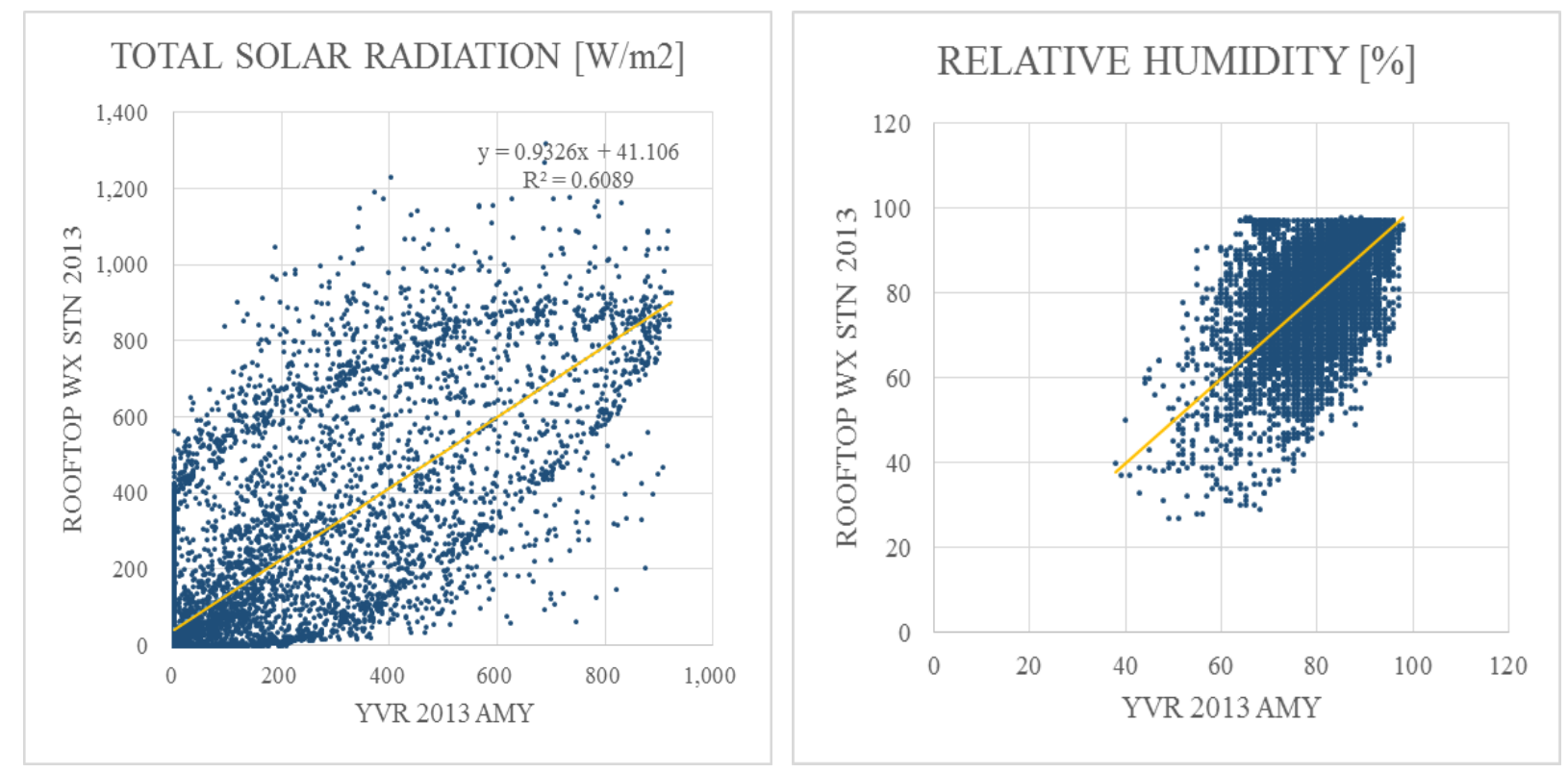

Figure 3-17: Total solar radiation and relative humidity regression analysis
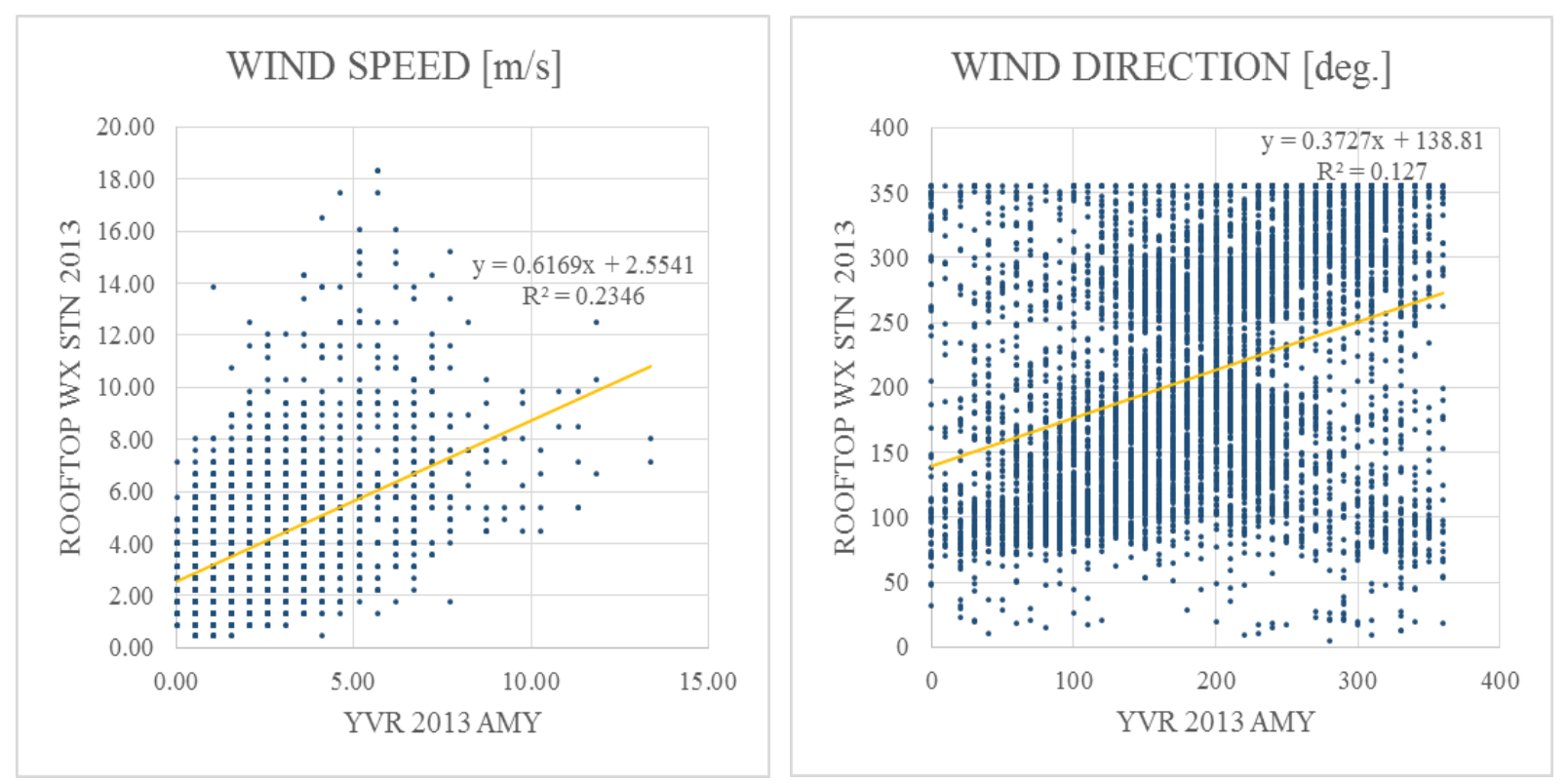

Figure 3-18: Wind speed and direction regression analysis 
Some of the corresponding variables between the two weather files do not match, as can be seen in the wind speed, wind direction, total solar radiation, and RH correlations, shown in Figure 3-17 and Figure 3-18 above. These variables are very sensitive to location and are strongly influenced by their surrounding environment. Although Vancouver airport is only $4.9 \mathrm{~km}$ away from the case study building site, it is located directly on the coastline on the Strait of Georgia, and as such would be subject to higher humidity levels. The case study building is located on a nearby hill, however it is surrounded by trees and other buildings which offer some shelter from the wind compared to the airport which experiences stronger winds off the water. Solar radiation is affected by cloud cover, and so is constantly changing. The changes in wind speed, direction, and solar radiation can be more rapid than the data gathering interval. So although these weather data measurements were taken at ten-minute time intervals and averaged over the hour, the above figures show that their correlation produces no clear linear trend. Despite this fact, the impact of an imperfect correlation of these four variables on the energy model is somewhat inconsequential. Only a very small portion of the data (less than 5\%) was determined in this manner, and the most impactful variable on the energy simulation is the outdoor ambient air temperature, which had a good correlation.

The final weather file was created with a software package called Elements ${ }^{\mathrm{TM}}$. This software allows the user to make adjustments to variables in order to maintain realistic psychrometric relationships, and break down the total solar radiation into its direct and diffuse components. Dew point temperatures for example, determined through the above regression analysis were found to create psychrometric impossibilities, and so new $\mathrm{T}_{\mathrm{dp}}$ values were calculated using Elements based on the corresponding $\mathrm{Tdb}, \mathrm{RH}, \mathrm{P}$ data for the final weather file. Normal and diffuse horizontal solar radiation values from the YVR AMY file were also input into Elements and then adjusted so that the global solar radiation values matched the total radiation values measured by the rooftop weather station on site. Simulations for the calibration of the energy model for the current condition building were run using this custom weather file. 


\subsection{Energy modelling}

Figure 3-19 below is a visualization of the energy model of the case study building, shown graphically in DesignBuilder ${ }^{\mathrm{TM}}$ software. DesignBuilder ${ }^{\mathrm{TM}}$ was used as the graphical interface for creating the geometry of the case study building and setting up the basic structure of the EnergyPlus ${ }^{\mathrm{TM}}$ Input Data File (IDF). The exported IDF file was used to make further refinements to the model through the calibration process, as well as to create the model of the building in its original condition (pre-2012), and the models for the proposed retrofit.

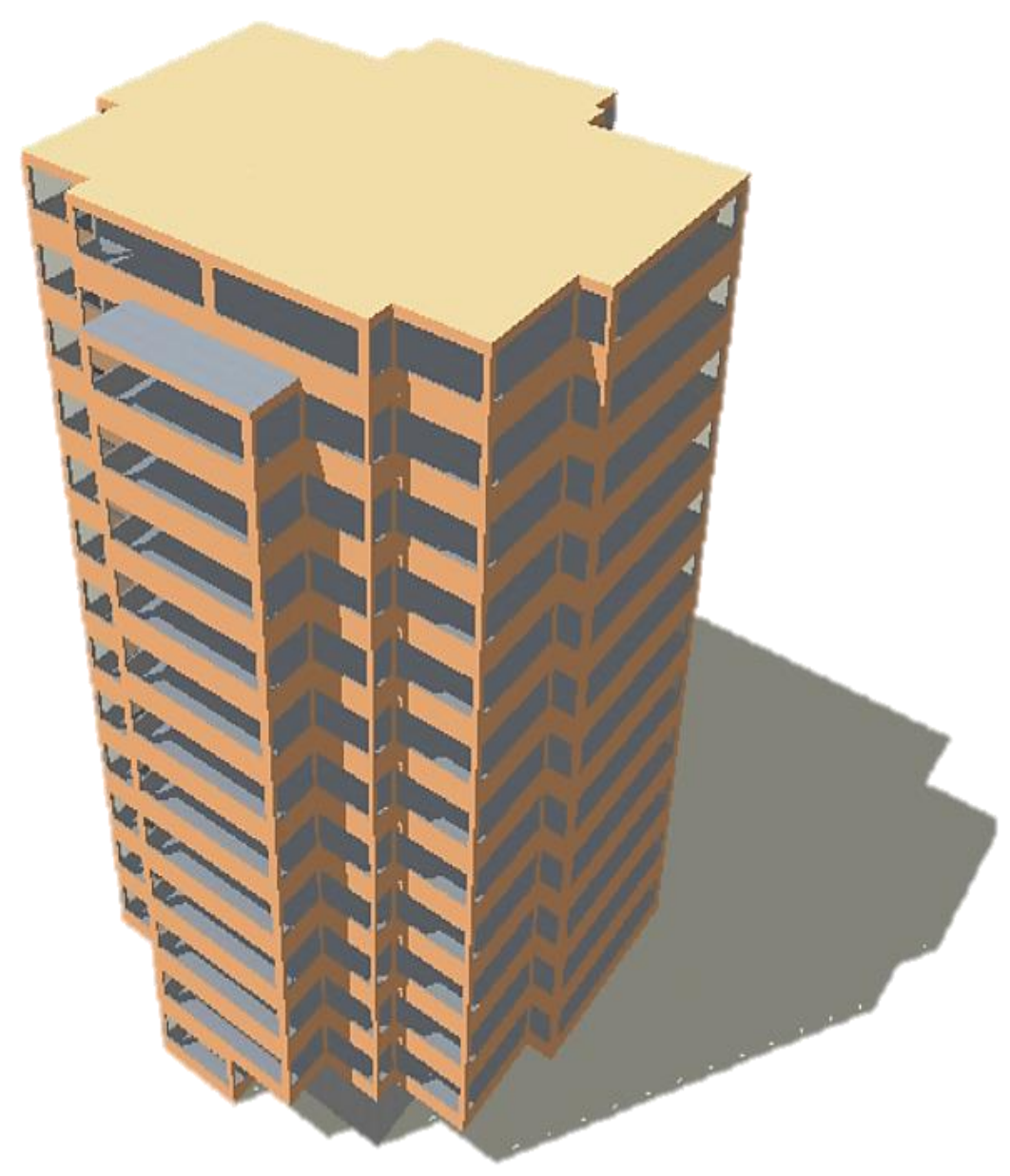

Figure 3-19: Visualization of case study building in energy model 


\subsubsection{Overview}

This Section is a detailed account of the energy modelling process used in this research. It outlines the creation of the baseline models and their calibration procedure, as well as the modifications to the baseline models to simulate the proposed compartmentalization and in-suite ventilation system (ISVS) retrofit.

The following naming convention is used for the four energy models used to answer the research questions. The naming convention is intended to more intuitively follow the building retrofit chronology, however the energy models are presented here and in the following chapters in the order they were created.

1) Base model B2: current condition (i.e. 2012 retrofitted enclosure) calibrated to metered energy consumption data, measured performance characteristics and custom local weather data

2) Retrofit model R2: proposed compartmentalization/ventilation retrofit to current building condition (retrofitted enclosure), applied to base model B2

3) Base model B1: base model B2 modified to original as-constructed enclosure condition (i.e. prior to 2012 retrofit), recalibrated to metered utility data using local weather data from the same time period

4) Retrofit model R1: proposed compartmentalization/ventilation retrofit on original building construction, applied to base model B1

Figure 3-20 below illustrates graphically the progression of case study building retrofits and the corresponding energy model naming convention. These four models were then used to examine the impact of the proposed retrofit on the case study building, with and without an enclosure retrofit. 




Figure 3-20: Base model and retrofit energy model naming convention

\subsubsection{Nodal network model}

Because the impact on energy consumption of the proposed retrofit is largely dependent on its influence on the airflows throughout the building, an attempt was made to model the internal airflows within the case study building as accurately as possible using a nodal network approach. A nodal network model of the building in its current condition was first created in an attempt to validate the capabilities of the EnergyPlus ${ }^{\mathrm{TM}}$ AirFlowNetwork object group in simulating stack effect. The background to the nodal network energy modelling approach was covered in Section 2.2.3. Initial success in producing buoyancy-driven airflows within the building led to further analysis of the available building performance data to support a calibration procedure which would require calibrating the model to both airflows and energy use together. A deeper understanding of the data required to do this, and the reliability of the data available, was gained through this exercise and eventually led to the abandonment of the nodal network approach. An account of the 
insights gained through this effort is given in Section Error! Reference source not found. as a eference for any future work in this field.

The building energy models used in this research were instead constructed with the more standard EnergyPlus $^{\mathrm{TM}}$ modular object architecture using prescribed airflow rates for the various airflow sources (e.g., ZoneInfiltration:DesignFlowRate, ZoneVentilation:DesignFlowRate, ZoneMixing, AirLoopHVAC, Fan:ZoneExhaust).

\subsubsection{Base model B2: current condition (retrofitted enclosure)}

This section describes the creation and calibration of the base model of the case study building in its current condition, which includes the enclosure retrofit done in 2012.

\subsubsection{Base model B2 setup}

\section{Construction}

Comprehensive physical and operational characteristics of the building were known from extensive observations and measurements at the site, and these data were incorporated into the building model. Input parameters were based on as-constructed drawings, a complete heating and ventilation equipment inventory, miscellaneous gas and electrical appliances, equipment nameplate data and/or performance spot measurements, operating and occupancy schedules, thermostat set points, and detailed site-based hourly weather data. Mechanical ventilation effectiveness testing results including measured air distribution rates to the corridors and suites were incorporated in the model. The airflow resistance characteristics of the enclosure (flow coefficient and exponent) from fan pressurization and depressurization testing were available, as well as some average pressure differential measurements across the exterior walls, allowing infiltration rates to be estimated for inputs in the model.

Table 3-2 below is a summary of some of the key passive physical characteristics which had an impact on the energy consumption. 
Table 3-2: Base model B2 inputs - key passive physical characteristics impacting energy use

\begin{tabular}{lcc} 
Performance characteristic & Value & Source \\
\hline Windows \& balcony doors & & \\
USI & $1.57 \mathrm{~W} / \mathrm{m}^{2}-\mathrm{K}$ & ASHRA \\
SHGC & 0.2 & ASHRA \\
VT & 0.7 & \\
Exterior enclosure & & $\mathrm{RDH}$ \\
Effective R-value - walls & $\mathrm{RSI}-2.84 \mathrm{~m}^{2}-\mathrm{K} / \mathrm{W}\left(\mathrm{R}-16.1^{\circ} \mathrm{F}-\mathrm{ft}^{2}-\mathrm{hr} / \mathrm{Btu}\right)$ & $\mathrm{RDH}$ \\
Effective R-value - roof & $\mathrm{RSI}-3.5 \mathrm{~m}^{2}-\mathrm{K} / \mathrm{W}\left(\mathrm{R}-19.9^{\circ} \mathrm{F}-\mathrm{ft}^{2}-\mathrm{hr} / \mathrm{Btu}\right)$ & $\mathrm{RDH}$ \\
Air leakage (avg.) & $1.81 \mathrm{~L} / \mathrm{s} / \mathrm{m}^{2} @ 75 \mathrm{~Pa}$ &
\end{tabular}

\section{Performance}

As discussed earlier in Section 2.3.5.3, the average mechanical ventilation rate reaching the suites was only approximately $8 \%$ of the total MAU airflow. This equates to approximately $3.1 \mathrm{~L} / \mathrm{s}$ per suite, which was used as an input in the B2 energy model.

Infiltration in the B2 model was set to $0.29 \mathrm{~L} / \mathrm{s} / \mathrm{m}^{2}$ 9of wall area) based on measured enclosure air tightness at a $4 \mathrm{~Pa}$ reference pressure, as described previously in Section 2.3.5.3. Transient increases in infiltration rates due to wind pressure (based on the measured wind velocities in the custom weather file) were then accounted for using the linear wind velocity coefficient of the ZoneInfiltration function in the energy model. A coefficient of 0.224 was used based on the DOE2 infiltration model (Gowri, Winiarski, \& Jarnagin, 2009).

Table 3-3 below summarizes the HVAC equipment performance specifications which were used in the B2 and B1 baseline models. 
Table 3-3: Base model B2 inputs - HVAC equipment performance specifications

\begin{tabular}{|c|c|c|}
\hline Equipment property & Value & Source \\
\hline Baseboard heater capacity (-01 suites) & $11.0 \mathrm{~kW}$ & $\mathrm{RDH}$ \\
\hline Baseboard heater capacity (-02 suites) & $7.0 \mathrm{~kW}$ & $\mathrm{RDH}$ \\
\hline Baseboard heater capacity (-03 suites) & $10.5 \mathrm{~kW}$ & $\mathrm{RDH}$ \\
\hline (zone setpoint temperature) & $23 \mathrm{C}$ & $\mathrm{RDH}$ \\
\hline Fireplace heating capacity & $8.8 \mathrm{~kW}$ & $\mathrm{RDH}$ \\
\hline Fireplace radiant fraction & 0.4 & $\mathrm{RDH}$ \\
\hline Fireplace heat fraction lost & 0.6 & $\mathrm{RDH}$ \\
\hline MAU flow rate & 1440 L/s (avg.) & Airflow testing $(\mathrm{RDH})$ \\
\hline MAU motor & $1.12 \mathrm{~kW}(1.5 \mathrm{hp})$ & $\mathrm{RDH}$ \\
\hline MAU supply fan efficiency & $60 \%$ & Engineered Air \\
\hline MAU heating coil capacity & $73.2 \mathrm{~kW}$ & $\mathrm{RDH}$ \\
\hline MAU heating coil efficiency & $80 \%$ & Engineered Air \\
\hline MAU supply air temperature & $20.7 \mathrm{C}$ & Test data (RDH) \\
\hline Bathroom fan exhaust rate & $33 \mathrm{~L} / \mathrm{s}$ & $\mathrm{RDH}$ \\
\hline Bathroom exhaust fan power & $60 \mathrm{~W}$ & $\mathrm{RDH}$ \\
\hline Bathroom fan efficiency & $60 \%$ & $\mathrm{RDH}$ \\
\hline Bathroom exhaust fan static pressure & $50 \mathrm{~Pa}$ & assumed \\
\hline DHW boiler capacity & $178.7 \mathrm{~kW}$ & $\mathrm{RDH}$ \\
\hline DHW supply temperature & $55 \mathrm{C}$ & $\mathrm{RDH}$ \\
\hline DHW boiler efficiency & $82 \%$ & $\mathrm{RDH}$ \\
\hline DHW consumption & $2.75 \mathrm{~L} / \mathrm{m}^{2}$-day & $\mathrm{RDH}$ \\
\hline DHW pump rated power & $250 \mathrm{~W}$ & $\mathrm{RDH}$ \\
\hline
\end{tabular}

\subsubsection{Base model B2 calibration}

The B2 energy model was calibrated to the energy end use breakdown determined in Section 3.1.1 according to the Whole Building Calibrated Simulation Performance Path of ASHRAE Guideline 14 using the statistical comparison technique (ANSI/ASHRAE, 2002). The Guideline outlines two statistical acceptability indices for calibration of energy models, the normalized mean bias 
error $(\mathrm{NMBE})$ and the coefficient of variation/root mean squared error (CV(RMSE)). The acceptability indices for monthly energy model calibrations are +/- 5\% NMBE and +/- 15\% CV(RMSE). The equations for the indices are as follows:

$$
\begin{gathered}
N M B E=100 \times \frac{\sum_{i=1}^{n}\left(y_{i, \text { sim }}-y_{i, \text { data }}\right)}{(n-p) \times \bar{y}_{\text {data }}} \\
C V(R M S E)=100 \times \frac{\sqrt{\frac{\sum_{i=1}^{n}\left(y_{i, \text { sim }}-y_{i, \text { data }}\right)^{2}}{n-1}}}{\bar{y}_{\text {data }}}
\end{gathered}
$$

Where:

$y_{i, \text { sim }}=$ simulated value

$y_{i, \text { data }}=$ measured value

$\bar{y}_{\text {data }}=$ mean value of measured data

$n=$ number of samples

$p=1$

Variables used for the B2 model inputs were collected from a number of sources including extensive raw field measurements of energy use, airflow characteristics, and weather data (described previously), as well as a number of published and unpublished reports from RDH Building Science Ltd., who were responsible for the design and execution of the enclosure retrofit, and collecting the field measurements. As described, the initial energy model was created in DesignBuilder in order to set up building geometry, equipment connections, various global schedules, etc. and create the initial EnergyPlus ${ }^{\mathrm{TM}}$ IDF file. Many standard default values for residential buildings were initially selected in this model. These iput data in the IDF model were then adjusted following the data source reliability hierarchy as described by Raftery, Keane, \& O’Donnell (2011). Unknown parameters (e.g., miscellaneous plug loads, lighting power density, etc.) were adjusted iteratively in the IDF file through successive simulations until the key performance outputs were within the calibration acceptability indices. Further refinements were made with adjustments to schedules governed by occupant behaviour (e.g., lights, fans, and 
window operation, etc.). These parameters were kept constant following the calibration of the B2 baseline model, and carried forward to the subsequent models (R2, B1, and R1). The changes which were made to these subsequent models are outlined in their corresponding Sections, to follow. A complete revision history was maintained using Microsoft Excel to record input adjustment values and their resulting impacts, as well as maintain version control on the energy model files. Input parameters and schedules can be seen in the IDF files, which are impractical to include as an appendix but can be made available by the author.

Simulations during the model calibration stage were run using the custom weather file compiled for the year corresponding to the detailed metered energy use (2013). The following sections describe the calibration procedure in more detail.

\section{Natural gas calibration}

First, the simulated natural gas consumption for each sub-metered end use (MAU, DHW,

fireplaces) was tuned to match the corresponding recorded usage profiles, outlined in the following sections. Calibration to natural gas use was done before electricity use because each sub-metered end use was distinct, with their driving factors fairly well understood. In contrast to the electricity data which included many different end uses, both regulated and unregulated. In addition, the MAU and fireplaces would have a strong influence on the heating energy portion of the electricity data, so their energy profiles needed to be tuned in before the electricity data could be disaggregated with any confidence.

\section{Natural gas for domestic hot water}

DHW natural gas consumption did not need to be estimated using assumptions of hot water usage rates, as the gas for the dedicated DHW boiler was metered directly. Because hot water usage is largely a weather-independent variable with a fairly constant baseline throughout the year, the simulated energy was easily aligned with the actual measured consumption. Nameplate boiler and pump sizes and efficiencies were inputs to the model and water usage schedules were adjusted until the energy profiles matched. 
Figure 3-21 below shows the resulting monthly DHW natural gas consumption for the calibrated B2 model against the actual metered value. Simulated results fell well within the acceptability indices, with $0.3 \% \mathrm{NMBE}$ and $5.6 \% \mathrm{CV}(\mathrm{RMSE})$.

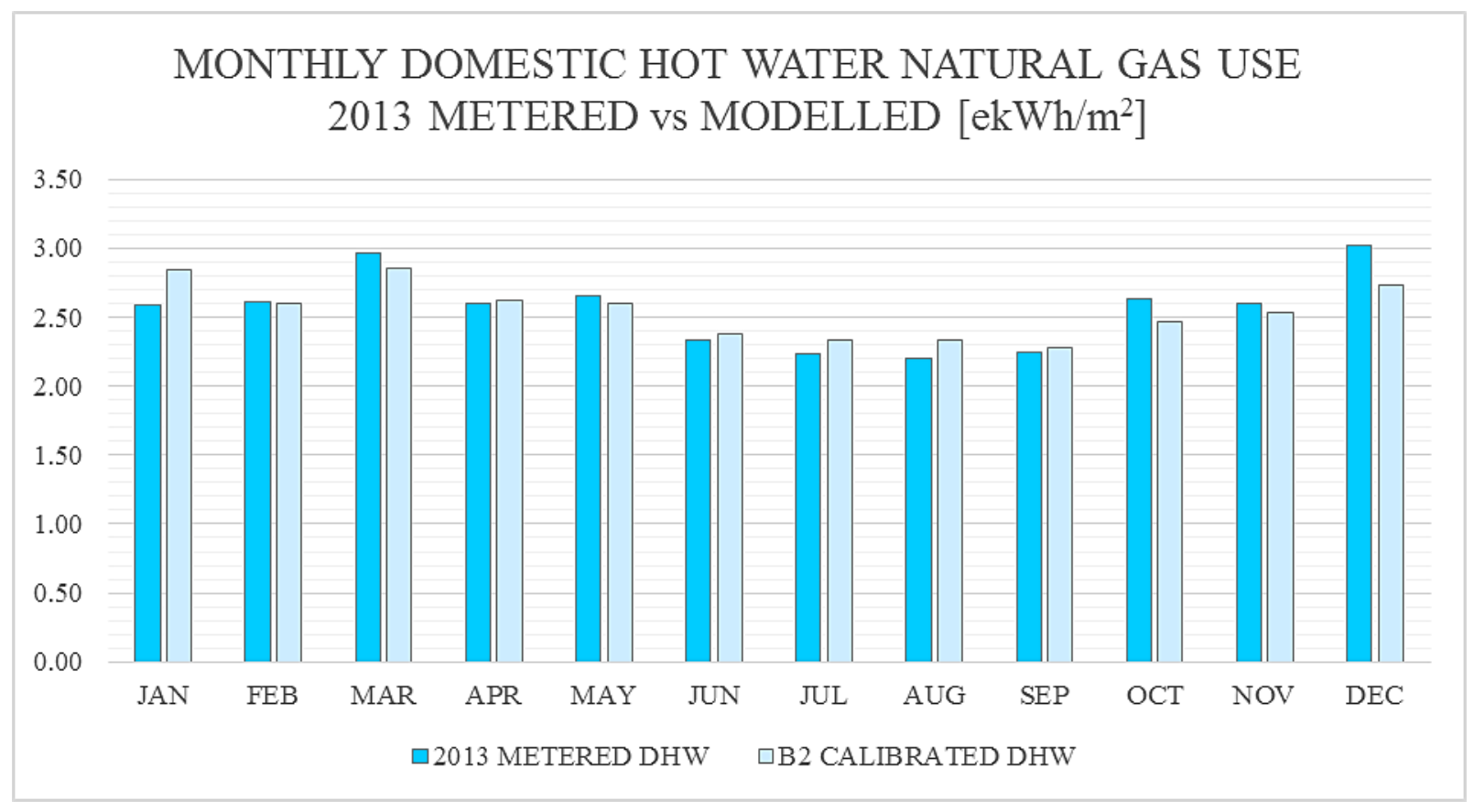

Figure 3-21: 2013 monthly metered vs modelled DHW natural gas consumption

\section{Natural gas for mechanical ventilation}

The MAU was a simple constant volume, always on, heating only, indirect-fired natural gas rooftop unit. As such, its natural gas consumption profile was easily reproducible as it was only a function of outside air temperature, burner efficiency, and airflow rate. Using the measured total volumetric flow rate, claimed efficiency, downstream supply air temperature, and data collected from the rooftop weather station only meters away, the MAU energy use profile was matched in the model with little required refinement. Supply air temperature data presented in Figure 3-22 was available for a period of approximately nine months spanning from August 2012 to May 2013. 


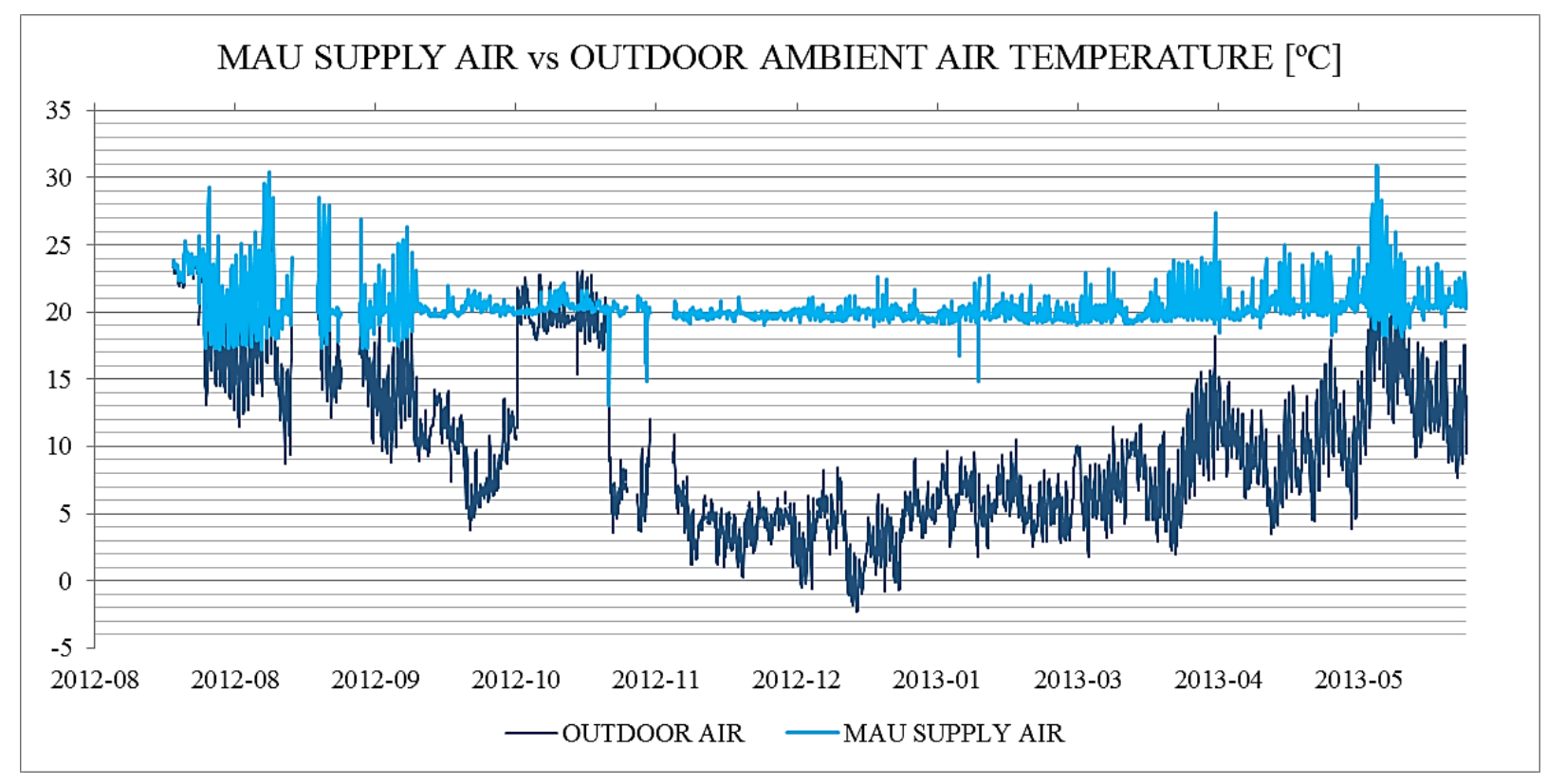

Figure 3-22: MAU supply air temperature vs. ambient outdoor temperature [degrees Celsius]

Unfortunately, a complete year of data wasn't available for 2013. However, monthly average supply air temperatures were available from August 2012 to May 2013, which spanned the summer, winter, and a shoulder season. Data from late summer 2012 appears to be very erratic, with unusually high temperatures. These data may in fact have been accurate and reflected some operational problem with the system, as there was another spike in temperatures in May when outside temperatures rose above $15^{\circ} \mathrm{C}$. Gaps visible in that early data however may also point to a sensor fault or equipment setup issue of some kind. For this reason, the first six weeks of data were not used in the analysis. Another anomaly occurs during in November 2012, where the outside air temperature climbs abruptly by ten degrees during a single day and remains at around $20^{\circ} \mathrm{C}$ for the first three weeks, falling abruptly back down by ten to $15^{\circ} \mathrm{C}$ after that. The pattern is not consistent with the general weather trend, and the temperature is also unusually high for any month in Vancouver, especially November. This points quite clearly to a measurement error as the outside air on certain days is higher than the supply air. The MAU has no cooling function making this scenario highly improbable. Although there is no indication that the supply air temperatures were also faulty during this time, any readings which were below the outside air temperature were ignored just to be conservative. An average temperature of $20.7^{\circ} \mathrm{C}$ was 
calculated based on the remaining measurements, which was used as a constant central ventilation supply air temperature for the model.

In addition to supply air temperature data, the MAU flow rate was also measured, as seen in Figure 3-23 below. Although these data also span only a portion of 2013, they cover the majority of the year, and the trend appears to be relatively flat following an abrupt flow rate increase in early May. This anomaly can be explained by a fan belt replacement occurring at that time and leading to a relatively constant flow rate around the manufacturer's specified capacity. The decreasing trend prior to that was due to slippage of a worn fan belt causing and the airflow to slowly taper off. Using these data, monthly MAU supply air flow rates were calculated for use in the model calibration procedure.

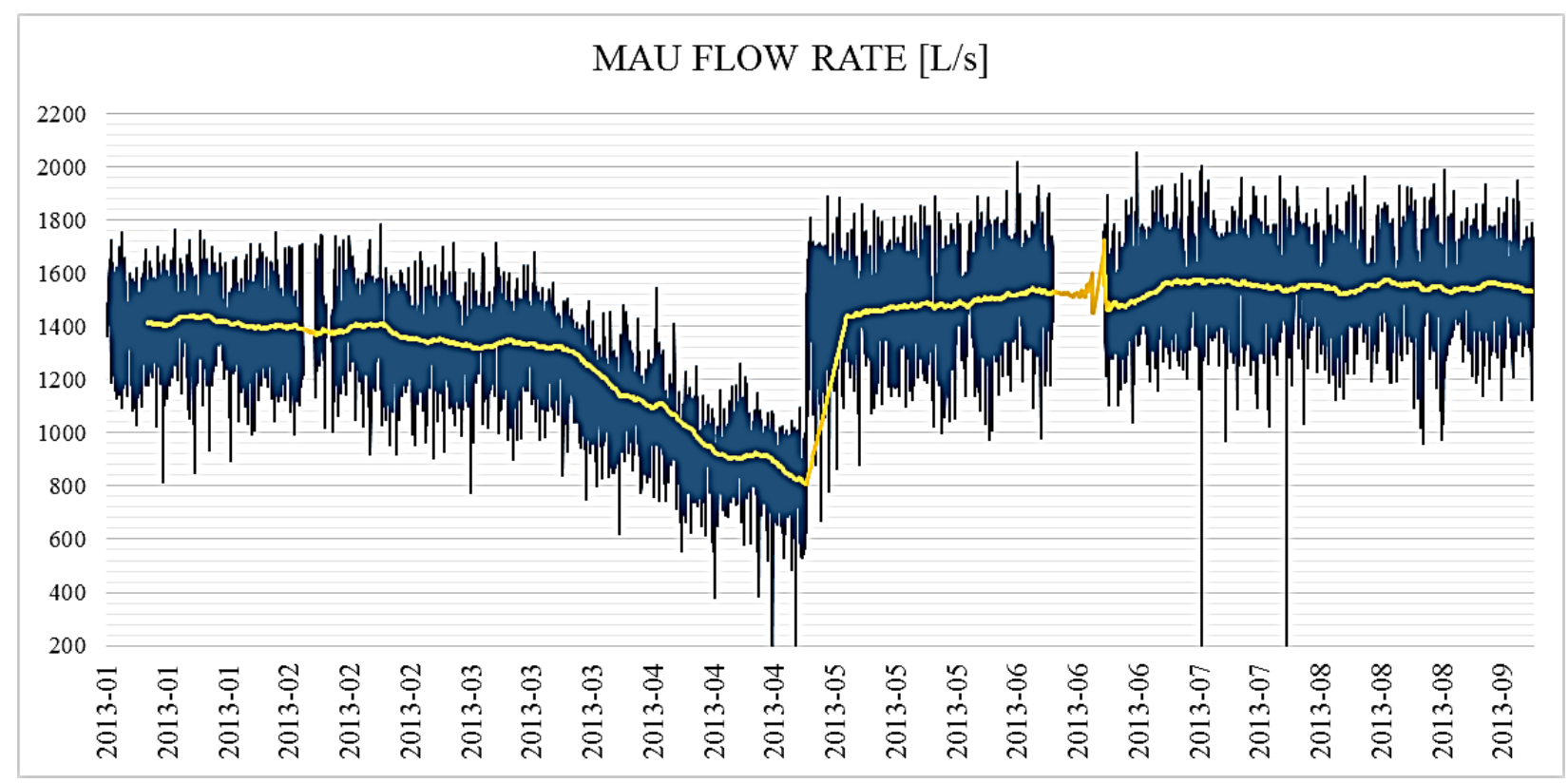

Figure 3-23: MAU measured airflow rate and 24 moving average

These monthly MAU performance data were used as model inputs, and Figure 3-24 below shows the resulting monthly MAU natural gas consumption for the calibrated B2 model against the actual metered value. Simulated results fell well within the acceptability indices, achieving 1.6\% NMBE and $14.9 \% \mathrm{CV}(\mathrm{RMSE})$. 


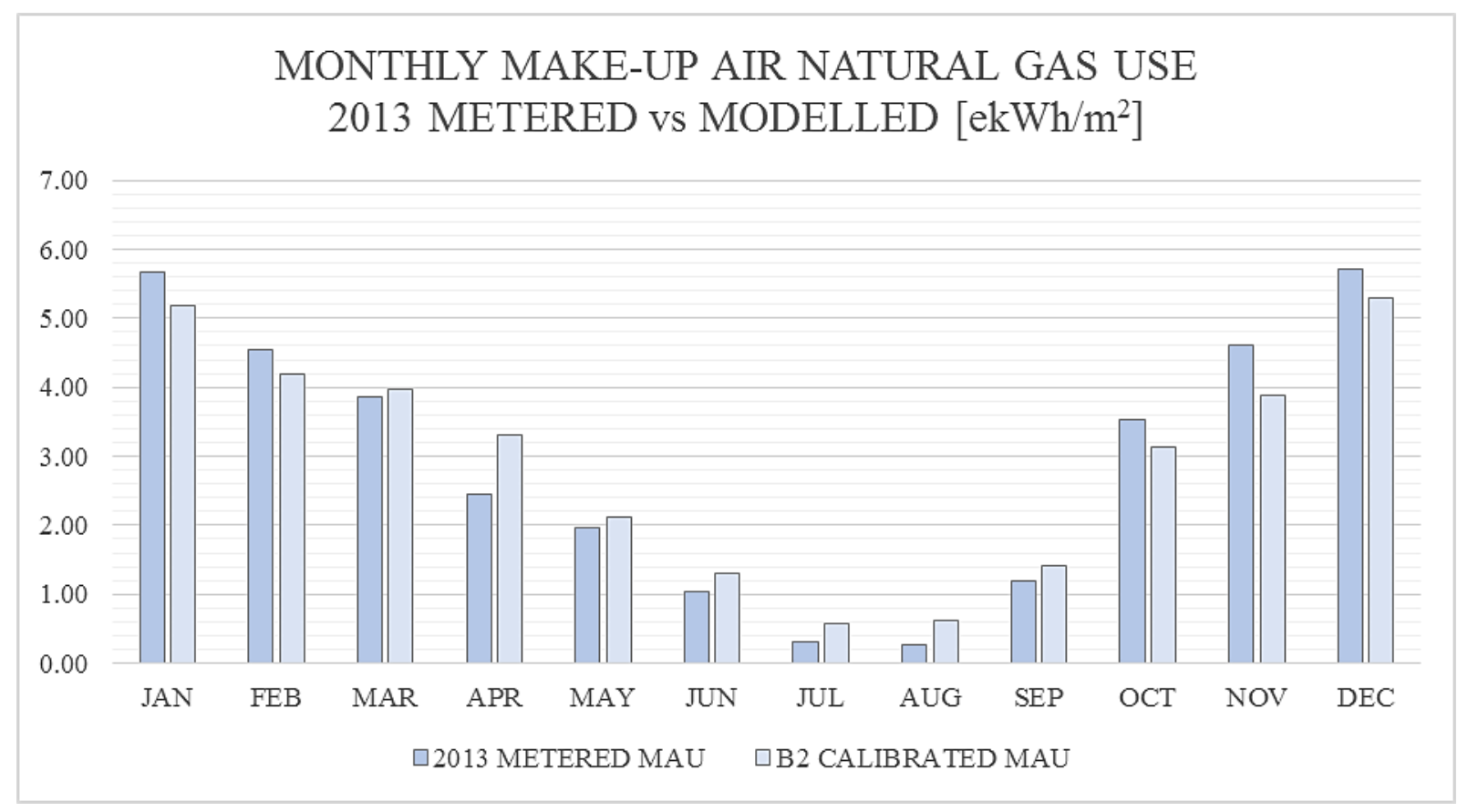

Figure 3-24: 2013 metered vs B2 modelled MAU natural gas consumption

\section{Natural gas for fireplaces}

The final adjustments to tune in the model's natural gas consumption were made to the monthly schedule for fireplace operation. An initial daily and monthly schedule had been created, with usage arbitrarily increasing in the winter months and decreasing again in the summer months. The monthly schedule was adjusted until the energy profile fell within the acceptable range of the calibration performance indices.

Figure 3-25 below shows the resulting monthly fireplace natural gas consumption for the calibrated B2 model against the actual metered value. Simulated results fell well within the acceptability indices, with $1.4 \% \mathrm{NMBE}$ and $3.3 \% \mathrm{CV}$ (RMSE). 


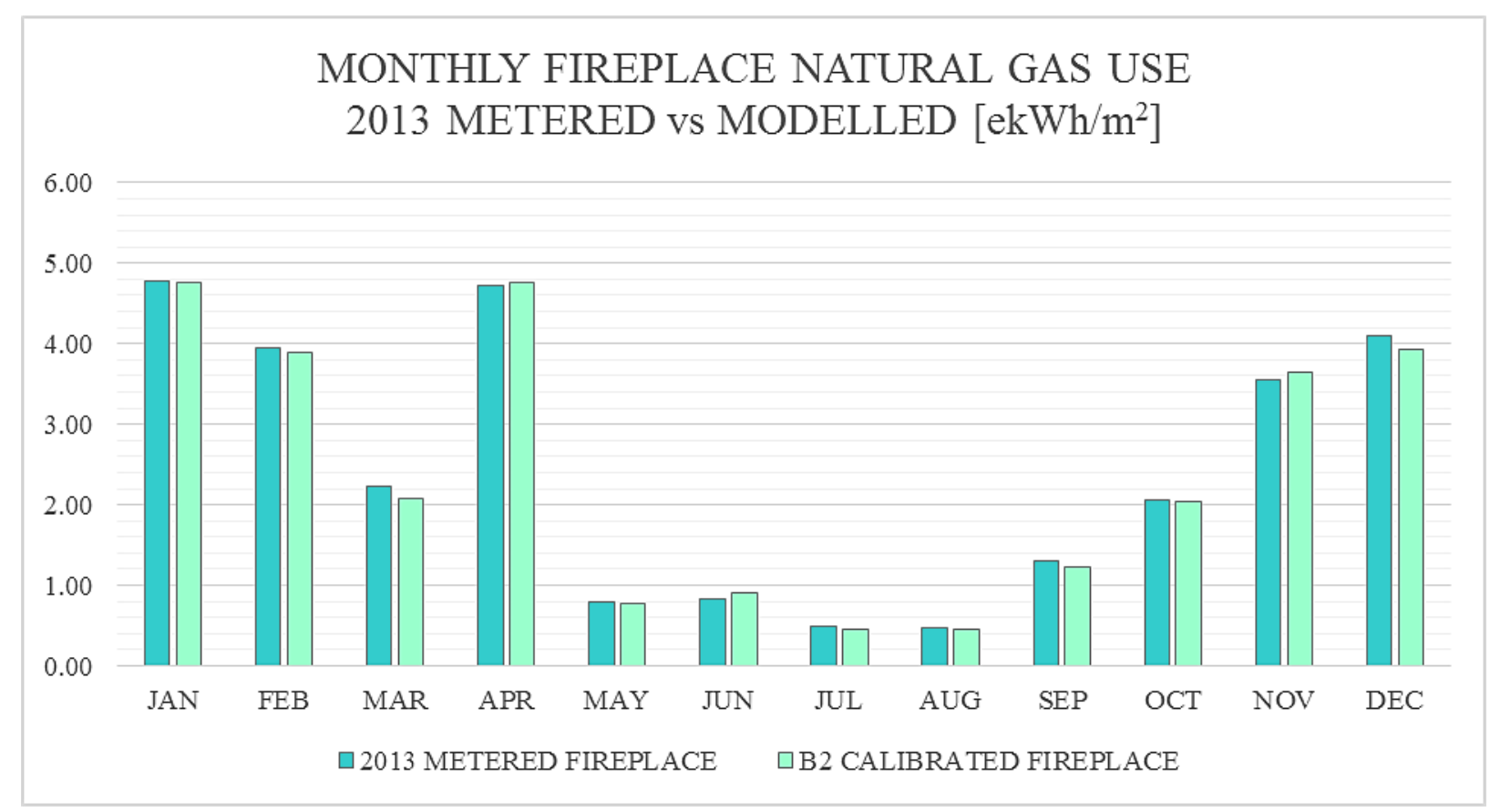

Figure 3-25: 2013 metered vs B2 modelled fireplace natural gas consumption

\section{Electricity}

Electricity consumption for the common areas of the building was a fairly steady operational base load defined by lighting and elevators and easily matched to the metered profile, shown in Figure 3-26 below. Simulated results fell well within the acceptability indices, with $0.7 \%$ NMBE and $4.5 \%$ CV(RMSE). 


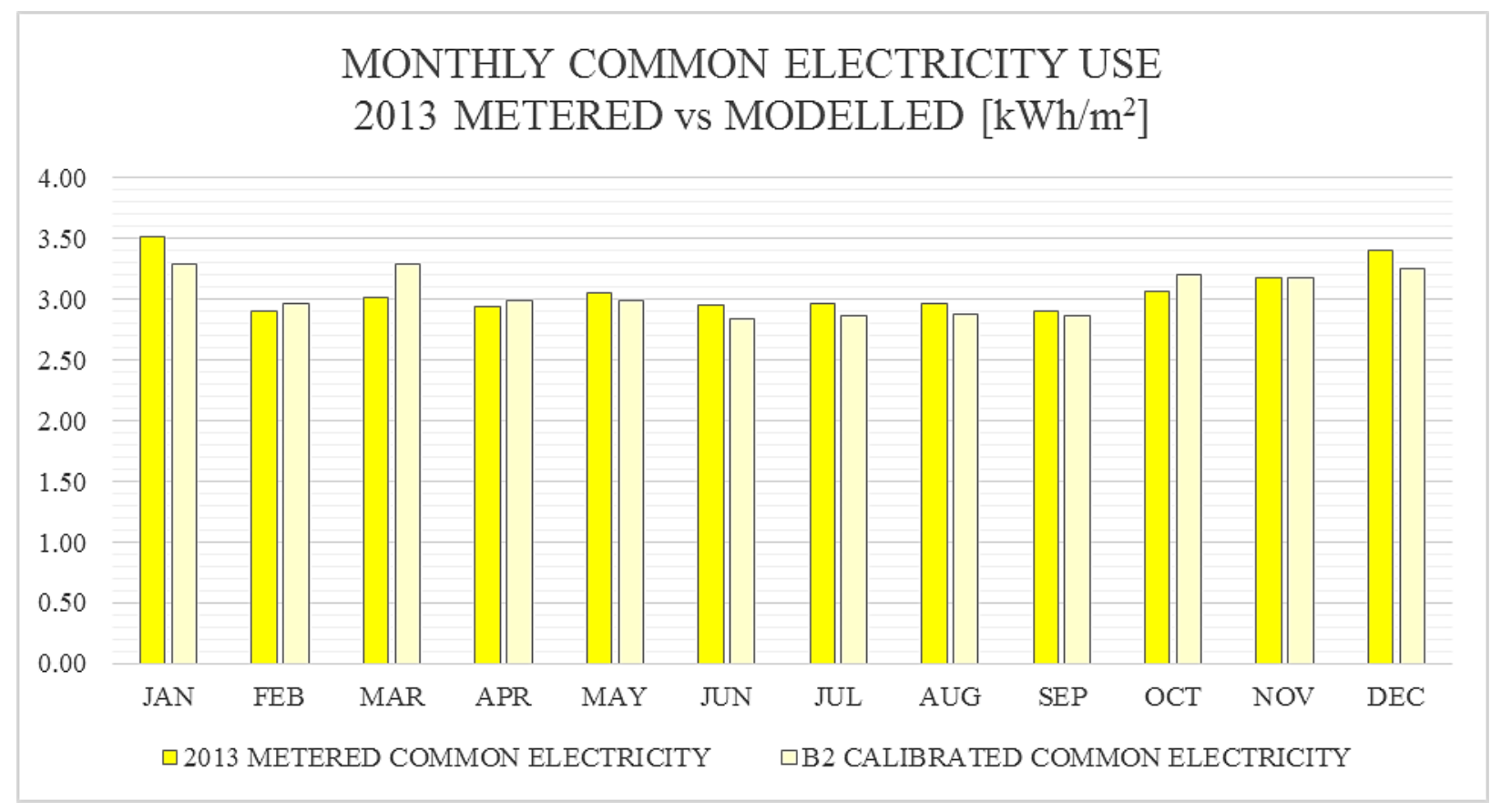

Figure 3-26: 2013 monthly common electricity consumption - B2 calibration

Overall suite-level electricity and its electric heating energy component were then calibrated simultaneously, as the unregulated suite-level loads also influenced heating energy.

Although baseboard heater energy data was not available, the heater capacities were known, and their simulated energy use was matched to the estimated profile in Section 3.1.1.2. Coarse calibration of electricity for heating was done with rate and schedule adjustments to natural ventilation, which had not been measured but observed to occur.

The monthly electric heating energy profile of the calibrated B2 model can be seen in Figure 3-27 next to the estimated actual electric heating energy determined previously from metered data. Simulated results fell well within the acceptability indices, with $0.5 \% \mathrm{NMBE}$ and $4.3 \%$ CV(RMSE). 


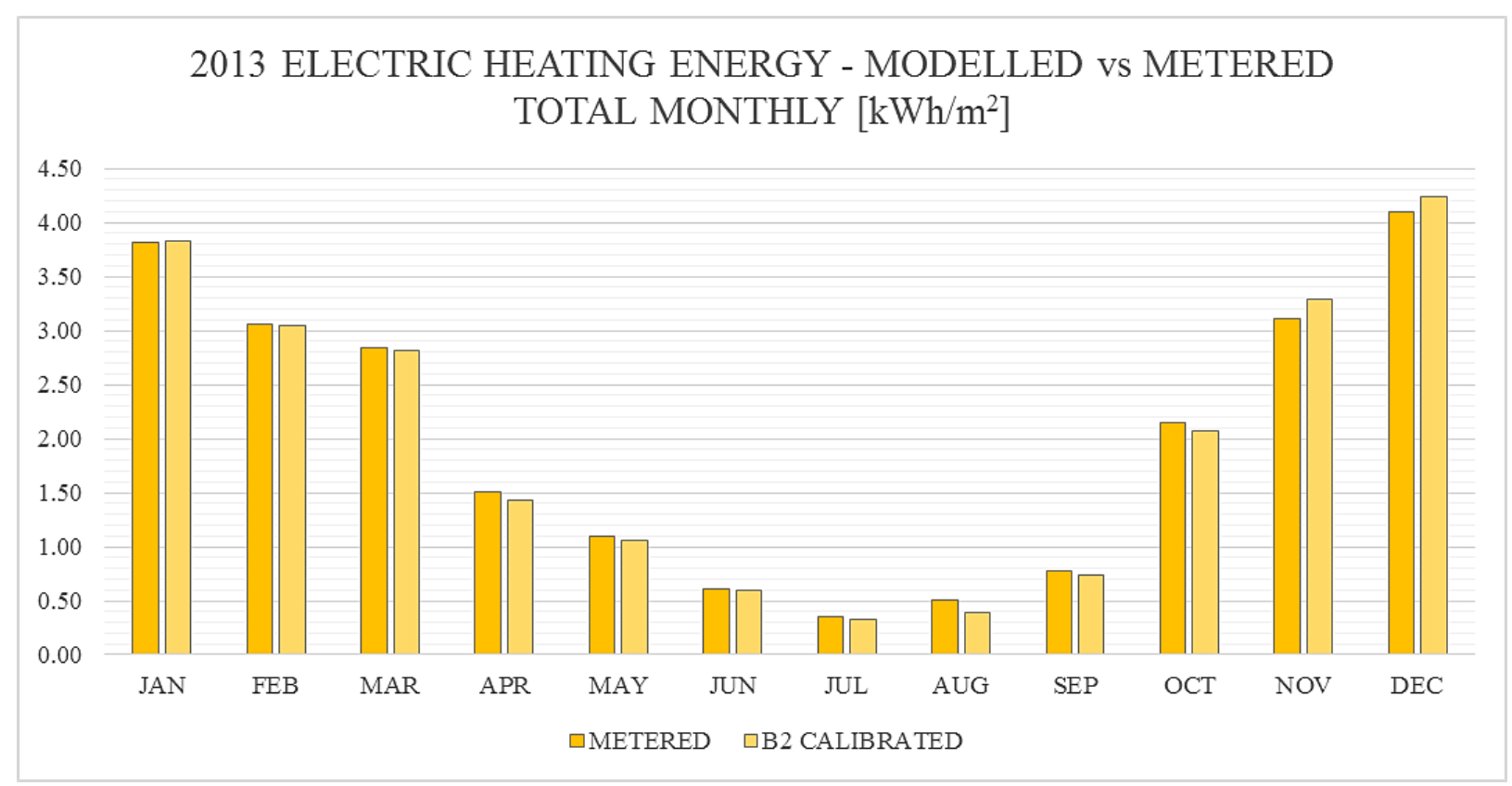

Figure 3-27: 2013 suite-level electric heating energy - B2 calibration

Fine adjustments were then made to lighting and equipment power, usage schedules, and related radiant and sensible heat gain fractions to refine the profile shape of both the heating and overall suite-level electricity use together.

Figure 3-28 below shows the simulated total suite-level electricity usage compared with the metered usage. Simulated results fell well within the acceptability indices, with -1.6\% NMBE and $13.8 \% \mathrm{CV}(\mathrm{RMSE})$. 


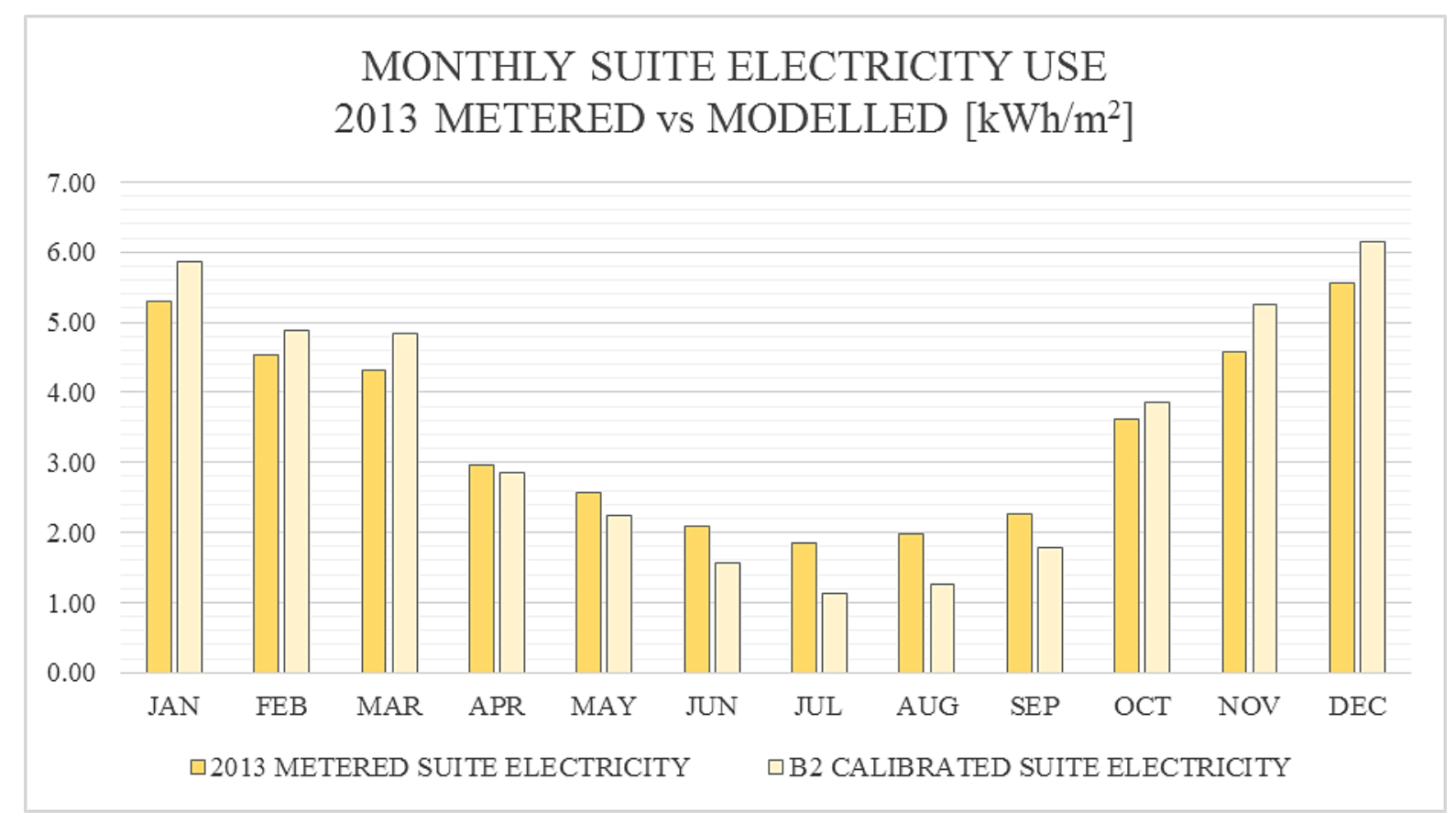

Figure 3-28: 2013 monthly suite-level electricity consumption - B2 calibration

\section{Overall heating energy}

The modelled total monthly heating energy profiles determined above from both fuel types, and the heating energy profile determined through metered data are compared below in Figure 3-29. 


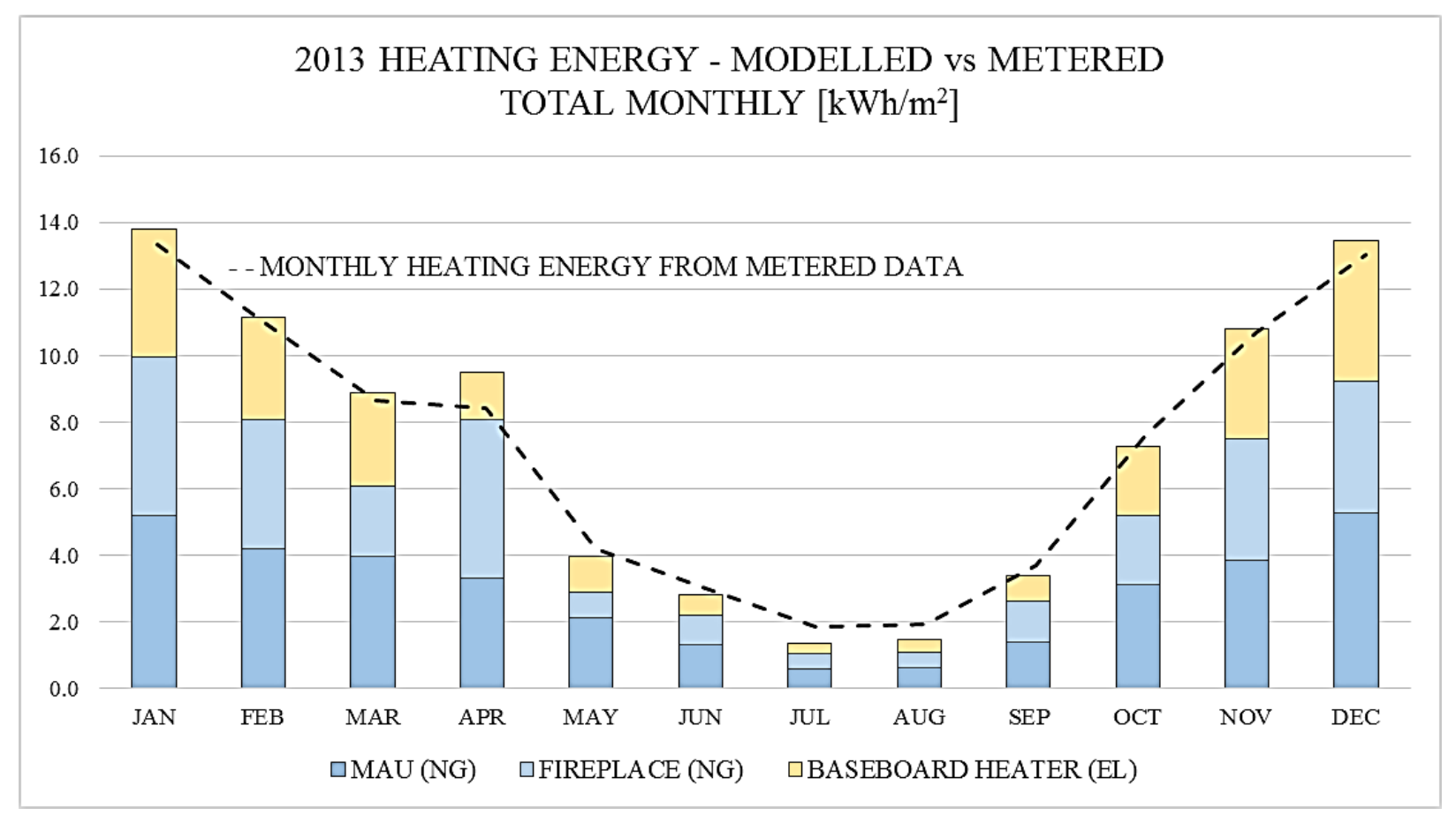

Figure 3-29: Calibrated monthly heating energy - 2013

Simulated results for both fuel types fell well within the acceptability indices, with total natural gas achieving $0.7 \% \mathrm{NMBE}$ and $6.8 \% \mathrm{CV}$ (RMSE), and overall electricity achieving $0.3 \% \mathrm{NMBE}$ and $8.9 \% \mathrm{CV}$ (RMSE).

A summary of the calibration performance indices for this final simulation is shown in Table 3-4 below. All energy use profiles fell well within the acceptability indices of $+/-5 \%$ mean bias error (NMBE) and +/- 10\% coefficient of variation (root mean squared error) (CV(RMSE)) for calibration to monthly data. 
Table 3-4: B2 calibration statistical indices for fuel type and end use

\begin{tabular}{lcc}
\hline & NMBE (+/- 5\%) & CV(RMSE) (+/- 15\%) \\
\hline Overall natural gas & $\mathbf{0 . 7 \%}$ & $\mathbf{6 . 8 \%}$ \\
Natural Gas for DHW & $0.3 \%$ & $5.6 \%$ \\
Natural Gas for MAU & $1.6 \%$ & $14.9 \%$ \\
Natural Gas for fireplaces & $1.4 \%$ & $3.3 \%$ \\
Overall electricity & $\mathbf{0 . 3 \%}$ & $\mathbf{8 . 9 \%}$ \\
Common area electricity & $0.7 \%$ & $4.5 \%$ \\
Suite-level heating electricity & $0.5 \%$ & $4.3 \%$ \\
Suite-level total electricity & $-1.6 \%$ & $13.8 \%$ \\
\hline
\end{tabular}

Figure 3-30 below shows the overall modelled energy profiles on an annual basis for each fuel type and end use for the whole building are compared to the corresponding metered data.

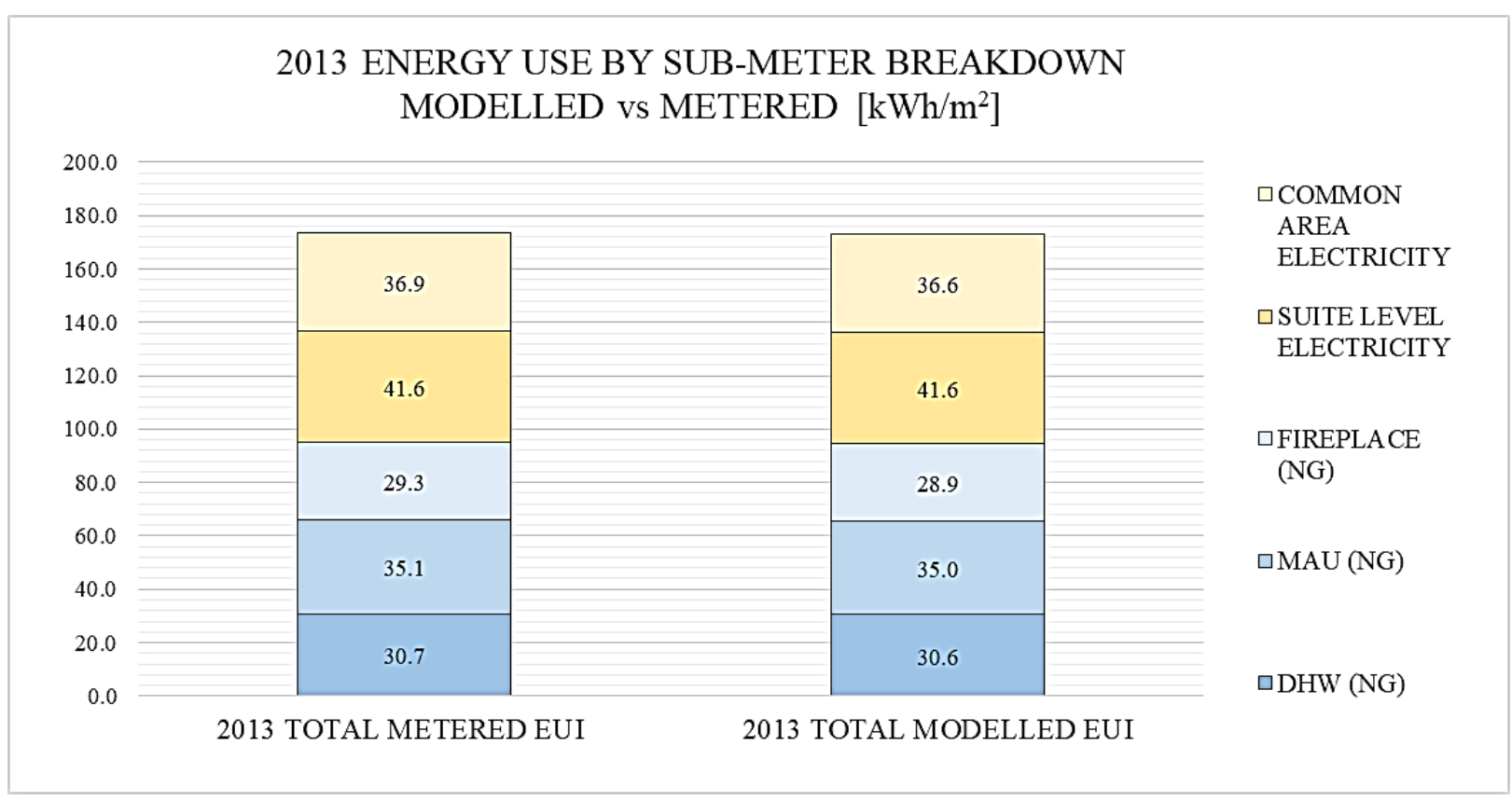

Figure 3-30: 2013 Energy use by sub-meter breakdown - modelled vs metered 
At this point the simulation was run again with a typical meteorological year weather file for the nearby airport (YVR CWEC) for comparison purposes with the other simulation runs to follow.

Because the B2 and R2 CWEC simulations are used to examine comparative performance, some changes to the baseline B2 model can be made following calibration provided the same change is made to the retrofit model, and the resulting impact would be the same for both models. Natural ventilation (from opening windows and balcony doors) and fireplace use were two such variables which were changed. Natural ventilation was eliminated in both CWEC simulations because natural ventilation is a function of occupant behaviour, not a fundamental performance characteristic of the building. The impact of natural ventilation on energy use is not of particular interest in examining the relative performance proposed retrofit. In reality, the proposed retrofit may result in a change in window operation habits by the occupants, but this behaviour change would only be speculative at this point. Fireplaces were also eliminated since they are not a typical building trait, were only installed on 5 floors, and were found to provide very little space heating energy while consuming a significant amount of natural gas.

\subsubsection{Retrofit model R2: proposed retrofit on current building condition (B2 base model)}

The compartmentalization retrofit of the suites was modelled by eliminating the mechanical ventilation airflow to the suites from the corridors. This was determined to be a conservative approach as any ventilation air that might enter the suites from the corridor in reality (when doors are opened, or through leakage from imperfect sealing) would have a negligible effect on the suite's heating load as it has already been conditioned by the MAU.

With the suites compartmentalized from the corridors, their internal air pressure would tend to equalize with the ambient outdoor air pressure, thus decreasing the driving force for airflow through the enclosure, as described in Section 2.4. As such, infiltration in the R2 model was adjusted by assuming the average pressure differential between each suite and outdoors would decrease from $4 \mathrm{~Pa}$ (used in the $\mathrm{B} 2$ calibrated model) to $1 \mathrm{~Pa}$. The resulting estimated infiltration rate was calculated to be $0.13 \mathrm{~L} / \mathrm{s} / \mathrm{m}^{2}$, using the same measured enclosure airflow resistance characteristics as B2 $(\mathrm{C}=9.99, \mathrm{n}=0.63)$. No published data was found which could be used as a benchmark for the average pressure difference across a building enclosure for high-rise MURBs 
with compartmentalized suites, so the sensitivity of the modelled performance to this assumption was checked and is discussed later in Section 4.1.1.4.

As with the B2 model, transient increases in infiltration rates due to wind pressure were accounted for using the linear wind velocity coefficient of the ZoneInfiltration function, with a coefficient of 0.224 based on the DOE-2 infiltration model.

The ventilation system retrofit was modelled by adding a balanced HRV to each suite. The bathroom exhaust fans were eliminated as their function would now be handled by continuous exhaust by the HRV. Continuous supply and exhaust rates were set to $55 \mathrm{~L} / \mathrm{s}$ to meet ASHRAE Standard 62.1-2010 area and occupancy requirements (44 L/s) and to account for a zone air distribution effectiveness factor of 0.8. HRV specifications were chosen based on currently available equipment for this design flow rate, with an estimated static pressure of $75 \mathrm{~Pa}$, a power draw of $70 \mathrm{~W}$, an efficiency of $75 \%$. To allow for ventilation demand control, a dynamic reset was incorporated to match the occupancy and area requirements of Section 6.2.7.1.2 in accordance with ASHRAE Standard 62.1 guidelines.

The total MAU supply air rate was then reduced to $0.3 \mathrm{~L} / \mathrm{s} / \mathrm{m}^{2}(188 \mathrm{~L} / \mathrm{s}$ total), in accordance with the ASHRAE guidelines for common corridors. The feasibility of this is discussed later in Section 4.4.3.

\subsubsection{Base model B1: original building construction}

The original as-built condition of the building was modelled in order to investigate the potential impact of the proposed compartmentalization and ventilation system retrofit if the enclosure retrofit had not occurred. This investigation was done in order to determine if the proposed compartmentalization and ISVS retrofit could have been an appropriate measure to apply on its own without improvements to the thermal performance of the enclosure. The motivation for this was discussed earlier in Section 2.1.2.3 regarding the negative impact of enclosure retrofits on pressurized corridor ventilation system effectiveness. 


\subsubsection{Base model B1 setup}

This section describes the changes made to the calibrated B2 base model to replicate the original construction of the building and produce the B1 base model.

\section{Construction}

The enclosure assembly specifications of the building's current condition (base model B2) were replaced with those of the original as-constructed condition: $140 \mathrm{~mm}$ poured concrete with $50 \mathrm{~mm}$ of rigid extruded polystyrene (XPS) foam insulation between steel studs. The insulation has a nominal R-value of approximately RSI-1.76 m²-K/W (R-10 hr- $\left.\mathrm{ft}^{2}-\mathrm{F} / \mathrm{Btu}\right)$. The effective R-value of the walls had been determined through three-dimensional heat transfer modelling by RDH Building Science. Thermal bridging due to the steel studs and uninsulated concrete slab edges projecting through the exterior walls resulted in an estimated $60 \%$ reduction in the overall effective R-value of the opaque wall, or approximately RSI-0.7 m²-K/W (R-4 hr- $\left.\mathrm{ft}^{2}-\mathrm{F} / \mathrm{Btu}\right)(\mathrm{RDH}, 2013)$. Modelling the effective R-values of the building enclosure was accomplished by reducing the thickness of the insulation so that the overall assembly thermal resistance matched the calculated value, without losing the thermal storage effect of the concrete.

The original roof construction was an inverted assembly with $30 \mathrm{~mm}$ of XPS foam insulation with effective R-value of approximately RSI-1.67 m²-K/W (R-9.5 hr-ft²-F/Btu) (RDH, 2013).

The original windows and balcony doors were air-filled double glazed with aluminum frames not thermally broken. A U-value of $4.1 \mathrm{~W} / \mathrm{m}^{2}-\mathrm{K}$ was used as a model input, an average of 3.73 and 4.48 for operable and fixed windows from ASHRAE Handbook of Fundamentals, Chapter 15 Table 4. From this handbook, an emissivity (e) of 0.6, a solar heat gain coefficient (SHGC) of 0.7 for uncoated double glazing, and visual transmittance (VT) of 0.8 were selected

Table 3-5 below summarizes the key passive physical characteristics impacting energy use used in Base model B1. 
Table 3-5: Base model B1 inputs - key passive physical characteristics impacting energy use

\begin{tabular}{lcc} 
Performance characteristic & Value & Source \\
\hline Windows \& balcony doors & & \\
USI & $4.1 \mathrm{~W} / \mathrm{m}^{2}-\mathrm{K}$ & ASHRAE \\
SHGC & 0.7 & ASHRAE \\
VT & 0.8 & ASHRAE \\
Emissivity & 0.6 & ASHRAE \\
Exterior enclosure & & \\
Effective R-value Roof & RSI- $1.67 \mathrm{~m}^{2}-\mathrm{K} / \mathrm{W}\left(\mathrm{R}-9.5^{\circ} \mathrm{F}-\mathrm{ft}^{2}-\mathrm{hr} / \mathrm{Btu}\right)$ & $\mathrm{RDH}$ \\
Effective R-value Opaque Wall & $0.7 \mathrm{~m}^{2}-\mathrm{K} / \mathrm{W}\left(4.0^{\circ} \mathrm{F}-\mathrm{ft}^{2}-\mathrm{hr} / \mathrm{Btu}\right)$ & $\mathrm{RDH}$ \\
Air leakage (avg.) & $3.97 \mathrm{~L} / \mathrm{s} / \mathrm{m}^{2} @ 75 \mathrm{~Pa}$ & $\mathrm{RDH}$
\end{tabular}

\section{Performance}

Mechanical HVAC systems of the original building were unchanged in the 2012 enclosure retrofit, with the exception of the domestic hot water boiler replacement, but the nominal efficiency of the new boiler was the same as the one it replaced (RDH, 2014). Because of this, a non-routine adjustment in the baseline model was unnecessary. HVAC equipment performance specifications remained the same as for the $\mathrm{B} 2$ baseline model.

The average mechanical ventilation airflow to the suites from the corridors was increased in model B1 proportionally with the inverse of the measured exterior enclosure air-tightness improvement. No measurements of the actual airflow rates from the corridors to the suites prior to the enclosure retrofit had been performed, so no data was available to use as model inputs. However, because the exterior enclosure represents the next barrier to airflow through the suites from the corridors after the suite door, the change in airflow rate, from the B2 to the B1 condition, was assumed to be proportional to the change in enclosure air-tightness from its 2012 retrofit. The central mechanical ventilation rate being delivered to the suites was therefore calculated using the same relationship as the measured air-tightness level for the exterior enclosure, pre- and post-retrofit, of $4 \mathrm{~L} / \mathrm{s} / \mathrm{m}^{2} @ 75 \mathrm{~Pa}$ and $1.8 \mathrm{~L} / \mathrm{s} / \mathrm{m}^{2} @ 75 \mathrm{~Pa}$ respectively. This approach determined an increase in MAU-supplied ventilation per suite from $3.1 \mathrm{~L} / \mathrm{s}$ for B2 to $6.5 \mathrm{~L} / \mathrm{s}$ for B1. This represents $17 \%$ of 
the total MAU supply air reaching the suites for B1, or about $15 \%$ of the recommended rate by ASHRAE 62.1-2010.

Outdoor air infiltration was calculated to be $0.69 \mathrm{~L} / \mathrm{s} / \mathrm{m}^{2}$ based on the airflow characteristics $(\mathrm{C}=$ 25.56, $\mathrm{n}=0.58$ ) determined through air-tightness testing prior to the enclosure retrofit. The pressure difference across the enclosure was again assumed to be $4 \mathrm{~Pa}$, as is convention, and a linear wind velocity coefficient of 0.224 was used in the ZoneInfiltration object.

To account for zone depressurization due to bathroom exhaust fan operation, the ZoneAirMassFlowConservation object was applied, which compensates for zone exhaust rates through infiltration and air mixing from adjacent zones (NREL, 2016).

\subsubsection{Base model B1 calibration}

\section{7 - 2011 calibration}

The B1 model simulation was run using the Vancouver CWEC weather file. The resulting energy use was compared to the results from the analysis of the building's performance from the five-year period 2007 - 2011, normalized and adjusted to the CWEC weather, as described earlier in Section 3.1.2. Figure 3-31 below shows the results of this simulation, with the dashed lines representing the simulated monthly energy against their corresponding metered values. 




Figure 3-31: B1 calibration - first attempt, using weather-normalized metered energy data and YVR CWEC file

The overall simulated energy use follows the metered energy use trends, appearing to need only a relatively minor downward shift to line up each month. Monthly calibration indices at this point were $-10.1 \%$ NMBE and $14.9 \% \mathrm{CV}(\mathrm{RMSE})$ for natural gas, and $-8.5 \% \mathrm{NMBE}$ and $18.4 \%$ $\mathrm{CV}(\mathrm{RMSE})$ for total electricity. Acceptable calibration of the suite-level electricity could have been accomplished simply with minor schedule adjustments to unregulated loads at the suite level. Natural gas use also could have been brought in line with the metered performance without major changes. DHW is the only real unregulated portion of the natural gas consumption, however DHW usage was historically quite constant and an adjustment of this magnitude did not seem reasonable, at least not without revisiting the previously calibrated B2 baseline model on which B1 was based. Fireplace usage could also have been reduced, but with the same implications for the B2 baseline model. Adjustments to the MAU could not be made as its condition and operation were unchanged before and after the enclosure retrofit. Simultaneous corresponding adjustments to the B2 model 
are not necessarily unreasonable, however they are undesirable as B2 was a better-informed calibration due to the much greater quantity of measured performance data it was based on.

The adjustments required for both simulated monthly natural gas and suite-level electricity use appear to both be similar in magnitude and direction, pointing to a reduction in overall heating load. It is possible that the thermal performance of the original enclosure assembly was better than what was calculated and used in the B1 model, however this would not have an effect on the MAU natural gas consumption. Instead, the overall heating load reduction indicates that the process of normalizing the 2007 - 2011 metered energy consumption to degree days, and further conversion using the CWEC file degree days, may have introduced enough error in the apparent heating load, essentially producing a colder simulation year. To investigate this hypothesis, a second approach was taken in order to compare results.

\section{AMY weather file calibration}

An actual meteorological year (AMY) weather file for Vancouver airport from 2011, the year prior to the enclosure restoration, was purchased (source: White Box Technologies) and used in place of the CWEC file. The B1 model was run again using this AMY file, and compared against the actual 2011 metered energy data.

The performance of this simulation was a significant improvement over the previous CWEC run. Very little change was required to bring the calibration within the acceptable performance indices. Some minor adjustments were made to the daily fireplace usage schedule for each month, as well as the daily miscellaneous plug load and natural ventilation (window opening) schedules to bring the simulated energy use in line with the metered use. These schedule changes would be reasonably foreseeable in the context of varying occupant behaviour over time.

Table 3-6 summarizes the performance indices for the calibration of base model B1 for the 2011 reference year. 
Table 3-6: Base model B1 calibration performance summary - 2011 reference year

\begin{tabular}{lcc} 
& NMBE $(+/-5 \%)$ & CV(RMSE) (+/- 15\%) \\
\hline Overall natural gas & -0.3 & 2.0 \\
Overall electricity & -1.3 & 2.7
\end{tabular}

Figure 3-32 below shows the results of the 2011 calibration, with the dashed lines representing the simulated monthly energy against their corresponding metered values. The fidelity of the simulated performance of base model B1 using the actual 2011 Vancouver airport weather file was improved over the earlier use of the CWEC weather file which required normalized energy use data, shown in Figure 3-31 above.

This highlights the importance of the influence of weather data on energy model performance. It is difficult to determine the accuracy of simulated performance, or even a reasonable level of precision, when the results are dependent on weather data which has been manipulated through various statistical operations.

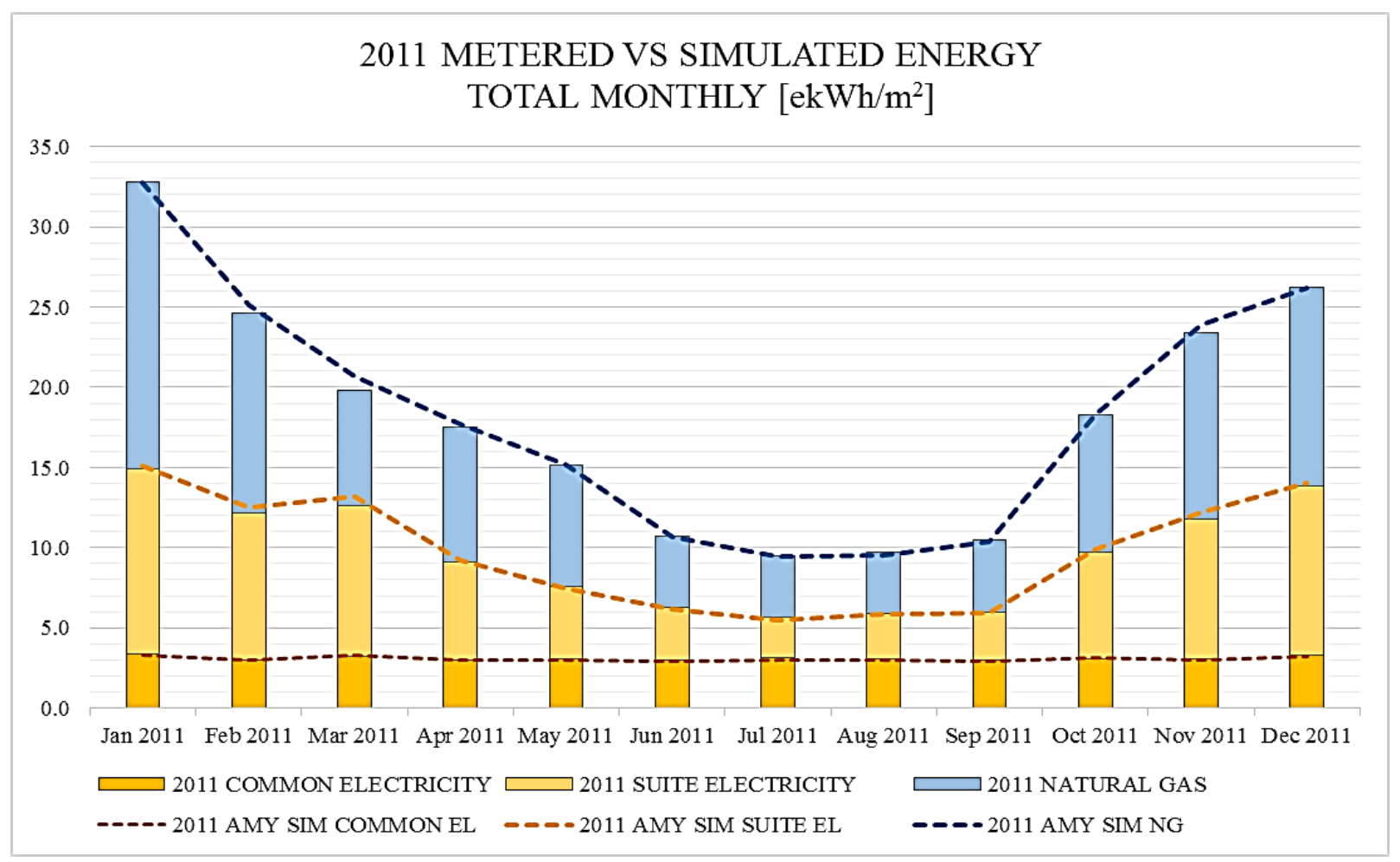


Figure 3-32: B1 calibration - 2011 metered vs. simulated energy use intensity

Although there was no actual further sub-metering of the utilities beyond that shown in Figure 3-32, an estimation of the end use breakdown was done using regression analysis against the 2011 monthly heating degree days. This was done for comparison purposes against the model, in order to check the simulated breakdown of natural gas and electricity consumption for heating and weather-independent energy use.

Figure 3-33 and Figure 3-34 below show the regression analyses of the actual metered monthly suite-level electricity and natural gas use, respectively, used to estimate the weather-independent base loads of each fuel type. Maintaining a balance point temperature of $19^{\circ} \mathrm{C}$, as determined previously, the estimated 2011 base loads were $6,612 \mathrm{kWh} / \mathrm{m}^{2}$ for suite-level electricity and 11,324 $\mathrm{ekWh} / \mathrm{m}^{2}$ for natural gas.

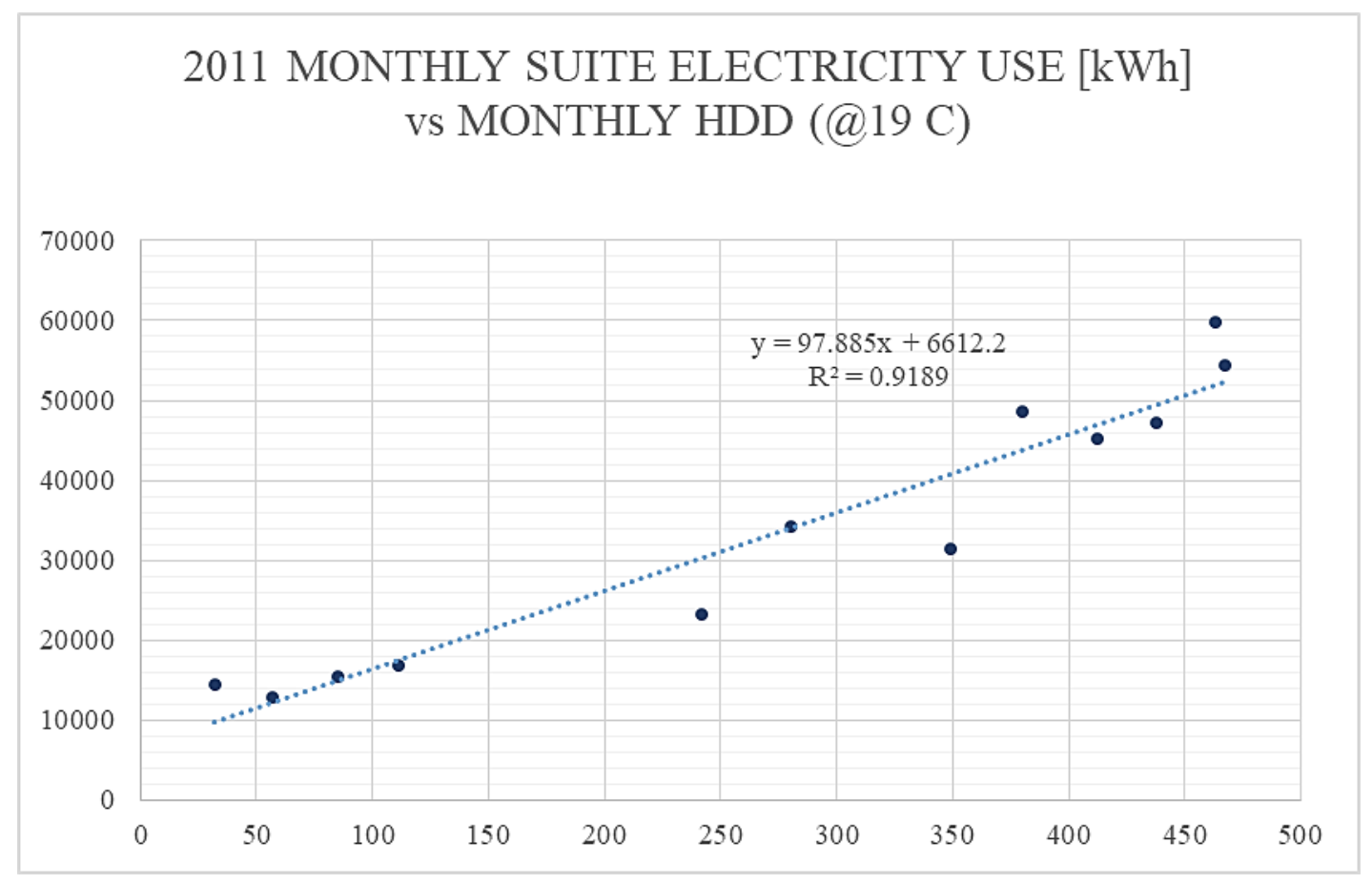

Figure 3-33: 2011 monthly suite electricity base load estimation 


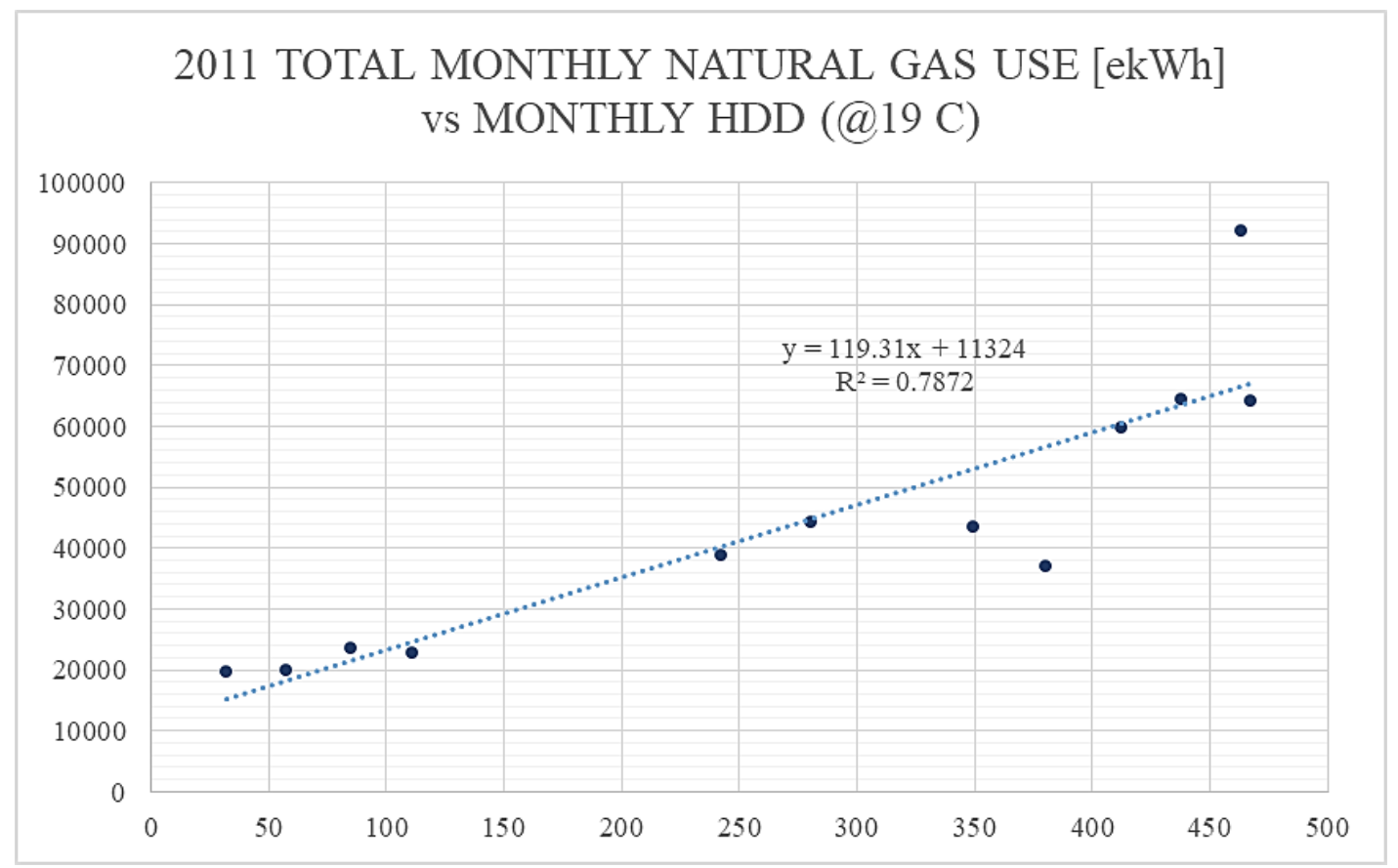

Figure 3-34: 2011 monthly natural gas base load estimation

Based on the results of the utility data regression analyses shown in Figure 3-33 and Figure 3-34, some further end use breakdown can be estimated. As discussed previously, the y-intercept represents the base load, or weather-independent, energy use. It is the minimum energy consumption, occurring when no heating energy is required, and is assumed to remain more or less a constant baseline for the entire year.

The baseline for suite electricity should approximately represent all electricity consumption at the suite level, excluding electric baseboard heater energy. Subtracting this estimated value from the total metered suite electricity consumption for 2011 leaves the electric heating energy of the baseboard heaters, which is compared to the simulated heating electricity.

Figure 3-35 below shows the results of this analysis for monthly suite-level electric heating energy, showing good correlation between estimated actual and simulated performance.

Note the acceptability indices for calibration are not calculated in the following monthly end use breakdowns because the actual energy use is only estimated and not sub-metered directly as was the case with the 2013 energy use data for the B2 model calibration. 




Figure 3-35: B1 monthly electric heating energy - 2011 simulated vs estimated actual

The natural gas base load consumption from the previous regression analysis, shown by the yintercept of 11,324 ekWh, should essentially represent the domestic hot water heating energy, as discussed previously. The results of the simulated monthly DHW heating energy are compared with this estimated actual DHW heating energy, and shown in Figure 3-36 below. 




Figure 3-36: B1 monthly DHW natural gas consumption - 2011 simulated vs. estimated actual

Because 2013 was the only year when natural gas consumption was sub-metered for each of the end uses, these data trends were used to estimate the corresponding 2011 breakdown of natural gas consumption. Fireplace and MAU natural gas use for 2013 were normalized to the monthly heating degree days, and then multiplied by the monthly heating degree days for 2011 to approximate their corresponding consumption for 2011. Figure 3-37 and Figure 3-38 show the regression analyses for 2013 fireplace and MAU natural gas consumption, respectively. 


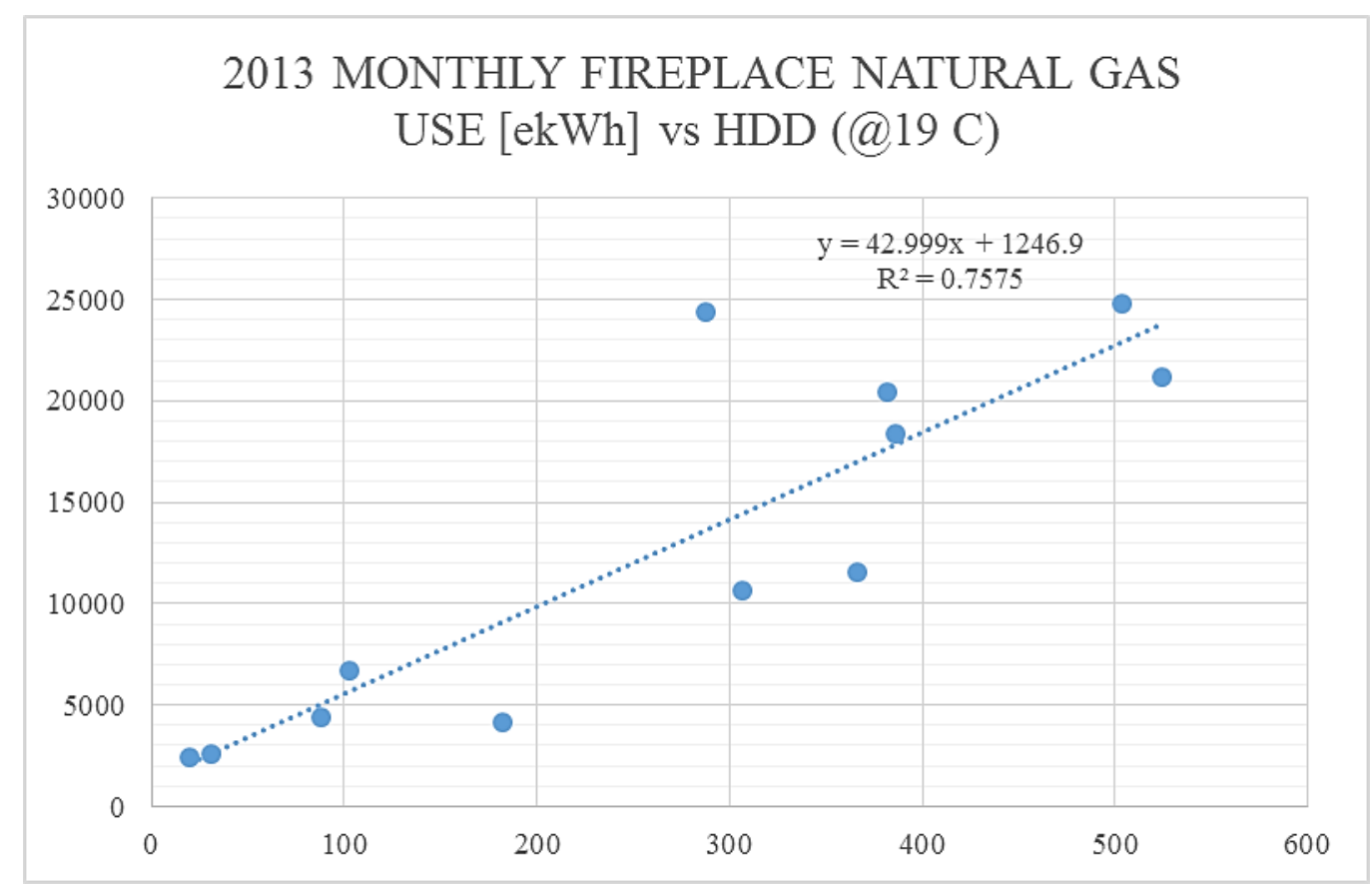

Figure 3-37: Fireplace natural gas consumption regression analysis

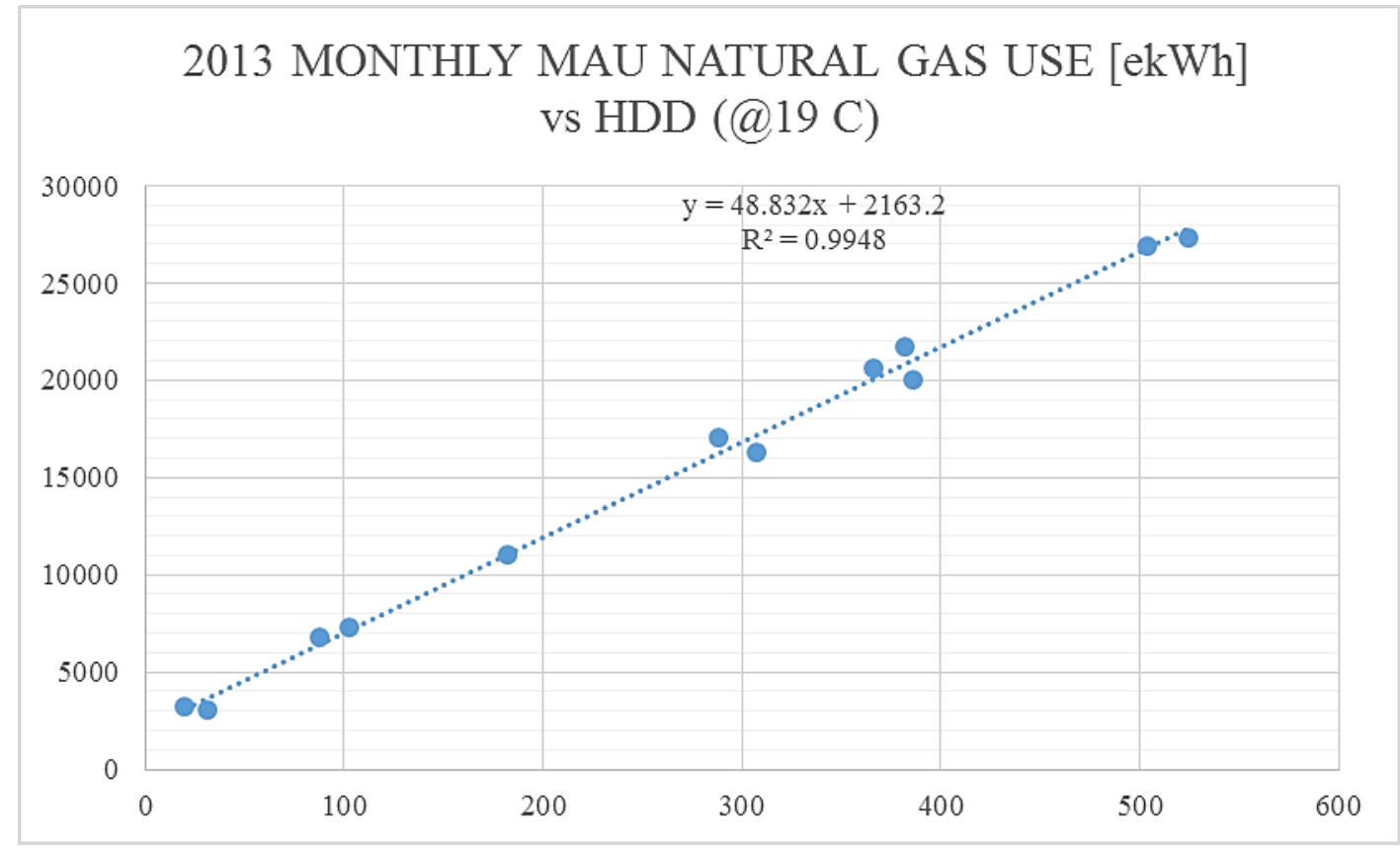

Figure 3-38: MAU natural gas consumption regression analysis 
The resulting estimated monthly natural gas consumption of the MAU for 2011 and the corresponding simulated energy are shown in Figure 3-39 below. Again, the acceptability indices were not calculated for the monthly end use breakdowns which were estimated, and not submetered. Monthly correlation is fairly good, differing by no more than $14 \%$. Simulated consumption appears high for each month, however because the estimated consumption is subject to error through the regression analysis an adjustment to the model could not be justified since the MAU equipment performance characteristics were well understood, and unchanged from the B2 condition. In addition, B1 is the base model for the R1 retrofit model (presented next) which will be compared to the R2 retrofit model, further justifying untampered MAU equipment specifications between the two base models.

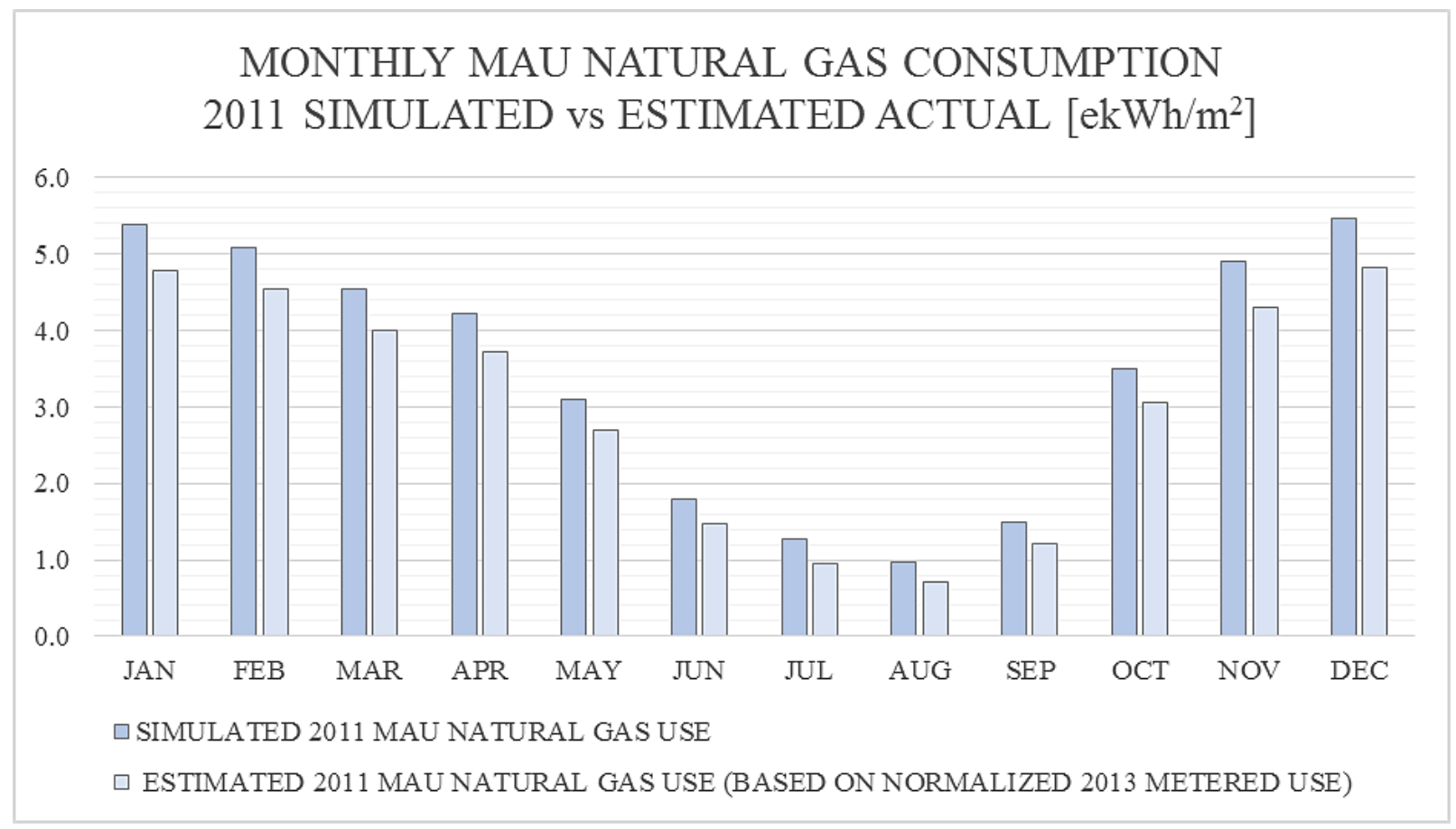

Figure 3-39: 2011 monthly MAU heating energy - simulated vs. estimated actual

The 2011 estimated monthly fireplace natural gas consumption from the same regression analysis based on the 2013 breakdown however was not as well matched to the simulated energy use of model B1 for 2011, as shown in Figure 3-40 below. Overall consumption for the entire 
year is fairly closely matched, however the discrepancies in January and March in particular are quite large, coincidentally balancing each other out. In reality, fireplace usage is not strictly weather-dependent, and these two anomalous months are largely a result of the calibration procedure. Consequently, using the 2013 data as a reference was not the best approach to estimate the 2011 fireplace usage.

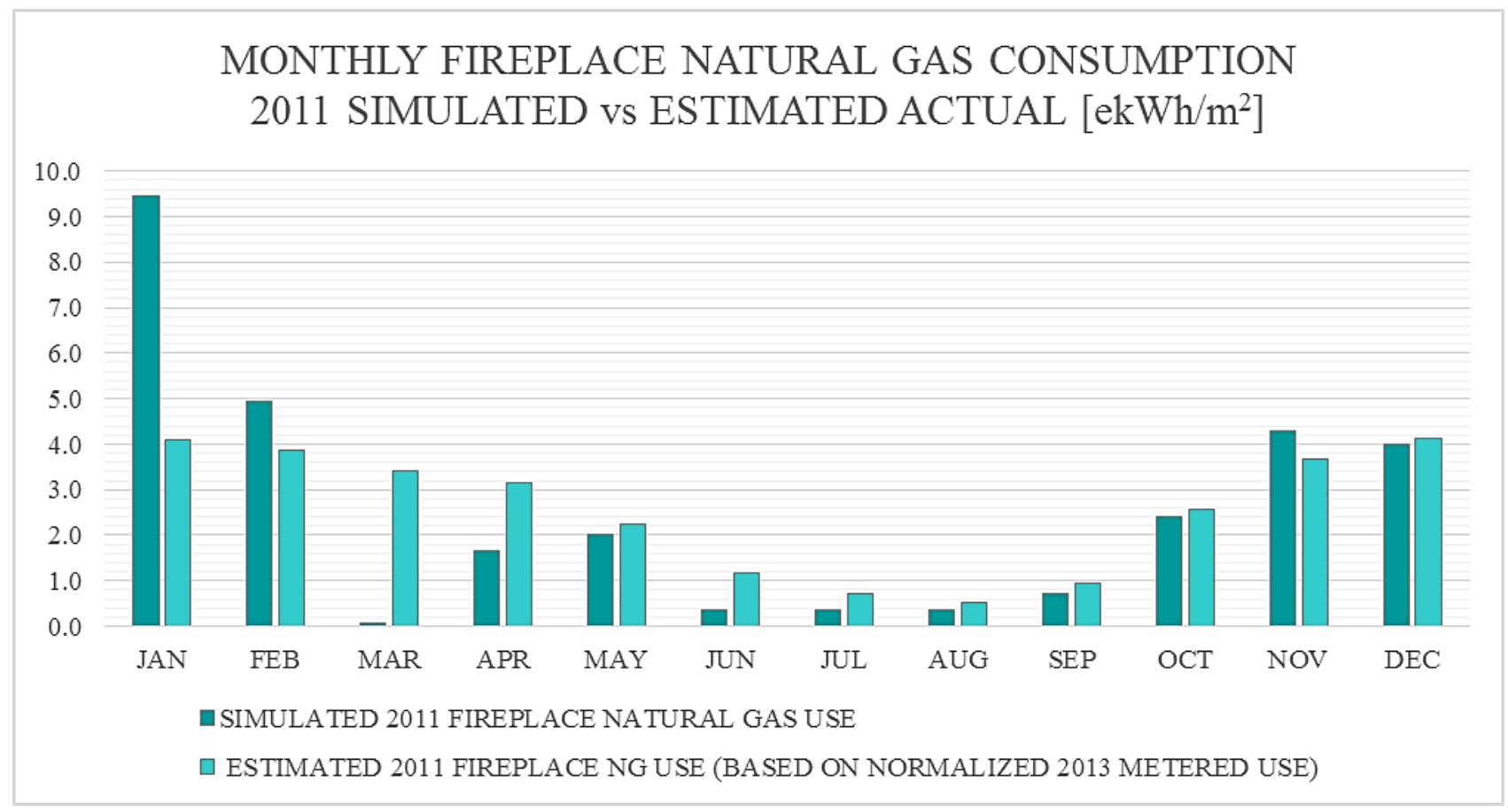

Figure 3-40: 2011 monthly fireplace heating energy - simulated vs. estimated actual

Since there are only three natural gas consumption sources, any one component can be determined as the difference of the other two from the total, as was done in the 2013 analysis for base model B2. Because fireplace usage is the least predictable of the three natural gas end uses, it was instead estimated by subtracting the monthly MAU and DHW consumption from the total.

Figure 3-41 below shows the actual metered and simulated total monthly natural gas consumption for 2011, and Figure 3-42 shows the resulting estimated portion for the fireplaces. The discrepancies between the estimated use and the simulated use for January and March are now much smaller, with the remainder of the year matching more consistently. 
Monthly calibration acceptability indices for total monthly natural gas were $-0.3 \%$ NMBE and $2.0 \% \mathrm{CV}(\mathrm{RMSE})$.

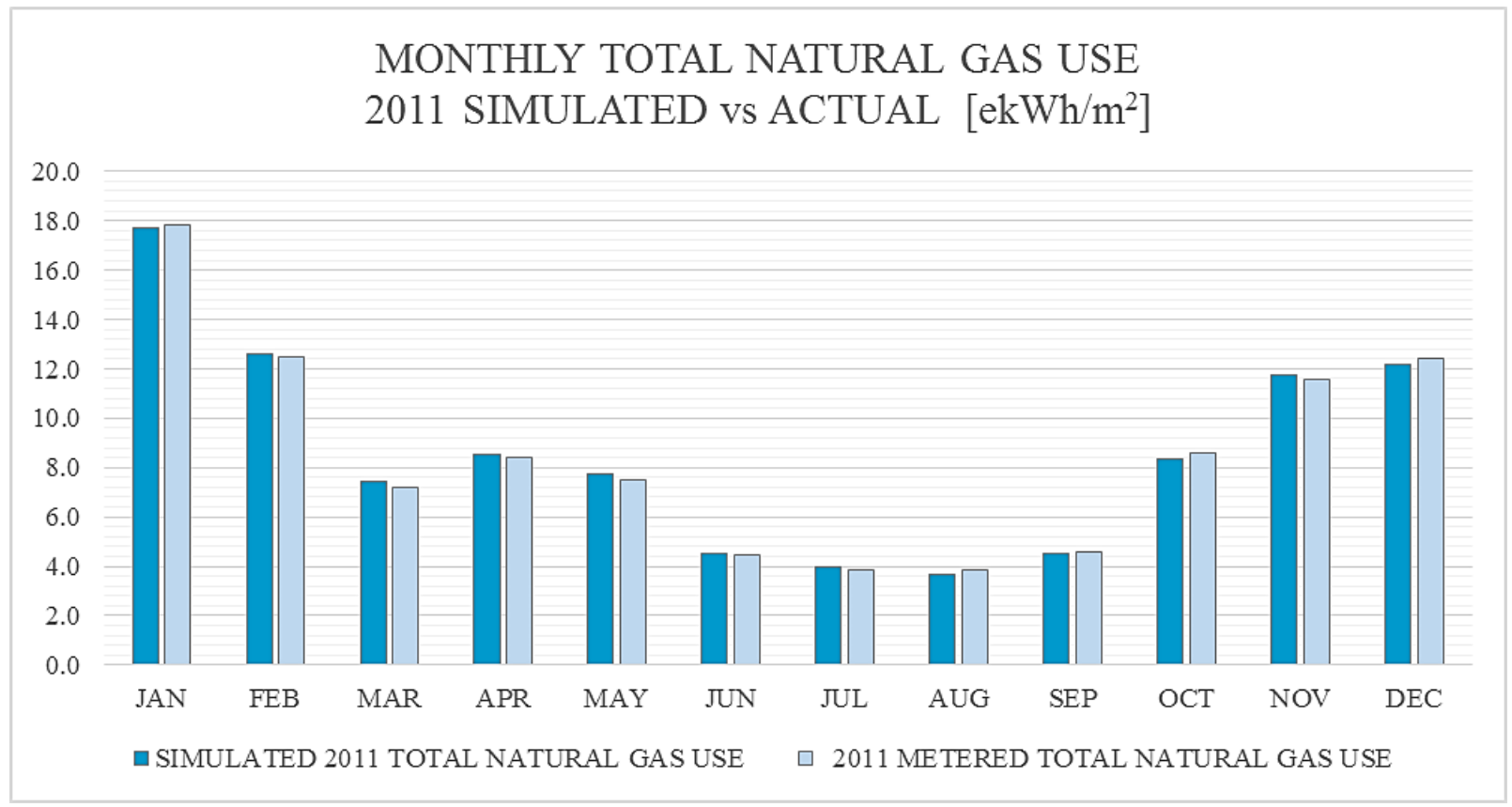

Figure 3-41: Monthly total natural gas consumption - 2011 simulated vs metered

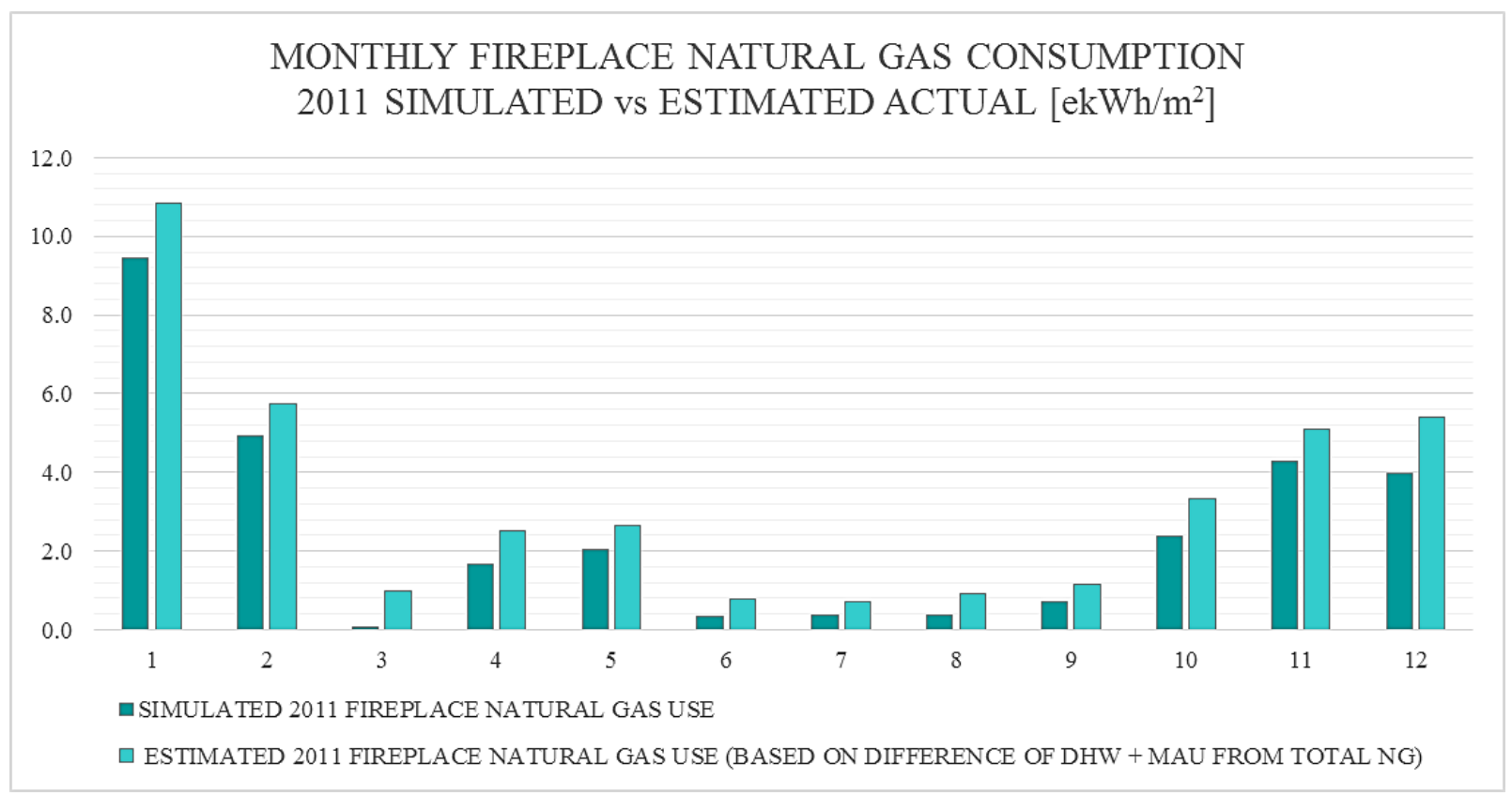


Figure 3-42: Monthly fireplace natural gas consumption - 2011 simulated vs estimated actual

Again, note the acceptability indices were not calculated for the other monthly end use breakdowns because the actual energy use is only estimated and not sub-metered directly as was the case with the 2013 energy use data for the B2 model calibration.

Once base model B1 was calibrated, the simulation was run again with the Vancouver typical meteorological year CWEC weather file in order to produce a more typical energy use profile, and to normalize results for comparison purposes with the other simulation runs. As was done with the B2 model, natural ventilation and fireplace use were eliminated in the B1 CWEC simulation and not included in its R1 retrofit model, for the reasons discussed in Section 3.3.3.2.

\subsubsection{Retrofit model R1: proposed retrofit on original building construction}

The $\mathrm{R} 1$ retrofit model was created with the identical modifications to B1 as were applied to B2 in the creation of the $\mathrm{R} 2$ model. The compartmentalization retrofit was modelled by eliminating the mechanical ventilation airflow to the suites from the corridors, balanced HRVs were added to each suite, and bathroom exhaust fans were eliminated.

Infiltration in the R1 model was also adjusted by assuming the average pressure differential between each suite and the outdoors would decrease from $4 \mathrm{~Pa}$ (used in the B1model) to $1 \mathrm{~Pa}$. The

resulting estimated infiltration rate was calculated to be $0.3 \mathrm{~L} / \mathrm{s} / \mathrm{m}^{2}$ using the same measured enclosure airflow resistance characteristics as $\mathrm{B} 1(\mathrm{C}=25.56, \mathrm{n}=0.58)$. A linear wind velocity coefficient in the ZoneInfiltration object of 0.224 was maintained. 


\section{Results and discussion}

Results of the proposed retrofit simulations are presented below in the order their models were created. The case study building in its current condition (B2) is compared against its retrofit condition (R2) first. A comparison of the building's original condition (B1) and its retrofit (R1) follows. A discussion of the results presented is included in each section for clarity and continuity. The focus of the analysis is on overall heating energy, for both the ventilation and space heating systems, and the associated GHG emissions.

Results presented from here on for all four models were produced through simulation with a typical meteorological year weather file (CWEC), so the results differ from the actual metered performance presented in Section 3.1.

\subsection{R2 vs B2 - Proposed compartmentalization and ISVS retrofit from current building condition}

Results presented here are a comparison of the performance of the building in its current condition (B2) to the predicted performance of the building after undergoing the proposed retrofit (R2). Individual contributions to heating energy are examined first, followed by a discussion of the building's overall heating energy.

\subsubsection{Heating energy}

This section examines the breakdown of heating loads associated with mechanical ventilation, as well as the overall heating energy for the baseline B2 and retrofit R2 buildings.

\subsubsection{MAU supply air heating energy}

Figure 4-1 shows the monthly breakdown of the MAU natural gas consumption. This represents the largest contribution to the fuel savings for the proposed retrofit, resulting from a significant decrease in the air flow rate of the central ventilation system. Because the MAU no longer needs to serve the living quarters of the building for the proposed retrofit, the supply rate can be reduced to that required for only the corridors and circulation area. In reality the MAU would likely need to be replaced with properly sized equipment, but that does not change the argument. The greatest 
monthly reduction for this particular simulation, based on the CWEC weather data, is for January, with a total natural gas savings of $5.12 \mathrm{ekWh} / \mathrm{m}^{2}$, or $87 \%$.

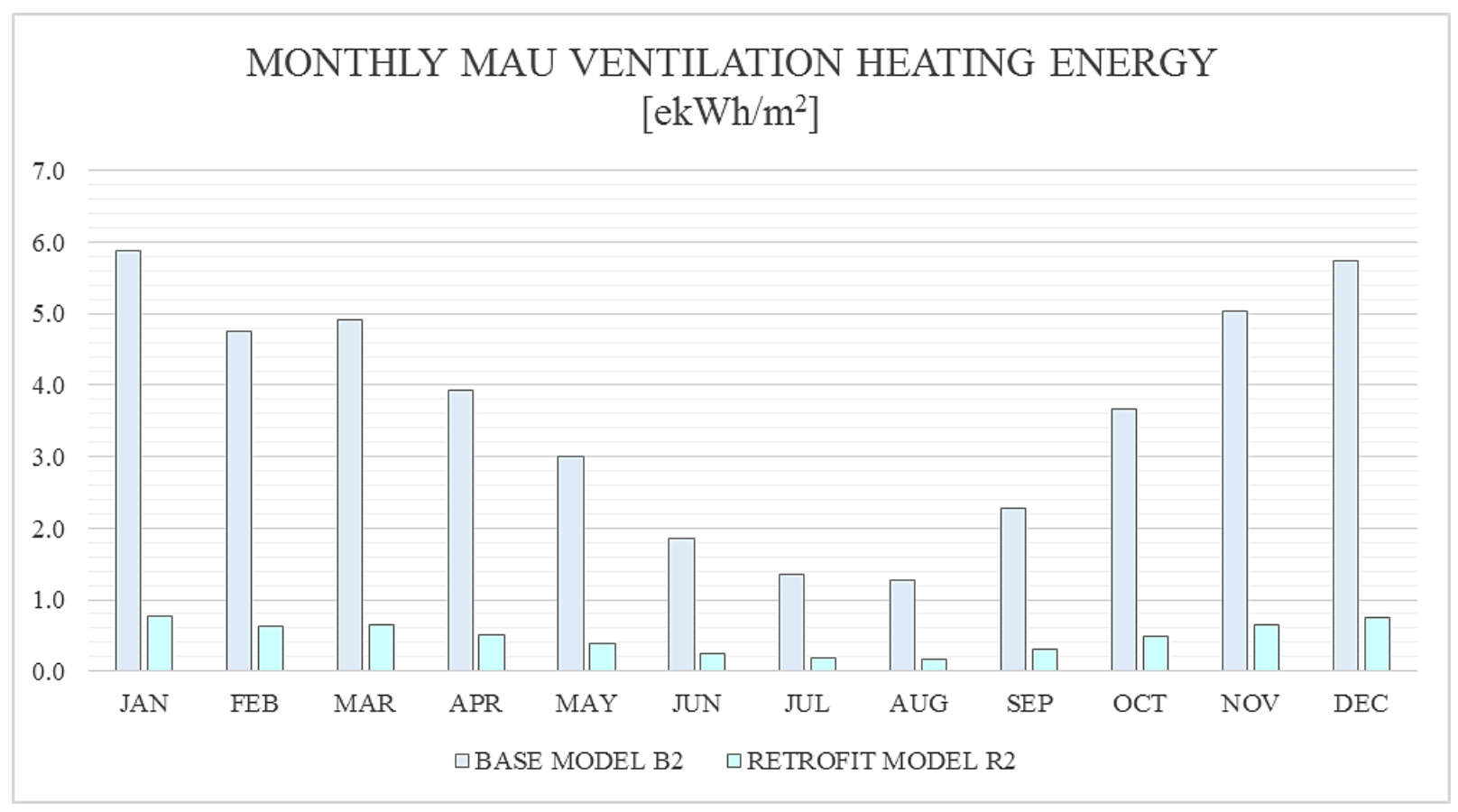

Figure 4-1: B2 vs R2 ventilation heating energy - monthly natural gas

It is worth noting also that the ventilation heating energy is being used more efficiently in the R2 retrofit. As described previously, measurements on the B2 building showed $60 \%$ of the MAU ventilation air was being lost through duct (or other unknown) leakage before reaching the corridors, and $80 \%$ of the remaining air was escaping the building through the vertical shafts without reaching the suites. So in fact the ventilation air for the baseline B2 building was for the most part only serving the corridors anyway, yet using more than seven times as much energy on an annual basis as the R2 building to do the same job $\left(43.7 \mathrm{ekWh} / \mathrm{m}^{2} \mathrm{vs} .5 .7 \mathrm{ekWh} / \mathrm{m}^{2}\right)$. Not only is this a significant waste of energy, but there is a $92 \%$ deficit in mechanical ventilation air to the suites where it is required, which cannot be reflected in an energy model.

Figure 4-2 below breaks down the ventilation energy of the previous Figure 4-1 to illustrate the relative inefficiency of the existing central ventilation system. 


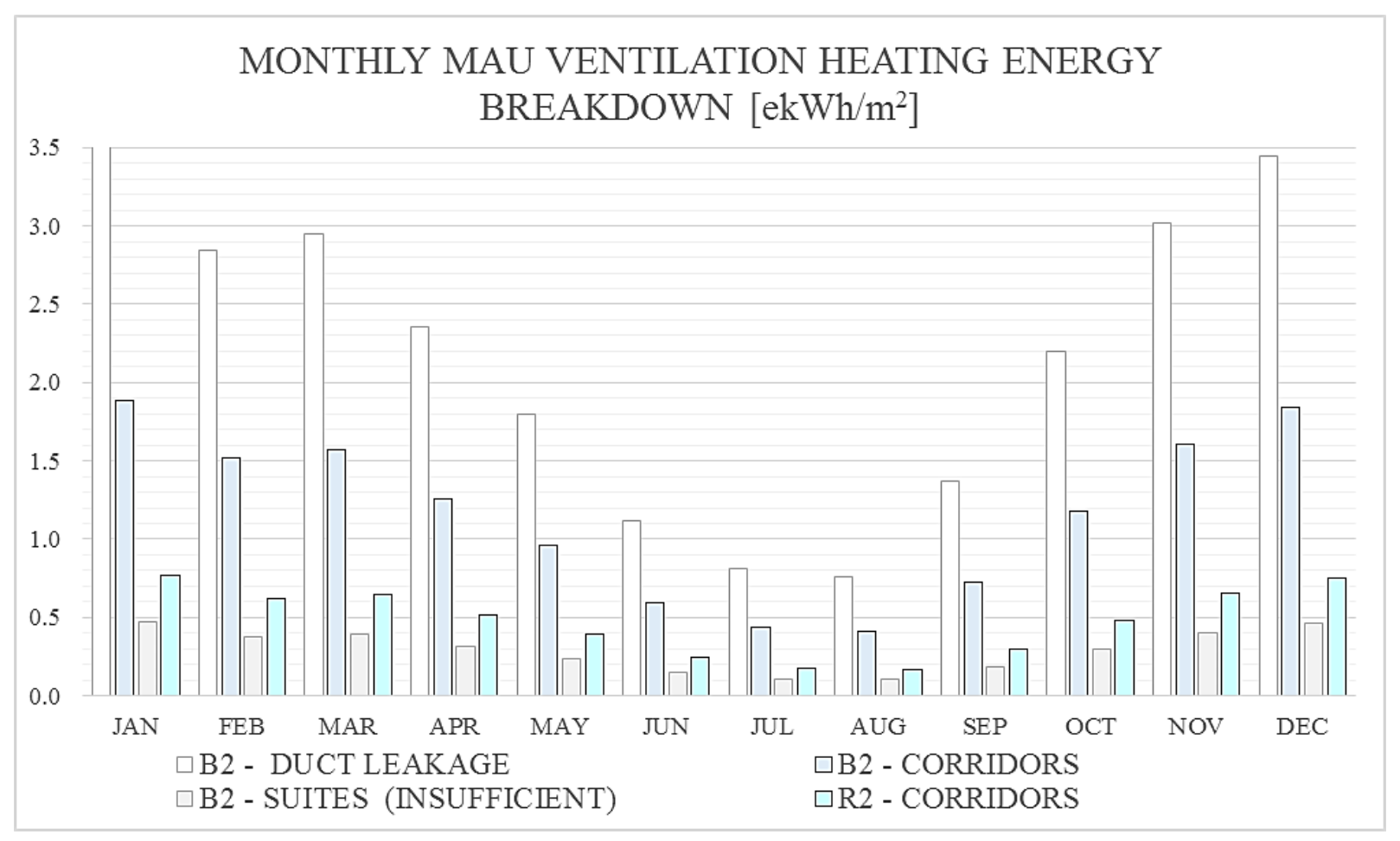

Figure 4-2: B2 vs R2 monthly ventilation heating energy breakdown

Even after separating the $60 \%$ initial loss, and the $8 \%$ which does reach the suites, the energy to heat the air which is only serving the corridors in the existing building (B2 baseline) is still nearly double what is required for the $\mathrm{R} 2$ building. In reality, the corridor supply air from the central system is ultimately intended for the suites, and the above breakdown is only done for comparison purposes, but is a valid comparison nonetheless since the majority of the central ventilation only serves the corridors.

\subsubsection{Space heating load due to mechanical ventilation}

Space heating energy, provided by electric resistance baseboard heaters in each suite, is a combination of the heat loss through the building enclosure and the energy required to heat new air introduced to the suites. Mechanical ventilation, natural ventilation, and infiltration make up the sources of air inducing a heating load in the suites. The focus of this section is on the 
contribution from mechanical ventilation specifically due to the change in ventilation strategy of the proposed retrofit. The overall space heating energy from all sources is discussed in the following Section (4.1.1.3).

The fact that the effectiveness of the existing pressurized corridor ventilation system and the insuite ventilation system of the proposed retrofit are so different makes a fair comparison of the impact on space heating energy of the two systems difficult. The suites in the R2 retrofit building are being ventilated by the HRVs according to ASHRAE Standard 62.1-2010 at 55 L/s per suite. While the average ventilation rate in the existing baseline building (B2) is only about $3 \mathrm{~L} / \mathrm{s}$ per suite. The mechanical ventilation rate of the suites in the proposed retrofit is almost 15 times higher than that of the baseline building. This discrepancy is of course part of the motivation behind doing the ventilation strategy retrofit.

Figure 4-3 below shows the mechanical ventilation component of the annual space heating load on the electric baseboard heaters for the $\mathrm{B} 2$ baseline and the $\mathrm{R} 2$ retrofit buildings. To make a more fair comparison however, the figure also shows the contribution of the MAU ventilation air on the space heating load if it were being delivered to the suites at the same design rate as the HRVs, instead of the measured $8 \%$. 


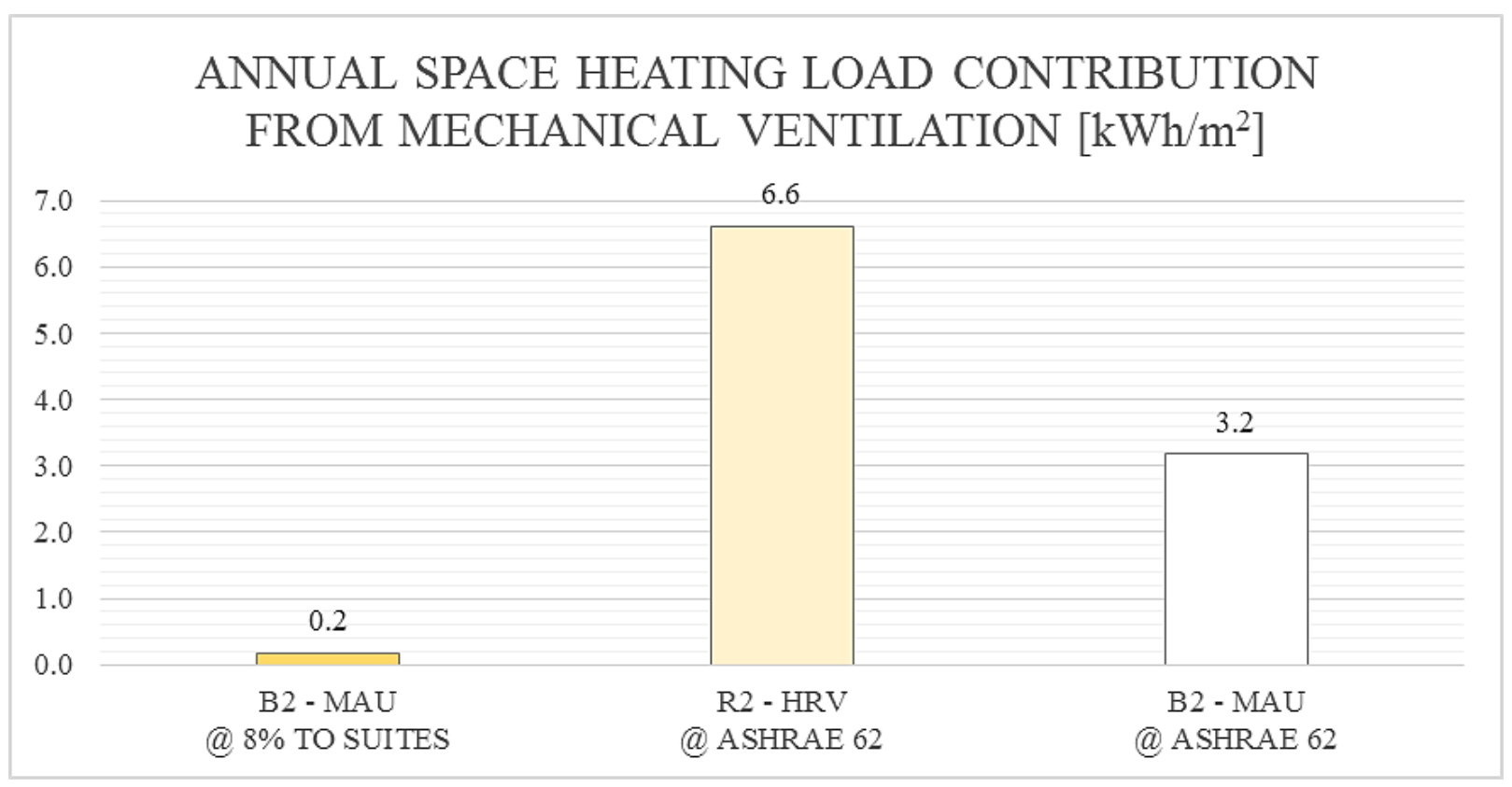

Figure 4-3: B2 vs R2 mechanical ventilation component of annual zone heating load

The annual space heating load due to the $8 \%$ MAU ventilation air reaching the suites was only 0.2 $\mathrm{kWh} / \mathrm{m}^{2}$. The contribution by the HRVs to the annual space heating energy at the full ASHRAE Standard 62.1-2010 ventilation rate was $6.6 \mathrm{kWh} / \mathrm{m}^{2}$. This increase in space heating energy is due to the difference in the ventilation rates being delivered to the suites between B2 and R2, and highlights its impact on the space heating system. The MAU contribution if it matched the HRV design rate would increase to $3.2 \mathrm{kWh} / \mathrm{m}^{2}$.

When the two systems are delivering ventilation air at the same rate, the contribution of the HRVs to the space heating load is more than double that of the MAU. The reason for this is that the temperature of the supply air delivered by the MAU and that delivered by the HRV is not the same. The resulting space heating loads shown above in Figure 4-3 only represent the portion of the energy provided by the electric baseboard heaters which is required to heat the ventilation air. The energy used to pre-condition the air (shown earlier in Figure 4-1) needs to be accounted for as well to understand the overall heating energy associated with mechanical ventilation. The overall ventilation heating energy is discussed next in Section 4.1.1.3, 


\subsubsection{Overall heating energy associated with mechanical ventilation}

Overall ventilation heating energy and the space heating load caused by mechanical ventilation are examined together in this section to illustrate the complete annual heating energy implications of the proposed retrofit $\mathrm{R} 2$ on the $\mathrm{B} 2$ building.

The supply air temperatures of the mechanical ventilation air being delivered to the suites by the MAU and the HRVs are not equal. The MAU pre-conditions the supply air to $20.7 \mathrm{C}$, while the HRVs deliver a variable supply air temperature which is a function of the outside air temperature and the efficiency of the heat exchanger.

Figure 4-3 showed that the in-suite ventilation system induces a greater space heating load on the electric baseboard heaters than the central ventilation system, however the MAU burns natural gas to pre-heat the air (Figure 4-1) and this needs to be accounted for. The HRVs by contrast pre-heat the supply air with recovered heat from the exhaust air stream.

Figure 4-4 below shows the combined results from the previous two Sections. It shows overall heating energy associated with mechanical ventilation, comprised of both the energy required to heat the ventilation air by the MAU, and the space heating load induced on the electric baseboard heaters (shown in Figure 4-3 above) by the central corridor pressurization system of the B2 building and the ISVS of the R2 retrofit building. The heating energy for R2 also includes the reduced MAU supply for ventilating the corridors. 


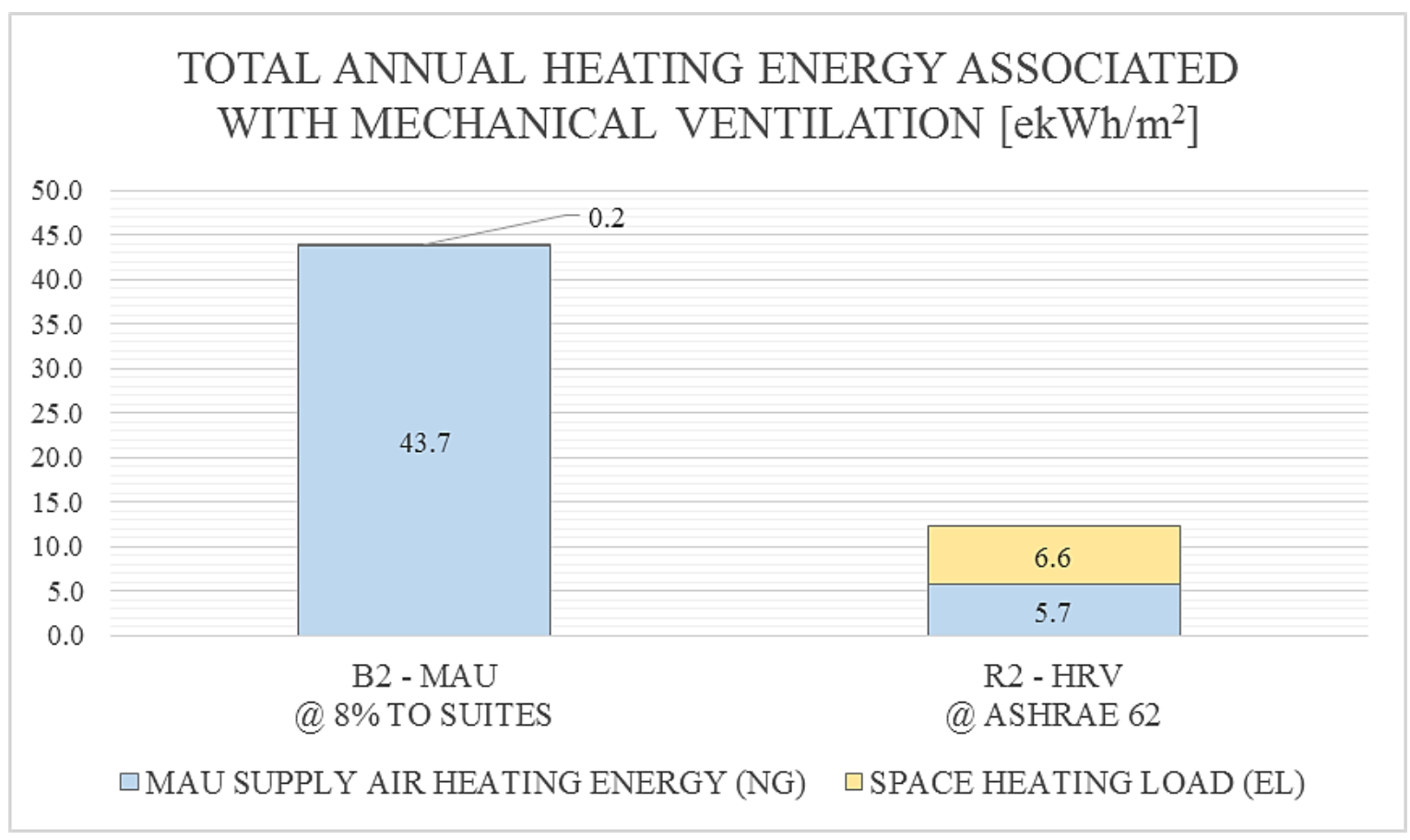

Figure 4-4: B2 vs R2 total annual heating energy associated with mechanical ventilation

Seeing the heating energy associated with mechanical ventilation in its entirety illustrates the overall energy savings advantage of the proposed retrofit. Despite the fact that the ISVS creates a greater space heating load on the baseboard heaters, when the central ventilation system savings are considered, the proposed retrofit uses $72 \%$ less total heating energy for mechanical ventilation air and its associated space heating load $\left(12.3 \mathrm{kWh} / \mathrm{m}^{2}\right.$ compared to $\left.43.9 \mathrm{kWh} / \mathrm{m}^{2}\right)$.

Again, a more fair comparison would be made if the existing pressurized corridor ventilation system was able to effectively deliver the full ventilation rate recommended by ASHRAE Standard 62.1-2010, equal to the rate being provided by the HRVs. Because testing had shown that only approximately $8 \%$ of the MAU supply air was reaching the suites, the total MAU airflow rate was increased in the energy model to compensate for the losses. Accordingly, the total MAU supply air rate was increased to $20,350 \mathrm{~L} / \mathrm{s}$, allowing the full $44 \mathrm{~L} / \mathrm{s}$ to be delivered to each suite. This was strictly an academic exercise for comparison purposes, and in no way addresses the feasibility or practicality of delivering such a high volume of air to the building, or the fact that the relationship between total MAU airflow rate and the percent reaching the suites would likely not be linear. The purpose of this exercise was to make a fair comparison with the 
in-suite ventilation system, and highlight the inefficiency of the existing central system in performing its designed function.

Figure 4-5 below shows this theoretical case alongside the results from Figure 4-4 for reference. The total combined heating energy associated with mechanical ventilation in this case would be $326.2 \mathrm{kWh} / \mathrm{m}^{2}, 30$ times higher than the $\mathrm{R} 2$ case.

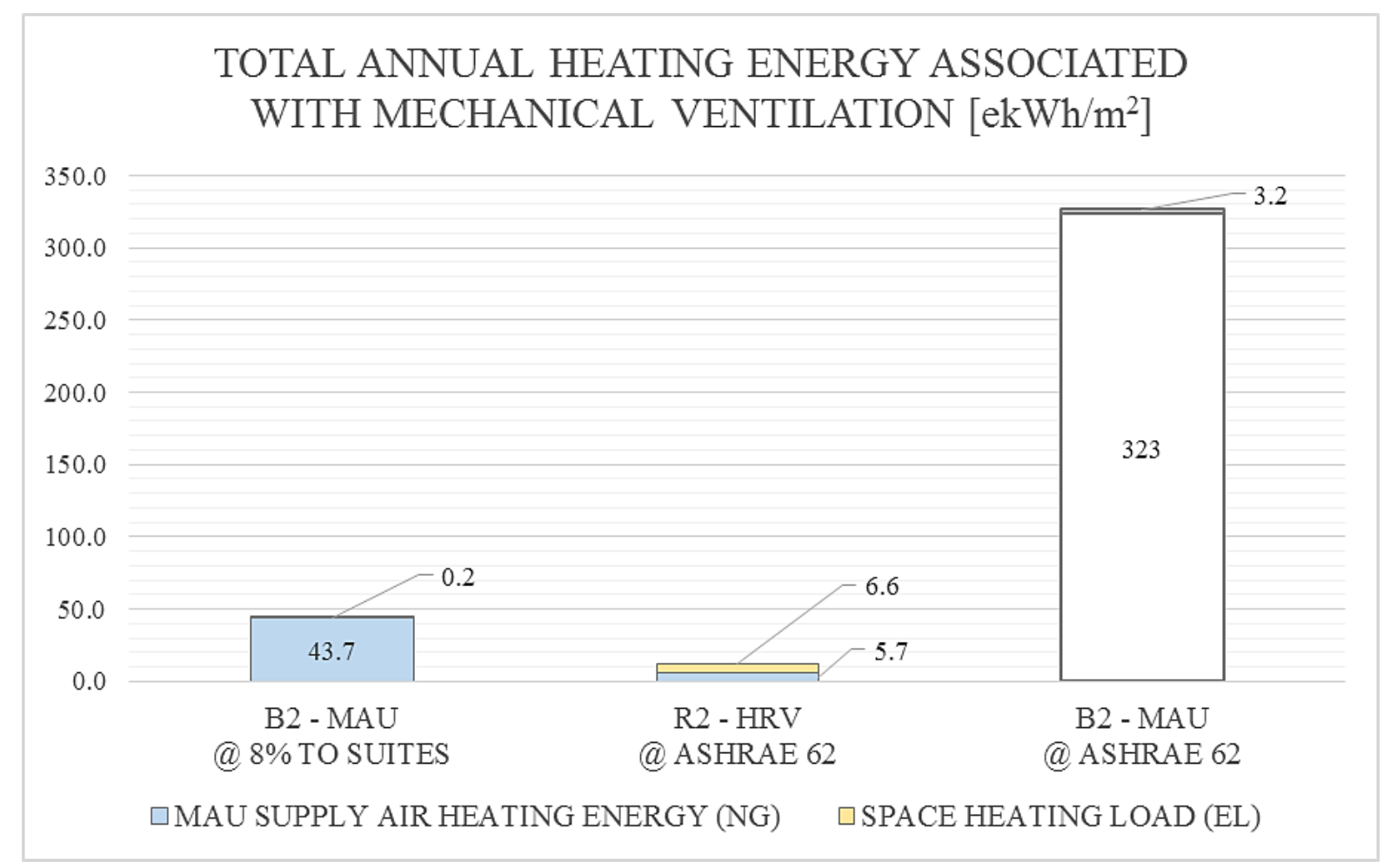

Figure 4-5: B2 vs R2 total annual heating energy from mechanical ventilation (incl. ASHRAE 62.1-2010 reference)

\subsubsection{Overall heating energy - all sources}

This section presents the building's total heating energy from all sources, which includes the energy associated with mechanical ventilation, as well as the contributions of infiltration and heat loss through the building enclosure. As mentioned previously, natural ventilation and fireplace use were only included as part of the calibration procedure of the baseline models and were not considered in the comparative simulations run with the CWEC weather file. 
Figure 4-6 below compares the total monthly suite-level electric heating energy for base model B2 and its retrofit R2. This is the total heating load on the baseboard heaters from all sources.

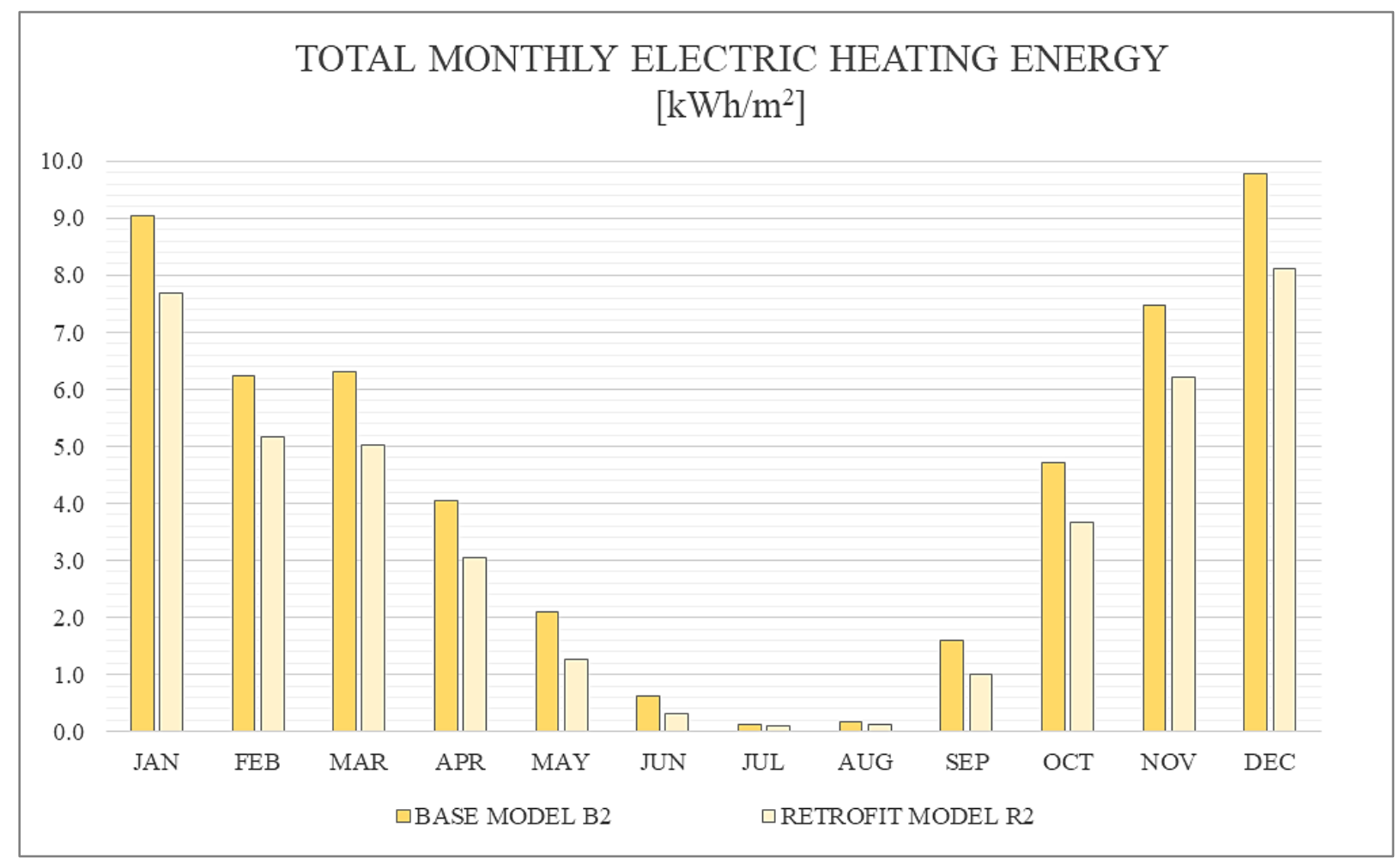

Figure 4-6: B2 vs R2 total monthly electricity heating energy

The monthly profile for $\mathrm{R} 2$ follows that of $\mathrm{B} 2$ with less electric heating energy being used each month in all seasons. Overall annual heating electricity for the R2 building decreased by $20 \%$, from $52.2 \mathrm{kWh} / \mathrm{m}^{2}$ per year for the baseline B2 building, down to $41.7 \mathrm{kWh} / \mathrm{m}^{2}$.

Figure 4-7 below shows the impact from all sources on overall annual heating energy for both fuels for the proposed retrofit. A total reduction of $51 \%$ in overall annual heating energy is seen. Overall annual heating energy for the building decreased from $95.9 \mathrm{ekWh} / \mathrm{m}^{2}$ down to 47.4 $\mathrm{ekWh} / \mathrm{m}^{2}$. 


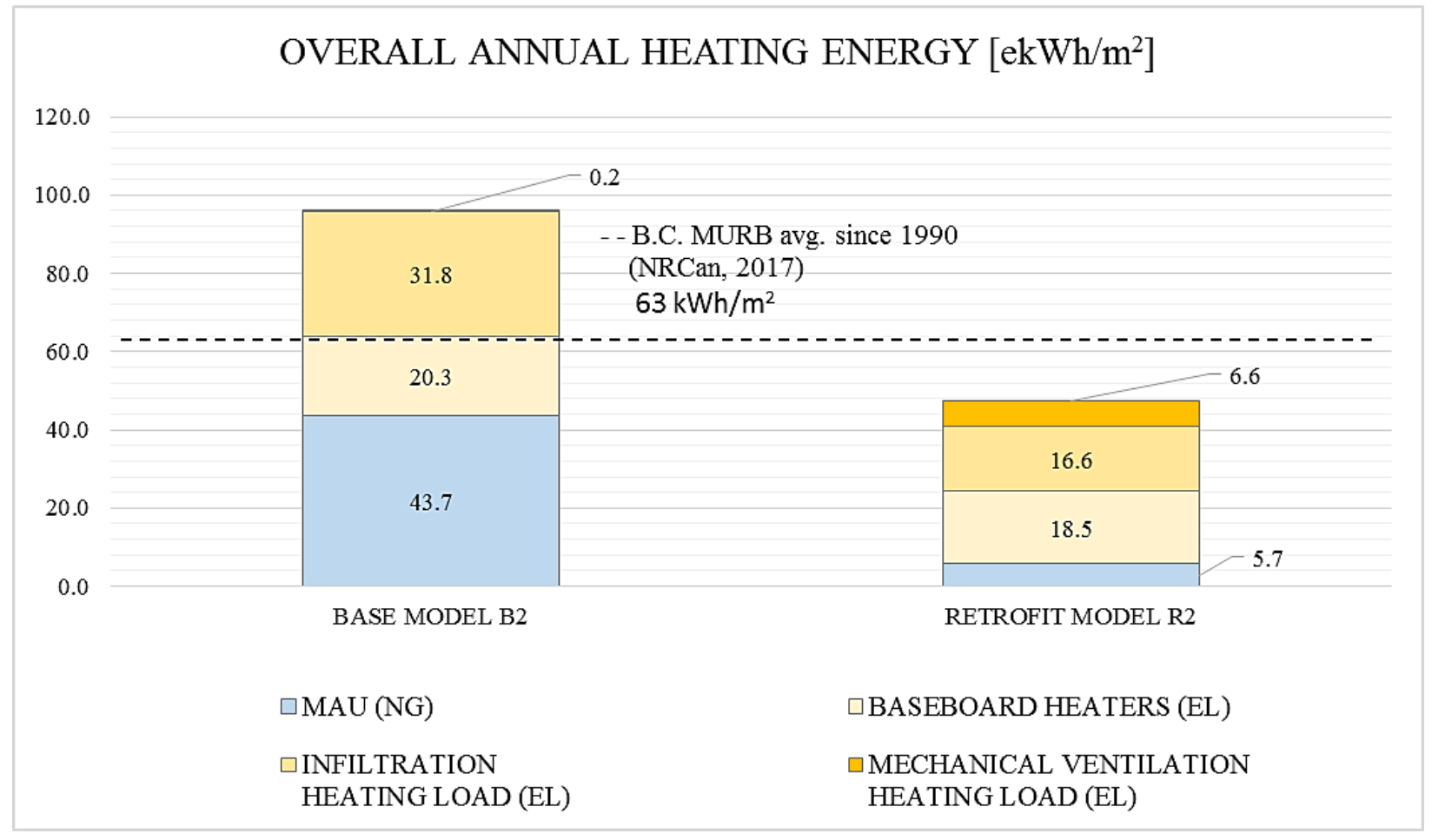

Figure 4-7: B2 vs. R2 - Total annual space heating energy

The contribution of infiltration on total annual heating energy for the B2 baseline building is 33\%, or $31.8 \mathrm{kWh} / \mathrm{m}^{2}$. This decreased for $\mathrm{R} 2$ by $48 \%$ to $16.6 \mathrm{kWh} / \mathrm{m}^{2}$, remaining proportionally about the same at $35 \%$ of the total heating energy.

To help understand the implications of the assumed average pressure difference of $1 \mathrm{~Pa}$ across the enclosure (on which the infiltration rate was based) for the R2 retrofit building, the relationship between heating energy and infiltration is examined here. The heating load due to infiltration is directly proportional to the infiltration rate, a function of the heat capacity of the incoming air, its flow rate, and the temperature difference from the air in the building. The proposed compartmentalization retrofit of the suites will result in the stack effect pressures acting on the partitions of the corridors, and the ambient air pressure within the suites will consequently tend toward equalization with the ambient outdoor air pressure, as described in Section 2.4. It should follow that the pressure difference across the building enclosure after the compartmentalization retrofit will be less than that of the current construction. Since the assumption of this new pressure difference has not been validated through experiment, and no published benchmarks were found, 
it is helpful to understand that the overall energy impact of infiltration on the compartmentalized building R2 should be no greater than that found for the baseline B2 building $\left(31.8 \mathrm{kWh} / \mathrm{m}^{2}\right)$, and in theory could be significantly less. It is also possible that it would be lower than the $16.6 \mathrm{kWh} / \mathrm{m}^{2}$ found if the suite and outdoor air pressures are equalized to less than $1 \mathrm{~Pa}$ difference. Even if the infiltration rate were not to decrease with suite compartmentalization, and the heating load remained equal to that of the $\mathrm{B} 2$ building $\left(31.8 \mathrm{kWh} / \mathrm{m}^{2}\right)$, the resulting overall annual heating energy for R2 would still be $17 \%$ less than for B2.

Another check was done to ensure that the annual peak power of the baseboard heaters was not reaching their design capacities $(7 \mathrm{~kW}, 10.5 \mathrm{~kW}$, and $11 \mathrm{~kW})$, as this would indicate the possibility of some unmet heating load. If the space heating peak power reaches design capacity of the baseboard heaters, then electrical heating energy is capped (i.e., no additional heating load can be met by the heaters), and the energy which should have been consumed to maintain the room setpoint temperature would be unaccounted for in the simulation results. The peak electric heating load of the suites did not exceed $2.5 \mathrm{~kW}(36 \%)$ of the smallest baseboard heater design capacity.

Overall annual natural gas heating energy decreased by $51 \%$ as a result of the reduction of the central ventilation system delivery rate, from $70.1 \mathrm{ekWh} / \mathrm{m}^{2}$ down to $34.6 \mathrm{ekWh} / \mathrm{m}^{2}$. Natural gas made up 59\% of the building's total heating energy (both fuel types combined) for the base model B2, and was reduced to $36 \%$ of the total heating energy for the retrofit model R2.

For reference, the average annual space heating energy for MURBs in British Columbia since 1990 is shown as well. This value was calculated to be approximately $63 \mathrm{ekWh} / \mathrm{m}^{2}$ based on data published by Natural Resources Canada in their Comprehensive Energy Use Database (NRCan, 2017). The case study building's annual heating energy is higher than this average value, however the published data includes a variety of MURB types from four storeys and up. It may not be a completely fair benchmark since mid-rise buildings are generally more energy efficient than highrise, having a lower percentage of glazing and suffering less from the heat losses due to stack effect. 


\subsubsection{Greenhouse gas emissions}

Figure 4-8 shows total annual GHG emissions associated with both electricity and natural gas consumption for base model B2 and its retrofit R2, based on a CWEC weather year. The graph shows GHG emissions are reduced overall by $29 \%$, or $20.2 \mathrm{tCO}_{2} \mathrm{e}\left(3.9 \mathrm{kgCO} 2 \mathrm{e} / \mathrm{m}^{2}\right)$. The majority of the savings comes from the reduction in natural gas use from the reduced MAU delivery rate.

The emissions from natural gas decreased by $51 \%$, or $35.5 \mathrm{tCO}_{2} \mathrm{e}\left(6.9 \mathrm{kgCO}_{2} \mathrm{e} / \mathrm{m}^{2}\right)$, and the emissions from electricity decreased by $10 \%$, or $1.3 \mathrm{tCO}_{2} \mathrm{e}\left(0.25 \mathrm{kgCO} 2 \mathrm{e} / \mathrm{m}^{2}\right)$.

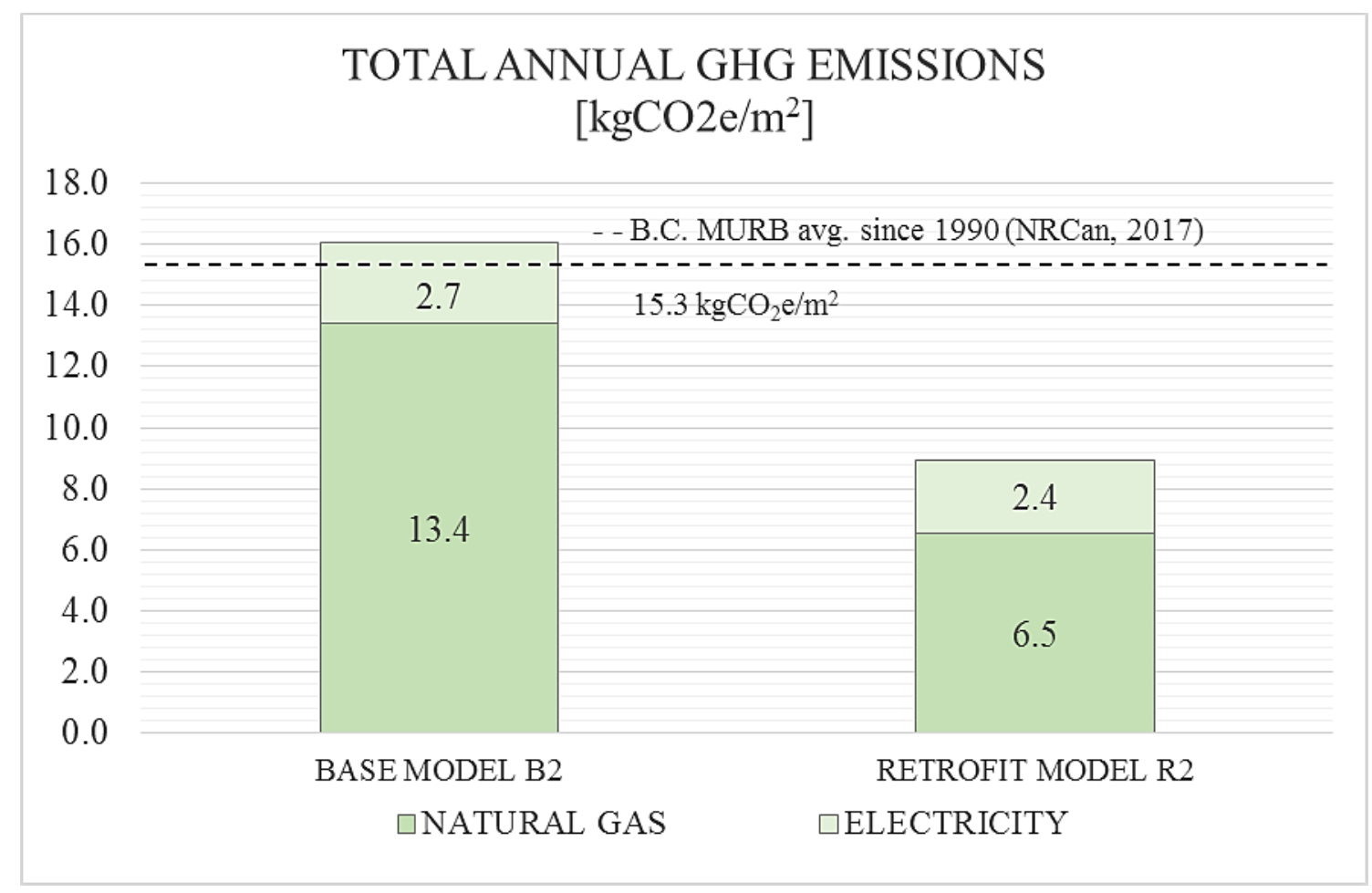

Figure 4-8: B2 vs R2 total annual greenhouse gas emissions by fuel type

The provincial average GHG emissions for MURBs in British Columbia since 1990 is included for reference, calculated from data published on the Natural Resources Canada website in their Comprehensive Energy Use Database (NRCan, 2017). It should be noted that the inclusion of midrise buildings in the provincial average building set is the likely reason why the average GHG emissions are lower than the case study building with its retrofitted high-performance enclosure. 
Many mid-rise MURBs in B.C. rely strictly on electric heating, which has a very low carbon footprint due to the dominance of hydro-electric production on the B.C. grid.

Carbon equivalent emissions are calculated using the procedure outlined in "2016/17 B.C. Best Practices Methodology For Quantifying Greenhouse Gas Emissions” published by the province (British Columbia Ministry of Environment, 2016). The procedure outlined in this document involves:

1) multiplying the emission factor for a GHG by the measure of consumption to produce the corresponding emissions for that GHG;

2) multiplying those emissions by its GWP to produce the corresponding $\mathrm{CO}_{2} \mathrm{e}$ emissions.

Emission factors are based on the figures published by the province in the British Columbia Greenhouse Gas Inventory Report (British Columbia Ministry of Environment, 2012), summarized in Table 4-1 below: 
Table 4-1: British Columbia GHG emissions factors (source: B.C. Greenhouse Gas Inventory Report)

Table 1: Stationary Fuel Combustion

\begin{tabular}{lccccc}
\hline \multirow{2}{*}{ Fuel Type } & $\begin{array}{c}\text { Energy Conversion } \\
\text { Factor }\end{array}$ & Bio CO & \multicolumn{3}{c}{ Emission Factor (kg/ GJ) } \\
& & - & $\mathrm{CO}_{2}$ & $\mathrm{CH}_{4}$ & $\mathrm{~N}_{2} \mathrm{O}$ \\
\hline Natural Gas & $0.03843 \mathrm{GJ} / \mathrm{m}^{3}$ & - & 49.86 & 0.0010 & 0.0009 \\
\hline
\end{tabular}

Table 16: Global Warming Potentials

\begin{tabular}{lcc}
\hline Greenhouse Gas & Chemical Formula & 100-Year GWP \\
\hline Carbon dioxide & $\mathrm{CO}_{2}$ & 1 \\
\hline Methane & $\mathrm{CH}_{4}$ & 21 \\
\hline Nitrous oxide & $\mathrm{N}_{2} \mathrm{O}$ & 310 \\
\hline
\end{tabular}

Table 3: Purchased Electricity

\begin{tabular}{lcc}
\hline \hline Public Utility & $\begin{array}{c}\text { Emission Factor (tCO2el } \\
\text { GWh) }\end{array}$ & $\begin{array}{c}\text { Emission Factor } \\
\text { (kg/ GJ) }\end{array}$ \\
\hline BC Hydro33 & 25 & 6.9 \\
\hline Kyuquot Power & 25 & 6.9 \\
\hline FortisBC & 6 & 1.7 \\
\hline City of Grand Forks & 6 & 1.7 \\
\hline City of Kelowna & 6 & 1.7 \\
\hline Nelson Hydro & 3 & 0.8 \\
\hline City of New Westminster & 25 & 6.9 \\
\hline City of Penticton & 6 & 1.7 \\
\hline City of Summerland & 6 & 1.7 \\
\hline Alberta & 870 & 242 \\
\hline Ontario & 133 & 37 \\
\hline
\end{tabular}

\subsection{R1 vs B1 - Proposed retrofit from original building condition}

Results presented here are a comparison of the performance of the building in its current condition (B1) to the predicted performance of the building after undergoing the proposed retrofit (R1). 


\subsubsection{Heating energy}

This section examines the breakdown of heating loads associated with mechanical ventilation, as well as the overall heating energy for the baseline B1 and retrofit R1 buildings.

\subsubsection{MAU supply air heating energy}

Figure 4-9 below shows the monthly breakdown of the MAU natural gas energy, representing the largest contribution of fuel savings for the proposed retrofit, resulting from a significant decrease in the air flow rate of the central ventilation system. The greatest monthly reduction in case (based on the CWEC weather simulation) is for January, with a total natural gas savings of $87 \%$, or $5.12 \mathrm{ekWh} / \mathrm{m}^{2}$. These results are the same as for the B2 - R2 simulations, as expected, since the MAU equipment did not change, its energy consumption is dependent only on the weather, and the supply air flow rate reduction was the same for R1 as it was for R2.

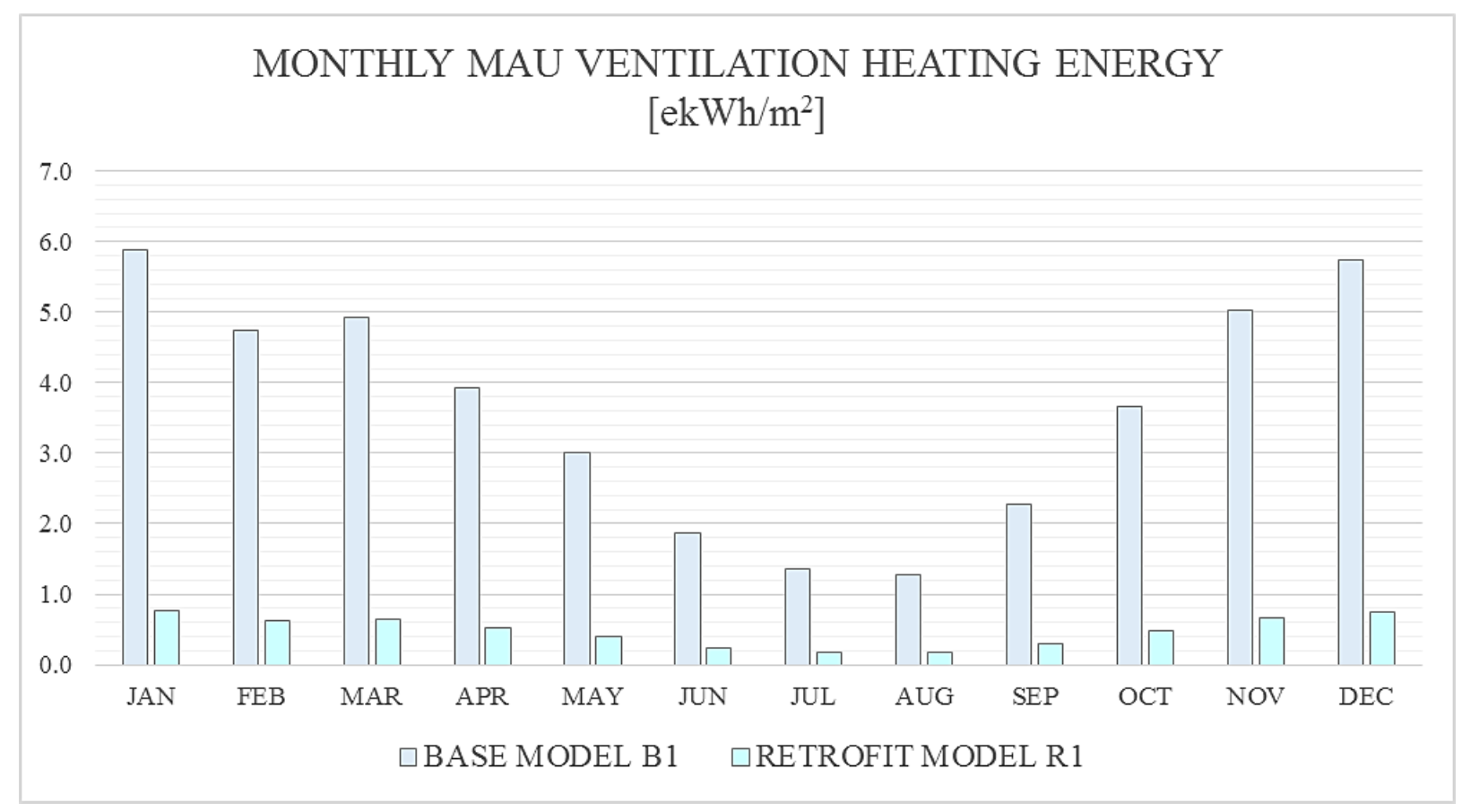

Figure 4-9: B1 vs R1 Monthly natural gas space heating EUI 


\subsubsection{Space heating load due to mechanical ventilation}

Figure 4-10 below shows the contribution to the annual space heating load on the electric baseboard heaters for the $\mathrm{B} 1$ baseline and the $\mathrm{R} 1$ retrofit buildings. As was done for the $\mathrm{B} 2-\mathrm{R} 2$ analysis, the figure also shows the contribution of the MAU ventilation air on the space heating load if it were being delivered to the suites at the same design rate as the HRVs, instead of the measured $8 \%$.

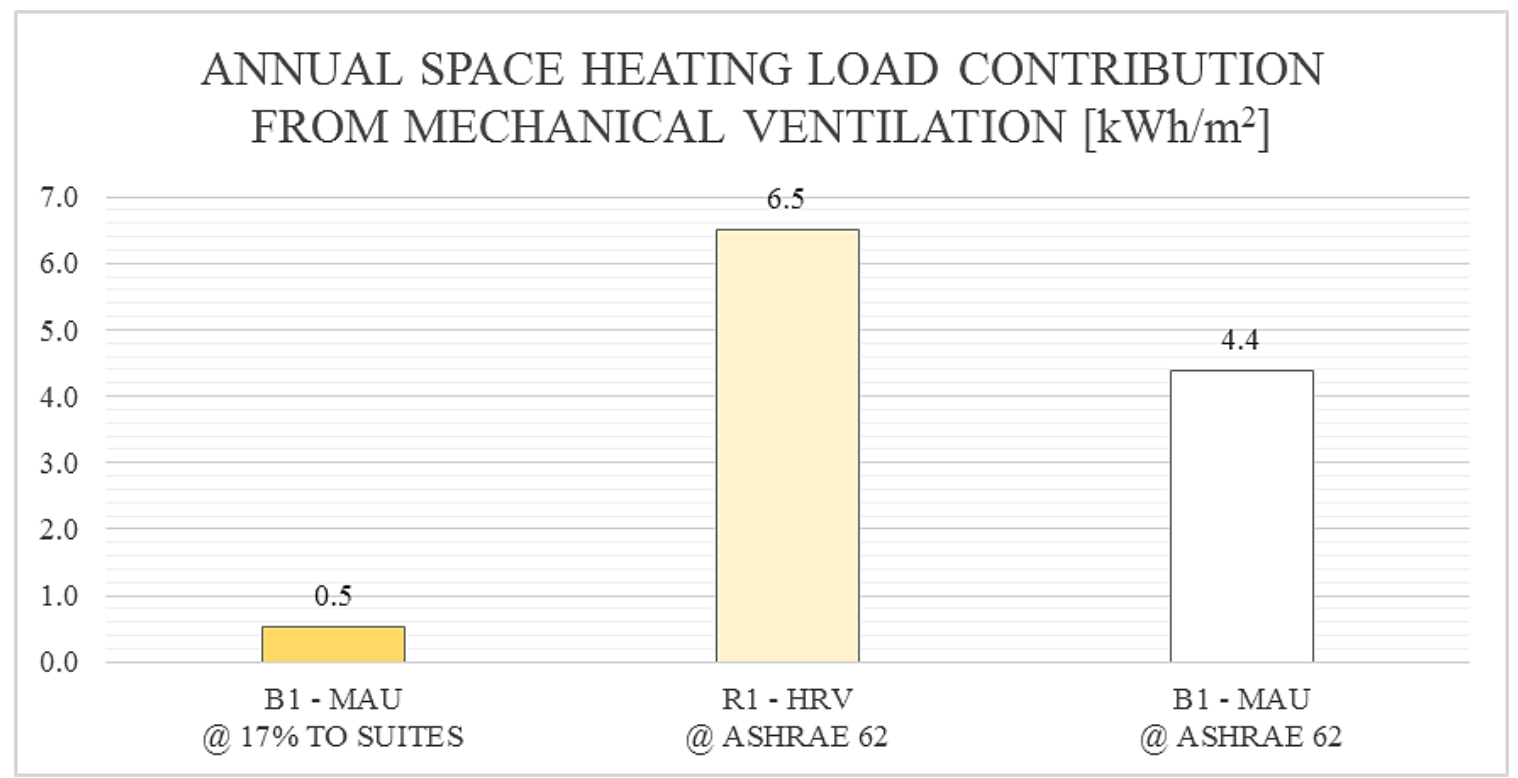

Figure 4-10: B1 vs R1 mechanical ventilation contribution to annual space heating energy

The annual space heating load due to the $8 \%$ MAU ventilation air reaching the suites was 0.5 $\mathrm{kWh} / \mathrm{m}^{2}$ in this case, while the contribution by the HRVs to the annual space heating energy at the full ASHRAE Standard 62.1-2010 ventilation rate was $6.5 \mathrm{kWh} / \mathrm{m}^{2}$. This increase in space heating energy is due to the difference in the ventilation rates being delivered to the suites between B1 and $\mathrm{R} 1$, as was the case with the $\mathrm{B} 2-\mathrm{R} 2$ comparison. The MAU contribution to the heating load at the same supply airflow rate as the HRV would increase to $4.4 \mathrm{kWh} / \mathrm{m}^{2}$. The energy used to precondition the air needs to be accounted for as well to understand the overall heating energy associated with mechanical ventilation (as was discussed previously), and are presented in the following Section. 


\subsubsection{Overall heating energy associated with mechanical ventilation}

Overall ventilation air heating energy and the space heating load caused by mechanical ventilation are presented together in this Section to show the implications of the proposed retrofit R1 on the B1 building. Figure 4-11 combines the results from the previous two sections to show the overall heating energy associated with mechanical ventilation.

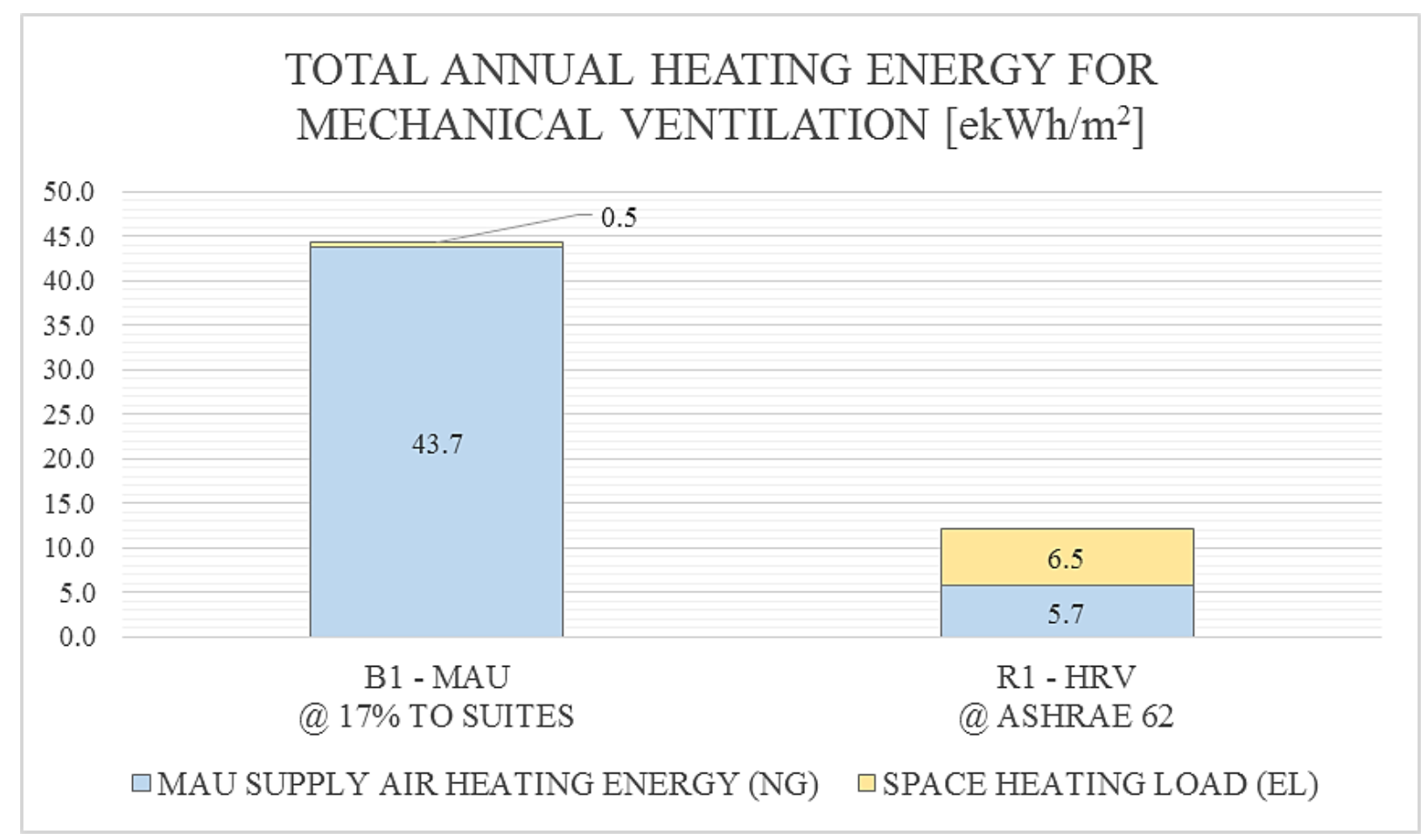

Figure 4-11: B1 vs R1 total annual heating energy associated with mechanical ventilation

When the complete energy consumption is considered, the R1 retrofit model uses $72 \%$ less total heating energy for mechanical ventilation air and its associated space heating load $\left(12.2 \mathrm{kWh} / \mathrm{m}^{2}\right.$ compared to $44.2 \mathrm{kWh} / \mathrm{m}^{2}$ ).

If the total MAU supply air rate was increased to $20,350 \mathrm{~L} / \mathrm{s}$, as was done for the $\mathrm{B} 2-\mathrm{R} 2$ comparison to see the impact on natural gas consumption, he MAU heating energy increases to $323 \mathrm{kWh} / \mathrm{m}^{2}$, as before. 


\subsubsection{Overall heating energy - all sources}

This section presents the building's total heating energy from all sources, as with the corresponding B2 - R2 Section. It includes the results shown above associated with mechanical ventilation, and the contributions of infiltration and heat loss through the building enclosure. As before, natural ventilation and fireplace use are excluded in these comparisons.

Figure 4-12 below shows the monthly suite-level electric heating energy for base model B1 and its retrofit $\mathrm{R} 1$.

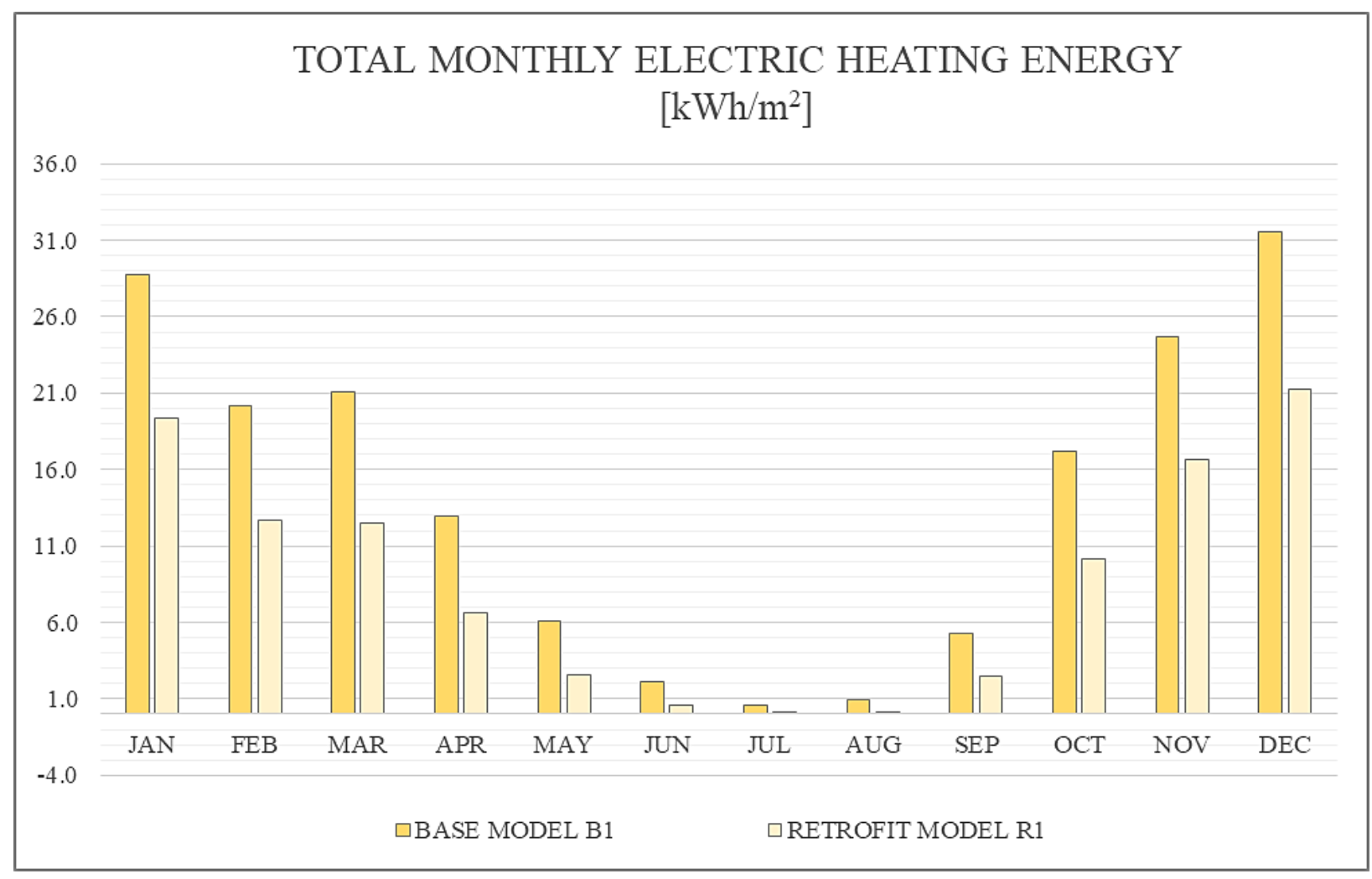

Figure 4-12: B1 vs R1 monthly electricity space heating energy

The monthly energy use profile shown here is similar to the one for the B2 - R2 simulation, but greater in magnitude. Overall annual heating electricity for the R1 building decreased by $39 \%$, from $171.5 \mathrm{kWh} / \mathrm{m}^{2}$ per year down to $41.8 \mathrm{kWh} / \mathrm{m}^{2}$, compared with the B1 building. The reduction 
is greater than for the $\mathrm{B} 2-\mathrm{R} 2$ case due to the poor performance of the original (B1) building enclosure. Electricity made up $80 \%$ of the building's total heating energy for the base model B1, and increased to $95 \%$ of the total heating energy for the retrofit model R1.

Figure 4-13 below shows the impact predicted by the simulation on annual heating energy by fuel type for the proposed retrofit. Overall, there is a $49 \%$ decrease in annual heating energy, from $215.2 \mathrm{ekWh} / \mathrm{m}^{2}$ down to $110.5 \mathrm{ekWh} / \mathrm{m}^{2}$. This is driven by the $54 \%$ decrease in infiltration from the original enclosure assembly.

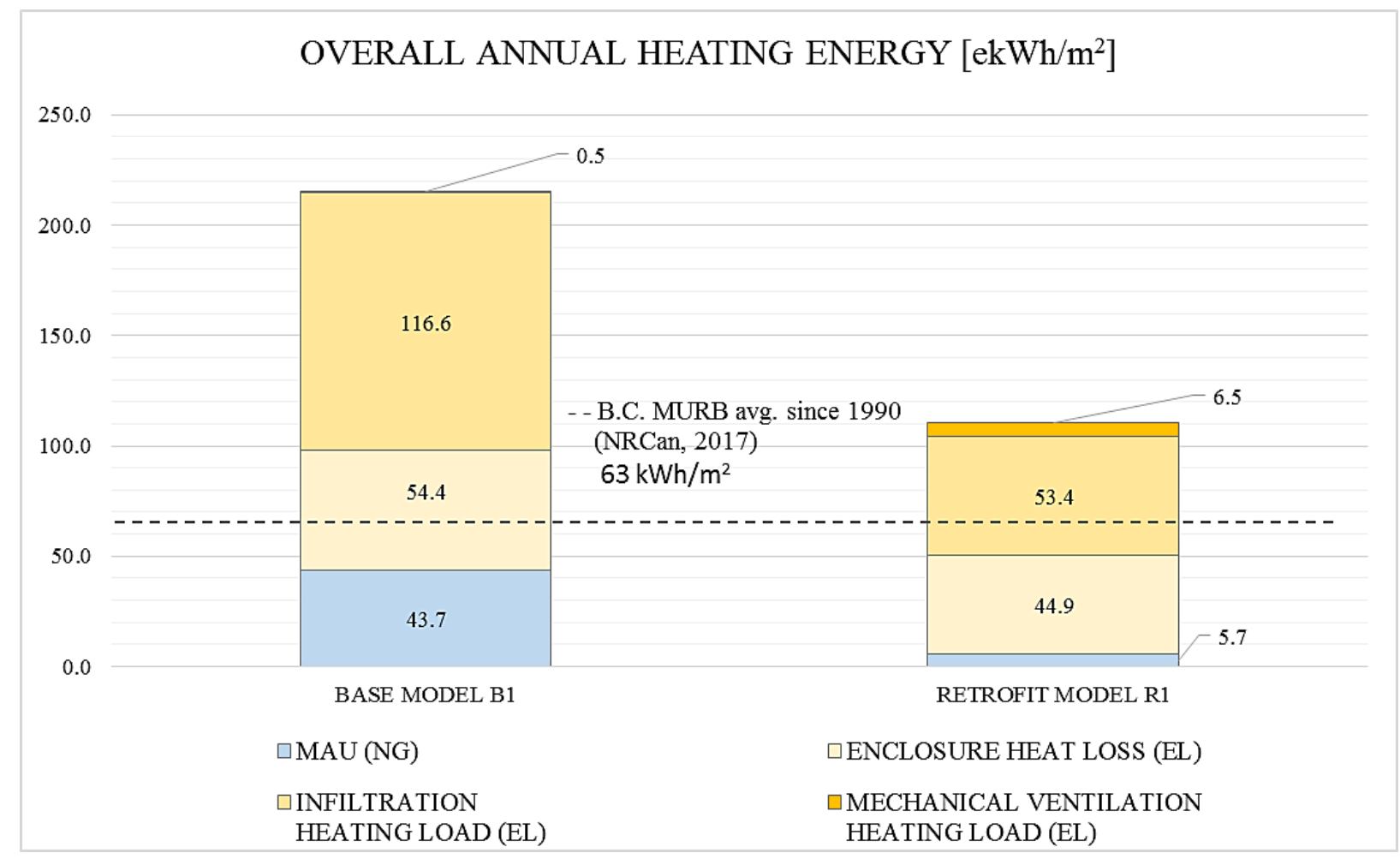

Figure 4-13: B1 vs R1 total annual space heating energy

Overall annual natural gas heating energy decreased by $87 \%$, as before, from $43.7 \mathrm{ekWh} / \mathrm{m}^{2} \mathrm{down}$ to $5.7 \mathrm{ekWh} / \mathrm{m}^{2}$. Natural gas made up $20 \%$ of the building's total heating energy (both fuel types combined) for the base model B1, and was reduced to $5 \%$ of the total heating energy for the retrofit model R1. 


\subsubsection{Greenhouse gas emissions}

Figure 4-14 shows total annual GHG emissions associated with both electricity and natural gas consumption for base model B1 and its retrofit R1, based on a CWEC weather year. The results are nearly identical to the $\mathrm{B} 2-\mathrm{R} 2$ case, and appear the same due to rounding. The graph shows an overall GHG emission reduction of $21 \%$, or $23.3 \mathrm{tCO}_{2} \mathrm{e}\left(4.5 \mathrm{kgCO}_{2} \mathrm{e} / \mathrm{m}^{2}\right)$. As before, the majority of the savings again comes from the reduction in natural gas use from the reduced MAU supply airflow rate.

Emissions from natural gas decreased by $36 \%$, or $34.4 \mathrm{tCO}_{2} \mathrm{e}\left(6.7 \mathrm{kgCO}_{2} \mathrm{e} / \mathrm{m}^{2}\right)$, and electricityrelated emissions decreased by $79 \%$, or $11.2 \mathrm{tCO}_{2} \mathrm{e}\left(2.2 \mathrm{kgCO}_{2} \mathrm{e} / \mathrm{m}^{2}\right)$.

Again, the provincial average GHG emissions for MURBs since 1990 is included for reference.

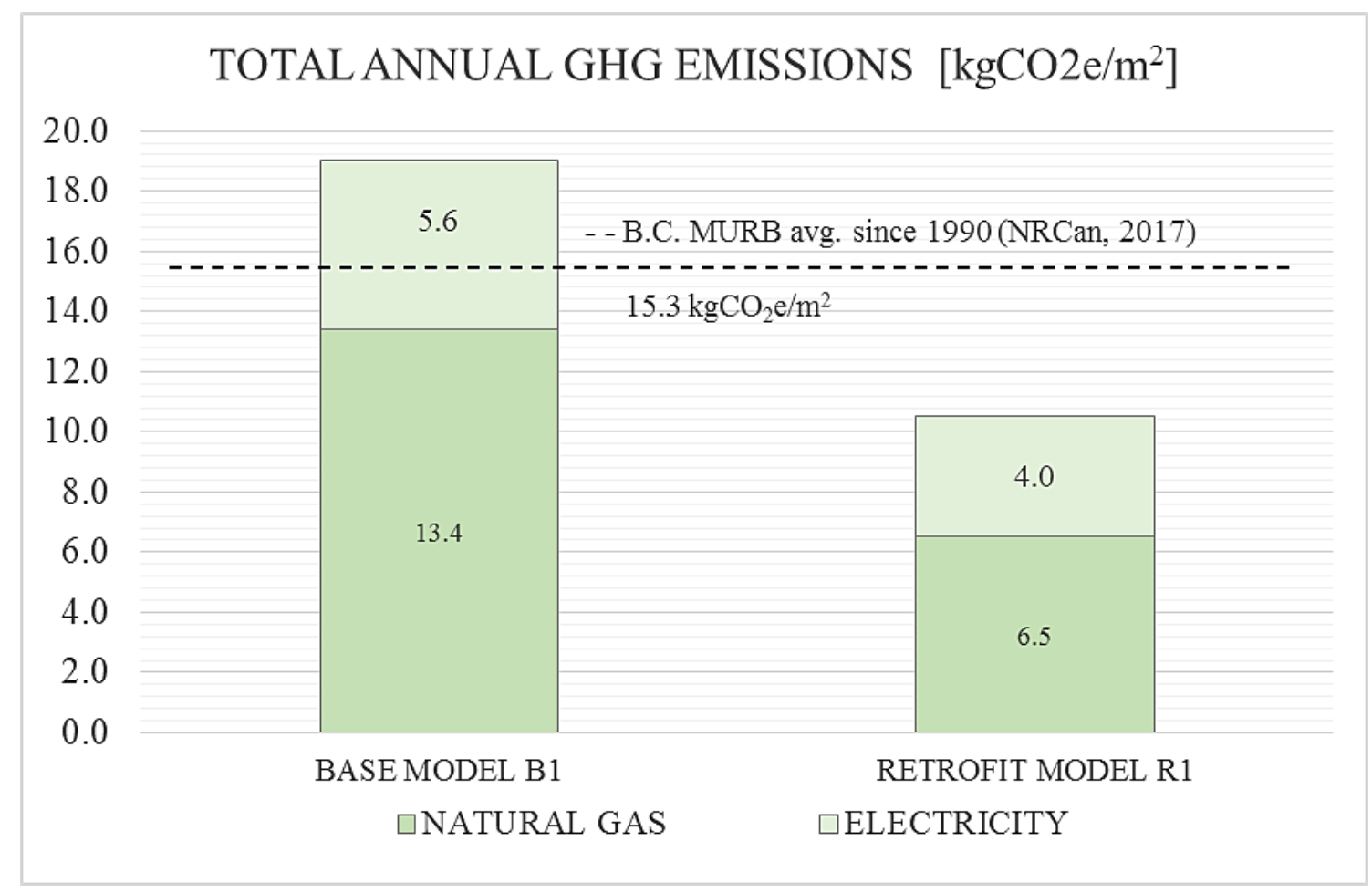

Figure 4-14: B1 vs R1 total annual greenhouse gas emissions by fuel type 


\subsection{Retrofit progression}

Figure 4.15 below is repeated from earlier for reference, but modified to illustrate the progression of retrofit options examined from the building's original condition, instead of highlighting the modelling methodology. The current condition, B2, includes a retrofit to improve the building enclosure's thermal performance and air-tightness, which occurred in 2012. The proposed retrofit was applied to each of these conditions to investigate the impact to energy consumption, and is represented by the $\mathrm{R} 1$ and $\mathrm{R} 2$ conditions.

This Section will now compare a progression of the three possible retrofit conditions from the building's original construction (including the enclosure retrofit which already occurred), and one from its current condition.

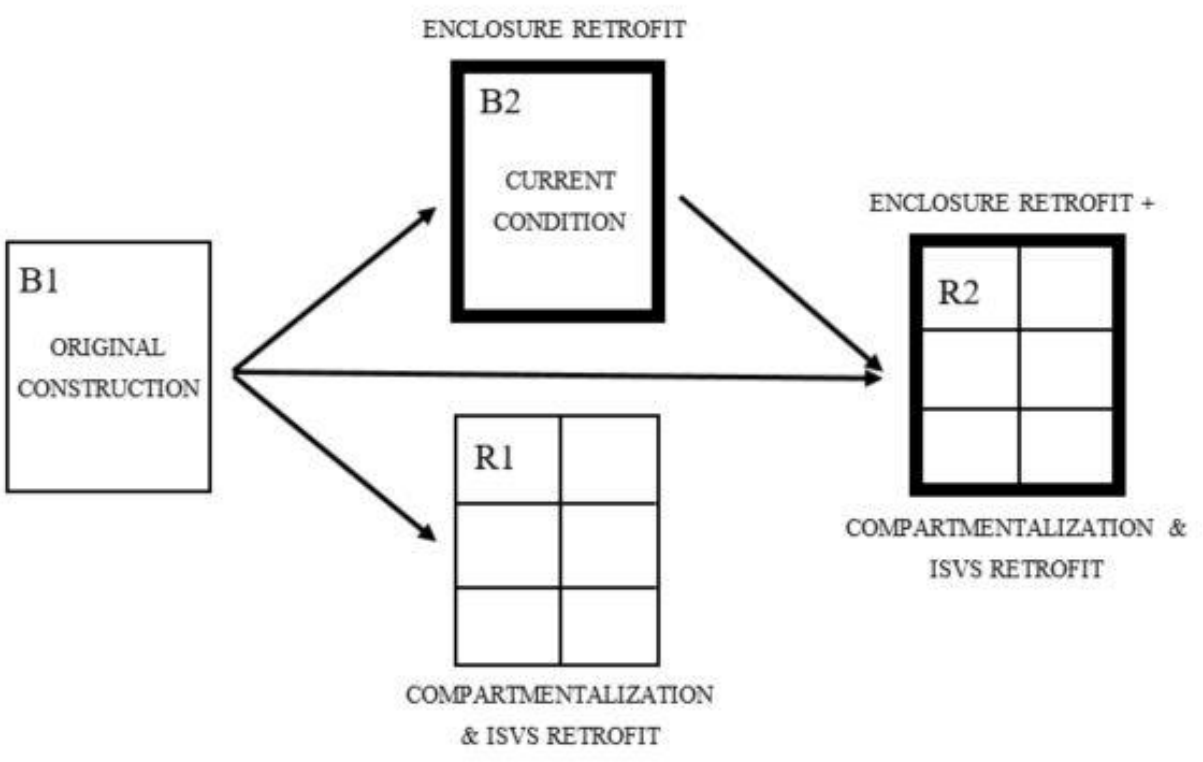

Figure 4-15: Retrofit progression from original and current base conditions 


\subsubsection{Heating energy}

Figure 4-16 below shows the annual heating energy changes for both natural gas and electricity for each of the 4 retrofit progressions mentioned above determined through simulation.

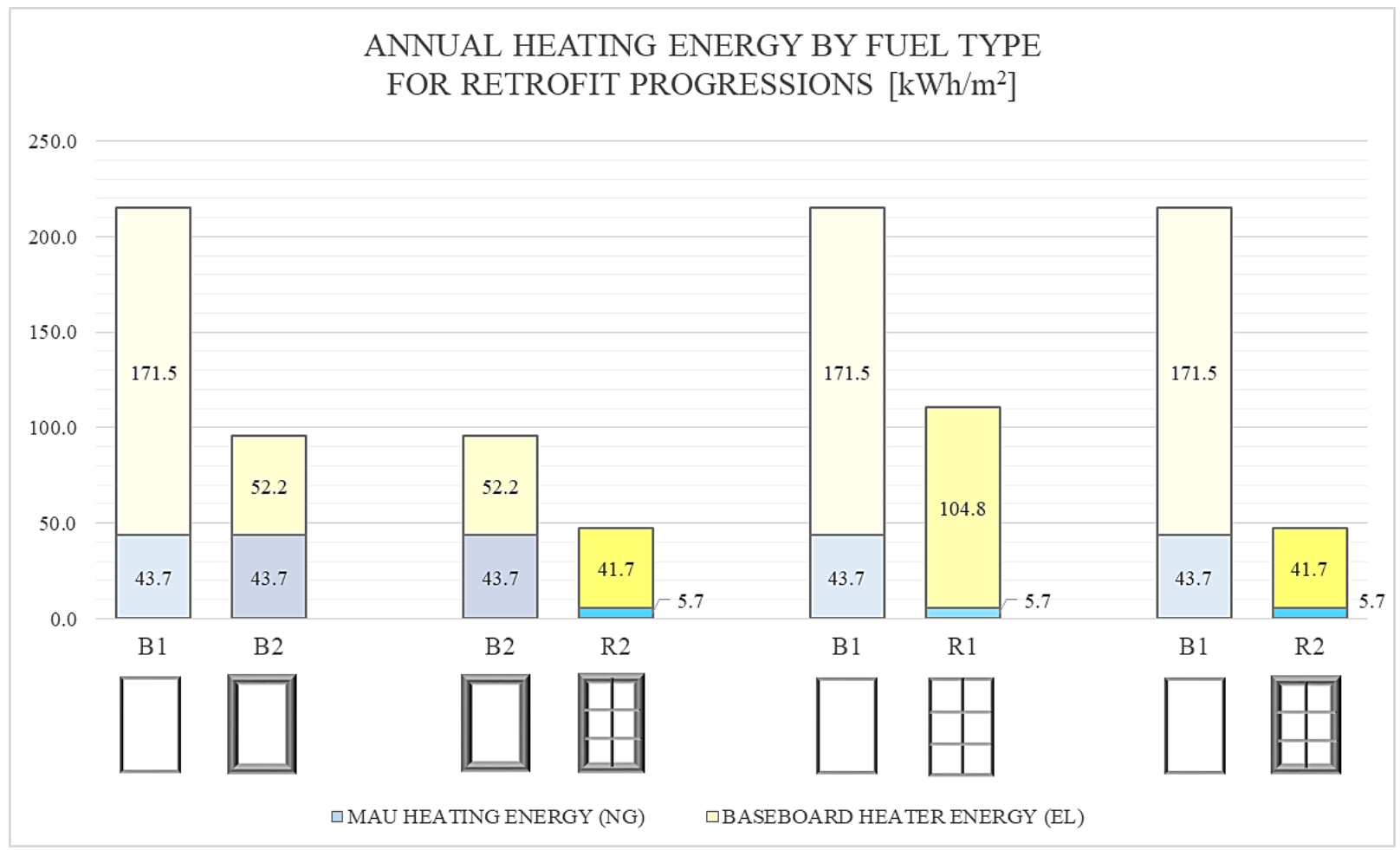

Figure 4-16: Annual heating energy comparison for progression of retrofits

\section{B1 - B2}

The first comparison shows the transition from the original building to its current condition, representing the two base cases used for the proposed retrofit simulations, and is included for reference. To reiterate, the energy consumption shown does not represent the actual performance of the building for any particular year, but the performance to a common standard reference year using a CWEC weather file after the two models had both been calibrated to actual performance data. 
Results show a total heating energy reduction of $55 \%$, or $119.3 \mathrm{ekWh} / \mathrm{m}^{2}$, with no change in the MAU consumption, and a $70 \%\left(119.3 \mathrm{kWh} / \mathrm{m}^{2}\right)$ reduction in the electric baseboard heater energy use. This performance improvement is comparable to the actual metered energy data on which these two models were calibrated, which showed a $66 \%$ reduction in electric heating energy after the enclosure retrofit.

Figure 4-17 shows the annual breakdown of the actual metered energy use used to calibrate both models. The breakdown of both the actual baseload and heating energy by fuel type for 2013 (determined previously) is shown, and the normalized energy breakdown for the pre-retrofit period applied to 2013 .

\begin{tabular}{|c|c|c|c|c|c|c|}
\hline \multirow{2}{*}{$\begin{array}{l}\text { B2: } 2013 \\
\text { POST-RETROFIT }\end{array}$} & & & \multirow{2}{*}{$\begin{array}{r}\text { FP } \\
\text { DHW } \\
\text { MAU }\end{array}$} & \multirow{2}{*}{\begin{tabular}{l|}
29 \\
31 \\
35
\end{tabular}} & \\
\hline & NG & 95 & & & \multicolumn{2}{|c|}{ 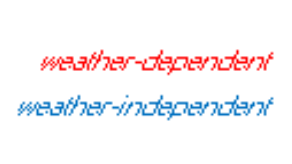 } \\
\hline SITE EUI [kWh/m $\left.\mathrm{m}^{2}\right]$ & & & & & & \\
\hline \multirow{3}{*}{$\begin{array}{l}\text { HDD@19 C } \\
3181\end{array}$} & EL & 78 & \multirow[t]{2}{*}{ SUITE } & \multirow[t]{2}{*}{42} & BSBRD & 23 \\
\hline & & & & & UNREG. & 19 \\
\hline & & & COMMON & 37 & & \\
\hline \multirow{2}{*}{\multicolumn{3}{|c|}{ B1: 2007-2011 }} & \multirow{3}{*}{$\begin{array}{r}\text { FP } \\
\text { DHW } \\
\text { MAU } \\
\end{array}$} & \multirow{3}{*}{\begin{tabular}{l|}
29 \\
31 \\
37 \\
\end{tabular}} & & \\
\hline & & & & & & \\
\hline PRE-RETROFIT 5 YR AVG: & NG & 97 & & & & \\
\hline SITE EUI $\left[\mathrm{kWh} / \mathrm{m}^{2}\right]$ & & & & & & \\
\hline \multirow{3}{*}{$\begin{array}{l}\text { NORMALIZED TO } \\
2013 \text { HDD (3181) }\end{array}$} & EL & 118 & \multirow[t]{2}{*}{ SUITE } & \multirow[t]{2}{*}{76} & BSBRD & 66 \\
\hline & & & & & UNREG. & 10 \\
\hline & & & COMMON & 42 & & \\
\hline
\end{tabular}

Figure 4-17: Metered energy use data for B1 \& B2 calibration - normalized to 2013 HDD for comparison

The 2013 data, which was sub-metered to the three natural gas and two electricity end uses, was used directly for the B2 model calibration, however in its monthly breakdown form. The 2007 2011 five-year average data was used indirectly to calibrate the B1 through a weather normalization process for compatibility with the CWEC weather file. Although this calibration was eventually exchanged with a calibration to 2011 data (described in Section 3.3.5.2), the two calibrations were close enough to one another for the following comparison to be made. 
The consumption data from these five years was normalized to the monthly heating degree days from the same period, and that relationship used to calculate the theoretical performance of the building for 2013, using the 2013 monthly HDD, for comparison purposes with the actual performance of the building that year with its upgraded enclosure.

Figure 4-18 below shows the percentage decrease in energy use of the building in 2013 as a result of the enclosure retrofit.

\begin{tabular}{|c|c|c|c|c|c|c|c|c|c|}
\hline \multirow[b]{4}{*}{ BASELOAD } & \multicolumn{6}{|c|}{ ENERGY USE INTENSITY $\left[\mathrm{kWh} / \mathrm{m}^{2}\right]$} & & & \\
\hline & \multicolumn{3}{|c|}{$\begin{array}{c}\text { B1 2007-2011 AVG } \\
\text { (NORMALIZED TO } 2013 \text { HDD) }\end{array}$} & \multicolumn{3}{|c|}{$\begin{array}{c}\text { B2 } 2013 \\
\text { (RETROFITTED ENVELOPE) }\end{array}$} & \multicolumn{3}{|c|}{ B $2 \%$ CHANGE } \\
\hline & NG & EL & TOT & NG & $\mathrm{EL}$ & TOT & NG & $\mathrm{EL}$ & TOT \\
\hline & 31 & 52 & 83 & 31 & 56 & 87 & $0 \%$ & $7 \%$ & $5 \%$ \\
\hline HEATING & 66 & 66 & 132 & 64 & 23 & 87 & $-3 \%$ & $-66 \%$ & $-34 \%$ \\
\hline TOTAL & 97 & 118 & 215 & 95 & 78 & 174 & $2 \%$ & $34 \%$ & $-19 \%$ \\
\hline
\end{tabular}

Figure 4-18: Baseload and heating energy reduction from B1 to B2

Most notably, suite-level electric heating energy decreased by $66 \%\left(43 \mathrm{kWh} / \mathrm{m}^{2}\right)$ due to the enclosure retrofit, and is comparable to the $70 \%$ reduction presented above from simulation results. The overall heating energy reduction of $34 \%$ differs from the simulated $55 \%$ because the simulation does not include fireplace heating energy and so the totals are different.

\section{B2 - R2}

This transition represents the proposed retrofit as applied to the case study building in its current condition, with its upgraded enclosure. The simulation results show an overall heating energy reduction of $51 \%$, or $48.5 \mathrm{ekWh} / \mathrm{m}^{2}$. A reduction in natural gas use drove the overall savings with an $87 \%$ reduction $\left(38.0 \mathrm{ekWh} / \mathrm{m}^{2}\right)$, and electrical space heating energy decreased by $20 \%$, or 10.5 $\mathrm{kWh} / \mathrm{m}^{2}$. 


\section{B1 - R1}

The results of the B1 - R1 simulation indicate that a compartmentalization and in-suite ventilation system retrofit applied to the case study building in its original condition would result in an overall heating energy reduction of $49 \%$, or $104.7 \mathrm{ekWh} / \mathrm{m}^{2}$, dominated by a natural gas consumption decrease $87 \%\left(38.0 \mathrm{ekWh} / \mathrm{m}^{2}\right)$ from the reduction in the central ventilation delivery by the MAU. Electrical heating energy decreased by $39 \%\left(66.7 \mathrm{kWh} / \mathrm{m}^{2}\right)$.

\section{$\mathbf{B 1}-\mathbf{R 2}$}

This transition represents both retrofit measures applied to the original building condition; the proposed retrofit combined with the enclosure retrofit. Results for the combined retrofit are predictably the most impactful, with an overall heating energy reduction of $78 \%$, or 167.8 $\mathrm{ekWh} / \mathrm{m}^{2}$. Natural gas savings are again estimated to be $87 \%\left(38.0 \mathrm{ekWh} / \mathrm{m}^{2}\right)$ from the reduced MAU airflow rate, and electrical heating energy decreased by $76 \%\left(129.8 \mathrm{kWh} / \mathrm{m}^{2}\right)$.

Table 4.2 below summarizes the annual heating energy changes for the retrofit progressions.

Table 4-2: Annual heating energy change summary for retrofit progressions

\begin{tabular}{|c|c|c|c|c|c|c|c|c|}
\hline \multirow[t]{2}{*}{ FUEL } & \multicolumn{2}{|c|}{ B1 - B2 } & \multicolumn{2}{|c|}{ B2 - R2 } & \multicolumn{2}{|c|}{ B1 - R1 } & \multicolumn{2}{|c|}{ B1 - R2 } \\
\hline & $\begin{array}{c}\text { change } \\
{\left[\mathrm{kWh} / \mathrm{m}^{2}\right]}\end{array}$ & $\begin{array}{l}\text { percent } \\
\text { change }\end{array}$ & $\begin{array}{c}\text { change } \\
{\left[\mathrm{kWh} / \mathrm{m}^{2}\right]}\end{array}$ & $\begin{array}{l}\text { percent } \\
\text { change }\end{array}$ & $\begin{array}{c}\text { change } \\
{\left[\mathrm{kWh} / \mathrm{m}^{2}\right]}\end{array}$ & $\begin{array}{l}\text { percent } \\
\text { change }\end{array}$ & $\begin{array}{c}\text { change } \\
{\left[\mathrm{kWh} / \mathrm{m}^{2}\right]}\end{array}$ & $\begin{array}{l}\text { percent } \\
\text { change }\end{array}$ \\
\hline MAU HEATING ENERGY (NG) & 0.0 & $0.0 \%$ & -38.0 & $-87 \%$ & -38.0 & $-87 \%$ & -38.0 & $-87 \%$ \\
\hline BASEBOARD HEATER ENERGY (EL) & -119.3 & $-70 \%$ & -10.5 & $-20 \%$ & -66.7 & $-39 \%$ & -129.8 & $-76 \%$ \\
\hline TOTAL HEATING ENERGY & -119.3 & $-55 \%$ & -48.5 & $-51 \%$ & -104.7 & $-49 \%$ & -167.8 & $-78 \%$ \\
\hline
\end{tabular}




\subsubsection{GHG emissions}

Figure 4-19 below shows the corresponding annual greenhouse gas emission changes for both natural gas and electricity for each of the 4 retrofit progressions. The proposed retrofit offers greater GHG emission reductions than the enclosure retrofit due to the decrease in natural gas consumption. Reductions in electricity usage result in a minimal impact because the GHG emission factor for electricity in B.C. is only $25 \mathrm{gCO}_{2} \mathrm{e} / \mathrm{kWh}$ from the abundance of hydroelectricity. In comparison, the 2013 Canadian national average was $150 \mathrm{gCO}_{2} \mathrm{e} / \mathrm{kWh}$ (Environment Canada, 2015).

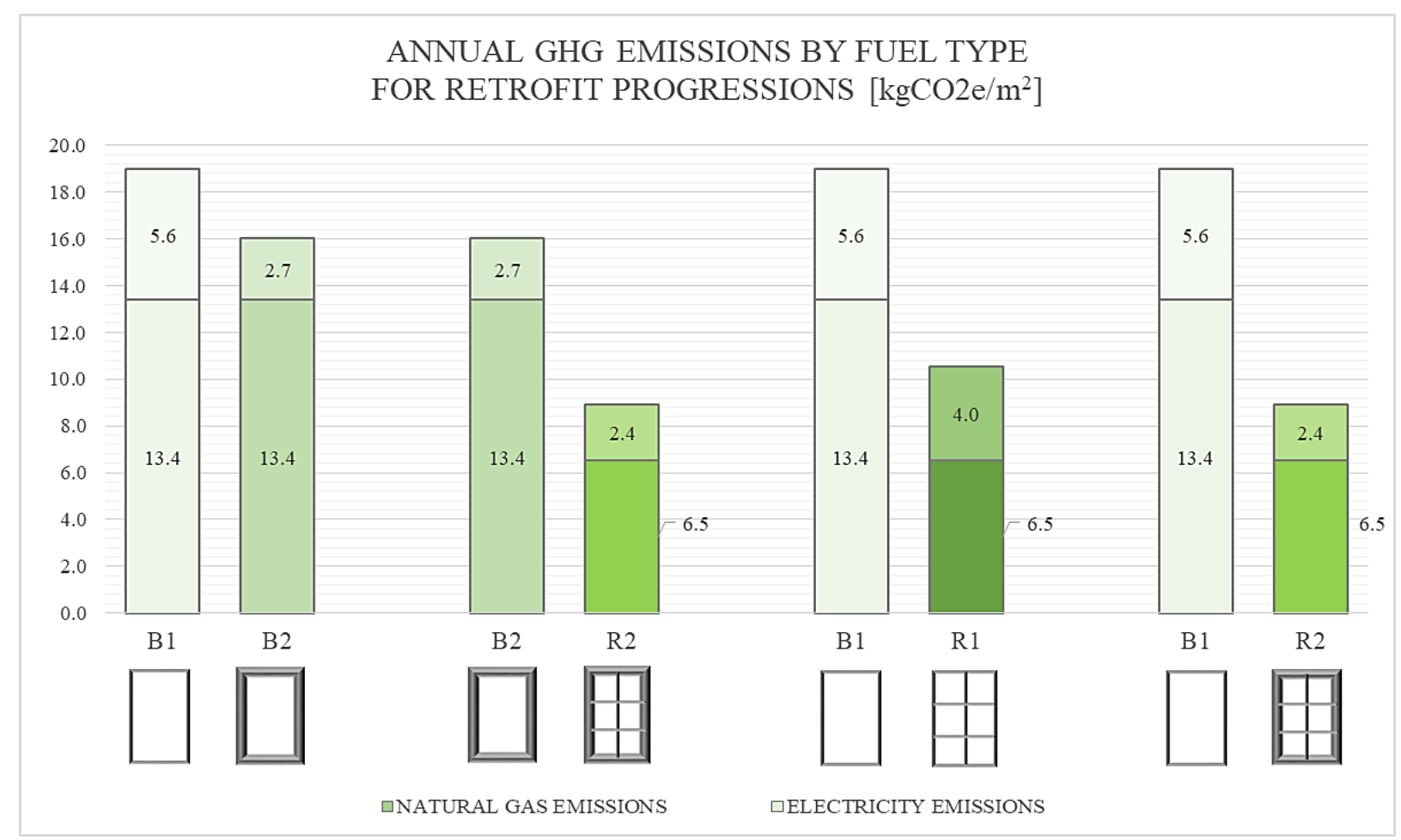

Figure 4-19: Annual GHG emissions by fuel type for progression of retrofits 
Table 4-3 shows a summary of the changes in GHG emissions by quantity and percentage for each of the retrofits presented in Figure 4-19.

Table 4-3: Annual GHG emission change summary for retrofit progressions

\begin{tabular}{|c|c|c|c|c|c|c|c|c|}
\hline & \multicolumn{2}{|c|}{ B1 - B2 } & \multicolumn{2}{|c|}{ B2 - R2 } & \multicolumn{2}{|c|}{ B1 - R1 } & \multicolumn{2}{|c|}{ B1 - R2 } \\
\hline & $\begin{array}{c}\text { change } \\
{\left[\mathrm{kWh} / \mathrm{m}^{2}\right]}\end{array}$ & $\begin{array}{l}\text { percent } \\
\text { change }\end{array}$ & $\begin{array}{c}\text { change } \\
{\left[\mathrm{kWh} / \mathrm{m}^{2}\right]}\end{array}$ & $\begin{array}{l}\text { percent } \\
\text { change }\end{array}$ & $\begin{array}{c}\text { change } \\
{\left[\mathrm{kWh} / \mathrm{m}^{2}\right]}\end{array}$ & $\begin{array}{l}\text { percent } \\
\text { change }\end{array}$ & $\begin{array}{c}\text { change } \\
{\left[\mathrm{kWh} / \mathrm{m}^{2}\right]}\end{array}$ & $\begin{array}{l}\text { percent } \\
\text { change }\end{array}$ \\
\hline NATURAL GAS EMISSIONS & 0.0 & $0 \%$ & -6.9 & $-51 \%$ & -6.9 & $-51 \%$ & -6.9 & $-51 \%$ \\
\hline ELECTRICITY EMISSIONS & -3.0 & $-53 \%$ & -0.3 & $-10 \%$ & -1.6 & $-29 \%$ & -3.2 & $-57 \%$ \\
\hline TOTAL EMISSIONS & -3.0 & $-16 \%$ & -7.1 & $-44 \%$ & -8.5 & $-45 \%$ & -10.1 & $-53 \%$ \\
\hline
\end{tabular}

\subsubsection{Fan energy}

An increase in electrical energy associated with powering fans can be expected for the proposed retrofit. The introduction of a constantly running HRV in each suite will add a significant electrical load on the building. Some energy will be saved due to the elimination of the bathroom fans, but since they are only operated intermittently the savings will not offset that of the HRVs. Figure 4-20 compares the estimated total fan energy for the proposed retrofit building with that of the baseline building. 


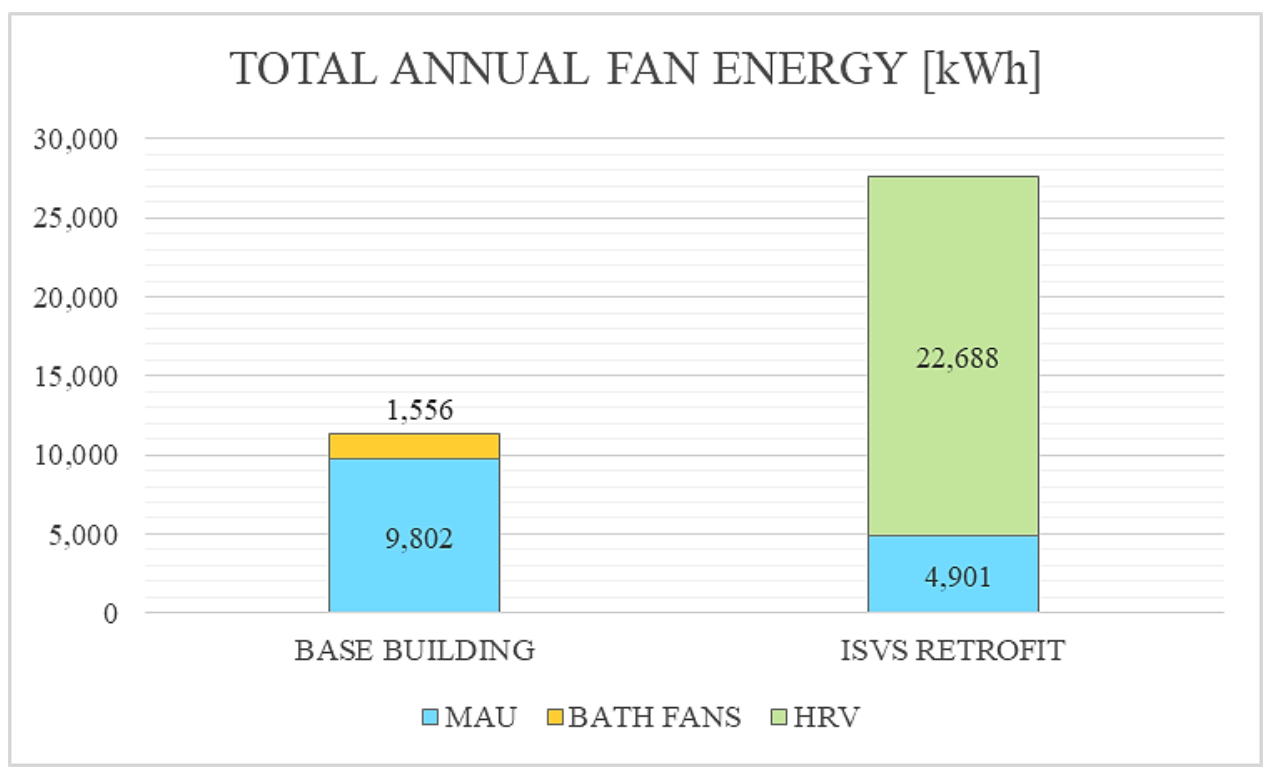

Figure 4-20: Total annual fan energy

Bathroom fans as modelled had a draw of $60 \mathrm{~W}$, with an hour operation each morning and an hour at night, resulting in a consumption of $1,556 \mathrm{kWh}$ per year. HRVs as modelled had a draw of $70 \mathrm{~W}$ continuous each, resulting in a consumption of 22,688 $\mathrm{kWh}$ per year. Some energy will also be saved with the decreased supply rate of the MAU fan. The current configuration, used in the baseline models, draws approximately $1.12 \mathrm{~kW}$ continuous, or $9,802 \mathrm{kWh}$ per year. For the retrofit, some assumptions had to be made to determine the draw for the reduced corridor supply rate. A $50 \%$ power reduction was chosen as a conservative estimate for an $87 \%$ supply rate reduction, resulting in an annual consumption of $4,900 \mathrm{kWh}$. In reality, this would be a more complex system design problem which would require an evaluation of the suitability of the existing duct sizing to deliver the new reduced rate, and the new associated static pressure. In addition, fan and motor selection may be problematic for the new supply rate as it is extremely low. The associated power draw would then depend on the new equipment's characteristics and whether or not it included a variable speed drive. The assumptions above were made in order to make a rough comparison of the fan energy impact of the proposed retrofit. Based on these assumptions, the total fan energy for the building would increase by about $143 \%$, or $16,231 \mathrm{kWh}$ per year $\left(3.14 \mathrm{kWh} / \mathrm{m}^{2} / \mathrm{a}\right)$. 


\subsection{General discussion}

\subsubsection{Energy modelling limitations}

Because the energy impact of the proposed retrofit is highly dependent on, and sensitive to, the resulting changes in airflow patterns, the base model was calibrated with as much fidelity as possible to the building's actual measured performance. Despite this, it has been demonstrated that it is not possible to fully predict airflow patterns at all times in any high-rise building due to the many fluctuating influences (Ricketts, 2014). As a result, there was significant uncertainty in the measured airflow characteristics of the building. An effort was made to minimize the use of data with the most uncertainty during the model calibration. However it remains that any predicted performance results for the proposed retrofit are dependent on the quality of the actual airflow performance data used, as well as the assumptions made for the retrofit model.

One source of error is introduced when extrapolating infiltration rates at a $4 \mathrm{~Pa}$ reference pressure using the power law equation by the fact that the characteristic flow coefficients and exponents for building elements are determined at much higher test pressures (up to $75 \mathrm{~Pa}$ ), which can impact airflow pathway geometry. Urquhart, Richman, \& Finch (2015) give a detailed analysis of flow characteristic measurement sensitivities specific to the case study building used in this thesis.

Another source of uncertainty is introduced by the convention of using this $4 \mathrm{~Pa}$ reference pressure in determining infiltration rates using the power law equation (Equation 2.1), as outlined by Sherman \& Grimsrud (1980). In reality the pressure differential across the envelope would change dynamically with outside temperature, wind forces, and internal pressure fluctuations due to mechanical ventilation, stack effect, and window operation. The original determination of $4 \mathrm{~Pa}$ as a reference pressure was in fact made in an attempt to find a suitable average for this dynamic range of pressures. Sherman (1980) reasoned that "In a real situation ... the pressure will ... vary between two limits (usually $-10 \mathrm{~Pa}$ to $+10 \mathrm{~Pa}$ )... Because the leakage area is multiplied by the square-root of the pressure, the average condition will be the average of the square-root of the pressure over the range. We have chosen the value of four pascals as the reference pressure at which we evaluate the leakage area.". This pressure range may not be suitable for high-rise buildings where the choice of reference pressure becomes particularly important. Pressures induced by wind and stack effect will depend on building height and environment, among other 
factors, but can be significant enough that corridor ventilation system designs typically use safety factors of $25 \mathrm{~Pa}$ up to $125 \mathrm{~Pa}$ to overcome these pressures (CMHC, 2003). Another study of three Canadian high-rise MURBs found that the pressure in the suites could be $15 \mathrm{~Pa}$ to $75 \mathrm{~Pa}$ below outside ambient pressure while one or more exhaust fan was operating (Canada Mortgage \& Housing Corporation, 2005).

As mentioned previously in Section 2.3.5.2, a monitoring program had been set up to measure pressure differentials across the exterior enclosure for the purpose of calculating infiltration airflow rates. Pressure taps collected hourly data from January to September of 2013, on floors 3 and 11 on all four sides of the building, shown in Figure 4-21 below.

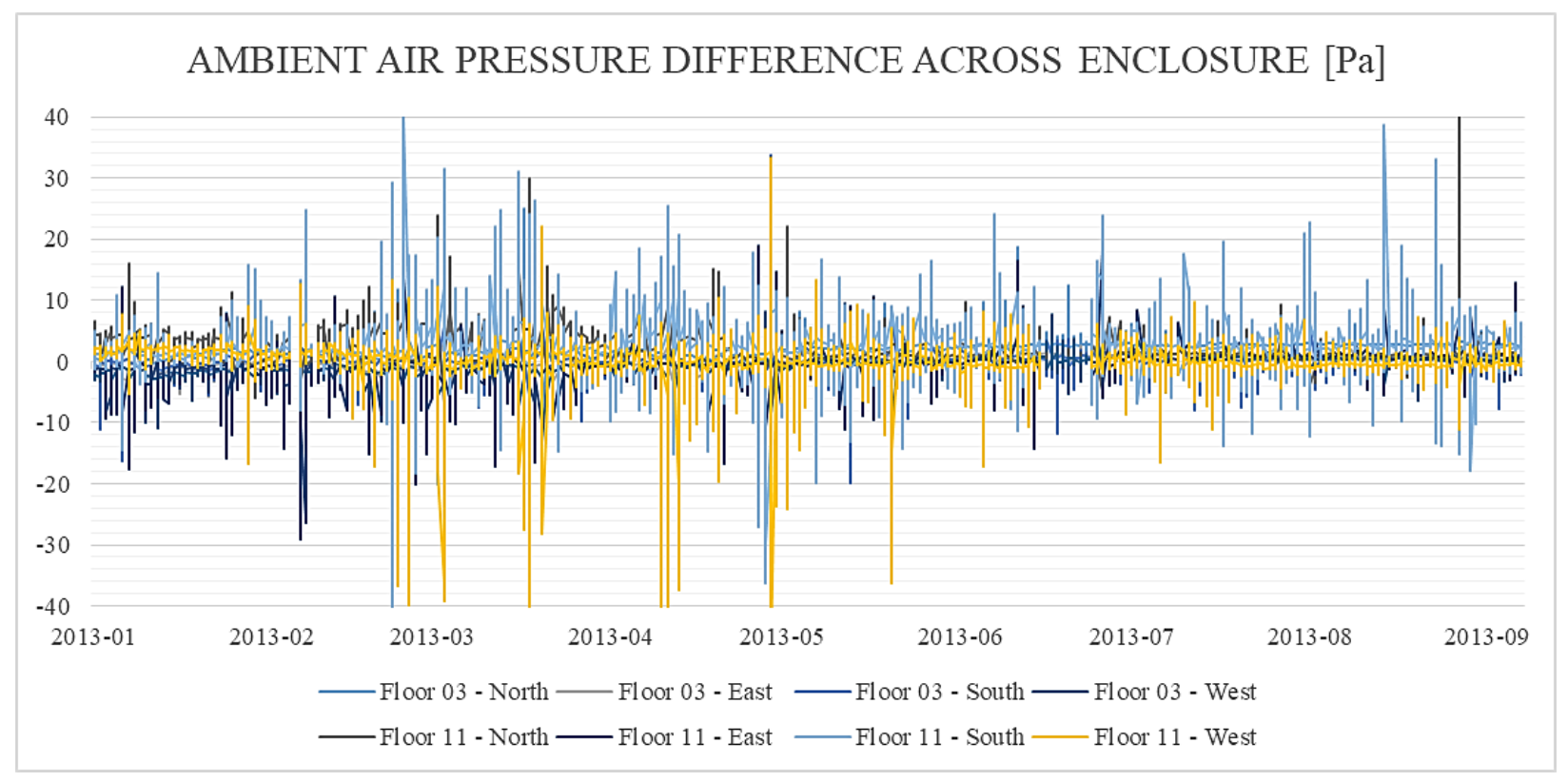

Figure 4-21: Exterior enclosure hourly pressure differentials

Figure 4-22 shows the average positive pressure differential across enclosure - causing exfiltration - for this time period for each direction on the monitored floors. Figure 4-23 shows the average negative pressure differential across the enclosure for the same time period, causing infiltration. This data could be ideally used to calculate average infiltration rates using the power law equation with the previously determined flow coefficients and exponents for the exterior enclosure. The 
measured average negative pressure differential of $-1.5 \mathrm{~Pa}$ for all 4 walls however was a surprising result however, considering the above discussion, and warranted further investigation.

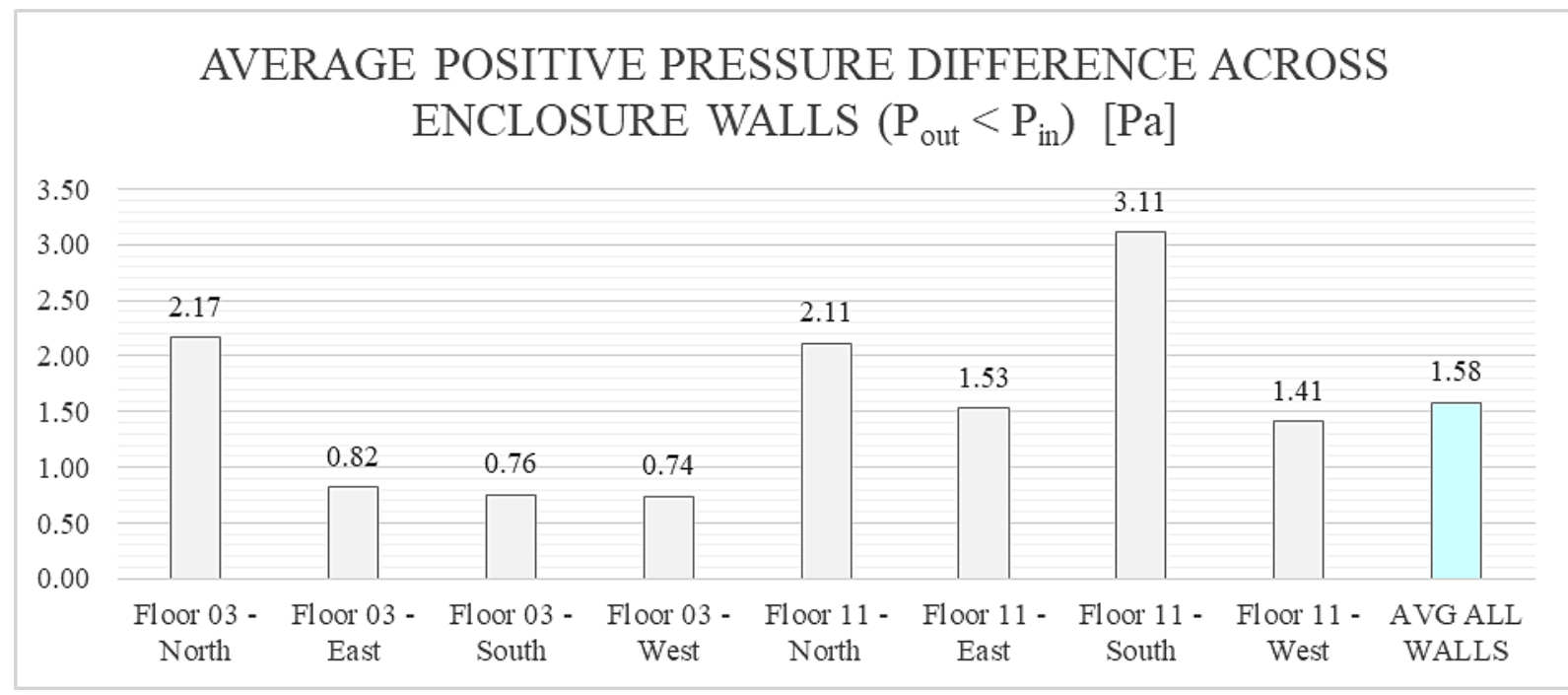

Figure 4-22: Average positive pressure differential across enclosure (exfiltration)

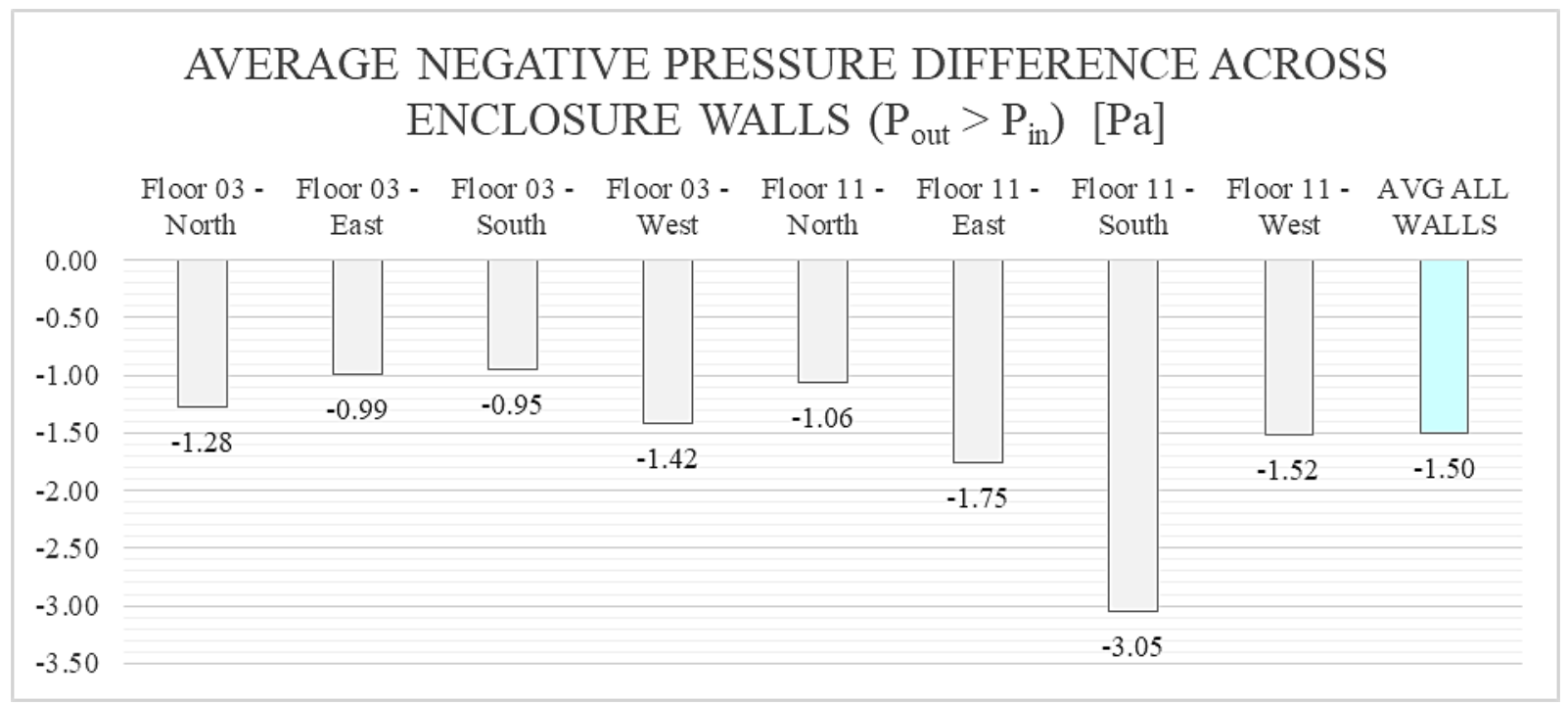

Figure 4-23: Average negative pressure differential across enclosure (infiltration)

For validation purposes, this pressure data was correlated to the hourly wind direction and speed data from the rooftop weather station data for the same period - January to September, 2013. 
Weather data from a $90^{\circ}$ sweep centred on each of the cardinal directions was binned (the case study building is situated squarely on the cardinal axes), and is presented in Table 4-4 below.

Table 4-4: Site wind direction, duration, and average speed, January - September 2013

\begin{tabular}{cccc} 
WIND DIRECTION & \# HOURS & $\%(2013)$ & AVG. SPEED $(\mathrm{m} / \mathrm{s})$ \\
\hline N (NW-NE) & 478 & $8 \%$ & 3.8 \\
E (NE-SE) & 654 & $11 \%$ & 3.9 \\
S (SE-SW) & 2938 & $49 \%$ & 4.3 \\
W (SW-NW) & 1918 & $32 \%$ & 4.0 \\
\hline
\end{tabular}

These average wind speeds recorded at the site were checked against the recorded monthly average wind speeds at Vancouver airport, and are the same order of magnitude, about $3.3 \mathrm{~m} / \mathrm{s}$ annual average. The wind direction and duration data from Table 4-4 is presented in a radar plot below (Figure 4-24) for illustrative purposes.

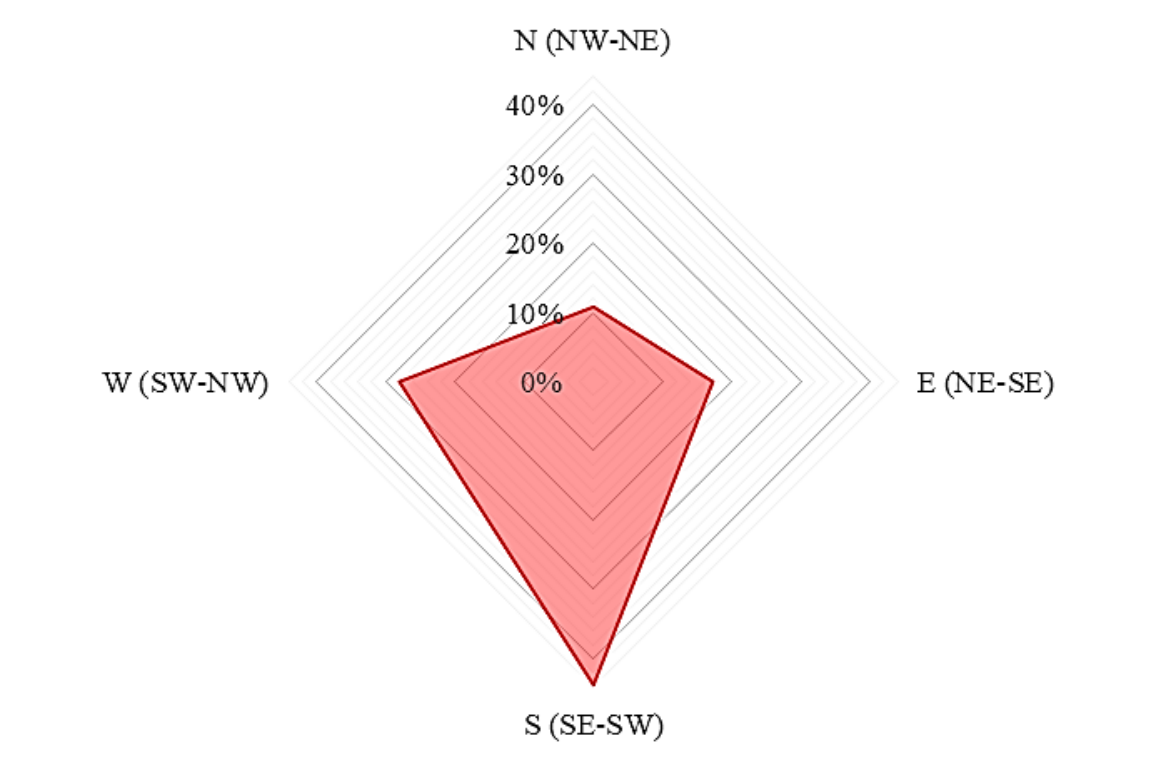

Figure 4-24: Site wind direction and duration, January - September 2013

Comparing this data with the negative pressure differentials presented in Figure 4-24 above, some correlation can be seen with the north and south wind speeds and duration. It is unclear 
however why the east and west data does not correlate. The westerly wind duration is three times that of the easterly, and slightly stronger, yet the wind pressures on the outside of those corresponding walls does not reflect this.

Adding to this confusion is that fact that both the summer and winter prevailing winds in Vancouver are easterly, coming out of the Fraser Valley (Nav Canada, 2000). Figure 4-25 below shows a radar plot of the wind direction and duration for 2013 at Vancouver airport, only $4.8 \mathrm{~km}$ from the building site. The trends seen here do not seem to match those recorded by the rooftop weather station. There may be local topographical reasons for this difference in wind pattern, or perhaps an equipment calibration issue shifting the data by $90^{\circ}$.

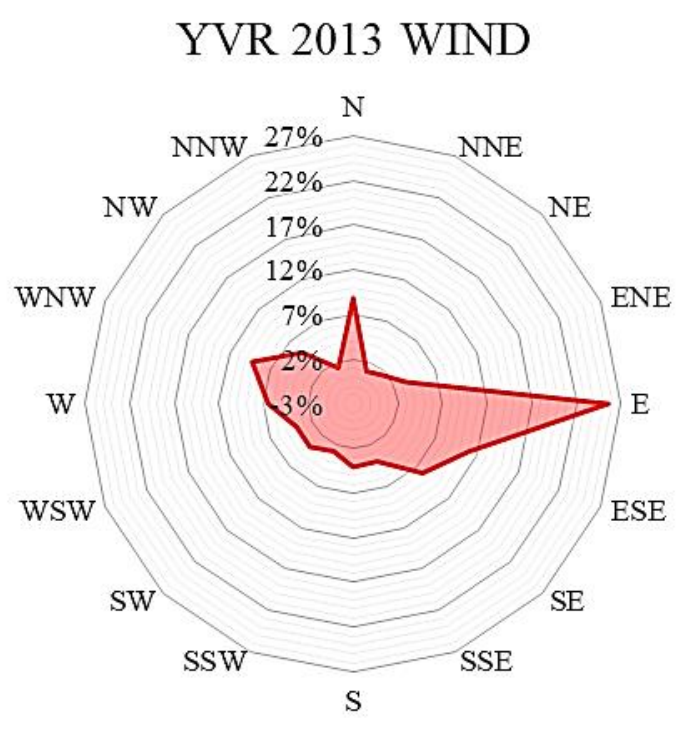

Figure 4-25: Wind direction and duration for Vancouver airport, 2013 (source: vancouver.weatherstats.ca)

Ultimately, there was too much uncertainty in the measured pressure differential data to confidently use it as a reference pressure for infiltration. If these recorded pressures are correct within their order of magnitude however, then they would support the conventional approach of using the $4 \mathrm{~Pa}$ reference pressure. They may not however support the use of the DOE-2 linear wind speed coefficient of 0.224, as recommended by Gowri, Winiarski, \& Jarnagin (2009) and used in this research. This coefficient dynamically increases the constant baseline infiltration rate (calculated from the reference pressure) based on wind speed. If the $4 \mathrm{~Pa}$ reference pressure is 
actually higher than the pressure differential experienced by the building enclosure, as the measured data indicate, then introducing an additive wind speed modifier would not be justified. Accurate modelling of infiltration rates is still the subject of contemporary research, and an important element in accurately simulating a building's energy performance. Han, Srebric, \& Enache-Pommer (2015) recently found that "the comparison between simulation results and utility data shows that time-dependent infiltration rates could increase the accuracy of energy simulations with $3-11 \%$ reduction in the ... CVRMSE, and 2-11\% reduction in the ... NMBE.".

The contribution of stack effect to infiltration was not incorporated in the model because the temperature differential modifier in the EnergyPlus ${ }^{\mathrm{TM}}$ ZoneInfiltration object applies to each zone individually, but does not account for air buoyancy on a multi-storey, whole-building level. A nodal network airflow model would be required to simulate this, as described previously, and further in Section 6.1. A dynamic pressure differential at each floor due to stack effect could be manually estimated using the hourly inside/outside air density difference, and the power law equation used to find the resulting dynamic infiltration rate. Increasing the overall infiltration rate in this way was deemed unnecessary at this point because its contribution to overall heating energy was already very high in the two baseline models. Infiltration was responsible for $54 \%$ of the total heating energy in model B1, and 33\% in model B2. A research report by Canada Mortgage \& Housing Corporation (2007) indicates that air leakage can account for up to $24 \%$ of heating energy in Canadian MURBs. It's not clear how similar the buildings in the study sample are to the case study building, but further increasing the modelled infiltration rate was deemed excessive. This may also indicate that the DOE-2 wind coefficient over-estimates infiltration in high-rise buildings.

The simulations performed for this research were intended to compare the relative performance of a baseline building state to the proposed retrofit, with the magnitude of change being more relevant than the magnitude of any individual result. Best judgement should be used when applying results presented here to other buildings, or to predict future performance for the proposed retrofit. Changing climate conditions and unpredictable occupant behaviour however may ultimately have the greatest impact on actual performance results achieved. 


\subsubsection{Execution of the proposed retrofit}

It would be a valuable exercise to carry out the proposed retrofit in order to gain insight into the actual performance improvements which result. Because of the implications for other similar buildings, as well as the GHG emissions reduction potential across the country, the proposed retrofit could provide wide-reaching benefits as a provincial or national research project.

If this retrofit is executed, another monitoring program should be set up to collect data on the building's performance characteristics both before and after the retrofit. Data relating to air change rates through suite-level PFT testing, as well as measurements of the new air-tightness characteristics through pressurization/depressurization testing should be collected. Data on window and door operation would also be important to collect as it could help to explain any observed airflow anomalies. Being able to isolate periods when window and door operation is a a minimum will also help identify critical time periods for data analysis. In addition, suite-level monitoring data would provide useful data for comparison to past performance. In the analysis of a 20-storey MURB in Toronto, Touchie and Pressnail (2014) found that suite-level air temperature measurements and sub-metered electricity use were the most beneficial in refining the building's energy model. Sub-metering of natural gas consumption should be implemented as well to disaggregate the heating energy portion and fairly determine the weather-dependent contribution of GHG emissions.

Prior to executing the proposed retrofit, it would be beneficial to monitor the indoor air quality (IAQ) on selected floors, particularly the bottom floors directly connected with the parking garage. Installing sensors to monitor $\mathrm{CO}, \mathrm{PM}_{2.5}, \mathrm{VOCs}, \mathrm{CO}_{2}$ for a period prior to and following the retrofit would help to validate whether or not the proposed retrofit strategy produced any improvements in IAQ. Indoor air quality improvement should be one of the primary motivations behind executing the proposed retrofit, and the opportunity to monitor results should be taken in order to validate or disprove the proposed retrofit as an effective strategy for improving IAQ.

The energy model should be recalibrated to the new post-retrofit condition and performance, and results normalized, in order to quantify any real benefit gained from the retrofit strategy. 


\subsubsection{Practical considerations for implementation}

There are several challenges and practical limitations for the implementation of a compartmentalization and ISVS retrofit on a high-rise MURB. The following is a brief list of general considerations which would apply to most buildings:

- Adequate separation of the intake and exhaust from each other and among all the suites is critical to avoid re-entrainment of exhaust air (ASHRAE, 2010), (Parker, 2012).

- Existing MAU duct work may be oversized for the new supply air delivery rate to be practical (static pressure and air velocity too low)

- It may be also difficult to find a commercial MAU small enough to deliver the reduced rate for corridors. Even distribution on all floors may be difficult at such low rates.

- Building maintenance requirements will likely increase due to the HRVs

- Door sealing is critical to maintaining the pressure boundary of the corridor to the suite and needs to be tamperproof. It also needs to be effective enough to avoid whistling sounds.

- Air sealing of vertical penetrations in both the suites and core of the building will assist in mitigating stack effect. This includes plumbing and electrical chases, garbage chute and stairwell doors, etc.

- Suite-corridor pressure differences need to be maintained at a level so that door opening forces do not exceed $130 \mathrm{~N}$. By air sealing the suite doors, the stack effect shifts to act predominantly on the suite-corridor partition. Because door open inward, the pressure gradient will make it more difficult to open doors on the lower floors of the building. Conversely, at the top of the building the pressure may provide an undesirable level of assistance in opening the doors.

Although there is a general desire to conserve energy by building occupants, the actual amount paid by them misrepresents their energy consumption and therefore they typically do not appreciate the total energy bill. There is a lack of awareness of how the activities of building users impact energy consumption as well as other building performance characteristics. For example, building occupants do not typically see their gas consumption associated with the operation of fireplaces, or heating of ventilation air as a result of open windows." (RDH Building Engineering Ltd., 2012). Separate metering of suite-level electricity, especially heating energy, offers a 
significant opportunity to create awareness of and encourage the reduction of individual energy use.

\subsubsection{Other buildings and other cities}

The overall energy implications of the proposed retrofit found in this research would be more pronounced in other Canadian cities as they are almost all located in colder climates. Cities which also have hotter summers than Vancouver would experience reverse stack effect if they are airconditioned. Toronto for example has more extreme annual weather fluctuations and experiences much hotter summers and colder winters than Vancouver. Buildings two, or three, or even four times the height of the case study building are not uncommon in some urban centres, and the stack effect phenomenon would be far greater than that experienced by the case study building. A taller building than the case study building in a colder city than Vancouver would be an ideal candidate to implement the proposed retrofit on.

\subsubsection{Greenhouse gas emissions}

A recent report by Pembina Institute found that “... measures announced in B.C.'s 2016 Climate Leadership Plan will not be sufficient to meet B.C.'s legislated economy-wide emissions reduction targets.". It was further noted that some of the policies proposed in the 2016 Climate Leadership Plan (e.g., the code requirement for net-zero ready buildings by 2032), were "insufficient to meet the proposed building sector targets, [and] additional policies are needed to reduce emissions, particularly from existing buildings." (Frappé-Sénéclauze, Heerema, \& Wu, 2017). The retrofit proposed in this thesis offers one possible avenue for helping to meet these emission reduction targets.

\subsubsection{Building code and health implications}

Today's high-rise MURBs continue to be designed with pressurized corridor ventilation systems

despite mounting evidence that this strategy is ineffective in performing its designed intention. If ventilation requirements are not required to be met in practice, then they cease to be requirements. 
In Canada, CSA Standard CAN/CSA-F326-M91 - Residential Mechanical Ventilation Systems follows closely the guidelines of ASHRAE Standard 62, noting that it "strongly influenced the ventilation air requirements of this standard" (Canadian Standards Association, 2010). ASHRAE Standard 62.1 Ventilation for Acceptable Indoor Air Quality, in addition to providing comprehensive ventilation design guidelines, recommends controlling $\mathrm{CO}_{2}$ concentrations to 700ppm above outdoor conditions (Montgomery, 2015). There is however no guideline for the many other airborne pollutants such as carbon monoxide $(\mathrm{CO})$, volatile organic compounds (VOCs), ozone, or various sized particulate matter, which are hazardous to the health (World Health Organization, 2010). Although perhaps not easy to implement in practice, setting concentration limits on these pollutants and guidelines to mitigate them may help to encourage a compartmentalized approach to high-rise construction since many of these pollutants originate in underground parking garages and are drawn up by stack-induced airflows.

It is interesting to note that a study of interactions with occupant-controlled HRVs in a recently constructed LEED-rated high-rise residential building in Toronto, having compartmentalized suites with dedicated ventilation, concluded that "HRV non-use does not seem to have a negative impact on IAQ from the inhabitants' perspective, and only marginally using real measurements....[a fact] poorly understood by designers, inhabitants and researchers alike." (Brown \& Gorgolewski, 2014). This observation may indicate that the compartmentalization design was poor and air change is occurring by other means, but may also indicate that current building code ventilation rates deserve further examination.

In general, poor performance of an existing building relative to more recent building code updates, or to the building's potential performance, is not a matter which can be resolved simply through mandate. Financial mechanisms need to be put in place to encourage deep energy retrofits, and guidelines should be put in place to support provincial goals. As an example, ASHRAE Standard 100-2015 Energy Efficiency in Existing Buildings is a standard developed in order to "provide criteria that will result in energy efficiency in existing buildings", proposing for example energy use intensity (EUI) targets for whole building performance. Although this standard has not been adopted in the B.C. Building Code, it has been suggested as an addendum in the near future. As well, the Standing Committee on Energy Efficiency for Buildings, recently advised the Canada Codes Centre to include existing buildings within the scope of the NECB as an interim update in 
the near future (Pape-Salmon, 2016). This move could be very effective in supporting energy and GHG reduction targets, and the retrofit proposed in this thesis could more easily be adopted.

\subsubsection{Financial barriers}

A major barrier to implementation of the proposed retrofit, as with any retrofit, is the capital cost of the project and its return on investment. A number of initiatives in British Columbia exist which offer financial support for energy efficiency upgrades to existing buildings as well as capitalizing GHG emission offsets related to energy retrofits. These programs are worth investigating for existing building owners prior to any retrofit feasibility study. They may even be a catalyst to initiate an unplanned retrofit feasibility study. A comprehensive summary of these available programs can be found in the report "Review of Potential Energy Efficiency Standards for Existing Buildings In BC" (Pape-Salmon, 2016).

\subsubsection{Recidivism}

Poor ventilation system effectiveness is not always immediately obvious to a building's occupants, and therefore rarely becomes a priority for repair or improvement unless it is badly underperforming. And because almost all high-rise residential buildings are ventilated in the same way, the majority of the general public is unaware that there are better ways to design a ventilation system, never having experience anything else. The fact that people generally accept the status quo removes incentive to make improvements, and tends to propagate the design in new construction. Increasing awareness among building occupants of the issues which can arise from poor ventilation system effectiveness, and association of those issues with their root cause, is fundamental to

creating a demand for remedies. Without this, the industry is unlikely to change its approach as there is little motivation to improve poorly performing ventilation systems in existing buildings, or to implement better strategies in future buildings. 


\section{Conclusion}

Computer simulation was used to examine the potential impact on overall heating energy, fuel mix, and carbon footprint of a compartmentalization and in-suite ventilation system (ISVS) retrofit strategy for a high-rise residential case study building in Vancouver. The impact of the proposed retrofit was examined for the building in its original 1983 as-built condition, as well as its current condition which incorporates an enclosure retrofit carried out in 2012. The main motivation behind the proposed retrofit is to improve the effectiveness of the ventilation system, which was found to be poor, and improve the indoor air quality for the building's residents. However, heating energy and GHG emission reductions are a collateral benefit of the proposed retrofit, and were the focus of this research.

For the proposed retrofit applied to the case study building in its current condition (retrofitted enclosure), results show:

- overall annual heating energy decreased by $51 \%\left(48.5 \mathrm{ekWh} / \mathrm{m}^{2}\right)$

- MAU natural gas consumption decreased by $87 \%\left(38.0 \mathrm{ekWh} / \mathrm{m}^{2}\right)$

- electrical space heating energy decreased by $20 \%\left(10.5 \mathrm{kWh} / \mathrm{m}^{2}\right)$

- overall annual GHG emissions decreased by $29 \%\left(20.2 \mathrm{tCO}_{2} \mathrm{e}\right.$, or $\left.3.9 \mathrm{kgCO} 2 \mathrm{e} / \mathrm{m}^{2}\right)$

- total emissions from natural gas decreased by $51 \%\left(35.5 \mathrm{tCO}_{2} \mathrm{e}\right.$, or $\left.6.9 \mathrm{kgCO} 2 \mathrm{e} / \mathrm{m}^{2}\right)$

- total emissions from electricity decreased by $10 \%\left(1.3 \mathrm{tCO}_{2} \mathrm{e}\right.$, or $\left.0.25 \mathrm{kgCO} 2 \mathrm{e} / \mathrm{m}^{2}\right)$

For the proposed retrofit applied to the case study building in its original 1983 as-built condition, results show:

- overall annual heating energy decreased by $49 \%\left(104.7 \mathrm{ekWh} / \mathrm{m}^{2}\right)$

- MAU natural gas consumption decreased by $87 \%\left(38.0 \mathrm{ekWh} / \mathrm{m}^{2}\right)$

- electrical space heating energy decreased by $39 \%\left(66.7 \mathrm{kWh} / \mathrm{m}^{2}\right)$

- overall annual GHG emissions decreased by $21 \%\left(23.3 \mathrm{tCO}_{2} \mathrm{e}\right.$, or $\left.4.5 \mathrm{kgCO} 2 \mathrm{e} / \mathrm{m}^{2}\right)$

- total emissions from natural gas decreased by $36 \%\left(34.4 \mathrm{tCO}_{2} \mathrm{e}\right.$, or $\left.6.7 \mathrm{kgCO}_{2} \mathrm{e} / \mathrm{m}^{2}\right)$

- total emissions from electricity decreased by $79 \%\left(11.2 \mathrm{tCO}_{2} \mathrm{e}\right.$, or $\left.2.2 \mathrm{kgCO} 2 \mathrm{e} / \mathrm{m}^{2}\right)$ 
If both retrofit measures were applied to the original building together - the enclosure retrofit and proposed compartmentalization and ISVS retrofit - results show:

- overall annual heating energy decreased by $78 \%\left(167.8 \mathrm{ekWh} / \mathrm{m}^{2}\right)$

- MAU natural gas consumption decreased by $87 \%\left(38.0 \mathrm{ekWh} / \mathrm{m}^{2}\right)$

- electrical space heating energy decreases by $76 \%\left(129.8 \mathrm{kWh} / \mathrm{m}^{2}\right)$

- overall annual GHG emissions decreased by $29 \%\left(20.2 \mathrm{tCO}_{2} \mathrm{e}\right.$, or $\left.3.9 \mathrm{kgCO} 2 \mathrm{e} / \mathrm{m}^{2}\right)$

- total emissions from natural gas decreased by $51 \%\left(35.5 \mathrm{tCO}_{2} \mathrm{e}\right.$, or $\left.6.9 \mathrm{kgCO} 2 \mathrm{e} / \mathrm{m}^{2}\right)$

- total emissions from electricity decreased by $57 \%\left(16.6 \mathrm{tCO}_{2} \mathrm{e}\right.$, or $\left.3.2 \mathrm{kgCO}_{2} \mathrm{e} / \mathrm{m}^{2}\right)$

The impact of the proposed retrofit if applied on its own to a high-rise MURB with a leaky and thermally inefficient envelope can reduce energy consumption by reducing infiltration due to stack effect, while improving mechanical ventilation distribution effectiveness. Because building enclosure air-tightness improvements can negatively impact ventilation air distribution to suites in buildings with pressurized corridor ventilation systems, the proposed measures should be applied in combination with, or before, any enclosure retrofit.

The findings of this research support the general hypothesis that suite compartmentalization in a high-rise MURB will reduce the energy losses due to uncontrolled airflows. The in-suite ventilation system necessary to supply air to the suites offers further energy savings through heat recovery, as well as enabling demand control to reduce energy while suites are unoccupied.

In 2013, 33\% of all natural gas in the province of B.C. was consumed by residential buildings (Statistics Canada, 2014), 58\% of which was used for space heating (NRCan, 2017). With apartment buildings alone accounting for $17 \%$ of all residential GHG emissions in the province (NRCan, 2017), the proposed retrofit is an opportunity to reduce provincial GHG output and support B.C.'s Greenhouse Gas Reductions Target Act (Province of British Columbia, 2017).

At the national level, residential buildings accounted for $15 \%$ of Canada's overall GHG emissions in 2013, with space heating making up $64 \%$ of the total residential sector output (NRCan, 2017). Although GHG emission factors and typical fuel mixes vary by province, the benefits of the 
proposed retrofit would apply across the other provinces of Canada. The GHG emission factor for electricity in B.C. is relatively low at $25 \mathrm{gCO}_{2} \mathrm{e} / \mathrm{kWh}$ compared to the 2013 Canadian national average of $150 \mathrm{gCO}_{2} \mathrm{e} / \mathrm{kWh}$ (Environment Canada, 2015), so the benefits of the proposed retrofit should be more significant in most other provinces. The GHG reduction potential would also be amplified in the other provinces as their climates are generally much colder than B.C.'s, resulting in higher heating energy demand and greater stack effect pressures. The proposed retrofit is therefore an opportunity to contribute to municipal, provincial, and national GHG emission reduction objectives across the country, and particularly in regions where the majority of grid electricity is produced from renewable sources. 


\section{Further research \& future recommendations}

The following is a summary recommendations for future research related to studying the impacts of compartmentalization retrofits or any measures to mitigate stack effect in high-rise buildings.

\subsection{Stack effect modelling}

Stack effect should be accounted for in energy models of high-rise buildings. Unmitigated airflows within a building due to stack effect cause variations in infiltration and energy use from floor to floor in a high-rise MURB which are currently unaccounted for in standard modelling practices. Research conducted by Gowri (2009) on this matter concluded that "though the current [energy modelling] approach addresses modeling wind-driven infiltration, further research is needed to model infiltration due to stack effect.".

A comprehensive review of contemporary literature indicated that the EnergyPlus ${ }^{\mathrm{TM}}$ AirFlowNetwork group of objects should be well suited for such an analysis. A conversation with the author of Airflow Network Modeling in EnergyPlus ${ }^{\mathrm{TM}}(\mathrm{Gu}, 2007)$ indicated that although the AirFlowNetwork function was not specifically intended for high-rise buildings (its treatment of stack effect in multi-storey buildings is unclear in the software reference documentation), that the underlying physics should be appropriate for that purpose (L. Gu, personal communication, July 21, 2016). Validation of the behaviour and accuracy of an AirFlowNetwork model through an energy and airflow model calibration exercise would offer many potential opportunities to improve future building performance analyses. This nodal network approach uses the underlying physics of stack effect, so it can be applied to other buildings more easily with potentially better predictability of retrofit implications. This is of particular value when examining taller buildings in colder cities, where the pressure differentials induced by stack effect are much greater, and the inputs required in a standard energy model for infiltration and other airflow patterns within the building are difficult to estimate.

The AirFlowNetwork object allows the modeller to set up a nodal network representing the zones in a building. Airflows are governed by the airflow resistance of the building partitions and the zonal pressure difference across them. The zonal pressures are then calculated by the software incorporating influences such as internal heat gains, supply and exhaust air, wind, etc. It also 
simulates the buoyant effects of air within a building, which is the driver for stack effect. The AirFlowNetwork also facilitates floor by floor analyses by allowing an examination of heating energy and ventilation rate inequities among the floors, which can be significant (Ricketts, 2014).

Although no other previous reports describing the use of the AirFlowNetwork to simulate stack effect were found, the fundamental function of the software was determined to be appropriate for the purpose of this research and a model was created to validate the theory. In theory, setting up a nodal network of zones using measured airflow resistance characteristics of the building partitions should allow for a more accurate representation of resulting transient airflows throughout the building compared to the standard modelling approach of using manually calculated airflow rates based on estimates of pressure differentials.

AirFlowNetwork could be used to study the impact of any retrofit strategy intended to control airflows within a building. It is simpler and more practical to estimate and investigate a range of achievable air-tightness levels of various building partitions and employ a nodal network analysis, rather than to try to estimate the resulting airflows of a compartmentalization retrofit to be used as inputs in a standard energy model. This is significant because the airflows within a building are governed by the zonal pressure distribution, which is dynamic, resulting in constantly varying airflows. Because AirFlowNetwork does an airflow mass balance for each zone, the combination of mechanical ventilation, natural ventilation, as well as stack effect- and wind-induced infiltration can be more accurately determined through first principles, as opposed to the constant steady state estimates typically used in energy models.

\subsubsection{Initial success}

It was determined through this research that the EnergyPlus ${ }^{\mathrm{TM}}$ AirFlowNetwork group of objects are capable of reproducing the stack effect phenomenon in an energy model. Initial success in producing buoyancy-driven airflows (stack effect) within the building led to further analysis of the available building performance data to support a calibration procedure involving both airflows and energy use. However, through this process a deeper understanding of the data required, and the reliability of the data available, was gained and eventually led to the abandonment of the nodal 
network approach. An account of the insights gained through this effort is given in this section as reference for future work.

Preliminary modelling using the nodal network approach first involved a simplification of the of the case study building geometry. The three suites on each floor were combined into a single perimeter zone surrounding the corridor and elevator shaft/stairwell. This was done primarily to reduce the number of calculations required by the software (and therefore reduce simulation time) since each zone represents a node in the network. The suites were combined also because the available suite-level electricity consumption data was not known on a per-suite basis, only as an aggregated value on a floor-by-floor basis. So each floor consist of three interior nodes, connected to each other, the nodes directly above and below, as well as to the exterior.

This floor-by-floor electricity was to be used as one of the performance metrics during the model calibration, so combining the suites together in the model was convenient for this purpose. In addition, modelling the airflows between suites on the same floor was of little interest and would have a minimal impact on the simulation results.

Figure 3.21 below shows the basic layout used for each floor, with a core and a perimeter zone.

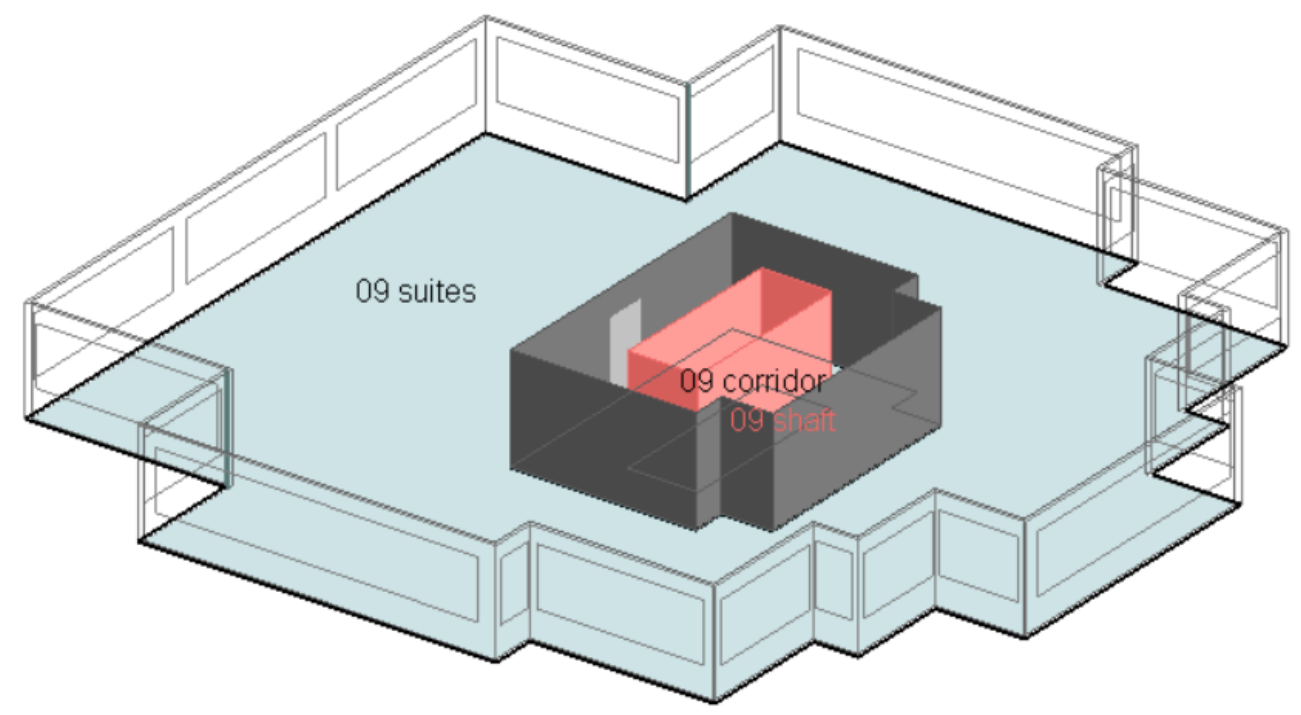

Figure 6-1: Typical floor layout showing perimeter and core zones 
The core zone includes the corridor, with an open elevator shaft running up the middle. The corridor is connected to both the perimeter "suite" zone and the elevator shaft by a doors with a defined airflow resistance. Each interior and exterior partition - walls, floors, ceilings - also has a defined airflow resistance.

Figure 3.22 below illustrates the whole building model to visualize the above floor plans in context.

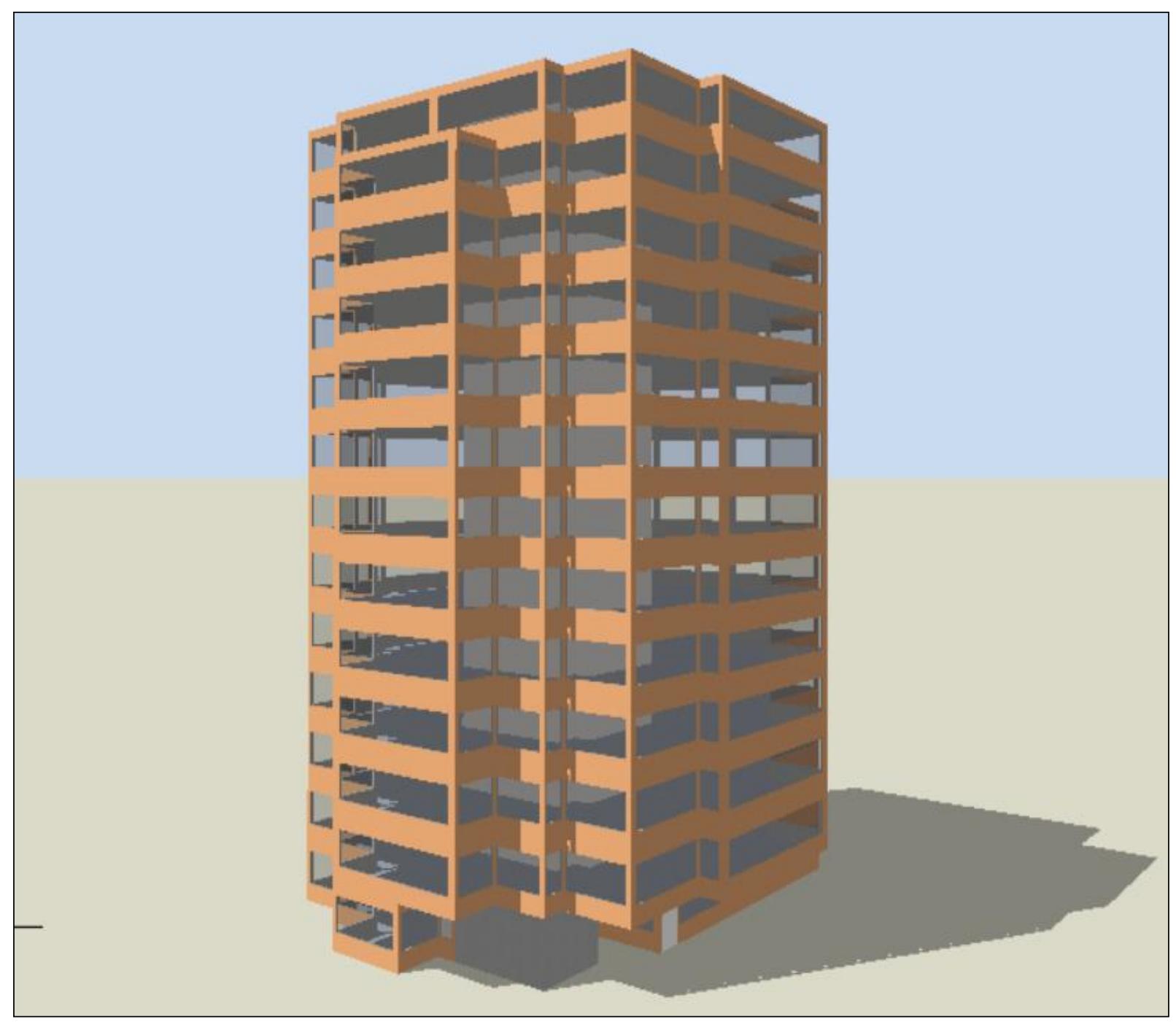

Figure 6-2: Visualization of nodal network building model geometry 
Simulation results showed that when the outside ambient air temperature is greater than the inside air temperature, air flows upward within the building model, as it would in reality. In addition, infiltration through the enclosure is induced on the lower half of the building, and exfiltration on the upper half. The figures below show these results on a floor by floor basis. Infiltration rates are greatest on the ground floor, decreasing to zero at the middle of the building where the air begins to flow outward. Vertical internal airflows are least at the ground floor, and increase to a maximum in the middle of the building from accumulation of infiltration air, then decrease again to a minimum at the top floor due to exfiltration on each floor.

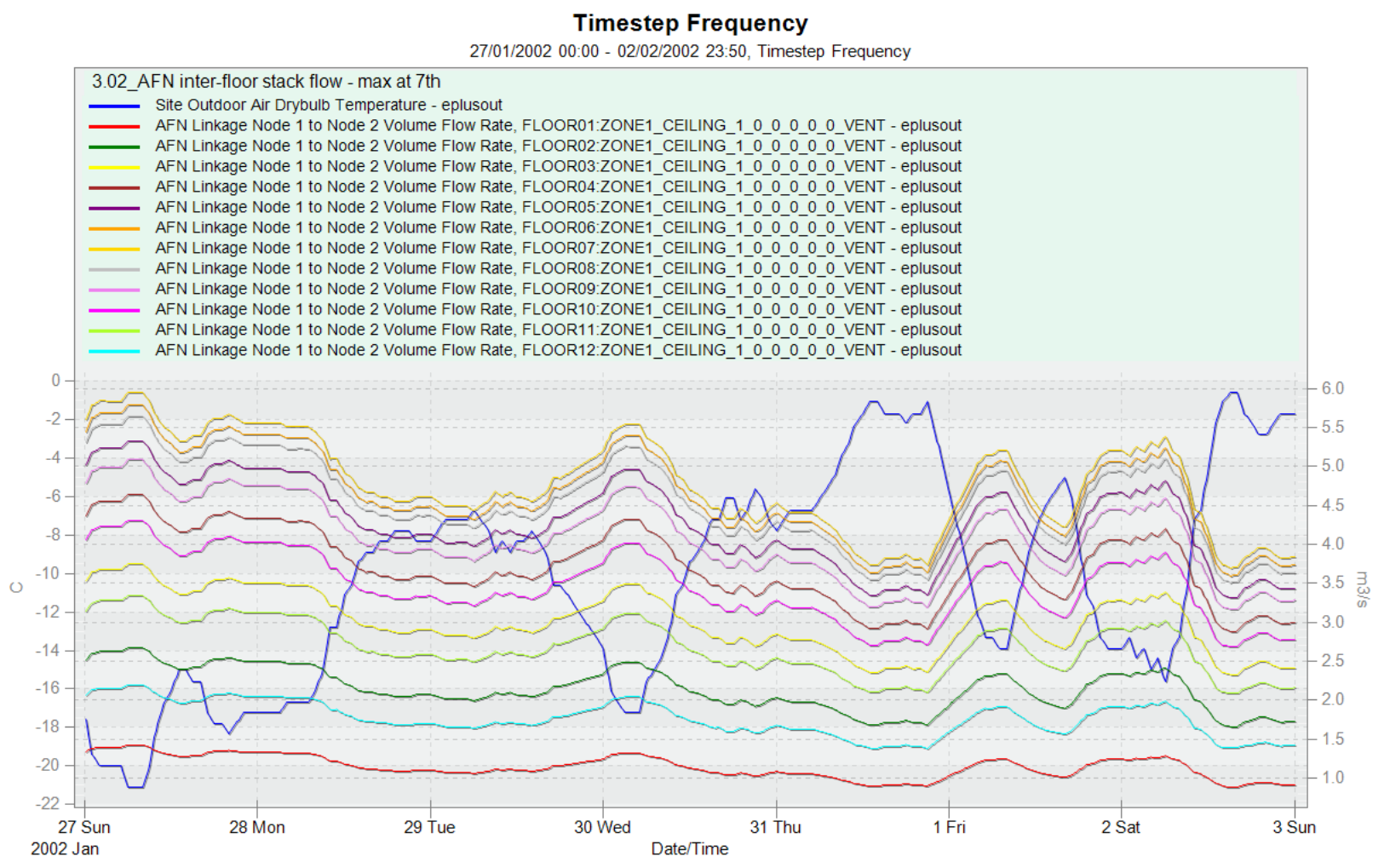

Figure 6-3: AirFlowNetwork stack-induced internal floor-to-floor airflows - maximum accumulation in middle 
Timestep Frequency

27/01/2002 00:00 - 02/02/2002 23:50, Timestep Frequency

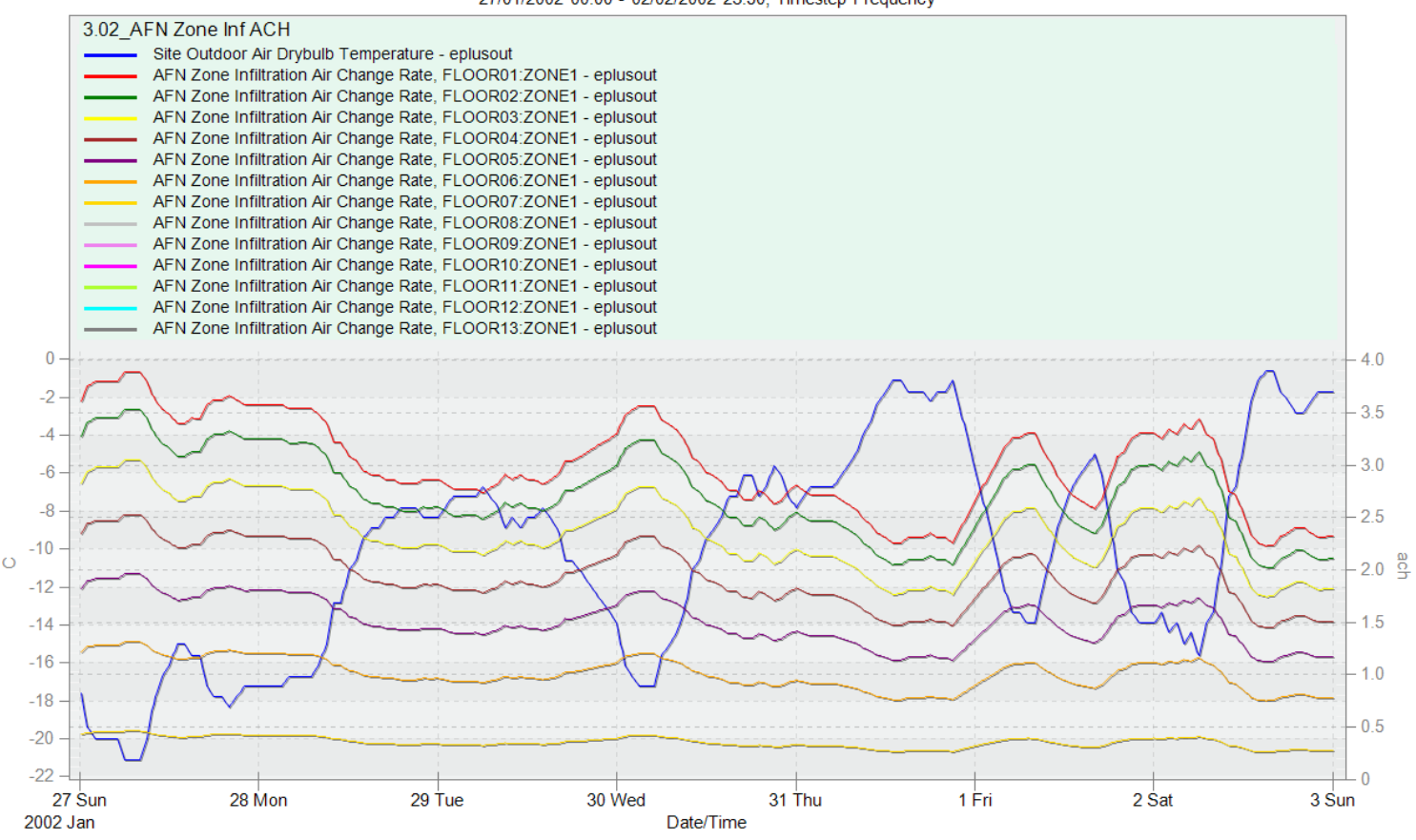

Figure 6-4: AirFlowNetwork stack-induced infiltration - floor by floor $\mathrm{ACH}$

Timestep Frequency

27/01/2002 00:00 - 02/02/2002 23:50, Timestep Frequency

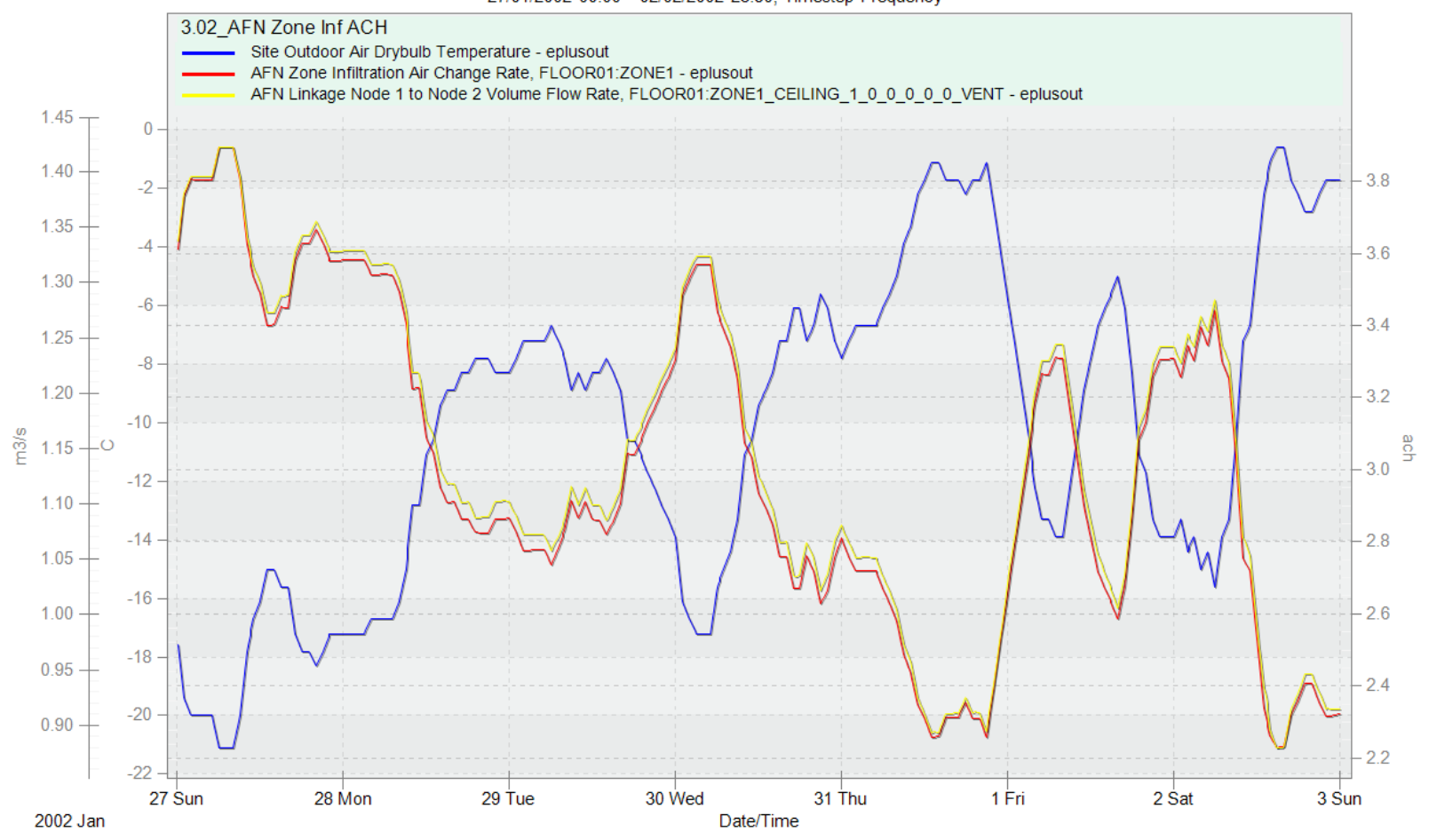

Figure 6-5: AirFlowNetwork stack-induced airflows ground floor - high infiltration, low vertical flow 


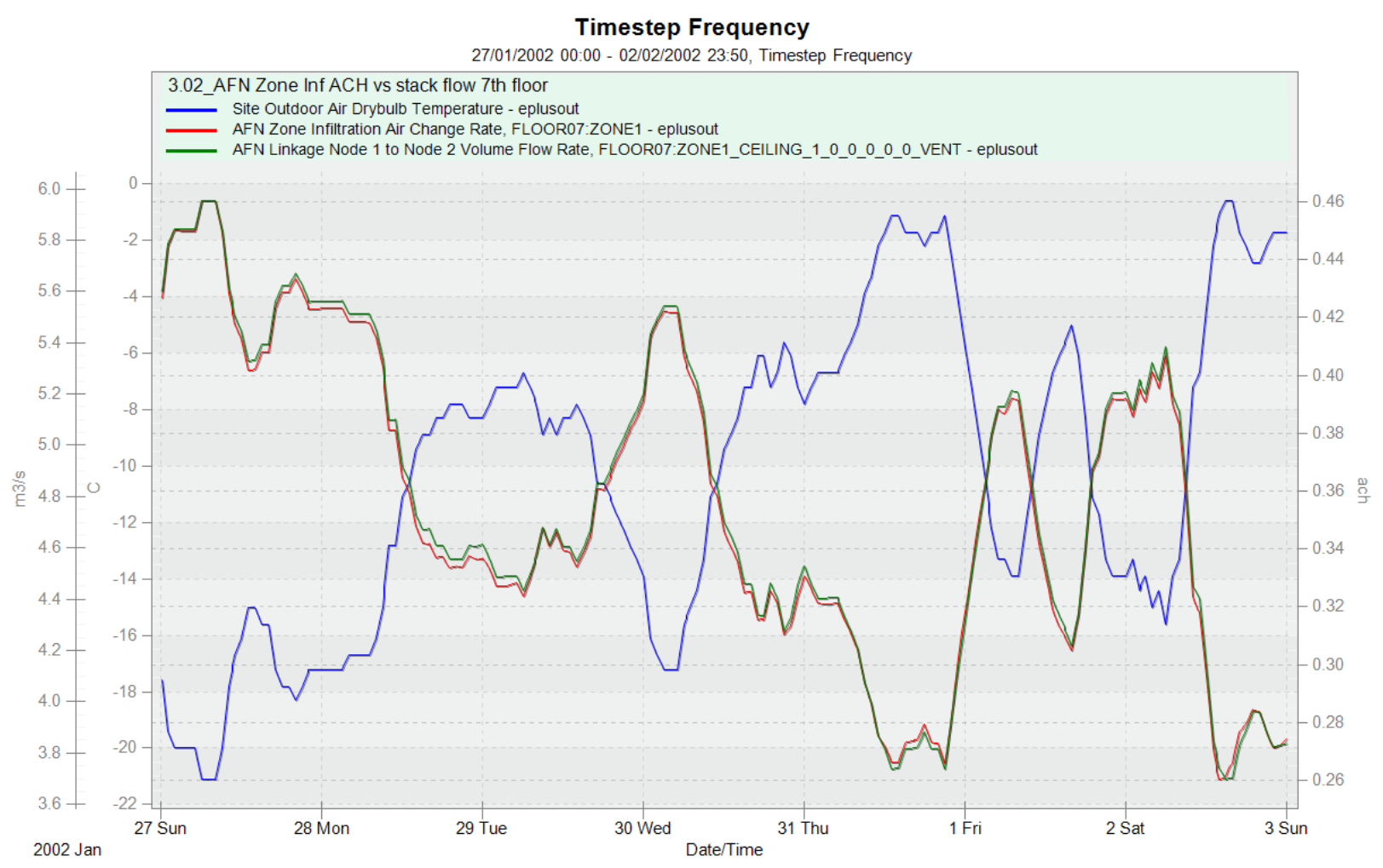

Figure 6-6: AirFlowNetwork stack-induced airflows middle floor - low infiltration, high vertical flow

\subsubsection{AirFlowNetwork input data limitations}

A thorough understanding of the various degrees of accuracy in the available measured building data, and its implications on the overall analysis of the airflows within the building and associated energy use, was only gained after efforts to model the building as a nodal network were made. As outlined in detail in Section 2.3.5, the degree of accuracy of the available building performance data was insufficient in some cases for a nodal network analysis, and overall not very well understood.

The nodal network modelling approach using AirFlowNetwork has the potential to provide more precision in its analysis of inter-suite and inter-floor airflows than the standard modular approach because of its basis in the underlying physics of airflows, and ability to simultaneously analyze their interplay. In addition, the airflow resistance characteristics of the building elements required as model inputs are relatively simple to measure, and can mostly be carried out as spot measurements without a need for any long term monitoring program. 
If calibration of the nodal network model is required, it could be done using airflow data from whole-building PFT testing (refer to Section 2.3.5.2 for potential areas of concern).

The nodal network's potential for improved accuracy and granularity in airflow predictions comes at a cost of being significantly more complicated and time consuming to set up than the standard modular energy modelling method, which employs independent, pre-defined functions for the various airflow rates (i.e., infiltration, natural ventilation, mechanical ventilation, zone air mixing, exhaust fans, etc.). The nodal network approach however offers no clear advantage in predicting the airflow changes due to retrofit measures without more accurate data on existing airflow characteristics to calibrate to.

The nodal network model was abandoned for the reasons described above as well as those outlined in Section 2.3.5.3 regarding the measured data.

\subsubsection{Continuation}

If the proposed compartmentalization retrofit were to be executed on the case study building then an attempt could be made to validate the AirFlowNetwork model as a predictive tool. Some of the building's airflow characteristics would need to be measured again prior to the retrofit, and then again afterward. Some post-retrofit energy performance would also be useful. The AirFlowNetwork model would need to be calibrated to the pre-retrofit condition using airflow data from tracer gas testing as well as energy data. Then modifications to the model could be made to emulate the retrofit using any new airtightness data, and the simulated performance checked against the new measured energy and airflow data. If the simulation proved to be effective at predicting the resulting performance of the compartmentalization then the nodal network approach could be applied to other buildings with greater confidence, provided there was sufficient data to set up an initial model.

In order to set up a nodal network model to validate the capability of AirFlowNetwork as a predictive tool in simulating changes in airflow, the following measurement data would need to be collected prior to, and following an air-tightness (compartmentalization or enclosure only) retrofit:

- enclosure air-tightness (whole building, or ideally samples at various heights) 
- interior partition air-tightness samples (corridor to suite separations, and ceilings or floors)

- mechanical ventilation delivery rates per corridor

- $\quad$ heating set points (ideally also measured temperatures to correlate)

- $\quad$ outside air temperatures, wind speeds and direction at site (nearest weather file may not suffice for wind)

- window and balcony door opening data (size, orientation, time and duration).

Calibration of the nodal network model would require the following measurement data, collected before and after the air-tightness retrofit:

- $\quad$ Tracer gas testing to verify actual overall ACH from various sources (samples from lower and upper floors ideally)

- Floor by floor heating energy (ideally each suite)

\subsubsection{AirFlowNetwork software limitations}

Incorporation of HVAC systems with the AirFlowNetwork in the current version of EnergyPlus ${ }^{\mathrm{TM}}$ (v.8.4) is limited to a single forced air system with a constant volume supply air fan, as well as to a single type of terminal unit. This is appropriate for the case study building baseline models, as it represents the current condition. For the proposed retrofit however, the addition of dedicated insuite HRV's could not be directly integrated into this model. It was possible to take an indirect approach by accounting for the zone-level impact of the HRV through other means. Because HRVs are balanced in their exhaust and delivery airflows, they do not have the effect of pressurizing or depressurizing the suites. For this reason they should have no significant impact on the calculation operations of the AirFlowNetwork object's determination of zonal air pressures at each time step. The impact should be limited to the electrical energy to drive the fans, and the net heating load introduced by the ventilation air after heat recovery from exhaust air. Because the zone-level heating is electric, the HRV energy could be applied manually to the zone-level electricity. HRV fan power could be calculated separately and manually added to the suite-level electricity as a miscellaneous plug load. 
The heating load introduced by the HRV however is a more complex variable to model as it would need to be a time-varying load based on the temperature difference between the room and outdoors, fresh air delivery rate, and the efficiency of the HRV. The additional fresh air to each zone could not be simply summed and added to the central ventilation system as the proposed retrofit eliminates the central air delivery to the suites. The HRV ventilation air could be represented by introducing a separate outside airflow to the zone as a time-varying fraction of the actual HRV airflow delivery rate based on its efficiency, and using a simple Fan:ZoneExhaust object to balance the zone pressure, however standard airflow objects such as ZoneInfiltration or ZoneVentilation are not compatible with the AirFlowNetwork object.

One possible work-around which was considered would be to build a secondary energy model of a single suite without AirFlowNetwork and run an independent simulation to determine the heating load introduced by the HRV operation. This power could then be added manually to the AirFlowNetwork model using an hourly schedule of that energy.

Despite the fact that using the AirFlowNetwork function to simulate stack effect and its associated energy impact within a tall building is yet to be validated, it was thought that, with the appropriate building performance data, it could be used to answer the research questions.

\subsubsection{Other applications - thermal resilience}

Understanding the thermal resilience of high-rise buildings in particular is becoming an important subject of research. Thermal resilience, broadly, is the ability for a building to remain comfortable without mechanical heating or cooling. Thermal resilience can be defined as being comprised of a building's "thermal autonomy" and its "passive surviveability" (O’Brien \& Bennet, 2016). Thermal autonomy is a measure of the number of hours during the year where a building, without mechanical HVAC equipment, is either comfortable, too hot, or too cold, given certain comfort criteria. Passive surviveability is a measure of the predicted number of hours a building will remain inhabitable after a power outage or HVAC system failure. In the winter the temperature threshold commonly used is $15^{\circ} \mathrm{C}$, and for summer $30^{\circ} \mathrm{C}$. 
In rapidly growing cities with aging energy infrastructure, the impact of more extreme weather events due to climate change is putting the occupants of many buildings at risk. Buildings can quickly become uninhabitable during the winter or a summer heat wave if a power outage occurs. Tall buildings are particularly at risk due the predominance of glass curtain wall enclosures. These buildings require a large amount of heating and cooling energy due to the poor thermal performance of their glazed facades, and limited ability to passively mitigate solar heat gain. It is starting to become more common to see early design development stage investigations into a building's thermal resilience, however any energy model which does not account for stack effect will not be capable of predicting passive surviveability times with any accuracy. This idea is also supported by the research done by O'Brien \& Bennet who concluded that thermal resilience studies of high-rise MURBs in particular need to incorporate stack effect in the energy model.

Some potential research questions relating to this subject which could be investigated using a nodal network approach to building energy modelling are:

- how does stack effect impact both summer and winter passive surviveability predictions?

- How would stack effect mitigation measures such as compartmentalization impact the passive surviveability time of a building?

- Could a simplified stack effect impact factor be determined for tall buildings to be used as part of a methodology for determining their passive surviveability?

- Is this an issue in winter with central NG hydronic systems if there is backup power for pumps?

- How does the presence of natural ventilation for night flushing help summertime passive surviveability times?

A nodal network model validation project could be part of a larger study for the Greater Toronto Area and provide useful insight into questions such as:

- What are the most vulnerable buildings in the city in terms of least inhabitable days during a heat wave or extreme cold period.

- How could compartmentalization retrofits (and other passive measures like shading devices), applied across a larger set of buildings support the GHG reduction goals for Toronto set out by TransformTO? 


\section{Appendices}

\section{Appendix A: Case Study Building - Layout and sections}

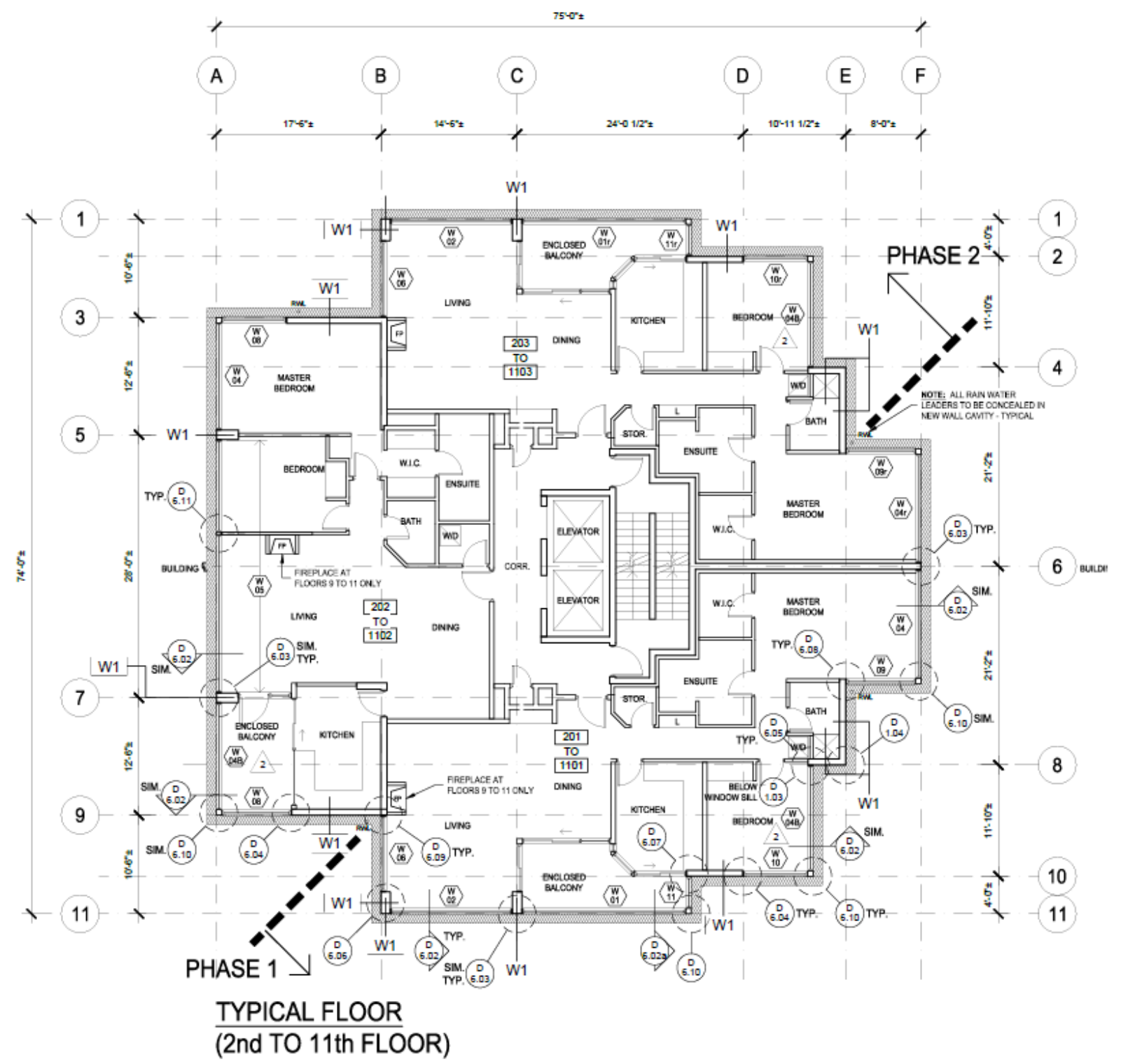

Figure 0-1: Floorplan of typical floor in case study building 


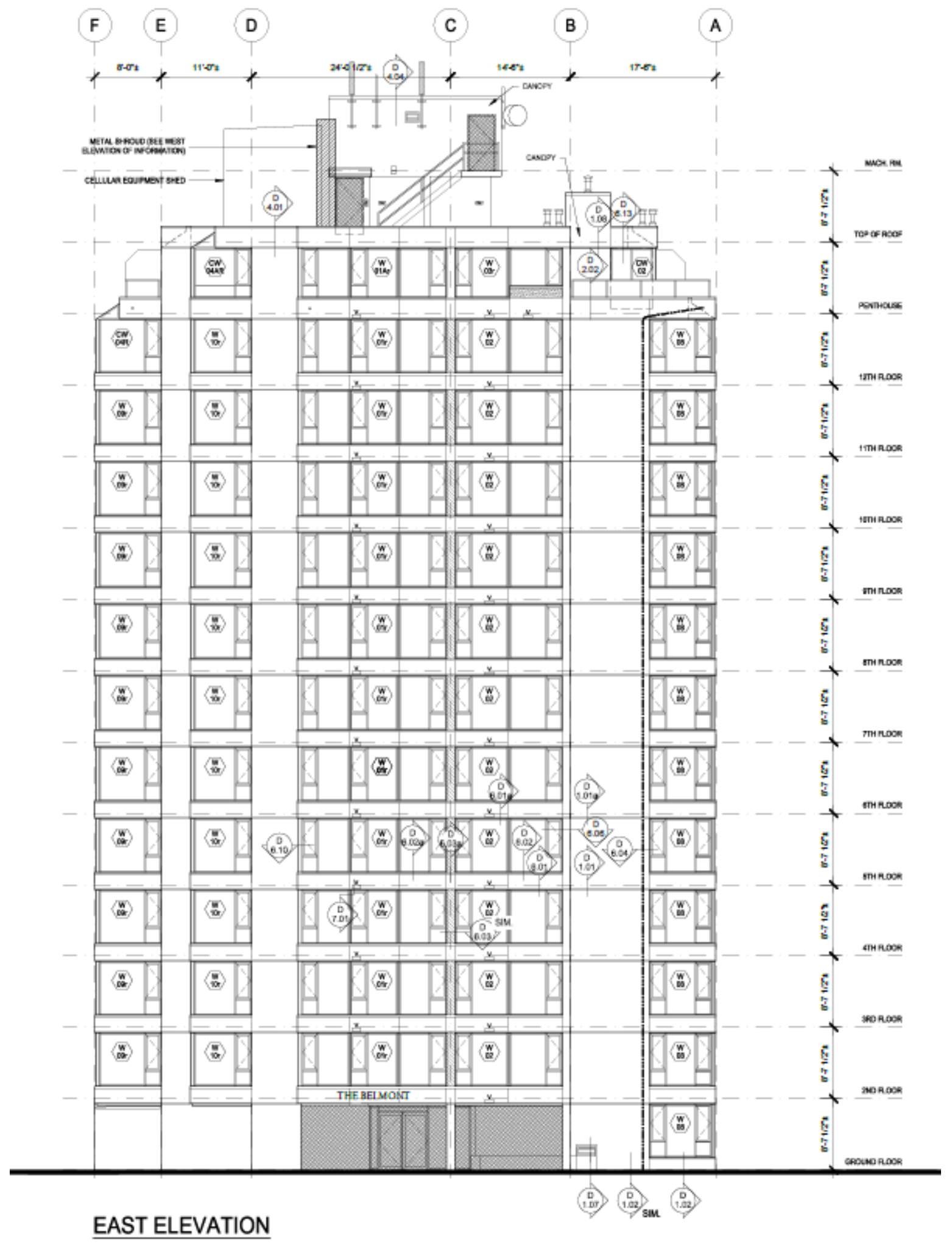

Figure 0-2: East elevation of case study building 


\section{References}

ANSI/ASHRAE. (2002). ASHRAE Guideline 14-2002 Measurement of Energy and Demand Savings. Ashrae, 8400, 170.

ASHRAE. (2010). ASHRAE STANDARD 62.1-2010 Ventilation for Acceptable Indoor Air Quality.

Bach, B., \& Lamb, M. (2012). Development of Energy Efficiency Requirements for the Toronto Green Standard : Final Report (Vol. 2012).

BC Housing. (2015). Heat Recovery Ventilation Guide for Multi-Unit Residential Buildings.

British Columbia Ministry of Environment. (2012). British Columbia Greenhouse Gas Inventory Report 2012. Retrieved from http://www2.gov.bc.ca/assets/gov/environment/climatechange/reports-and-data/provincial-ghg-inventory-report-bcs-pir/pir-2012-full-report.pdf

British Columbia Ministry of Environment. (2016). 2016/17 B.C. BEST PRACTICES METHODOLOGY FOR QUANTIFYING GREENHOUSE GAS EMISSIONS. Building Simulation. http://doi.org/10.1007/s12273-013-0159-y

Brown, C., \& Gorgolewski, M. (2014). Understanding the role of inhabitants in innovative mechanical ventilation strategies. Building Research \& Information, (October), 1-13. http://doi.org/10.1080/09613218.2015.963350

Canada Mortgage \& Housing Corporation. (1999). Field Testing to Characterize Suite Ventilation in Recently Constructed Mid-and High-Rise Introduction Residential Buildings.

Canada Mortgage \& Housing Corporation. (2003). Ventilation Systems for Multi-Unit Residential Buildings : Performance Requirements and Alternative Approaches, Technical(October), 16.

Canada Mortgage \& Housing Corporation. (2005). Assessment of Suite Compartmentalization and Depressurization in New High-Rise Residential Buildings. Research Highlight.

Canadian Standards Association. (2010). CSA Standard CAN/CSA-F326-M91 Residential Mechanical Ventilation Systems. 
CMHC. (2003). Ventilation Systems for Multi-unit Residential Buildings - Performance Requirements and Alternative Approaches.

CMHC. (2013). Air Leakage Control in Multi-Unit Residential Buildings - Development of Testing and Measurement Strategies to Quantify Air Leakage in MURBs.

Edwards, C. (1999). Modelling of Ventilation and Infiltration Energy Impacts in Mid and HighRise Apartment Buildings.

Emmerich, S. J., Anis, W., \& McDowell, T. (2005). Investigation of the Impact of Commercial Building Envelope Airtightness on HVAC Energy Use.

EnergyLens. (n.d.). Degree Days - Handle With Care. Retrieved from http://www.energylens.com/articles/degree-days

Environment Canada. (2015). National Inventory Report 1990-2013. Greenhouse gas sources and sinks in Canada - Part 3, 1-85. http://doi.org/ISSN: 1719-0487

Frappé-Sénéclauze, T.-P., Heerema, D., \& Wu, K. T. (2017). Deep emissions reduction in the existing building stock: Key elements of a retrofit strategy for B.C.

Gowri, K., Winiarski, D., \& Jarnagin, R. (2009). Infiltration Modeling Guidelines for Commercial Building Energy Analysis.

Gu, L. (2007). Airflow network modeling in EnergyPlus. Building Simulation 2007, (February), 964-971.

Han, G., Srebric, J., \& Enache-Pommer, E. (2015). Different modeling strategies of infiltration rates for an office building to improve accuracy of building energy simulations. Energy and Buildings, 86, 288-295. http://doi.org/10.1016/j.enbuild.2014.10.028

Hanam, B., Finch, G., \& Hepting, C. (2011). Meter Calibrated Energy Simulation Of High Rise Residential Buildings: Lessons Learned.

Health Canada. (2012). Guidance for Fine Particulate Matter (PM2.5) in Residential Indoor Air. Lorenzetti, D. M., \& Wray, C. P. (2014). Air-Handling System Modeling in EnergyPlus : Recommendations for Meeting Stakeholder Needs. 
Lstiburek, J. W. (2000). Toward an Understanding and Prediction of Air Flow in Buildings.

Montgomery, J. (2015). Air Quality in Multi-Unit Residential Buildings. RDH Technical Bulletin, (9).

Nav Canada. (2000). British Columbia Airport Climatology.

NRCan. (2017). Comprehensive Energy Use Database. Retrieved from http://oee.nrcan.gc.ca/corporate/statistics/neud/dpa/menus/trends/comprehensive_tables/list. $\mathrm{cfm}$

NREL. (2016). EnergyPlus Input Output Reference.

O’Brien, W., \& Bennet, I. (2016). Simulation-based evaluation of high-rise residential building thermal resilience. ASHRAE Transactions, 122, 455-468.

Pape-Salmon, A. (2016). Review of Potential Energy Efficiency Standards for Existing Buildings In $B C$.

Parker, C. A. (2012). Improving the Effectiveness of In-Suite Ventilation Systems with Respect to Cross Contamination and Odour Transmission in MURBs by.

Proskiw, G., \& Phillips, B. (2001). Air Leakage Characteristics, Test Methods and Specifications for Large Buildings, 1-4.

Province of British Columbia. (2017). Greenhouse Gas Reduction Targets Act. Retrieved from http://www.bclaws.ca/EPLibraries/bclaws_new/document/ID/freeside/00_07042_01

RDH. (2013). Report 1 : Retrofit Building Candidate Feasibility Assessment.

RDH. (2014). Report 5 : Enclosure Retrofit Energy Utilization Impacts | Project 3033 . 40.

RDH Building Engineering Ltd. (2012). Energy Consumption and Conservation in Mid-and HighRise Residential Buildings in British Columbia.

Richman, R. C. (2002). Using the Inverse Method to Predict Air Flow in Buildings.

Ricketts, L. (2014). A Field Study of Airflow in a High-Rise Multi-Unit Residential Building. University of Waterloo. 
Ricketts, L., \& Straube, J. (2014a). A Field Study of Airflow in a High-Rise Multi-Unit Residential Buildings. In 14th Canadian Conference on Building Science and Technology (pp. 1-12).

Ricketts, L., \& Straube, J. (2014b). Corridor Pressurization System Performance in Multi-Unit Residential Buildings. ASHRAE Transactions, 120.

Sherman, M. H., \& Grimsrud, D. T. (1980). INFILTRATION-PRESSURIZATION CORRELATION: SIMPLIFIED PHYSICAL MODELING.

Statistics Canada. (2014). Report on Energy Supply and Demand in Canada - 2014 Preliminary (57-003-X). Retrieved from http://www5.statcan.gc.ca/olc-cel/olc.action?ObjId=57-003$\mathrm{X} \&$ ObjType $=2 \&$ lang $=$ en $\&$ Limit $=1$

Touchie, M. F., \& Pressnail, K. D. (2014). Using suite energy-use and interior condition data to improve energy modeling of a 1960s MURB. Energy and Buildings, 80, 184-194. http://doi.org/10.1016/j.enbuild.2014.05.014

Urquhart, R., Richman, R., \& Finch, G. (2015). The effect of an enclosure retrofit on air leakage rates for a multi-unit residential case-study building. Energy and Buildings, 86, 35-44. http://doi.org/10.1016/j.enbuild.2014.09.079

World Health Organization. (2010). WHO guidelines for indoor air quality: selected pollutants (Vol. 9).

Wray, C., Theaker, I., \& Moffatt, P. (1998). Field Testing to Characterise Suite Ventilation in Recently Constructed Mid and Residential Buildings. 